\title{
Integração Semântica das Bases de Dados do Sistema Único de Saúde: Um Estudo de Caso com o Município de São Paulo
}

\author{
Débora Lina Nascimento Ciriaco Pereira
}

\author{
DissertaÇÃo APRESENTADA \\ $\mathrm{AO}$ \\ Instituto De MatemáticA E EstatísticA \\ DA \\ Universidade DE SÃo PAUlo \\ PARA \\ OBTENÇÃO DO TÍTULO \\ $\mathrm{DE}$ \\ Mestrado em Cî̂nCiA DA COMPUtAÇÃO \\ Programa: Ciência da Computação \\ Orientadora: Profa. Dra. Renata Wassermann
}

Esta pesquisa é parte do INCT da Internet do Futuro para Cidades Inteligentes financiado pelo CNPq proc. 465446/2014-0, Coordenação de Aperfeiçoamento de Pessoal de Nível Superior Brasil (CAPES) - Código de Financiamento 001, FAPESP proc. 14/50937-1, e FAPESP proc. $15 / 24485-9$. 


\title{
Integração Semântica das Bases de Dados do Sistema Único de Saúde: Um Estudo de Caso com o Município de São Paulo
}

\begin{abstract}
Esta versão da dissertação contém as correções e alterações sugeridas pela Comissão Julgadora durante a defesa da versão original do trabalho, realizada em 19/12/2019. Uma cópia da versão original está disponível no Instituto de Matemática e Estatística da Universidade de São Paulo.
\end{abstract}

Comissão Julgadora:

- Profa. Dra. Renata Wassermann - IME-USP

- Profa. Dra. Laís do Nascimento Salvador - UFBA

- Prof. Dr. Paulo Roberto Miranda Meirelles - UNIFESP 


\section{Agradecimentos}

Gostaria de expressar minha gratidão a todos que fizeram parte dessa jornada, me apoiando e incentivando a continuar. Agradeço à professora Renata Wassermann, por sua dedicação e paciência ao me orientar. Obrigada por aceitar o desafio de ter uma aluna que não veio da computação, seus conselhos e direção foram extremamente importantes para mim. Sua forma de conduzir o projeto (e a vida!) e maneira leve, amável e ao mesmo tempo séria será algo que levarei para toda a minha trajetória. Agradeço também à professora Laís Nascimento Salvador, que esteve presente em todas as fases do meu projeto, sendo uma fonte de ajuda e direcionamento, sempre muito empenhada. Certamente meu projeto não teria a mesma força sem ela.

Deixo meu agradecimento aos colegas da IBM Research, por estarem comigo em uma das fases mais difíceis para mim, o período das disciplinas. Vocês foram essenciais! Agradeço ao pessoal do LIAMF, vocês tiraram minhas dúvidas, deram suporte e me esperaram para o chá! De fato vocês fizeram a diferença nessa caminhada.

Agradeço à minha casa, por serem meu porto seguro nos tempos calmos e de tempestade. Vocês sabem o quanto precisei de vocês para chegar até aqui. Agradeço ao meu amado, pela compreensão

e apoio. Também aos meus irmãos em Cristo, pelas orações que com certeza me ajudaram a seguir sempre.

A todos que apostaram e depositaram sua confiança em mim nesse mestrado, obrigada! 


\section{Resumo}

Pereira, D. L. N. C. Integração Semântica das Bases de Dados do Sistema Único de Saúde: Um Estudo de Caso com o Município de São Paulo 2019. 134 f. Dissertação de Mestrado Instituto de Matemática e Estatística, Universidade de São Paulo, São Paulo, 2019.

O grande incentivo à disponibilização de dados populacionais, principalmente em formatos abertos, tem gerado interesse para a realização de análises voltadas à gestão pública. Entretanto, a ausência de informações contextuais e semânticas apresenta um desafio, mesmo para áreas com terminologias já bem estabelecidas, como a da saúde. A execução da integração semântica das bases de dados tem sido uma solução apontada para a melhora na compreensão dos dados, levando assim ao maior aproveitamento destes. Desse modo, foi escolhida e adaptada uma metodologia de integração semântica das bases de dados de nascimento (SINASC) e mortalidade (SIM) do Sistema Único de Saúde, relacionadas à saúde materno-infantil no município de São Paulo. Foi realizado um estudo de caso relacionado ao desenvolvimento do indicador de saúde de Dias Potenciais de Gravidez Perdidos DPGP. Utilizando a metodologia híbrida de integração semântica, foram criadas três camadas para a solução, cada uma contendo pelo menos uma ontologia, com sua especificação e mapeamentos necessários. As ontologias foram então povoadas com os dados das bases de dados advindos do Ministério da Saúde através do DATASUS e dados já linkados da Secretaria Municipal da Saúde de São Paulo, fruto da parceria realizada no contexto do projeto do indicador de saúde DPGP. As ontologias foram então avaliadas quanto à capacidade de responder às questões de competência eleitas pelos especialistas. A solução composta pelas ontologias e mapeamentos mostrou-se útil no processo de integração semântica dos dados, apresentando uma visão global das bases de dados e como estas se relacionavam. Por fim, as ontologias povoadas por dados públicos foram disponibilizadas para a comunidade.

Palavras-chave: Integração Semântica de Bases de Dados, Ontologias, Linked Data, Bases de Dados Populacionais, Sistemas de Informação em Saúde, Sistema Único de Saúde. 


\section{Abstract}

Pereira, D. L. N. C. Semantic Data Integration for the Brazilian Public Health System:

A Case Study with São Paulo. 2019. 134 f. Dissertação de Mestrado - Instituto de Matemática e Estatística, Universidade de São Paulo, São Paulo, 2019.

The great incentive to make population data available, mainly in open formats, has generated interest in carrying out analyzes aimed at public management. However, the absence of contextual and semantic information presents a challenge, even for areas with well-established terminologies, such as health care. The semantic integration of databases has been a solution aimed at improving the understanding of data, thus leading to greater use of them. In this way, a methodology for semantic integration of the birth (SINASC) and mortality (SIM) databases of the Brazilian Unified Health System (SUS), related to maternal and child health in the city of São Paulo, was chosen and adapted. A case study was carried out related to the development of the health indicator of Missed Potential Days of Pregnancy - DPGP.

Using the hybrid semantic integration methodology, three layers were created for the solution, each containing at least one ontology, with its specification and necessary mappings. The ontologies were then populated with data from the databases from the Ministry of Health through DATASUS and data already linked from the Municipal Health Secretariat of São Paulo, as a result of the partnership carried out in the context of the DPGP health indicator project. The ontologies were then evaluated for their ability to answer questions of competence elected by experts. The solution made up of ontologies and mappings proved to be useful in the process of semantic data integration, presenting a global view of the databases and how they were related. Finally, the ontologies populated by public data were made available to the community.

Keywords: Semantic Data Integration, Ontology, Linked Data, Population Health Datasets, Health Information Systems, Brazilian Public Health System. 


\section{Conteúdo}

Lista de Abreviações $\quad$ ix

Lista de Figuras $\quad$ xi

Lista de Tabelas $\quad$ xiii

1 Introdução $\quad 1$

1.1 Motivação . . . . . . . . . . . . . . . . . . . . . . . . 3

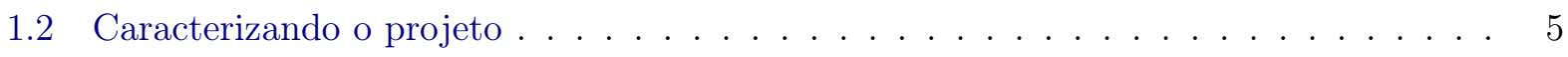

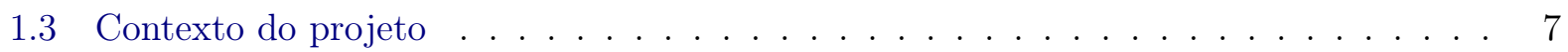

1.4 Publicações e Apresentações . . . . . . . . . . . . . . . . . . . 7

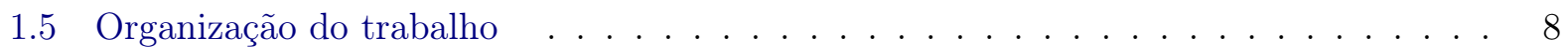

2 Conceitos $\quad 9$

2.1 Integração de dados . . . . . . . . . . . . . . . . . . . . . . 9

2.2 Integração Semântica dos Dados . . . . . . . . . . . . . . . . . . . . . . . 10

2.2 .1 Web Semântica . . . . . . . . . . . . . . . . . . . 11

2.3 Ontologias: Definições, Modelagem e Usos . . . . . . . . . . . . . . . . . . . . 14

2.3.1 Engenharia de Ontologias . . . . . . . . . . . . . . . . 16

2.3 .2 Ontologias na integração de dados . . . . . . . . . . . . . . . 18

2.4 Integração de dados baseada em ontologias - OBDI . . . . . . . . . . . . . . 18

2.4 .1 Abordagens de ODBI . . . . . . . . . . . . . . . . . . 20

3 Metodologia de Desenvolvimento da Solução $\quad 23$

3.1 Compreensão do Problema e Escolha das Fontes de Dados . . . . . . . . . . . . . . . 23

3.2 Escolha da abordagem de OBDI . . . . . . . . . . . . . . . . . . 26

3.3 Desenvolvimento da solução ODBI híbrida . . . . . . . . . . . . . . . . . . . . . . 29

3.3 .1 Arquitetura da solução . . . . . . . . . . . . . . . . . . . . . . . . . 29

4 Desenvolvimento das ontologias e mapeamentos independentes da aplicação $\quad 33$

4.1 Avaliação das Fontes de Dados . . . . . . . . . . . . . . . . . . . 33

4.2 Desenvolvimento das Ontologias da Camada OF . . . . . . . . . . . . . . . . 34

4.3 Desenvolvimento dos Mapeamentos FD_OF . . . . . . . . . . . . . . 42 
5 Desenvolvimento das ontologias e mapeamentos dependentes da aplicação

5.1 Desenvolvimento da Ontologia da Camada OD . . . . . . . . . . . . . . . . 47

5.1 .1 Cenário Motivador . . . . . . . . . . . . . . . . . . . . . 48

5.1 .2 Questões de Competência Informais . . . . . . . . . . . . . . . . . . . . 48

5.1 .3 Especificação Formal: Terminologia . . . . . . . . . . . . . . . . . . . . . 51

5.1 .4 Formalização das Questões de Competência . . . . . . . . . . . . . . . . . . . 54

5.2 Desenvolvimento das Ontologias da Camada OI: Primeira Parte . . . . . . . . . . . . 59

5.3 Desenvolvimento dos Mapeamentos OD_OI . . . . . . . . . . . . . . . . . 59

5.4 Desenvolvimento dos Mapeamentos OF_OI . . . . . . . . . . . . . . 60

5.5 Desenvolvimento das Ontologias da Camada OI: Segunda Parte . . . . . . . . . . . . 61

5.6 Desenvolvimento dos Links sameAs . . . . . . . . . . . . . . . . . . 62

5.7 Desenvolvimento dos Mapeamentos OI_OD . . . . . . . . . . . . . . 62

6 Conclusão $\quad 65$

6.1 Trabalhos Futuros . . . . . . . . . . . . . . . . . . . 66

$\begin{array}{ll}\text { A Diagramas Entidade Relacionamento } & 67\end{array}$

$\begin{array}{ll}\text { B Consultas nas ontologias da camada OF } & 69\end{array}$

$\begin{array}{ll}\text { C Questões de Competência } & 71\end{array}$

$\begin{array}{ll}\text { D Dicionário de Mapeamento de Termos entre OFs e OD } & 77\end{array}$

$\begin{array}{ll}\text { A Bases de dados para integração } & 85\end{array}$

B Exemplo da Declaração de Nascido Vivo $\quad 89$

$\begin{array}{ll}\text { C Variáveis do SINASC } & 91\end{array}$

$\begin{array}{ll}\text { D Exemplo da Declaração de Óbito } & 99\end{array}$

$\begin{array}{ll}\text { E Variáveis do SIM } & 101\end{array}$

$\begin{array}{lll}\text { F } & \text { Variáveis da DNDO } & 109\end{array}$

$\begin{array}{ll}\text { Bibliografia } & 113\end{array}$ 


\section{Lista de Abreviações}

$\begin{array}{ll}\text { AIDS } & \text { Síndrome da Imunodeficiência Adquirida } \\ \text { APAC } & \text { Autorização de Procedimentos de Alta Complexidade } \\ \text { API } & \text { Application Programming Interface } \\ \text { BPA-I } & \text { Boletim de Produção Ambulatorial Individualizado } \\ \text { CBO } & \text { Classificação Brasileira de Ocupações } \\ \text { CENTERMS } & \text { Centro Nacional de Terminologias em Saúde } \\ \text { CEP } & \text { Código de Endereçamento Postal } \\ \text { CID } & \text { Classificação Internacional de Doenças } \\ \text { CIDACS } & \text { Centro de Integração de Dados e Conhecimento para Saúde } \\ \text { CIT } & \text { Comissão Intergestores Tripartite } \\ \text { CMD } & \text { Conjunto Mínimo de Dados } \\ \text { CNES } & \text { Cadastro Nacional de Estabelecimentos de Saúde } \\ \text { CNS } & \text { Cartão Nacional de Saúde } \\ \text { CPF } & \text { Cadastro de Pessoa Física } \\ \text { CSV } & \text { Comma-separated Values } \\ \text { DATASUS } & \text { Departamento de Informática do Sistema Unico de Saúde } \\ \text { DBC } & \text { Database Container (extenção) } \\ \text { DBF } & \text { Database file (extenção) } \\ \text { DL } & \text { Description Logic - Lógica de Descrição } \\ \text { DN } & \text { Declaração de Nascimento } \\ \text { DO } & \text { Declaração de Óbito } \\ \text { DPGP } & \text { Dias Potenciais de Gravidez Perdidos } \\ \text { ePing } & \text { Padrões de Interoperabilidade de Governo Eletrônico } \\ \text { HTTP } & \text { Hypertext Transfer Protocol } \\ \text { FIOCRUZ } & \text { Fundação Oswaldo Cruz } \\ \text { HTTP } & \text { Hypertext Transfer Protocol } \\ \text { GAV } & \text { Global-as-View } \\ \text { GLAV } & \text { Global-and-Local-as-View } \\ \text { GSS } & \text { Gestão de Sistemas de Saúde } \\ \text { IBGE } & \text { Instituto Brasileiro de Geografia e Estatística } \\ \text { ICICT } & \text { Instituto de Comunicação e Informação Científica e Tecnológica em Sacional de Ciência e Tecnologia } \\ \text { INCT } & \text { Instito } \\ & \end{array}$


KOS Knowledge Organization Systems

LAV Local-as-View

LD Linked Data

LDM Linked Data Mashup

LOD Linked Open Data

OBDA Ontology-Based Data Access

OBDI Ontology-Based Data Integration

OD Ontologia de Domínio

OF Ontologias de Fonte

OI Ontologias de Integração

OWL Ontology Web Language

RDF Resource Description Framework

RNDS Rede Nacional de Dados em Saúde

RTS Repositório de Terminologias em Saúde

SAMHPS Sistema de Atenção Médico-Hospitalar da Previdência Social

SIA

Sistema de Informação Ambulatorial

SIGA Sistema Integrado de Gestão da Assistência à Saúde

SIGTAP Sistema de Gerenciamento da Tabela de Procedimentos, Medicamentos, Órteses/Próteses e Materiais Especiais do SUS

SIH Sistema de Informações Hospitalar

SIM Sistema de Informações de Mortalidade

SINASC Sistema de Informações de Nascidos Vivos

SIS Sistemas de Informação de Saúde

SisPreNatal Sistema de Acompanhamento da Gestante

SMS-SP Secretaria Municipal da Saúde de São Paulo

SNOMED-CT SNOMED Clinical Terms

SPARQL SPARQL Protocol and RDF Query Language

SQL Structured Query Language

SUS Sistema Único de Saúde

SWEO Semantic Web Education and Outreach

TANU Triagem Auditiva Neonatal Universal

UBS Unidade Básica de Saúde

URI Uniform Resource Identifier

USP Universidade de São Paulo

UTF-8 8-bit Unicode Transformation Format - Padrão de codificação de caracteres

W3C World Wide Web Consortium

XLS Extensão do Excel

XML Extensible Markup Language 


\section{Lista de Figuras}

1.1 Representação do framework de 4 camadas . . . . . . . . . . . . . . . . . . . 6

2.1 Representação de parte da ontologia Semantic Web for Resource Community . . . . 15

2.2 Metodologia para Engenharia de Ontologia . . . . . . . . . . . . . . . 17

2.3 Representação dos elementos de uma solução OBDI . . . . . . . . . . . . . . . . . . 20

2.4 Abordagens de OBDI . . . . . . . . . . . . . . . . . . . . 20

3.1 Fluxograma da metodologia seguida e referência de localização no texto . . . . . . . 23

3.2 Variáveis selecionadas da base de dados do SINASC . . . . . . . . . . . . . . . . 24

3.3 Variáveis selecionadas da base de dados do SIM . . . . . . . . . . . . . . . . . . . . . . . . . . . . . . . . . .

3.4 Seleção das bases terminológicas . . . . . . . . . . . . . . . . . 26

3.5 Abordagens de OBDI, destaque para a OBDI híbrida . . . . . . . . . . . . . . . 27

3.6 Árvore de Recomendação de abordagens de OBDI . . . . . . . . . . . . . . . . . . . 28

3.7 Esquema da solução OBDI híbrida desenvolvida . . . . . . . . . . . . . . . . . . . . 29

3.8 Arquitetura da solução OBDI híbrida desenvolvida, com o fluxo de conceitos e a ordem de criação . . . . . . . . . . . . . . . . . . . . . . . 31

3.9 Arquitetura da solução OBDI híbrida desenvolvida, com o fluxo das informações durante as consultas . . . . . . . . . . . . . . . . . . 32

4.1 Legenda para os diagramas das ontologias . . . . . . . . . . . . . . . . . . . . . . . . . .

4.2 Diagrama correspondente a ontologia $O F_{S I N A S C} \ldots \ldots \ldots \ldots \ldots$

4.3 Diagrama correspondente a ontologia $O F_{S I M} \ldots \ldots \ldots \ldots \ldots$

4.4 Diagrama correspondente a ontologia $O F_{D N D O} \ldots \ldots \ldots \ldots \ldots$

4.5 Recorte da ficha de preenchimento do SINASC . . . . . . . . . . . . . 39

4.6 Classes da ontologia $O F_{S I N A S C}$ e propriedades da classe GestacaoEParto . . . . . . 39

4.7 Propriedade de Objeto diagnosticadoCom da ontologia $O F_{S I N A S C} \ldots \ldots$. . . . 40

4.8 Exemplo da ontologia $O F_{S I N A S C}$ preenchida com indivíduos da Família Real Britânica 41

4.9 Consulta exemplo das declarações de nascimento do SINASC que tiveram óbito re-

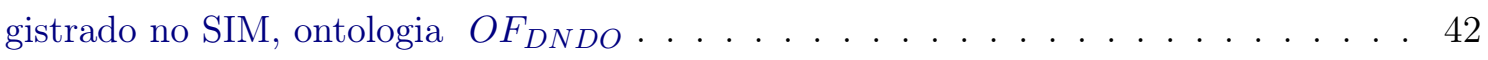

4.10 Configuração do plug-in do Ontop no Protégé . . . . . . . . . . . . . . . . . . . 42

4.11 Aba Mapping assistant, do Ontop . . . . . . . . . . . . . . . . . . . . . . 43

4.12 Mapeamento de uma classe com suas propriedades de dados . . . . . . . . . . . . . 44

4.13 Mapeamento de uma classe com suas propriedades de objetos . . . . . . . . . . . . 44

4.14 Indivíduos da base de dados do SINASC materializados na ontologia OF SINASC $_{2} .45$

4.15 Exemplo de consulta SPARQL com os indivíduos virtualizados . . . . . . . . . . 45 
4.16 Exemplo de consulta SPARQL com os indivíduos materializados 46

5.1 Arquitetura da solução OBDI híbrida desenvolvida, com o fluxo de conceitos e a ordem de criação, destaque para a etapa dependente da aplicação . . . . . . . . . . . 47

5.2 Diagrama da ontologia de domínio, $O D_{S M I} \ldots \ldots \ldots \ldots \ldots \ldots \ldots$

5.3 Recorte do diagrama da ontologia $O D_{S M I}$, foco nas classes superclasse Diagnostico - Diagnóstico e suas subclasses . . . . . . . . . . . . . . . 5 53

5.4 Recorte do diagrama da ontologia $O D_{S M I}$, foco nas classes que precisam de definições externas, como Neonato - Neonato . . . . . . . . . . . . . . . . 53

5.5 Resultado da análise do OOPS! para a ontologia $O D_{S M I} \ldots \ldots \ldots \ldots \ldots$

5.6 Indivíduos de teste da $O D_{S M I} \ldots \ldots \ldots \ldots \ldots \ldots \ldots \ldots$

5.7 Resposta da questão de competência sobre óbito materno após o parto, ontologia

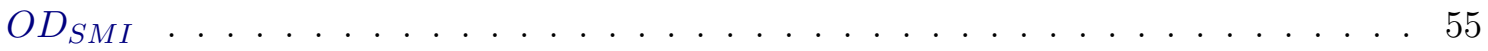

5.8 Resposta da questão de competência sobre registro de abortos ou perdas fetais anteriores ao parto, ontologia $O D_{S M I} \ldots \ldots \ldots \ldots \ldots \ldots$

5.9 Resposta da questão de competência sobre o peso do filho ao nascer, ontologia $O D_{S M I} 56$

5.10 Resposta da questão de competência sobre óbito de recém nascido com diagnóstico de anomalia congênita no SINASC, ontologia $O D_{S M I} \ldots \ldots \ldots \ldots$

5.11 Diagrama representando o caminho percorrido para responder à questão de competência Houve óbito de algum recém nascido que tem registro de anomalia congênita no SINASC . . . . . . . . . . . . . . . . . . . . . . 57

5.12 Resposta da questão de competência sobre as causas do óbito de recém nascido,

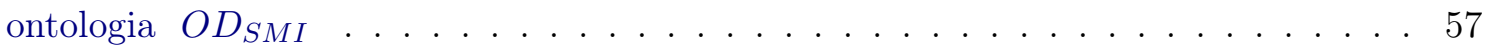

5.13 Resposta da questão de competência sobre a presença de diagnóstico de anomalia congênita do recém nascido, ontologia $O D_{S M I} \ldots \ldots \ldots \ldots$. . . . . 58

5.14 Resposta da questão de competência sobre a quantidade de consultas pré-natal realizadas durante a gestação, ontologia $O D_{S M I} \ldots \ldots \ldots \ldots \ldots$

5.15 Resposta da questão de competência sobre a existência de óbito fetal, ontologia $O D_{S M I} 58$

5.16 Resposta da questão de competência sobre a hora do nascimento do recém nascido,

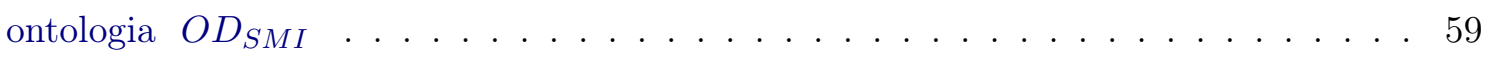

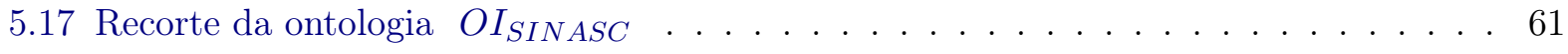

5.18 Recorte da tela do framework SILK já com as ontologias $O I_{S I N A S C}$ e $O I_{S I M} \ldots \ldots 2$

A.1 Diagrama Entidade Relacionamento - SINASC . . . . . . . . . . . . . . . 67

A.2 Diagrama Entidade Relacionamento - SIM . . . . . . . . . . . . . . . 68

B.1 Consulta exemplo de recém nascidos presentes na ontologia $O F_{S I N A S C}$ - FR . . . 69

B.2 Consulta exemplo de recém nascidos com anomalia congênita presentes na ontologia

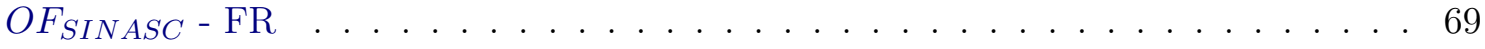

B.3 Consulta exemplo de óbitos de menores de 1 ano presentes na ontologia $O F_{S I M}$ - FR 70

B.4 Consulta exemplo da data de nascimento dos óbitos de menores de 1 ano presentes na ontologia $O F_{S I M}-\mathrm{FR} \ldots \ldots \ldots \ldots \ldots$

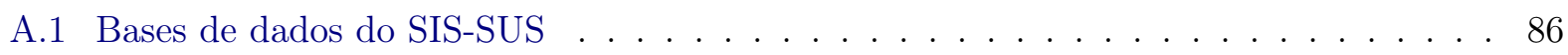




\section{Lista de Tabelas}

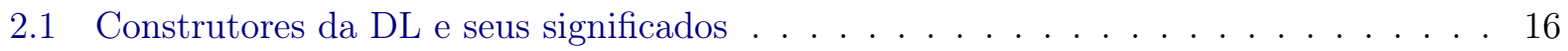

4.1 Tipos de indivíduos encontrados na integração das bases de dados do SINASC e SIM 34

5.1 Campos referentes ao CNES . . . . . . . . . . . . . . . . . . 60

5.2 Apresentação da idade na tabela do SIM . . . . . . . . . . . . . . . 60

C.1 Descrição das questões de competência - Objeto de estudo: Mãe . . . . . . . . . . . 73

C.2 Descrição das questões de competência - Objeto de estudo: Nascido Vivo, Filho ou Recém Nascido $(\mathrm{RN}) \ldots \ldots$. . . . . . . . . . . . . . . . . . 74

C.3 Descrição das questões de competência - Objeto de estudo: Gestação . . . . . . . . . 75

C.4 Descrição das questões de competência - Objeto de estudo: Parto . . . . . . . . . . 75

D.1 Anomalia Congênita . . . . . . . . . . . . . . . . . 77

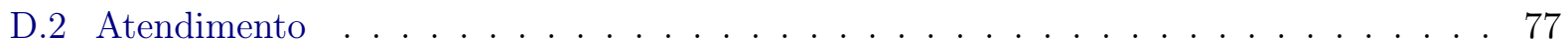

D.3 Atendimento Ambulatorial . . . . . . . . . . . . . . . . 77

D.4 Consulta Ambulatorial . . . . . . . . . . . . . . . . . . . . . 78

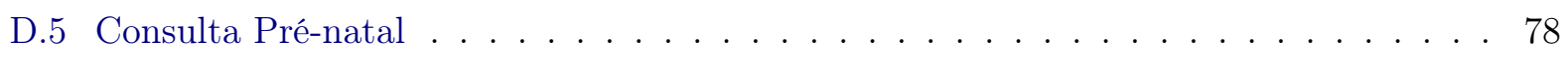

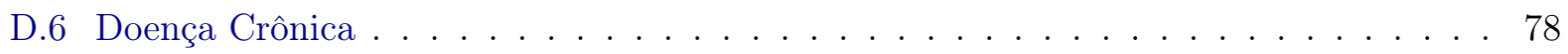

D.7 Doença Transmissível . . . . . . . . . . . . . . . . . . . . . . 78

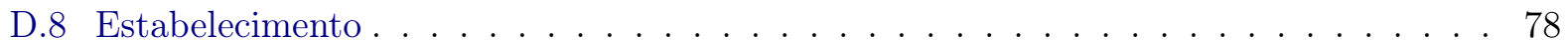

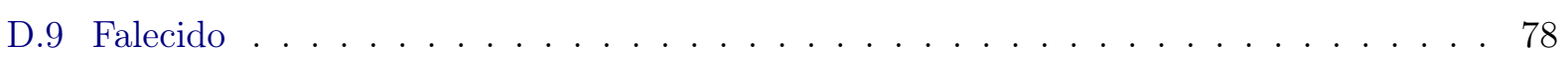

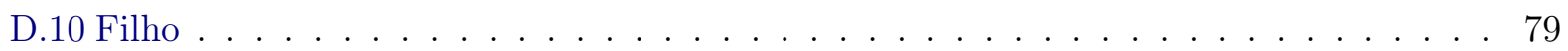

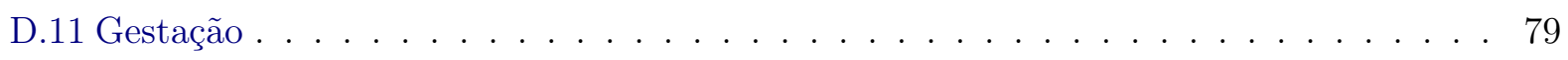

D.12 Internação . . . . . . . . . . . . . . . . . . . . . . . . . . . . 79

D.13 Internação Relacionada à Gravidez . . . . . . . . . . . . . . . . . . . . . . . 79

D.14 Localização da Ocorrência . . . . . . . . . . . . . . . . . . . . . . . . . . 80

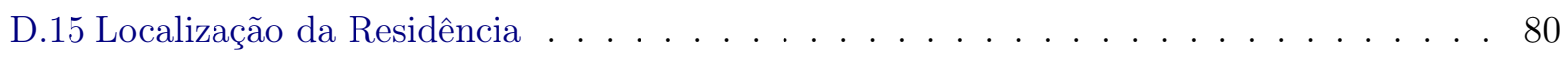

D.16 Localização do Estabelecimento . . . . . . . . . . . . . . . . . . . . . . . . . 81

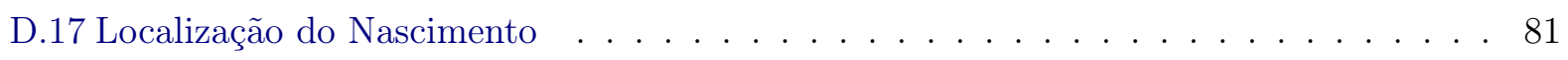

D.18 Mãe . . . . . . . . . . . . . . . . . . . . . . . . . . . . . 81

D.19 Nascido Vivo . . . . . . . . . . . . . . . . . . . . . . . . 81

D.20 Nascimento . . . . . . . . . . . . . . . . . . . . . . . . . . . . 82

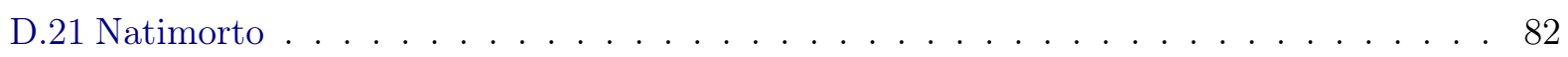

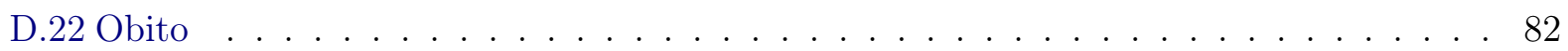

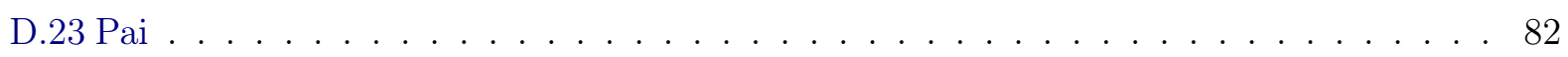


D.24 Parto . . . . . . . . . . . . . . . . . . . . . . . . . . 83

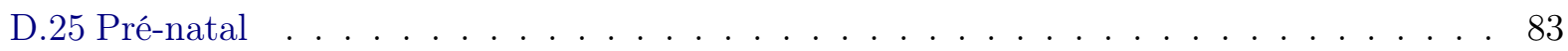

D.26 Procedimento . . . . . . . . . . . . . . . . . . . . . . 83

D.27 Recém-nascido . . . . . . . . . . . . . . . . . . . . . . . 83

D.28 Trabalho de Parto . . . . . . . . . . . . . . . . . . . . . . 84

D.29 Usuário . . . . . . . . . . . . . . . . . . . . . . . . . . . . . . . 84

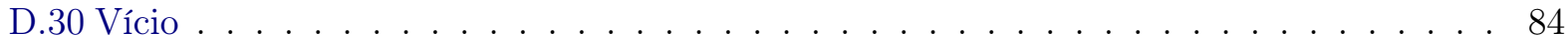




\section{Capítulo 1}

\section{Introdução}

O avanço da tecnologia tem levado a uma maior disponibilização de fontes de dados, das mais diversas áreas do conhecimento [MSAPLC $\left.{ }^{+} 17\right]$. É nesse cenário marcado pelo incentivo à publicação e uso de dados em que a divulgação de dados populacionais chama a atenção para as possibilidades de novas análises voltadas tanto à melhoria da gestão pública quanto aos novos campos de pesquisa.

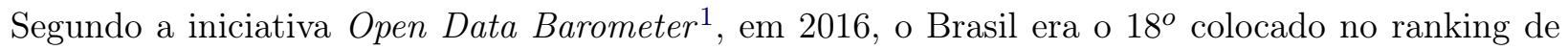
144 países avaliados quanto à disponibilidade e qualidade dos dados públicos de seus municípios, em áreas como saúde, educação, finanças, legislação, entre outras. Embora bem colocado e com diversas iniciativas para a publicação dos $\operatorname{dados}^{2}$, a necessidade de melhoria da qualidade das fontes é perceptível, principalmente no que diz respeito à licenças para uso aberto, identificadores únicos para os registros e formatos legíveis por máquinas, como CSV e XML.

Com a ideia da disponibilização das fontes de dados, surge a necessidade de integração das mesmas e de, desta forma, obter análises mais complexas, com visões mais completas. Segundo [DC $\left.{ }^{+} 17\right]$, ao longos dos anos, foi observado um crescente interesse em integração dos dados, também, para assegurar a interoperabilidade entre as fontes de dados heterogêneas. O uso de modelos (semânticos) de representação do conhecimento, especialmente de ontologias, tem se tornado uma abordagem significante para a complexa tarefa de integração. Esta abordagem é difundida por iniciativas como: a Semantic Web, de [BHBL09, BL06], que busca atribuir um sentido, uma semântica, ao conteúdo presente na Web; e FAIR Data [WDA+16], que fala sobre a disponibilização de dados em boas condições para o reúso, ou seja com qualidade e documentação de contexto. [BPDH10] descreve sobre a necessidade de interoperabilidade das bases de dados apresentando alguns casos de sucesso onde a ligação só foi possível por meio de uma união entre governo e empresas privadas, ambos possuidores de diferentes tipos de dados.

A área da saúde, apesar de manter grande repositórios de dados, bem como glossários e padrões terminológicos, também padece dos mesmos problemas referentes à qualidade e heterogeneidade dos dados [SB06]. Em [MSAPLC $\left.{ }^{+} 17\right]$ são citados pelo três cenários que envolvem e dificultam a integração de dados na área da saúde:

- O primeiro está relacionado às diferenças entre os propósitos de criação e diferentes usos para os dados de origem clínica, como prontuários eletrônicos, dados advindos de pesquisas clínicas e aqueles de saúde pública. No Brasil ainda existe a diferença entre os dados gerados pelo SUS - Sistema Único de Saúde e pela saúde suplementar: os planos e seguradoras de saúde e os atendimentos financiados pelo próprio usuário. Esse viés de formação dos sistemas dificulta a integração, uma vez que não surgiram para serem integrados, podendo possuir falhas de segurança, confiabilidade e níveis inapropriados de agregação;

- O segundo cenário está ligado à crescente diversidade de fontes de dados, devido às várias

\footnotetext{
${ }^{1}$ Open Data Barometer: https://opendatabarometer.org/?_year=2016\&indicator=ODB

${ }^{2}$ Algumas iniciativas nacionais para a disponibilização de dados: Imprensa Nacional: http://portal.imprensanacional.gov.br/

Portal da Transparência: http://www.portaltransparencia.gov.br/downloads/
} 
origens e tecnologias utilizadas. Isso impõe conhecimentos distintos, carecendo, muitas vezes, de equipes multidisciplinares;

- O último cenário refere-se ao gerador do dado. Antes, os dados eram gerados num modelo centrado no provedor de saúde, agora eles são centrados no paciente. Isso tem reflexos na modelagem dos sistemas de informação, na assistência a saúde e na tomada de decisão ao nível de gestão. A forma a interpretação dos dados também sofre mudanças, bem como seu nível de confiabilidade.

Ao sistema de saúde brasileiro, além das questões supracitadas onde destacou-se a dificuldade de interoperabilidade, somam-se sistemas de informação independentes e redundantes [Bra15]. Embora existam iniciativas e indícios de progresso, nota-se que ainda há muito a ser feito, principalmente para manterem integradas as bases de dados atuais com as que surgirão no futuro. É possível destacar cinco propostas do Governo Federal e do Ministério da Saúde relacionadas à integração das informações:

- ePing - Padrões de Interoperabilidade de Governo Eletrônico ${ }^{3}$ : Iniciativa mais geral relacionada ao Governo Federal que regulamenta a utilização de tecnologia a fim de obter a interoperabilidade dos sistemas de informação públicos brasileiros. Nele são apresentadas as soluções recomendadas para adoção nos sistemas, como o uso de UTF-8 para os caracteres de texto das publicações oficiais e a terminologia padrão para termos clínicos em saúde o SNOMED-CT. $\mathrm{Na}$ caracterização dos modelos destaca-se que o desenvolvimento e manutenção de ontologias é preconizado como o padrão para a interoperabilidade dos dados na dimensão semântica dos sistemas de informação;

- CENTERMS - Centro Nacional de Terminologias em Saúde ${ }^{4}$ : O CENTERMS, que responde ao Ministério da Saúde, tem como objetivo propiciar discussões e gerenciar atividades técnicas relacionadas às terminologias de saúde utilizadas pelos sistemas eletrônico de dados em saúde a fim de que eles obtenham uma interoperabilidade semântica.

- RTS - Repositório de Terminologias em Saúde ${ }^{5}$ : É um portal desenvolvido pelo Ministério da Saúde, instituído pela Resolução CIT - Comissão Intergestores Tripartite $\mathrm{n}^{\circ} 39$ de 22 de março de 2018, com o objetivo de gerenciar e publicizar as terminologias em saúde utilizadas pelos sistemas de informação do Brasil, tais como CID - Classificação Internacional de Doenças, CNES - Cadastro Nacional de Estabelecimentos de Saúde, CBO - Classificação Brasileira de Ocupações e outras.

- CMD - Conjunto Mínimo de Dados ${ }^{6}$ : Instituído pelo Decreto de 29 de novembro de 2017 e pela Resolução CIT n ${ }^{\circ}$ 6, de 25 de agosto de 2016, o CMD é o sistema de coleta os dados de todos os atendimentos em saúde que ocorrem no território nacional, tanto do SUS quanto da saúde suplementar. Ele está em fase de implementação, já capturando informações sobre a atenção básica no SUS. O objetivo é substituir alguns sistemas de informação utilizados atualmente, tais como a APAC - Autorização de Procedimento Ambulatorial, o SIA - Sistema de Informação Ambulatorial e o SIH - Sistema de Informação Hospitalar.

- Conecte SUS ${ }^{7}$ : Lançada pelo Ministério da Saúde no dia 11 de novembro de 2019, a mais nova estratégia de informatização e integração dos dados de saúde dos pacientes do SUS visa integrar os sistemas por meio do CPF - Cadastro de Pessoa Física, ao invés do CNS Cartão Nacional de Saúde, até então considerado o principal identificador para os usuários do

\footnotetext{
${ }^{3}$ ePing: http://eping.governoeletronico.gov.br/

${ }^{4}$ CENTERMS: https://proadi.wixsite.com/centerms

${ }^{5}$ RTS: https://rts.saude.gov.br

${ }^{6}$ CMD: https://conjuntominimo.saude.gov.br

${ }^{7}$ Notícia sobre o programa Conecte SUS: http://www.saude.gov.br/noticias/agencia-saude/ 45989-saude-sera-conectada-em-todo-brasil
} 
SUS e priorizado nas ações anteriores, como o CMD. Como resultado o Ministério terá um único sistema de dados em saúde do SUS, o RNDS - Rede Nacional de Dados em Saúde. O projeto piloto, que foi iniciado no estado de Alagoas na data do lançamento do programa irá informatizar as UBS - Unidades Básicas de Saúde e em seguida integrar as bases de dados da atenção básica.

Dado o contexto dos diversos esforços para a integração e disponibilização dos dados em saúde, principalmente os do SUS, foi desenvolvida a proposta do presente projeto. Desse modo, o objetivo geral deste trabalho é realizar a integração semântica das bases de dados dos sistemas de natalidade - SINASC e mortalidade - SIM do SUS, ambas relacionadas à saúde materno-infantil e ao desenvolvimento do indicador de saúde DPGP - Dias Potenciais de Gravidez Perdidos [DRQK $\left.{ }^{+} 19\right]$. A integração foi testada com os dados do município de São Paulo, filtrando as variáveis que são úteis para o problema de pesquisa. Para isso, durante o curso da dissertação, foi eleita e adaptada uma metodologia de integração de bases de dados por meio de ontologias. Os objetivos específicos estão listados a seguir:

- Mapear as terminologias utilizadas nas bases de dados SINASC e SIM da cidade de São Paulo.

- Avaliar a abordagem de OBDI - Ontology Based Data Integration, integração de dados baseada em ontologia, que melhor se adéqua ao problema de pesquisa;

- Adaptar a metodologia escolhida à proposta da dissertação;

- Desenvolver as ontologias, considerando o reúso de ontologias existentes, contendo as terminologias e os schemas (ou parte deles) presentes nas bases de dados SINASC e SIM;

- Integrar as bases de dados SINASC e SIM por meio das camadas ontológicas criadas;

- Avaliar a qualidade da integração;

- Realizar buscas nas bases por meio das ontologias criadas;

- Disponibilizar os dados que já estavam públicos em um formato Linked Open Data.

De acordo com a literatura, com a integração das bases é possível transformar as informações acessíveis para humanos e máquinas [DH05] e assim seguir os pacientes por todo o fluxo de cuidado [MGL ${ }^{+}$09], localizá-los [GPS ${ }^{+}$15], aumentar a quantidade de informações sobre um indivíduo [MSMS17], reduzir o retrabalho, melhorar o acompanhamento clínico e aumentar a confiabilidade dos dados.

É esperado que, com esse trabalho, o conhecimento presente nas duas bases de dados possa ser visto por inteiro, auxiliando na compreensão dos dados, seu fluxo e contexto, por pessoas que não são especialistas no domínio. Será possível assim realizar um mapeamento dos termos presentes nos dados e nas relações entre os conceitos, tornando clara a determinação dos sujeitos das bases e auxiliando na realização de buscas, uma vez que o vocabulário será unificado. Outro resultado dessa abordagem é a possibilidade de reutilização da estrutura de integração para a realização de outros casos de uso que também utilizem o SINASC e o SIM.

\subsection{Motivação}

O panorama atual dificulta encontrar respostas a perguntas como:

- Quantos pacientes são atendidos pela rede de saúde?

- Quais foram os procedimentos realizados pelo paciente na última internação?

- Dado um filho recém nascido, qual o histórico de saúde da mãe? 
- A mãe possui registro de diagnóstico de diabetes ou sífilis anteriores a esta gestação?

- Caso o óbito tenha ocorrido em uma criança maior de 1 ano, qual foi o peso desta criança ao nascer?

- O recém nascido diagnosticado com anomalia congênita na TANU também tem seu registro realizado no SINASC?

Devido à fragmentação dos sistemas, redundância das informações é evidenciada em temas como o reporte das anomalias congênitas (malformações de órgãos ou partes do corpo durante o desenvolvimento no útero ${ }^{8}$ ). Afinal, seus dados estão distribuídos em oito bases independentes:

- SINASC: Sistema de Informações de Nascidos Vivos. A principal fonte de dados sobre o tema;

- SIM: Sistema de Informações de Mortalidade;

- SIH: Sistema de Informações Hospitalares;

- BPA-I: Boletim de Produção Ambulatorial Individualizado;

- APAC: Autorização de Procedimentos de Alta Complexidade;

- TANU: Triagem Auditiva Neonatal Universal;

- GSS: Gestão de Sistemas de Saúde;

- SIGA: Sistema Integrado de Gestão da Assistência à Saúde. Sistema presente no município de São Paulo onde há o cadastro de usuários do SUS do município, os atendimentos e os registros do SISPreNatal, sistema para o registro e acompanhamento de gestantes.

Muitos desses sistemas têm seus dados disponibilizados no site do DATASUS ${ }^{9}$. Os dados podem ser adquiridos em formato CSV a partir de uma interface online de filtragem, o TABNET ${ }^{10}$. Caso seja necessária a aquisição da base completa, sem filtros por colunas, o acesso se dá a partir da página de arquivos de dados ${ }^{11}$. Nesta página os arquivos são disponibilizados em formato DBF (uma extensão originária das bases de dados dBase que ainda hoje é a padrão para exportação de dados no SUS) ou DBC (uma extensão de compactação do DBF). Esses arquivos devem ser transformados em CSV pelo usuário do conjunto de dados.

Além das páginas do DATASUS, é possível obter dados do SUS das seguintes maneiras:

- Acessando a plataforma PCDAS - Plataforma de ciência de dados aplicada a saúde ${ }^{12}$, do Icict - Instituto de Comunicação e Informação Científica e Tecnológica em Saúde, da Fiocruz. A plataforma desenvolvida pela Fiocruz do Rio de Janeiro tem a finalidade de ampliar o acesso aos dados do SUS de maneira fácil e intuitiva, apresentando os dados de alguns sistemas do SUS, já previamente tratados. Há ainda a opção de visualização dos dados e a disponibilização de ferramentas de análise de dados, como o R Studio Server ${ }^{13}$.

- Acessando iniciativas de distribuição de dados pelo Governo Federal ou pelas Secretarias Estaduais ou Municipais de Saúde, tais como os portais Brasileiro de Dados Abertos ${ }^{14}$, Governo Aberto SP ${ }^{15}$, Dados Abertos da Prefeitura de São Paulo ${ }^{16}$ e o portal Conecta SUS, do governo de Goiás ${ }^{17}$.

\footnotetext{
${ }^{8}$ Anomalias congênitas: http://decs.bvs.br/cgi-bin/wxis1660.exe/decsserver/

${ }^{9}$ DATASUS: http://www2.datasus.gov.br/DATASUS/index.php?area $=02$

${ }^{10}$ TABNET: http://www2.datasus.gov.br/DATASUS/index.php?area $=060804$

${ }^{11}$ Arquivos de dados DATASUS: http://www2.datasus.gov.br/DATASUS/index.php?area=0901

${ }^{12}$ ICICT: https://bigdata.icict.fiocruz.br/

${ }^{13} \mathrm{R}$ Studio: https://rstudio.com/products/rstudio/

${ }^{14}$ Portal de Dados Abertos: http://dados.gov.br/dataset?organization=ministerio-da-saude- $\mathrm{ms}$

${ }^{15}$ Governo Aberto SP: http://www.governoaberto.sp.gov.br/

${ }^{16}$ Prefeitura de São Paulo: http://dados.prefeitura.sp.gov.br/pt_PT/

${ }^{17}$ Conecta SUS, Governo de Goiás: http://www.conectasus.go.gov.br/campanhas-conecta-sus/
} 
- Realizando o cadastro para ter acesso controlado à Plataforma de Dados Integrados do Cidacs ${ }^{18}$, o Centro de Integração de Dados e Conhecimento para Saúde, da FIOCRUZ de Salvador. A plataforma possui dados de uma Coorte de 100 milhões de brasileiros, com os indivíduos presentes nos sistemas Cadastro Único, responsável pelo cadastro dos cidadãos que recebem benefício social, SINASC e SIM.

- Parcerias locais com o Ministério da Saúde, por meio do DATASUS e/ou FIOCRUZ ou com as Secretarias Municipais e Estaduais, como é o caso deste projeto.

Os dados disseminados publicamente são devidamente anonimizados a fim de não comprometer a identidade dos pacientes e profissionais que atuaram no cuidado. Como consequência, a tarefa de ligação dos registros das bases, que depende do acesso aos dados identificados, precisa estar relacionada a um órgão mantenedor dos registros originais.

Do ponto de vista epidemiológico, ter as informações dispersas entre as bases significa não saber ao certo quantos pacientes foram diagnosticados e quais estão em tratamento. A falta de informações leva à erros no número de notificações, o que enviesa a elaboração de indicadores demográficos e de saúde, dificultando a acurácia do desenvolvimento de sistemas de vigilância e estabelecimento de políticas de saúde [Sã12].

Ao inquirir soluções, é observado que questões como a compreensão da terminologia utilizada para o preenchimento dos registros e a necessidade de análises extremamente contextualizadas, dificultam iniciativas de profissionais de fora da área da saúde. Por outro lado, lidar com tamanho das bases e a complexidade computacional que as permeia é um fator limitador para os profissionais da saúde. Isto é agravado quando a população alvo é a da cidade de São Paulo, que em 2010 era de mais de 11 milhões ${ }^{19}$. Conforme apresentado em conversa com técnicos da SMS-SP - Secretaria Municipal da Saúde de São Paulo, a cidade possui complexidade de uma unidade da federação, o que dificulta a adequação dos seus sistemas de informação às soluções gerais, como a de e-Saúde, sugerida pelo Ministério da Saúde [Bra17].

\subsection{Caracterizando o projeto}

Apresentadas as circunstâncias em que o projeto está inserido, os desafios tanto computacionais quanto específicos do domínio da saúde, tornam-se perceptíveis, sendo necessário contar com uma equipe multiprofissional. Para a realização desta pesquisa, foi desenvolvida uma parceria com a SMS-SP e com a Faculdade de Saúde Pública da USP. Com o auxílio da equipe de especialistas (composta por aproximadamente 20 profissionais, entre especialistas nas bases de dados e técnicos da SMS-SP e professores e alunos de pós graduação da Faculdade de Saúde Pública da USP) foi possível compreender o domínio e levantar as questões supracitadas. Da colaboração também veio o acesso às bases individualizadas não identificadas do SINASC e do SIM para o município de São Paulo e as questões de competências que foram utilizadas para validar as ontologias desenvolvidas.

Os especialistas guiaram a escolha das bases de dados e do caso de uso: saúde materno-infantil voltada para o desenvolvimento do indicador de saúde DPGP, utilizando os dados do município de São Paulo. O desenvolvimento do indicador de saúde se dá no contexto do projeto Dias Potenciais de Gravidez Perdidos (DPGP): uma medida inovadora da idade gestacional para avaliar intervenções e resultados de saúde materno-infantil. $\mathrm{O}$ objetivo do projeto é a realização de um estudo sobre a avaliação da idade gestacional e das consequências de nascimentos precoces para a população. A partir disso, é esperado o desenvolvimento de um indicador de saúde que medirá a perda no tempo de gestação, comparando-a com o tempo de gestação esperado [DRQK $\left.{ }^{+} 19\right]$. No entanto, a elaboração do indicador necessita da integração das bases de dados de natalidade e mortalidade, da compreensão das variáveis e de como se dá o seu preenchimento. A necessidade de técnicas de integração que levam em conta o uso de contexto foi determinante na escolha deste estudo de caso.

\footnotetext{
${ }^{18}$ Cidacs: http://cidacs.bahia.fiocruz.br/

${ }^{19}$ IBGE, São Paulo, SP : https://cidades.ibge.gov.br/brasil/sp/sao-paulo/panorama
} 
Outros trabalhos que utilizaram uma metodologia integração semântica de bases de dados e que serviram como parâmetro para a dissertação podem ser citados: [dMMV15, FPB16, RP16, $\mathrm{SGW}^{+}$18, SGSK18, ZHZZ07, MBM12, BGB $\left.{ }^{+} 16\right]$.

A abordagem técnica utilizada para a realização da integração semântica foi influenciada pelos trabalhos de dMMV15, FPB16, RP16, $\mathrm{SGW}^{+} 18$, SGSK18, ZHZZ07, MBM12, BGB ${ }^{+} 16$. No entanto, foram os trabalhos de $\mathrm{VCA}^{+} 15$, LVO16b, LOV17 que mais trouxeram contribuições. Neles, os autores desenvolveram um framework baseado em ontologias para a especificação formal de visões Linked Data Mashup (LDM). Onde mashups são um tipo de aplicação web que oferece novas funcionalidades ao combinar, agregar e transformar recursos pré-existentes. O framework possui 4 camadas e manutenção incremental de acordo com as necessidades do usuário final, sendo apresentado na Figura 1.1.

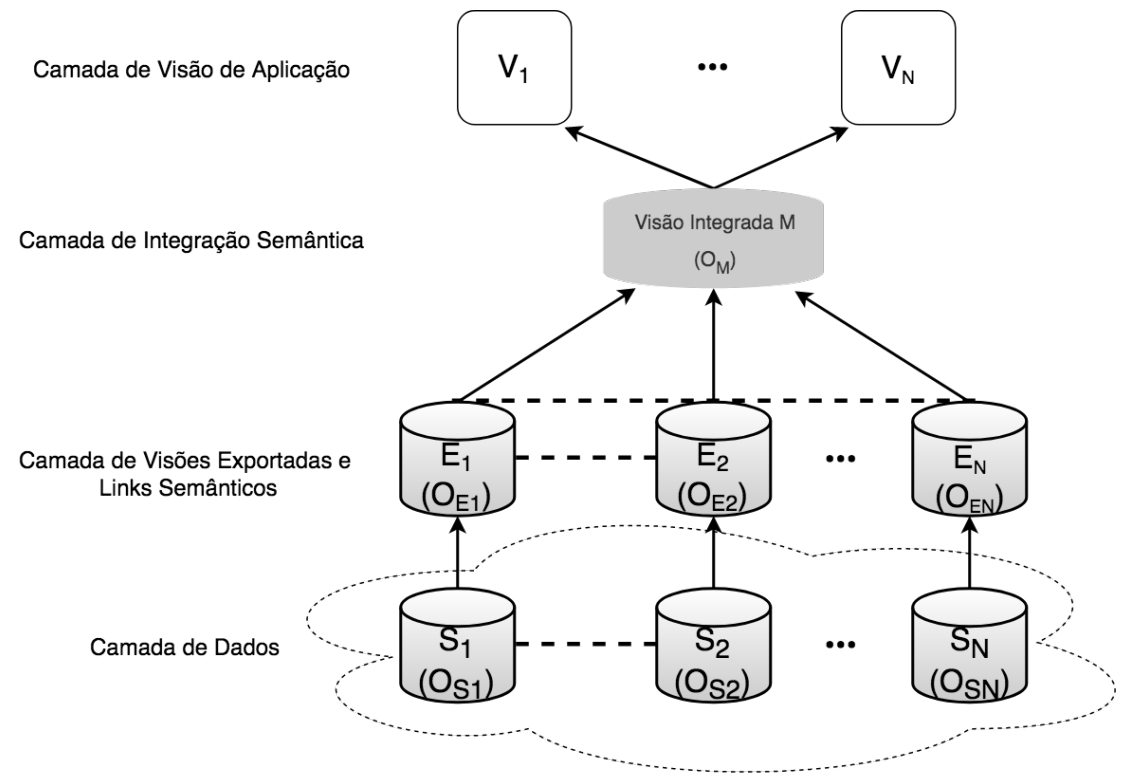

Figura 1.1: Representação do framework de 4 camadas. Imagem apresentada no artigo [LVO16b]

Iniciando das camadas inferiores até as superiores, temos:

- Camada de dados: Onde estão localizadas as bases de dados, denominadas fontes de dados $S_{i}$. Cada fonte de dado $S_{1} \ldots S_{N}$ dá origem a uma ontologia $O_{S i}$ que a descreve, de acordo com os princípios do Linked Data.

- Camada das visões exportadas e links semânticos: É composta pelas diversas visões exportadas $E_{1} \ldots E_{N}$ a partir das ontologias da camada de dados $O_{S 1 \ldots S_{N}}$. Assim, são geradas novas ontologias $O_{E 1 \ldots E_{N}}$ que refletem a visão exportada. As novas ontologias são $O_{E 1} \ldots O_{E N}$. Nesta camada também são definidas as regras para a descoberta dos links semânticos. Cada link semântico aponta a similaridade entre dois objetos do mundo real localizados em bases distintas.

- Camada de integração semântica: Camada que contém a ontologia de domínio $O_{M}$. Esta representa a visão integrada homogênea $M$ sobre as fontes de dados $S_{1}, \ldots, S_{N}$ unificadas.

- Camada de visão de aplicação: Construída a partir de parâmetros passados pelo usuário final, esta camada possui as diversas visões de aplicações $V_{1} \ldots V_{N}$, construídas para cada contexto.

Como parte do resultado desses estudos o grupo publicou um site ${ }^{20}$ contendo um aprofundamento do método e alguns estudos de caso. No principal deles, o grupo realizou uma prova de

\footnotetext{
${ }^{20}$ SemanticSUS: https://semanticsus.github.io/semanticSUS/index.html
} 
conceito com as bases do e-SUS (que contém dados clínicos dos indivíduos) e do SINASC, através de uma parceria com a Secretaria Municipal da Saúde de Tauá-CE, cuja população, no Censo do IBGE de 2010, era de 55.716 habitantes $^{21}$. Foi então desenvolvida uma ferramenta que visa auxiliar a tomada de decisão dos gestores públicos por meio de acompanhamento e previsão de casos de mortalidade materno-infantil no município, associando-os aos hábitos maternos [LVO16a].

\subsection{Contexto do projeto}

Este trabalho foi desenvolvido no contexto do subprojeto Combining Data for Better Health$\operatorname{care}^{22}$, do INCT de Cidades Inteligentes InterSCity - Enabling the Future Internet for Smart Ci$t_{i e s}{ }^{23}$, financiado pela FAPESP, CAPES e CNPq. Para a realização da dissertação estiveram envolvidos técnicos da SMS-SP e professores e alunos da Faculdade de Saúde Pública da USP envolvidos no projeto Dias Potenciais de Gravidez Perdidos (DPGP): uma medida inovadora da idade gestacional para avaliar intervenções e resultados de saúde materno-infantil, financiado pelo CNPq e pela Fundação Bill e Melinda Gates. Contou-se também com a colaboração do grupo de pesquisa liderado pela professora Vânia Vidal, da Universidade Federal do Ceará.

\subsection{Publicações e Apresentações}

Durante o desenvolvimento da dissertação foram publicados os seguintes trabalhos:

- Pereira, Débora Lina N. Ciriaco, Renata Wassermann, e Laís Salvador. "Integração Semântica das Bases de Dados do Município de São Paulo: Um Estudo de Caso com Anomalias Congênitas." Em ONTOBRAS (http://ceur-ws.org/Vol-2228/abstract2.pdf), pp. 276-281. 2018.

- Ciriaco, Debora Lina, Alexandre Pessoa, Laís Salvador, e Renata Wassermann. Semantic Data Integration for Public Health in Brazil. LatinX in AI Research at ICML 2019, Jun 2019, Long Beach, Estado Unidos. (https://hal.archives-ouvertes.fr/hal-02266921/document)

E realizadas apresentações nos seguintes eventos:

- $2^{\circ}$ Seminário da pesquisa "Dias potenciais de gravidez perdidos (DPGP): uma medida inovadora da idade gestacional". Ontologia e integração semântica - avanços e desafios. 24-25 de Outubro 2019, São Paulo, Brasil.

- $1^{\circ}$ Seminário da pesquisa "Dias potenciais de gravidez perdidos (DPGP): uma medida inovadora da idade gestacional". Ontologia do nosso objeto: avanços e desafios. 07 de Julho 2019, São Paulo, Brasil.

- Innovative Engineering Solutions for Affordable Health Technologies for Latin America. DIASUS: Data, Integration and Analysis for Brazilian Public Health System. 13-15 Maio 2019, Rio de Janeiro, Brasil.

- $2^{\mathrm{o}}$ Workshop do Projeto InterSCity do Instituto Nacional de Ciência e Tecnologia da Internet do Futuro para Cidades Inteligentes. DIA-SUS: Data, Integration and Analysis for Brazilian Public Health System. 15-17 Abril 2019, São Sebastião, Brasil.

\footnotetext{
${ }^{21}$ IBGE, cidade de Tauá- CE: https://cidades.ibge.gov.br/brasil/ce/taua/panorama

${ }^{22}$ DataHealth: https://interscity.org/research_themes/combining-data-better-health-care/

${ }^{23}$ INCT InterSCity: https://interscity.org/
} 


\subsection{Organização do trabalho}

No capítulo 2, são apresentados os principais conceitos concernentes a este trabalho. Os capítulos seguintes expõem a metodologia seguida neste trabalho. No capítulo 3, a metodologia geral é descrita, assim como as escolhas de arquitetura. Os dois capítulos seguintes mostram o desenvolvimento das ontologias e dos seus respectivos mapeamentos, primeiro os independentes da aplicação (capítulo 4) e depois os dependentes (capítulo 5). Finalmente, no capítulo 6 a conclusão do trabalho é apresentada, incluindo uma seção de trabalhos futuros. 


\section{Capítulo 2}

\section{Conceitos}

Neste capítulo serão apresentados os conceitos necessários para a compreensão da proposta de dissertação.

\subsection{Integração de dados}

A invenção da internet e a revolução dos computadores levou o acesso ao dado digital a bilhões de pessoas. Assim, manipulá-lo e obter o máximo do seu potencial é algo desejado por muitos. Entretanto, diferente do isolamento dos sistemas de informação tradicionais, atualmente tem crescido a necessidade por sistemas integrados e interoperáveis. A integração de dados promove a manipulação transparente dos mesmos entre as múltiplas fontes [CX05]. No entanto, o processo de integração dos dados é cheio de desafios: por questões de sistemas, como montar uma estrutura de comunicação entre as bases de dados; por razões lógicas, como a heterogeneidade semântica das múltiplas bases de dados; ou pelo acesso, organização e gestão dos dados [DHI12a].

As fontes de dados podem se heterogêneas na sintaxe, no esquema ou na semântica. A heterogeneidade sintática é resultado de diferentes modelos e linguagens de dados. Já a heterogeneidade esquemática é fruto de diferenças estruturais, enquanto que a semântica é causada pela diferença do significado ou interpretação do dado em um determinado contexto [CX05].

Segundo [Chr12], integrar dados advindos de diferentes fontes é um processo que consiste de três tarefas. A seguir essas tarefas serão apresentadas e discutidas:

- Alinhamento de esquema - schema matching: Essa tarefa consiste em identificar as diversas fontes de dados, bem como seus atributos, estruturas, vocabulários e completude. Aqui também é importante notar como se dará o acesso aos dados e se há alguma restrição em termos de privacidade. O componente principal do alinhamento de esquema é o Mapeamento de esquema - Schema mapping.

- Mapeamento de esquema - Schema mapping: É no mapeamento do esquema onde ocorrerá a especificação de quais dados existem e de como os termos utilizados nas fontes de dados se relacionarão com o esquema que mediará a integração. Existem várias classes de mapeamento de esquema, entre elas as mais conhecidas, de acordo com [DHI12b], são:

* Global-as-View - GAV: Aqui, o esquema mediador, ou global, é definido como um conjunto de visões sobre as fontes de dados. A principal vantagem do GAV é a sua simplicidade metodológica. Para reformular uma consulta basta refazer as conexões do esquema geral com as fontes de dados. Sua principal limitação está na adição e remoção de fontes de dados, que resultará na remodelagem de todas as conexões;

* Local-as-View - LAV: Essa abordagem segue exatamente o oposto da anterior. Aqui, as fontes de dados servem de visões para o esquema global, descrevendo-as da maneira mais precisa e independente o possível. Assim, sua maior vantagem é a possibilidade de combinar os dados de diversas fontes, sendo fácil adicioná-los e removê-los. 
No entanto essa facilidade demanda uma maior complexidade na formulação das consultas;

* Global-and-Local-as-View - GLAV: O formalismo das duas abordagens anteriores é expresso na abordagem GLAV. Aqui, são realizadas duas consultas, uma a partir do esquema global e outra a partir das fontes locais, o que permite aproveitar dos benefícios de ambas as abordagens.

Muitos artigos sobre integração semântica de dados (que será vista nos tópicos posteriores) apresentam essas abordagens para guiar as metodologias de integração. No entanto, com o passar dos anos e com a especialização das técnicas semânticas, a contextualização dessa abordagem tem caído em desuso.

- Linkage dos registros - data matching: A principal tarefa do linkage dos registros é identificar e relacionar os mesmos indivíduos do mundo real nos diferentes registros das fontes de dados. Um caso especial de linkage dos registros é a detecção de duplicidades (presença do mesmo indivíduo em uma única fonte de dados). Há diferentes métodos para realização desses relacionamentos, no entanto eles geralmente são divididos entre:

- Linkage determinístico: No linkage determinístico os registros idênticos de acordo uma ou mais variáveis é tido como pertencente ao mesmo indivíduo;

- Linkage probabilístico: No linkage probabilístico são executados algoritmos de proximidade entre os registros. Aqueles registros que atingirem um nível aceitável de similaridade são considerados pertencentes ao mesmo indivíduo. Existem diversos algoritmos, como o Soundex e suas variações e ferramentas que auxiliam na realização desse processo, como o Reclink ${ }^{1}$ e o Merge Toolbox ${ }^{2}$.

Em $2006 \mathrm{STV}^{+} 06$ realizou uma revisão sistemática da literatura que apontou 71 publicações, referentes a 40 estudos que realizaram o linkage das bases de dados públicas brasileiras. A maioria dos trabalhos trata de linkage da base do SIM e do SINASC. Foi observado que, embora não seja um trabalho recente, as metodologias apontadas pouco sofreram alteração, como pode ser visto em $\left[\mathrm{MGL}^{+}\right.$09, BPDH10, RROB11, SF14, MSMS17]. A evolução das metodologias está mais relacionada aos softwares utilizados para a realização do linkage probabilístico, como o Epi Info ${ }^{3}$ e o OpenRecLink ${ }^{4}$, do que a uma mudança no paradigma das junções. Apesar disso, é possível observar incrementos metodológicos, como o de [PPS $\left.{ }^{+} 18\right]$ e o de [GPS $\left.{ }^{+} 15\right]$, que utilizou uma união entre a metodologia de linkage de dados probabilística com a codificação fonética.

- Fusão dos dados - data fusion: A terceira tarefa consiste em unificar os registros que foram classificados como sendo o mesmo indivíduo. Quando esse processo é aplicado em uma única base de dados ele é chamado de deduplicação.

\subsection{Integração Semântica dos Dados}

Ainda que de menor modo a integração semântica dos dados, na forma como geralmente é realizada, trate sobre o conteúdo semântico, é sabido que um maior esforço é necessário para a explicitação e compreensão do contexto por trás do dados. Afinal é sabido que, para que os dados coletados pelos sistemas sejam plenamente úteis, é essencial que haja mais do que o acesso aos dados, é fundamental que exista o entendimento do seu significado, das suas relações e do contexto, portanto que exista um componente semântico. Essa necessidade é tornada mais evidente quando é preciso integrar ou ter uma visão geral de sistemas cujos modelos de dados são diversos, as

\footnotetext{
${ }^{1}$ Reclink: http://reclink.sourceforge.net/

${ }^{2}$ Merge Toolbox: https://pro.arcgis.com/en/pro-app/tool-reference/data-management/merge.htm

${ }^{3}$ Epi Info: https://www.cdc.gov/epiinfo/index.html

${ }^{4}$ OpenRecLink: http://reclink.sourceforge.net/
} 
propriedades heterogêneas e a terminologia vasta. No entanto, comumente, durante o processo de modelagem de bases de dados relacionais e de planilhas, o componente semântico fica implícito nos nomes das tabelas e das variáveis, dificultando o entendimento para qualquer um que não seja o criador do conjunto de dados [CP17]. O mesmo ocorre quando os dados fazem parte de um sistema que distancia o preenchimento dos dados dos seus usuários finais, como é o caso das fichas de preenchimento do SUS. Ao longo do processo, a estrutura inicial é esquecida e o conteúdo semântico do preenchedor do dado, perdido.

Foi percebida então, a necessidade de ter sistemas que fossem capazes de expressar as conexões semânticas nos dados e entre os diferentes tipos de dados. Esses sistemas deveriam apresentar as nuances de contexto e, ao mesmo tempo, ser formal o suficiente para permitir que tanto softwares quanto seres humanos realizassem inferências baseadas no que está representado [CP17]. Quando, num processo de integração, há uma grande preocupação com os conceitos e as relações presentes nos conjuntos de dados, diz-se que há um processo de integração semântica. Nele, os dados semanticamente heterogêneos são integrados com uma menor perda de informação e uma maior recuperação do contexto [CX05].

Entretanto, estabelecer conexões semânticas entre bases de dados pode ser uma tarefa difícil, principalmente se as fontes de dados forem grandes e complexas. Os autores CP17 apontaram como desafios no processo de integração semântica dos dados: $\mathrm{O}$ acesso aos dados, o acesso ao contexto e a interpretação real dos dados e o estabelecimento de relações significativas entre os dados.

\subsubsection{Web Semântica}

Uma vez vencida a barreira do acesso aos dados, o acesso ao contexto e o estabelecimento das relações é algo que ainda dificulta o processo de integração, principalmente quando é necessário realizar um trabalho em larga escala. Ainda que nem todos os dados sejam disponibilizados na web e que a integração não seja feita com esse foco, o conceito de Web Semântica mudou a forma como se interage com o conhecimento representado, dando um novo fôlego para a área de integração semântica. A ideia de ter uma web conectada e com significado foi proposta por Tim Berners-Lee em 2001 [BL06] e tem gerado contribuições até os dias de hoje.

Como resultado da Web conectada, é possível ter a representação do mesmo objeto de diversas maneiras e ainda sim garantir sua identidade e as relações que esse objeto tem com outros objetos. As tecnologias e padrões relacionados à Web Semântica permitem a criação de um ambiente onde as aplicações são capazes de fazer consultas e inferências sobre os objetos e suas relações [? ]. Assim, ganha-se também a possibilidade de compreensão do conceito tanto por máquinas quanto por humanos. Usualmente a Web é compreensível por humanos, que conseguem interpretar seu conteúdo por meio dos textos escritos nas páginas e do conhecimento prévio do contexto em que o texto está inserido, no entanto é incompreensível por máquinas devido a ausência de marcadores de informação e de conectores entre os conceitos presentes nos diferentes sites.

Para que isso ocorra, no entanto, é necessário que os dados e as relações entre dados sejam disponibilizadas em um padrão. Ao nome da colação de fontes de dados inter-relacionados padronizadas presentes na Web chama-se Linked Data ${ }^{5}$.

\section{Linked Data}

Como dito anteriormente, Linked Data ou Dados Conectados é o nome dado à coleção de dados integrados presentes na Web. Um exemplo de uma grande quantidade de dados conectados no formato preconizado pela Web Semântica é a DBpedia ${ }^{6}$. Nela, o conteúdo da Wikipedia está disposto em RDF - Resource Description Framework ${ }^{7}$, um dos padrões da Web Semântica, o que permitiu a integração com outras fontes de dados da Web, como a Geonames ${ }^{8}$, uma base de dados

\footnotetext{
${ }^{5}$ Linked Data: https://www.w3.org/standards/semanticweb/data.html

${ }^{6}$ DBpedia: https://wiki.dbpedia.org/

${ }^{7}$ Framework é arcabouço conceitual que une um conjunto de códigos para a definição de uma metodologia geral para resolução determinada questão.

${ }^{8}$ Goenames: https://www.geonames.org/
} 
geográfica contendo países e nomes de lugares. O formato em que esses dados estão apresentados também permite a excussão de consultas, inclusive relacionadas ao conteúdo presentes em mais de uma fonte. Como resultado é obtida uma visão agregada sobre os conceitos modelados. Esta visão é tanto interpretável e reutilizável por máquinas, quanto enriquecida semanticamente para uma melhor compreensão por seres humanos, uma vez que a classificação dos dados se dá a partir de conceitos previamente definidos.

Outro exemplo do uso dos conceitos de Linked data é o projeto Linked Open Data (LOD) ${ }^{9}$, fundado em 2007 e que tem o suporte do grupo Semantic Web Education and Outreach - SWEO ${ }^{10}$, do $\mathrm{W}_{3} \mathrm{C}^{11}$. A iniciativa apoia a publicação de bases de dados em formato RDF, de acordo com os princípios do Linked Data e com a licença aberta [BHBL09]. O projeto começou em janeiro de 2017 com a disponibilização de 12 fontes de dados e em março de 2019 já possuía 1239 fontes de dados, inclusive a DBpedia.

Há uma série de características que tornam os dados melhor ou pior classificados como LOD. Para isso, criou uma classificação de cinco estrelas. Quanto mais estrelas, mais fácil é o acesso e a possibilidade de uso dos dados por outras pessoas. São elas:

1. Disponibilização dos dados na web(independente do formato), mas em uma licença aberta;

2. Disponibilização dos dados em formato compreensível por máquinas (como arquivos de tabelas ao invés de imagens de tabelas);

3. Disponibilização dos dados em formatos não proprietários como o csv e não xls ou dbf, além de seguir os itens anteriores;

4. Utilização de formatos abertos apoiados pelo W3C para identificar objetos, além de seguir os itens anteriores;

5. Ligação entre os dados disponibilizados aos de outras bases públicas, além de seguir os itens anteriores.

Como pode ser visto na classificação apresentada, a construção de páginas web que seguem o princípio da Web Semântica exige o uso de diversos padrões, os formatos abertos apoiados pelo W3C, tais como RDF, URI, OWL e SPARQL [CP17]. Esse padrões serão brevemente apresentados a seguir.

\section{Padrões da Web Semântica}

Os dados na Semantic Web são modelados e representados no padrão RDF, como discutido em [CP17]. Este modelo de dados permite uma descrição flexível dos objetos do mundo e ainda assim garante a descrição do contexto e a legibilidade por parte das máquinas (computadores) [HB11]. O RDF tem uma estrutura de triplas (composição de três elementos) baseada em grafos dirigidos, do tipo sujeito-predicado-objeto:

\footnotetext{
Sujeito: <http://www. semanticweb.org/DIASUS/SINASC\#AnomCongenita/Q246>

Predicado: rdf: type

Objeto: <http://www. semanticweb.org/DIASUS/SINASC\#AnomCongenita>
}

Tanto o sujeito quanto o objeto da tripla identificam um componente e um conjunto de caracteres. Já o predicado da tripla especifica como o sujeito e o predicado estão relacionados. Ambos são representados por meio de URIs [HB11]. O Uniform Resource Identifiers - URI é um padrão da web utilizado para identificar recursos abstratos ou físicos, sendo composto por uma sequência compacta de caracteres. No exemplo acima tanto o Sujeito quanto o predicado foram apresentados na forma

\footnotetext{
${ }^{9}$ Iniciativa LOD: http://lod-cloud.net/

${ }^{10}$ SWEO: https://www.w3.org/blog/SWEO/

${ }^{11}$ W3C: https://www.w3.org/
} 
de uma URI. A Uniform Resource Locator - URL é um subgrupo da URI, onde além de prover um identificador, possui um significado de localização [BLFM98]. Também no exemplo, o sujeito AnomCongenita/Q246 é um rdf:type do tipo do objeto AnomCongenita, onde rdf:type representa que o indivíduo AnomCongenita/Q246 é uma instância da classe AnomCongenita.

A fim de adicionar semântica ao modo de representação dos dados surgiu um complemento do RDF, o RDFS - RDF Schema. No RDFS há a adição de domínio e escopo (range), além de propriedades, características e relações hierárquicas aos conceitos. Com isso é possível representar informações como "Ser humano tem uma anomalia congênita", que é formalizado na seguinte tripla:

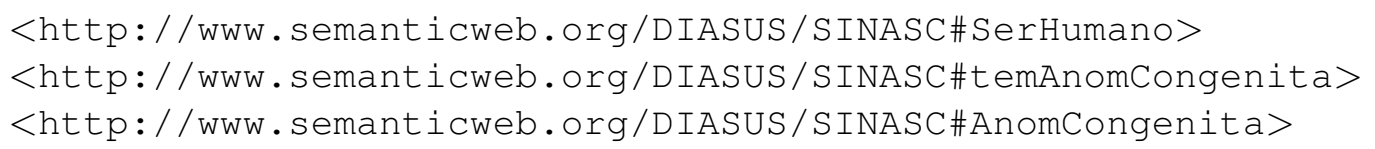

Entretanto, mesmo o RDFS possui limitações na estrutura de representação semântica, segundo AVH04, uma vez que não apresenta construtores lógicos, como o encadeamento de propriedades. Não há possibilidade, por exemplo de especificar restrições de cardinalidade. Assim, é impossível expressar que um ser humano possui exatamente dois genitores. Assim, a fim entender o RDF Schema, o W3C recomendou o uso da linguagem OWL - Web Ontology Language [AVH04]. O $\mathrm{OWL}^{12}$ é uma linguagem que mantém a sintaxe do RDF mas vai além da semântica proposta pelo RDF Schema, uma vez que basea-se em lógica de descrição (DL). Esse componente lógico permite a realização de intersecções de conceitos, bem como a determinação da cardinalidade, como mencionado anteriormente.

Para a excussão de consultas nos arquivos modelados em RDF (e consequentemente RDFS e OWL) foi desenvolvido o SPARQL - SPARQL Protocol and RDF Query Language. Essa linguagem compreende a sintaxe e o modelo de dados do RDF e também é baseado num modelo de grafos [AVH04]. Uma consulta que retornará todos os padrões de triplas cujo sujeito é um rdf:type e o objeto um rdfs:Class pode ser escrita como:

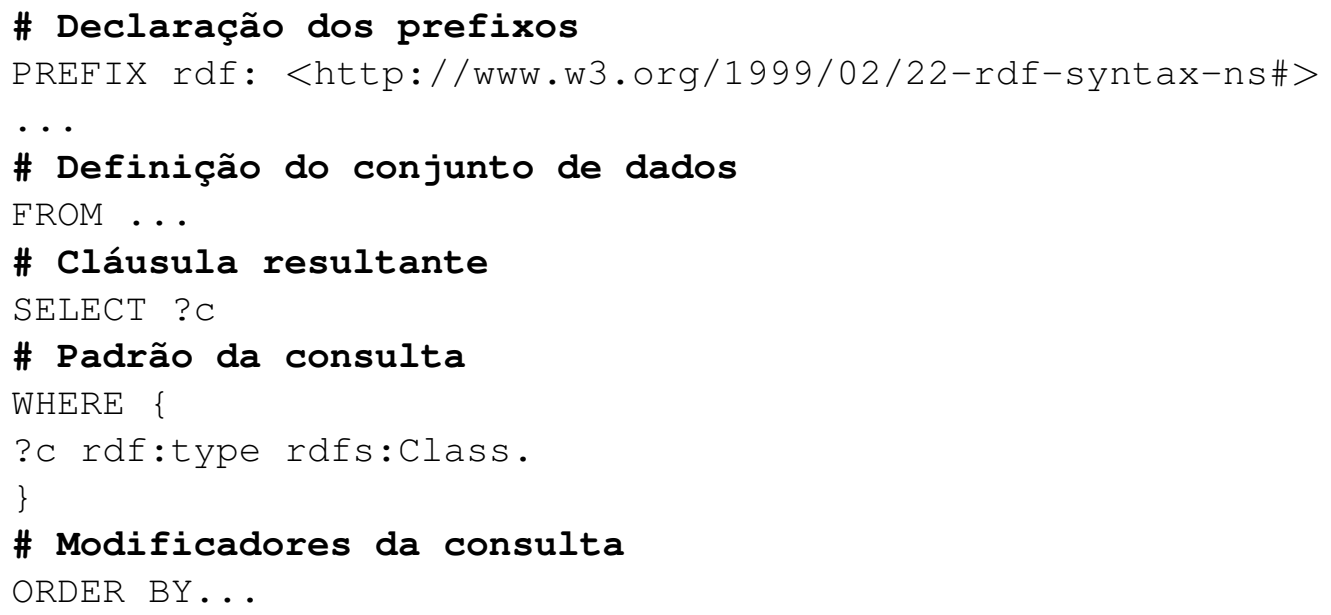

A consulta é composta por: i) Declaração dos prefixos, que são pseudônimos, abreviações das URIs. Geralmente os prefixos são utilizados para o acesso aos dicionários de tipos de dados e à própria ontologia; ii) Definição do conjunto de dados, o uso do FROM, entretanto é opcional na escrita da consulta. Caso não seja especificado é assumido que a busca está sendo realizada na ontologia do sistema da busca [AVH04]; iii) Cláusula resultante, que identifica quais informações deverão ser retornadas da consulta; iv) Padrão da consulta, que especifica o que será consultado do conjunto de dados; v) Modificadores da consulta, também opcionais, ordenam e reorganizam os resultados da consulta. Em SPARQL a representação das variáveis sempre é iniciada com uma interrogação (?), elas podem combinar quaisquer nós quem compõem o arquivo.

\footnotetext{
${ }^{12}$ OWL: https://www.w3.org $\backslash \mathrm{T} 1 \backslash$ guilsinglrightOWL
} 
Baseadas nesses padrões, são preconizadas boas práticas. Ao publicar seu artigo sobre Linked Data, Tim Berners-Lee estabeleceu quatro regras ou princípios para o conteúdo na web semântica [BL06]. A seguir são apresentados os princípios com explicações baseadas no trabalho de [HB11]:

1. Utilização de URIs para nomear objetos: Este princípio evoca a utilização de URIs não apenas para documentos presentes na Web ou nos meios digitais, mas também para objetos reais e conceitos abstratos. Isto ocorreu no exemplo de URI apresentado no tópico anterior, onde: <http://www. semanticweb.org/DIASUS/SINASC\#AnomCongenita/Q246>é a URI para a Anomalia Congênita Q246. O mesmo ocorre para a URI sobre Health Informatics da DBpedia: <http://dbpedia.org/page/Health_informatics>;

2. Utilização de URIs HTTP, assim as pessoas poderão consultar os objetos: URIs HTTP são nomes, não endereços. Assim, este princípio leva a identificar objetos e extrair conceitos a partir desse padrão. Ao nomear os objetos, seu acesso tona-se mais amplo. O exemplo da URI sobre Informática em Saúde apresentado no item anterior também é uma URI HTTP. Ao abrir o endereço em um navegador de Linked Data, como o LODmilla ${ }^{13}$, ou num navegador comum;

3. Fornecimento de informação útil, utilizando os padrões (RDF, SPARQL), para pessoas que consultam uma URI: Ao consultar uma URI é esperado que as informações estejam em formatos voltados para a compreensão do contexto, como o RDF e a linguarem de buscas SPARQL e não em um arquivo compactado;

4. Inclusão de links para outras URIs, assim será possível descobrir novos objetos: Aqui é incentivada a prática de criação de relações com outros conceitos, como pode ser visto na aba Links out, apresentada na Figura ??.

\subsection{Ontologias: Definições, Modelagem e Usos}

A seção anterior falou brevemente sobre OWL, a Web Ontology Language, mas não apresentou o conceito de ontologia, nem o que significa o OWL ser baseado em lógica de descrição. Aqui, esses conceitos serão esclarecidos com a apresentação de definições e exemplos, bem como serão apresentadas metodologias para a criação de ontologias.

Ao representar os dados presentes em uma rede de conhecimento, como por exemplo na Web, por meio de conceitos e ligações entre os conceitos (e assim, com semântica), estes são apresentados em ontologias. No entanto, o conceito de ontologias é anterior ao surgimento da Web semântica, assim como seu uso na ciência da computação.

A definição de ontologia mais utilizada pela ciência da computação é a do Gru93, na qual, ontologia é uma "especificação formal e explícita de uma conceitualização compartilhada". Onde, de acordo com CX05, "especificação formal" significa a possibilidade de compreensão por um computador, uma vez que é representada com um formalismo lógico-matemático; "explícita", o conjunto de conceitos, relações e restrições são explicitamente definidos; "conceitualização", é a representação em um modelo abstrato de um domínio de conhecimento que identifica os conceitos relevantes do domínio; e "compartilhada", significa que o conhecimento modelado é aceito por um grupo. Para além desta definição hoje é aceito que as ontologias podem ser utilizadas para descrever semanticamente as informações a fim de tornarem o conhecimento explícito e auxiliarem no processo de integração das fontes de dados $\left[\mathrm{WVV}^{+} 01\right]$. As fontes de dados, ao terem suas correspondentes em ontologias, podem ser usadas na identificação e associação de correspondências semânticas dos conceito, de modo que o conhecimento explicitado na ontologia assumirá uma forma de organização diferente ao apresentado nas bases de dados.

No entanto, é importante notar que nas ciências biomédicas o termo ontologia é frequentemente utilizado em um sentido mais amplo que o de representação formal baseada em lógica, sendo associado a tesouros, taxonomias e hierarquias terminológicas. A esse tipo de ontologias não formais, o

\footnotetext{
${ }^{13}$ LODmilla: http://lodmilla.sztaki.hu/lodmilla/
} 
W3C nomia de sistemas de organização do conhecimento - knowledge organization systems (KOS) [GPR16].

A presente dissertação utilizará o conceito de ontologia tal como a ciência da computação o faz de modo formal mas também levando em conta seu uso como forma de representação do conhecimento que explicita a semântica auxiliando na compreensão dos dados por parte dos especialistas.

A seguir, na Figura 2.1, é apresentado o diagrama da ontologia Semantic Web for Resource Community, descrita por CP17. Ao observar essa ontologia, é possível perceber que ela é composta por alguns tipos de entidades, como segue:

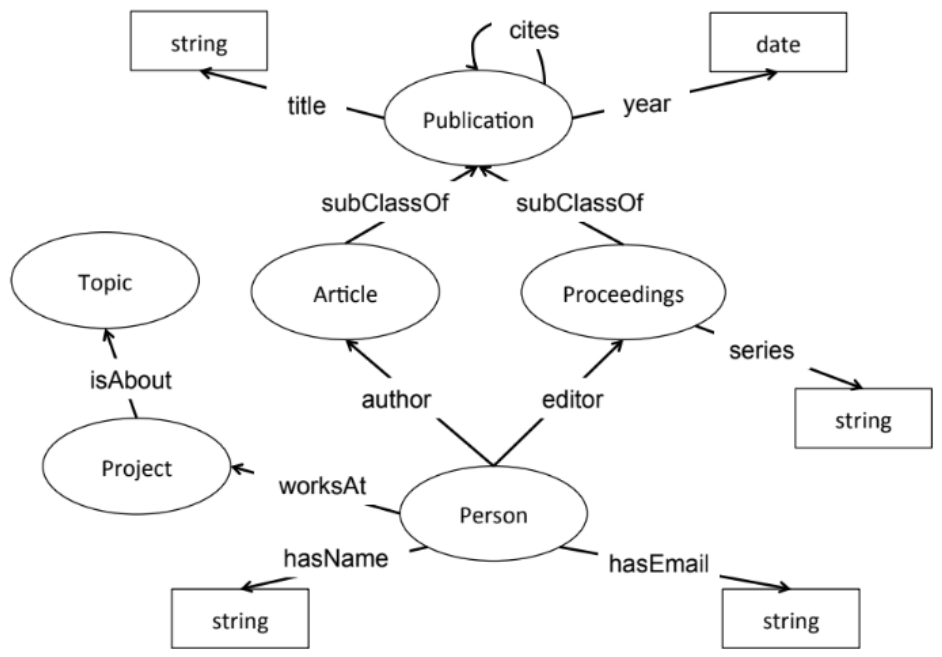

Figura 2.1: Representação de parte da ontologia Semantic Web for Resource Community criada por CP1\%.

- Classes: Representadas no diagrama pelas elipses, as classes são conceitos chaves de um domínio, podendo haver hierarquia como entre Publication e Article;

- Propriedades de objeto: Representadas como o rótulo das setas entre as classes, pois representam os relacionamentos entre as classes, como isAbout, entre Project e Topic;

- Propriedades de dados: Também representadas como o rótulo das setas, mas agora entre uma classe e um tipo de dado. É compreendida como uma característica da instância de uma classe, como ocorre com a propriedade hasName, que refere-se a classe Person e o tipo de dados string. Há ainda outros tipos de propriedade, que não está representada no diagrama, como a propriedade de anotação, que como o nome sugere serve para guardar informações sobre uma entidade ou outras propriedades;

- Tipos de dados - Datatype: Representadas pelos retângulos, os tipos de dados especificam a que tipo de dado as instâncias de determinado conceito corresponderão. No exemplo temos que a classe Person tem um nome - hasName e esse nome será do tipo string;

- Instâncias: Embora não estejam representadas no diagrama, as instâncias da ontologia são os objetos das classes. Uma instância da classe Person pode ser, por exemplo, Tom Gruber.

As classes e propriedades de uma ontologia pertencem ao esquema da ontologia, ou ao T-Box ("T" de terminológica). Já as instâncias da ontologia pertencem ao A-Box ("A" de asserção, afirmação) pois contém informações sobre os indivíduos que usam o conteúdo descrito na T-Box [CP17]. Quando bases de dados relacionais são convertidas em ontologias formam um volume muito maior na ABox que na T-Box, isso influencia no modo como serão realizadas as consultas e as inferências. No entanto, independente dos tamanhos da A-Box e da T-Box as inferência são realizadas por meio de um motor de inferências (reasoner), que reconhecerá fatos adicionais aos que estão formalmente descritos na ontologia, mas que não estão explícitos [AVH04]. 
A formalidade da ontologia leva a compreensão de que sua estrutura é baseada em lógica. Nesse sentido, as lógicas de descrição (DL) têm sido amplamente utilizadas para o desenvolvimento de ontologias. Essas lógicas permitem a especificação de classes e vários operadores, tais como união e intersecção [CGL $\left.{ }^{+} 18\right]$. A presença desses operadores lógicos dá o nome e caracteriza a DL e consequentemente da a expressividade da ontologia. A seguir na Tabela 2.1 são apresentados os principais construtores:

Tabela 2.1: Construtores da DL e seus significados, adaptado de [KPTR $\left.{ }^{+} 06\right]$

\begin{tabular}{c|c}
\hline Símbolo & Significado \\
\hline $\mathcal{U}$ & União entre os conceito \\
$\mathcal{A} \mathcal{L}$ & Intersecção entre os conceitos e restrição \\
$\mathcal{C}$ & de valores para os conceitos \\
$\mathcal{E}$ & Negação do conceito \\
$\mathcal{N}$ & Quantificação existencial do conceito \\
$\mathcal{O}$ & Presença de cardinalidade em um conceito \\
$\mathcal{I}$ & Presença de conceitos nominais \\
$\mathcal{H}$ & (enumeração de instâncias) \\
$(\mathcal{D})$ & Inversão de papeis entre conceitos \\
$\mathcal{S}$ & Presença de papeis hierárquicos \\
$\mathcal{R}$ & Presença de restrições de tipos de dados \\
\hline
\end{tabular}

\subsubsection{Engenharia de Ontologias}

Existem diversos trabalhos que tratam das metodologias para a criação ontologias [CFLGP03], [PM04], [NM01], [HKR $\left.{ }^{+} 04\right]$, [DNM16],[MFD16] no entanto aqui apresentaremos duas delas que foram utilizadas na metodologia da dissertação. A primeira, fruto do estudo [HMS17], é voltada para o desenvolvimento de ontologias a partir de bases de dados estruturadas pré-existentes. Já a segunda, de, está voltada para o desenvolvimento de ontologias a partir da eleição de questões de competências.

\section{Metodologia apresentada em [HMS17]}

O artigo [HMS17] é uma revisão da literatura de metodologias para a construção de ontologias a partir de bases de dados relacionais. Neste artigo os autores também sinterizaram os métodos em nove passos e os descreveram como gerais para o processo de engenharia. Esses passos serão apresentados a seguir:

1. Mapeamento de tabelas para classes $O W L$ : Neste passo há a definição dos nomes das classes das ontologias a partir no nome de cada uma das tabelas na base de dados;

2. Tratamento de tabelas de atributos multi-valorados: Aqui, as tabelas com atributos multi-valorados ${ }^{14}$ são localizadas nas bases de dados, afinal sua modelagem será diferente das demais, devendo ser mapeadas futuramente como propriedade de objetos;

3. Mapeamento dos relacionamentos de integridade referenciais para hierarquia de herança: Aqui, as classes correspondentes às tabelas que possuem chave estrangeira ${ }^{15}$ são

\footnotetext{
${ }^{14}$ Atributo multi-valorado é aquele atributo que pode receber mais de um valor ao mesmo tempo. Um exemplo é o campo de diagnóstico num Registro Eletrônico de Saúde, que pode conter mais de um CID para um paciente.

${ }^{15}$ Chave estrangeira é o campo de uma tabela que foi herdado de uma segunda tabela, sendo que, na tabela de origem ele é a chave primária. Chave primária, por sua vez, consiste do campo que é o identificador único dos registros da tabela.
} 
rearranjadas para se tornarem subclasses da classe da tabela de origem da chave estrangeira;

4. Mapeamento de colunas de integridade não referenciais para propriedades de tipos de dados: Aqui todas as colunas das tabelas da base de dados são convertidas em propriedades de dados, com exceção das chaves primárias, que se tornarão parte do mapeamento das propriedades de objeto na etapa 6;

5. Representação de propriedades de dados como dominio e tipos de dados como range: Nesta etapa, é feita a inclusão do domínio das propriedades de dados, que são as classes a que essas propriedades pertencem. São adicionados também os ranges, que são os tipos de dados correspondentes aos tipos de dados das variáveis de cada tabela;

6. Mapeamento dos relacionamentos (chave estrangeira) para propriedades do objeto: Nesse passo, cada relacionamento expresso na base de dados como sendo uma chave estrangeira é mapeado como uma propriedade de objeto. E assim devem ser criadas duas propriedades de objeto, uma para casa relação chave primária - chave estrangeira e uma para o inverso;

7. Representação das propriedades do objeto: Aqui serão representadas as propriedades de objeto e adicionados o domínio e o escopo de cada propriedade;

8. Mapeamento de tuplas para indivíduos: Aqui todas as tuplas da base de dados são mapeadas para tornarem-se indivíduos (instâncias) da ontologia;

9. Mapeamento de restrições de integridade de chave para propriedades de cardinalidade: Nesta última etapa as restrições de integridade de chave, como variáveis não nulas, são mapeadas como propriedades de cardinalidade na ontologia.

\section{Metodologia apresentada em [GF95]}

Nesta metodologia os autores especificam seis etapas para o desenvolvimento de ontologias, como o esquematizado na Figura 2.2.

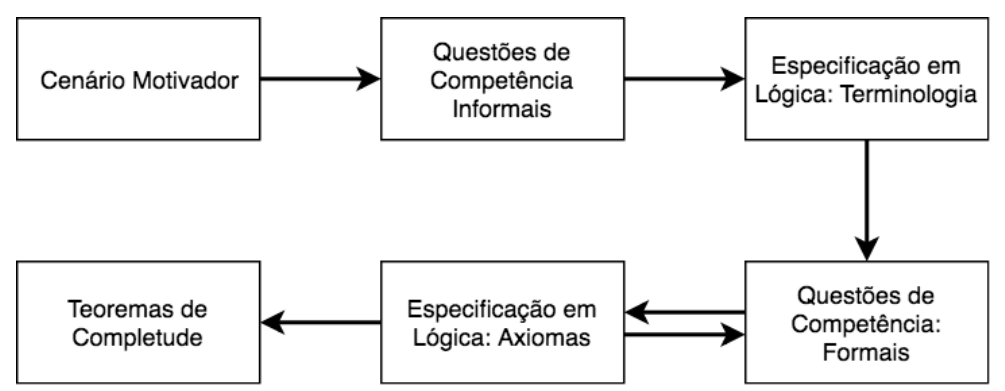

Figura 2.2: Metodologia para Engenharia de Ontologia apresentada em [GF95].

As etapas apresentadas pelos autores são:

- Cenário Motivador: A descrição do contexto em que a ontologia será produzida facilitará na delimitação da extensão da mesma, bem como de seu propósito na aplicação. Nesta etapa deve haver a especificação, geralmente em forma de história, de quais soluções foram testadas e se há a possibilidade de reúso de outras ontologias.

- Questões de Competência Informais: As questões de competência delimitarão o que conterá na ontologia e ao fim do processo, avaliarão a expressividade dela. Desse modo, as questões são consideradas requisitos aos quais a ontologia deve responder. Nesta etapa as questões de competência são consideradas informais porque não há nenhuma linguagem formal lógica definindo-as. 
- Especificação em Lógica: Terminologia: Nesta etapa é necessário especificar a terminologia que será utilizada na ontologia em alguma linguagem lógica. O primeiro passo para a especificação da terminologia de uma ontologia é a identificação de objetos, com atributos, relações e restrições.

- Questões de Competência: Formais: As questões de competência devem ser formalizadas independente da ontologia a fim de garantir o processo de validação. É necessário que todos os conceitos presentes nas questões de competência também estejam presentes na ontologia.

- Especificação em Lógica: Axiomas Os axiomas nas ontologias especificam a definição dos termos da ontologia, bem como das restrições de interpretação, desse modo há a garantia de significado ou semântica para os termos. Caso os axiomas sejam insuficientes para representar o significado final é necessário adicionar outros axiomas e questões de competências.

- Teoremas de Completude: Ao finalizar a construção da ontologia é necessário verificar se ela está completa, respondendo às questões de competência propostas.

\subsubsection{Ontologias na integração de dados}

Como discutido anteriormente, as ontologias têm sido utilizadas durante o processo de integração dos dados, principalmente quando há o desejo de acrescentar semântica e contexto aos dados. O trabalho de CX05 identificou cinco tipos usos para ontologias no processo de integração dos dados:

- Representação de metadados: As ontologias podem servir como uma linguagem única para a representação dos metadados (tais como dicionários de dados e esquemas de bases de dados) advindos de várias fontes. Nesse caso, cada metadado pode ser representado como uma ontologia local que enriquece o conhecimento representado sobre cada fonte;

- Conceitualização global: Aqui as ontologias podem promover uma visão global sobre as diversas fontes de dados independente da estrutura dessas fontes. Para isso uma ontologia global deverá ser construída;

- Auxílio para a realização de consultas em alto nível: Uma vez obtida uma visão global das fontes de dados é possível formular consultas sem o conhecimento prévio da estrutura das fontes de dados. Para isso as consultas serão reescritas em sub-consultas baseadas na semântica e nos mapeamentos entre as fontes de dados e as ontologias (tanto locais quanto global);

- Mediação declarativa: Aqui as ontologias assumem um papel de mediadoras para a realização de consultas nas bases de dados, principalmente quando o sistema de integração possui diversas fontes de dados;

- Suporte aos Mapeamentos: Uma vez formalizado o conhecimento por meio de ontologias, essas podem servir de suporte para o mapeamento de outras fontes de dados ou de processos que envolvem as fontes de dados.

\subsection{Integração de dados baseada em ontologias - OBDI}

As ontologias podem ser utilizadas em diferentes etapas durante o processo de integração de dados. Seja no acesso ao dado, na caracterização dele ou na visão global, o uso das ontologias têm se tornado cada vez mais frequente. Nessa seção serão apresentadas algumas metodologias e estudos de caso de integração de dados quem utilizam ontologias. À solução que faz uso de ontologias para promover uma visão unificada dos dados integrados é dado o nome de ODBI - Ontology-Based Data Integration. 
Semelhantemente à solução de integração de dados convencional onde existe um esquema global, na solução OBDI há a presença de uma ontologia que descreve o domínio de interesse e o conecta com o conjunto de dados (já existente, normalmente em bancos de dados relacionais). No entanto, as abordagens se diferem quando a OBDI apresenta uma descrição semântica sobre o domínio de interesse, bem como o relacionamento entre os conceitos, permitindo assim uma remodelagem dos dados sem mexer na estrutura real deles, armazenada nas bases de dados. Como resultado há uma independência entre o que é conceitualmente modelado e os dados [CGL ${ }^{+} 18, \mathrm{KRMZ13]}$. Desse modo, um aspecto importante numa solução OBDI é o fato de uma mesma entidade conceitual poder ser armazenada em bases de dados diferentes, sendo representadas por identificadores distintos $\left[\mathrm{XHB}^{+} 18\right]$. Um exemplo é a representação de uma pessoa por seu nome e CPF em uma base e em outra pelo número do Cartão Nacional de Saúde.

Segundo $\mathrm{CGL}^{+}$18, uma visão minimal de solução de OBDI possui três componentes essenciais: i) a(s) ontologia(s), podendo existir uma ou mais camadas de ontologias e cada uma dela pode conter uma ou mais ontologias; ii) a(s) fonte(s) de dado(s), que geralmente são numerosas, heterogêneas e independentes, mas que pode ser uma só, passando a nomear a solução de OBDA - OntologyBased Data Access, já que não há fontes de dados para integrar; iii) e os mapeamentos entre os dois componentes anteriores, que são especificações precisas da correspondência entre os dados e os conceitos presentes na(s) ontologia(s) $\left[\mathrm{CGL}^{+} 18\right]$.

Já ESS $^{+} 17$ apresenta uma visão de software de uma solução OBDI, com mais componentes de inter-relação do sistema, como pode ser visto na Figura 2.3. Os autores argumentam que um sistema OBDI contém pelo menos três camadas, representadas pelas caixas maiores, com traço contínuo: i) as fontes de dados; ii) as ontologias; iii) A aplicação de software que se utilizará da solução. Eles também alegam que existem variáveis a serem consideradas na hora de desenvolver a solução e as representam dentro das caixas pontilhadas da Figura. Essas variáveis são:

- Aquisição e acesso de fontes de dados: A aquisição dos dados e o acesso a eles vai depender do formato em que as fontes de dados estão descritas e o nível de acesso fornecido a elas. Geralmente as fontes de dados estão em formato estruturado, mas nem sempre elas estarão disponíveis em um banco de dados para que o acesso ocorra através deles. Para que uma única ontologia tenha acesso a várias fontes de dados diretamente é necessário que se faça uso de artifícios como a virtualização das mesmas, empregando o software Teeid ${ }^{16}$, por exemplo;

- Mapeamento e transformação entre ontologias: Caso o desenvolvedor da solução opte por uma abordagem com mais de uma camada de ontologias, o mapeamento e a transformação dos conceitos entre as camadas de ontologia deverá ocorrer de modo que a comunicação entre as camadas seja atingida. Para isso, podem ser utilizadas linguagens de mapeamento, como o $\mathrm{RML}^{17}$ e frameworks que auxiliam no mapeamento dos conceitos, como o SILK ${ }^{18}$;

- Armazenamento do conteúdo das ontologias e dos dados: O conteúdo das ontologias pode ser armazenado em um banco de dados próprio para ontologias (uma RDF Triple Store) como o Virtuoso $^{19}$ ou o StarDog ${ }^{20}$, localmente (com a materialização ou não dos dados) ou em bases de dados relacionais e acessado os dados virtualmente por meio de soluções como o Ontop ${ }^{21}$;

- Linguagem e framework para a construção das ontologias: Geralmente a linguagem utilizada para a construção das ontologias é o RDF/RDFS em conjunto com o OWL, mas isso não é uma regra;

- Acesso à solução de ODBI: O resultado o sistema deverá ser acessado por outras soluções ou pelo usuário final. Usualmente a resposta do sistema é o resultado das consultas executadas.

\footnotetext{
${ }^{16}$ Teeid: http://teiid.io/

${ }^{17}$ RML: http://rml.io/index.html

${ }^{18}$ SILK: http://silkframework.org/

${ }^{19}$ Virtuoso: https://virtuoso.openlinksw.com/

${ }^{20}$ StarDog: https://www.stardog.com/

${ }^{21}$ Ontop: https://ontop.inf.unibz.it/
} 


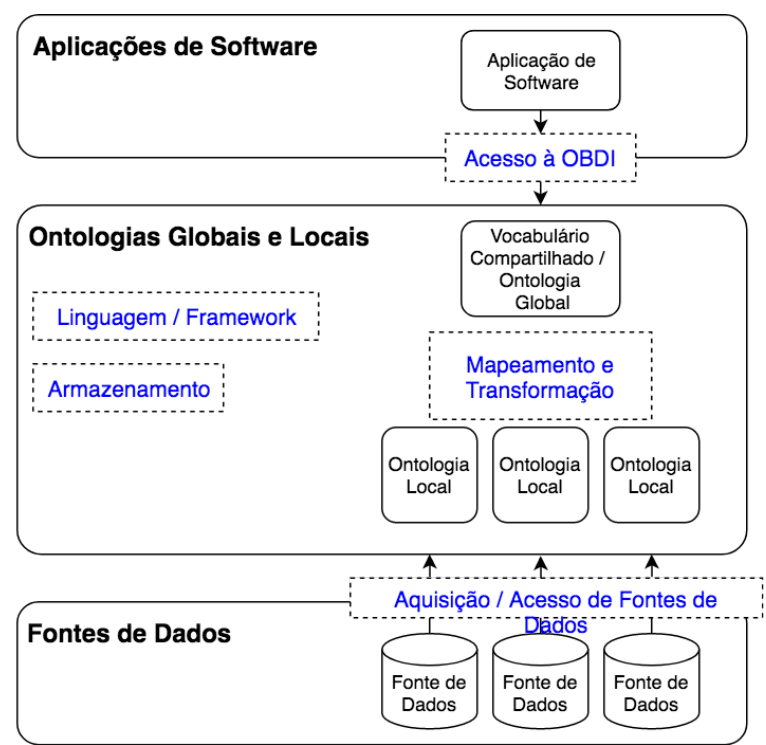

Figura 2.3: Representação dos elementos de uma solução OBDI. Figura apresentada no artigo [ESS $\left.{ }^{+} 17\right]$ e adaptada pela autora

\subsubsection{Abordagens de ODBI}

A disposição das ontologias na solução pode variar de acordo com a abordagem escolhida. Em [ESS $\left.{ }^{+} 17\right]$ os autores apresentam as abordagem mais utilizadas, dentre elas as mais clássicas: abordagem de ontologia única; de múltiplas ontologias; e híbrida, primeiramente sintetizadas em $\left[\mathrm{WVV}^{+} 01\right]$. A seguir será apresentada a Figura $2.4 \mathrm{com}$ a esquematização dessas abordagens. A Figura apresenta quatro camadas $[\mathrm{A}]$ das fontes de dados, $[\mathrm{B}]$ relativa às ontologias locais, $[\mathrm{C}]$ a camada da ontologia global ou vocabulário compartilhado e [D] a camada das aplicações de software que acessarão a solução. As setas pontilhadas indicam o acesso aos dados por meio das aplicações. As setas contínuas representam a transformação ou a virtualização do acesso aos dados. As setas tracejadas representam as relações implícitas de herança entre as ontologias. Já as elipses com os números representam a sequencia de desenvolvimento das soluções.

1) Abordagem de Ontologia Única $\quad$ 2) Abordagem de Múltiplas Ontologias

3) Abordagem Híbrida

4) Abordagem GAV

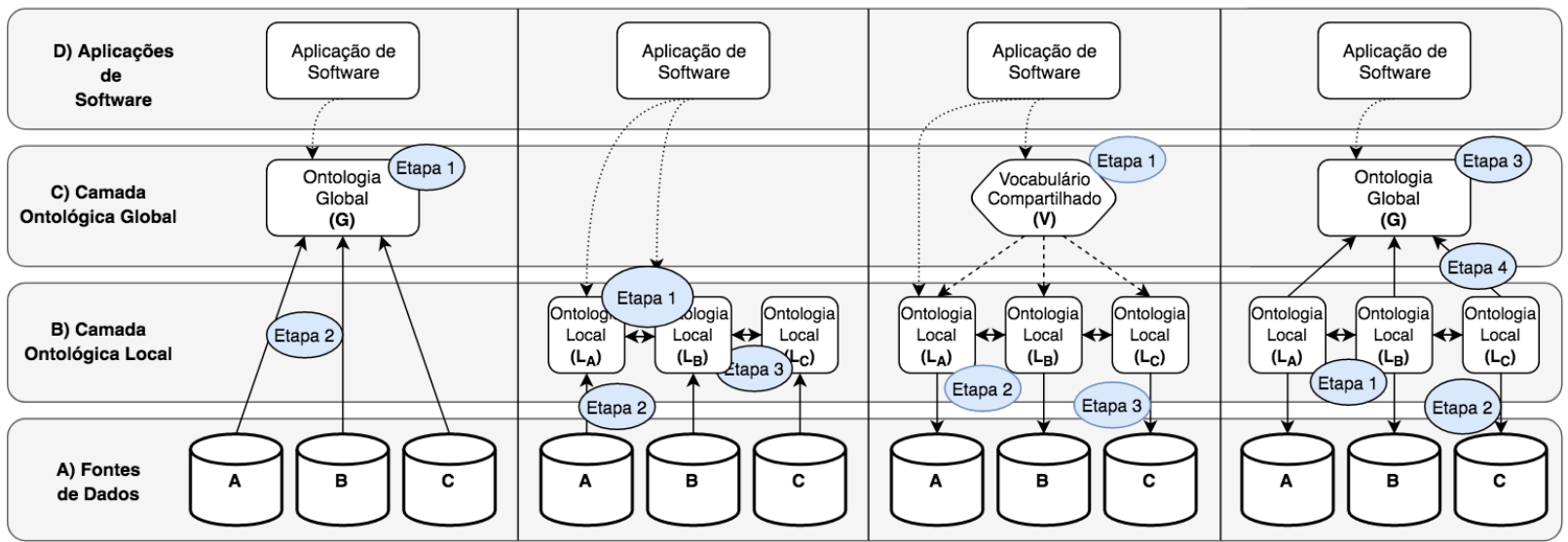

Figura 2.4: Abordagens de OBDI. Criada por ESS 17 e adaptad pela autora

As abordagens apresentadas são:

- Abordagem de Ontologia Única: Nessa abordagem uma única ontologia global é construída. Desse modo o processo de desenvolvimento consiste em definir a ontologia global e realizar os mapeamentos das fontes de dados para a ontologia. Essa abordagem é a mais 
simples e rápida, porém é a mais difícil de manter, principalmente quando há adição ou atualização de fontes de dados [ESS $\left.{ }^{+} 17\right]$. Ainda sim, esse tipo de abordagem é recomendada quando todas as fontes de dados são estáveis e possuem a mesma visão do domínio [WVV $\left.{ }^{+} 01\right]$;

- Abordagem de Múltiplas Ontologias: Nessa abordagem são construídas apenas ontologias locais das respectivas fontes de dados, os mapeamentos entre as fontes de dados e as ontologias e os mapeamentos entre as ontologias. Esse último tipo de mapeamentos busca encontrar conceitos similares entre as ontologias, o que pode não ser uma tarefa simples, dependendo muito do especialista do domínio. Outro ponto a ser ponderado é que a cada nova fonte de dados novos mapeamentos entre ontologias devem ser feitos [ESS $\left.{ }^{+} 17\right]$.

- Abordagem Híbrida: Essa abordagem utiliza os mecanismos das duas abordagens anteriores, onde há o desenvolvimento de ontologias locais para cada uma das fontes de dados e um vocabulário compartilhado, que pode ser também uma ontologia global. Desse modo há inicialmente a construção do vocabulário compartilhado e a partir dele as ontologias locais são construídas, auxiliando os mapeamentos entre as ontologias. Em seguida o conteúdo das ontologias locais é então mapeado para as fontes de dados [ESS $\left.{ }^{+} 17\right]$. Embora o desenvolvimento dessa abordagem seja mais complexo, a vantagem consiste na facilidade de adição de fontes de dados, uma vez que o vocabulário comum não sofrerá alterações, sendo necessária apenas o acréscimo dos mapeamentos relativos a essa nova fonte $\left[\mathrm{WVV}^{+} 01\right]$.

- Abordagem GAV: Nessa abordagem proposta pelos autores de [ESS ${ }^{+}$17] são desenvolvidas as ontologias globais e as locais, no entanto o acesso ao sistema se dá unicamente através da ontologia global. O primeiro passo no desenvolvimento do sistema é a determinação do vocabulário das ontologias locais, seguido pela realização dos mapeamentos dessas ontologias com as fontes de dados. Depois é desenvolvida a ontologia global que receberá o mapeamento do vocabulário das ontologias locais. Essa abordagem é indicada quando há a presença de ontologias legadas e existe a necessidade de preservar a estrutura dessas ontologias.

Nesse capítulo foram expostos conceitos a fim de apresentar, esclarecer e alinhar alguns pontos dispersos pelas literaturas de banco de dados, integração de bases de dados, análise e engenharia de dados, ontologias e web semântica. Nele foram abordados os principais conceitos para a compreensão do que será tratado nos três capítulos seguintes: o desenvolvimento da solução de integração semântica dos dados. 


\section{Capítulo 3}

\section{Metodologia de Desenvolvimento da Solução}

Neste capítulo será exposto o método que foi utilizado para a realização da integração semântica do conteúdo das bases de dados do Sistema Único de Saúde do município de São Paulo, relacionadas à saúde materno-infantil. A solução proposta nessa dissertação segue o fluxo apresentado na Figura 3.1 .

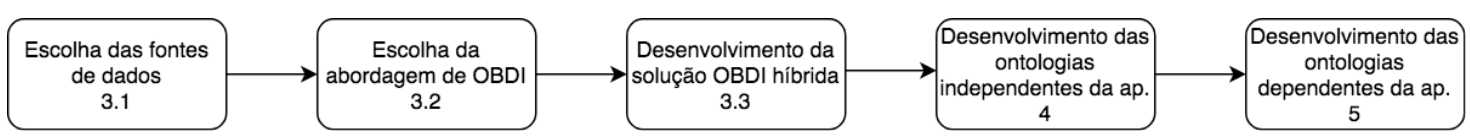

Figura 3.1: Fluxograma da metodologia seguida e referência de localização no texto

O presente trabalho tem a aprovação do comitê de ética da Faculdade de Saúde Pública da Universidade de São Paulo - FSP/USP, com o parecer de número 2.958.248.

\subsection{Compreensão do Problema e Escolha das Fontes de Dados}

Após reuniões com os técnicos da SMS-SP e integrantes da Faculdade de Saúde Pública da USP, foi identificada a necessidade de integração dos registros presentes em algumas das suas bases de dados. Durante as conversas, diversos exemplos foram apresentados a fim de confirmar a ausência de soluções e as consequências para o trabalho na SMS-SP. Os dados necessários para realizar algumas análises ou acompanhamentos a médio e longo prazo estão em bases de dados distintas e o processo para a realização da integração é custoso, atualmente sendo realizado quase que manualmente ou em ferramentas como o Microsoft Access ${ }^{1}$, voltadas para bancos de dados e soluções menores e menos complexas. Além disso, algumas considerações sobre o significado dos dados das bases dependem de pessoal especializado no conteúdo e formatação das bases, sendo difícil para um profissional com pouca experiência realizá-las, ainda que este seja da área da saúde.

Como resultado das discussões, surgiu uma lista com as bases de dados elegíveis a integração que estavam relacionadas a saúde materno-infantil e uma seleção prévia das variáveis para o desenvolvimento deste projeto, apresentada no Anexo A.

No entanto, a fim de delimitar o escopo desta etapa do projeto, por questões de importância e facilidade de acesso, foi definido que apenas as bases de dados dos sistemas de nascidos vivos SINASC $^{2}$ e de mortalidade - $\mathrm{SIM}^{3}$ deveriam ser modeladas e integradas.

O Sistema de Informações de Nascidos Vivos - SINASC, destacado na Figura 3.2, oficialmente implantado a partir de 1990, é o principal documento quando necessita-se obter informações sobre a saúde materno-infantil. Ele é um sistema de notificação compulsória, o que significa que todos os

\footnotetext{
${ }^{1}$ Microsoft Access: https://products.office.com/pt-br/access

${ }^{2}$ SINASC: http://www2.datasus.gov.br/DATASUS/index.php?area=060702

${ }^{3}$ SIM: http://www2.datasus.gov.br/DATASUS/index.php?area=060701
} 
nascidos vivos dentro do território brasileiro devem ser registrados nele, não importando o local de nascimento (em uma instituição de saúde ou fora dela) ou a forma de financiamento (realizada pelo SUS ou não), a ficha do SINASC é a primeira a ser preenchida após o nascimento. O SINASC é composto pelo preenchimento das Declarações de Nascido Vivo (DN), assim, cada DN preenchida se transformará em uma tupla no SINASC. O formulário de preenchimento da DN possui um identificador numérico, este número é único e gerado pelo Ministério da Saúde. A partir dele é lavrada a Certidão de Nascimento emitida por Cartório de Registro Civil [Bra11a]. O exemplo de uma ficha de Declaração de Nascido Vivo que alimentará o SINASC está no Anexo B.

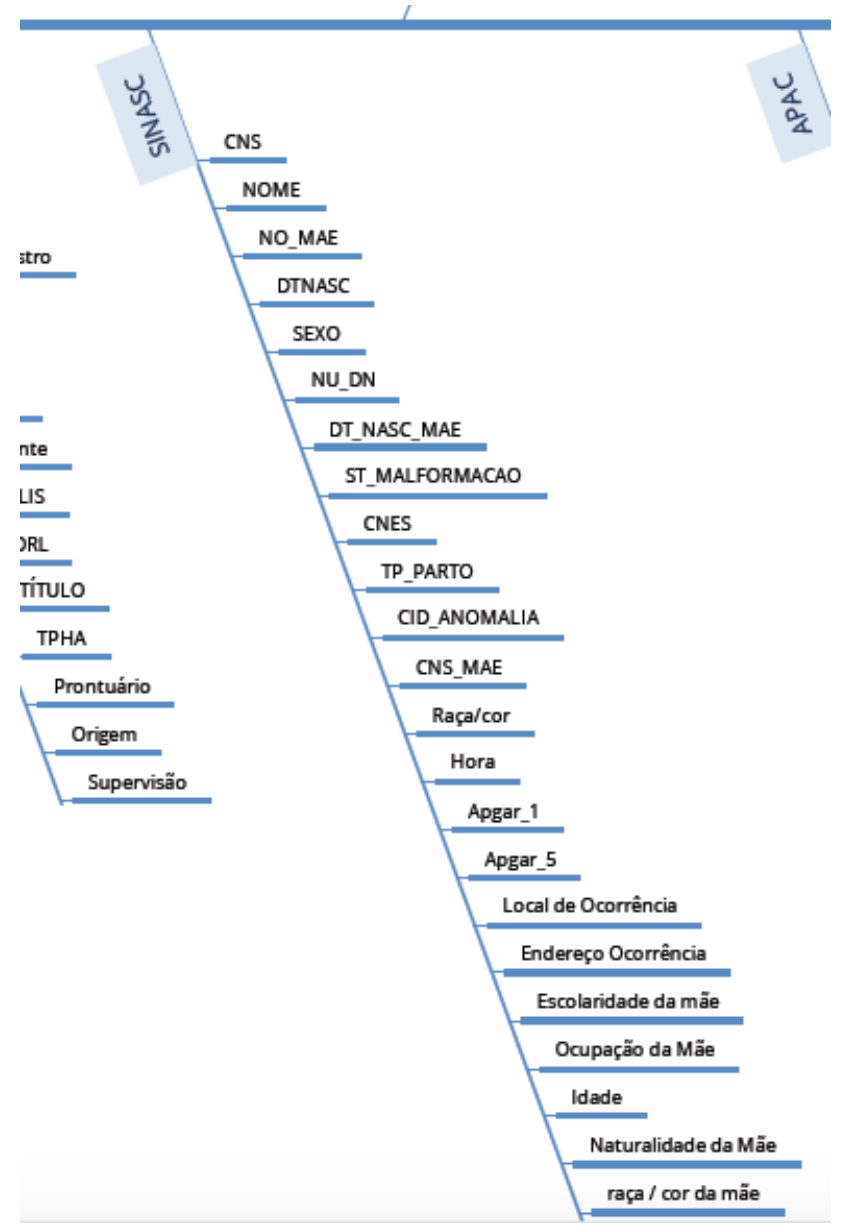

Figura 3.2: Variáveis selecionadas da base de dados do SINASC

A DN possui 52 variáveis que abrangem dados estatísticos, sócio-demográficos e epidemiológicos. Essas estão decompostas em oito blocos contextuais ou capítulos, são eles:Identificação do recém nascido; Local da ocorrência; Mãe; Pai; Gestação e parto; Anomalia congênita e Preenchimento.

O dicionário de dados com a descrição das variáveis é apresentado no Anexo C. Devido a sua importância e a fim de garantir a qualidade de preenchimento dos dados, o município de São Paulo criou um prêmio, o Selo SINASC [PdMdSP10], o que tornou o município referência na qualidade dos dados do SINASC. Sendo assim, o SINASC foi eleito o ponto de partida para a construção do sistema de integração semântica deste estudo. Desse modo, as questões de competência e as ontologias serão guiadas e respondidas com parte da informação contida nele;

O Sistema de Informações de Mortalidade - SIM, destacado na Figura 3.3, é o instrumento que contabiliza, desde 1976, todas as declarações de óbito(DO) no território nacional. Assim como ocorre com a DN, a DO é obrigatória para a confecção de um documento legal, a Certidão de Óbito. Este sistema contém informações que permitem realizar uma análise retrospectiva do que levou ao evento óbito [Bra11b]. Para o caso de um evento de óbito neo-natal, o registro da DN e os dados maternos, embora pertencentes a DN, estarão contidos também na DO. A presença desses campos 
tornará possível a ligação dos registros do SIM com a base do SINASC.

O formulário para o preenchimento da DO está no Anexo D, Ele possui 59 variáveis, apresentadas no dicionário de dados, no Anexo E e descritas em nove capítulos. Os capítulos ou blocos são: Identificação; Residência; Ocorrência; Fetal ou menor que 1 ano; Condições e causas do óbito; Médico; Causas externas; Cartório e Localidade sem médico.

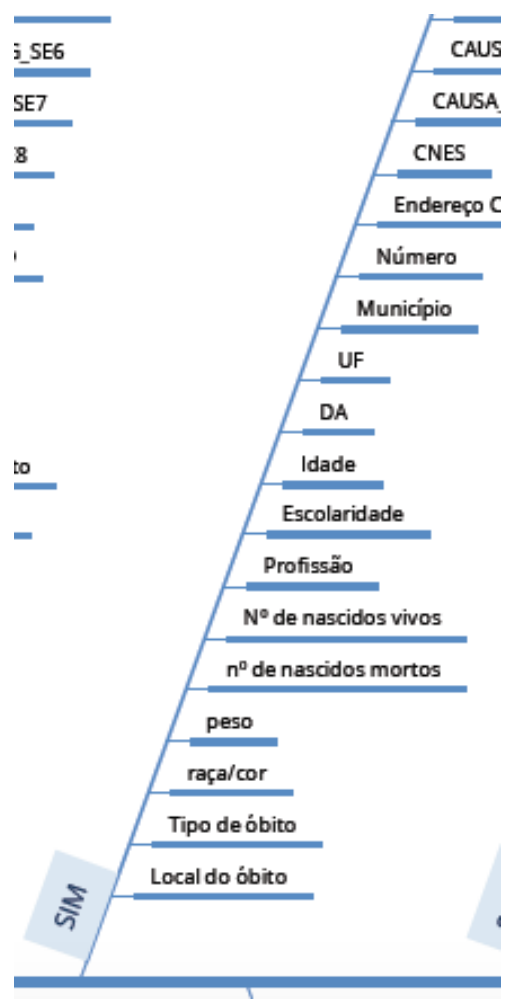

Figura 3.3: Variáveis selecionadas da base de dados do SIM

A Figura 3.4 traz parte do diagrama apresentado no Apêndice A, desta vez destacando cinco bases terminológicas contendo metadados, utilizadas no processo de integração. São elas:

- Procedimentos: A tabela de procedimentos tem origem no sistema $\mathrm{SIGTAP}^{4}$, que contém informações sobre os procedimentos custeados pelo SUS, tais como o tipo de procedimento, o código CID associado a ele e o código da CBO do profissional que deve executá-lo;

- Especialidades: A tabela apresenta as especialidades dos profissionais de saúde que executam os procedimentos registrados;

- CNES ${ }^{5}$ O Cadastro Nacional de Estabelecimentos de Saúde possui em sua base de dados informações sobre os estabelecimentos de saúde brasileiros, tais como, se há prestação de serviços ao SUS, o tipo de unidade de saúde e a quantidade de leitos;

- CID-106 : O Código Internacional de Doenças utilizado em sua 10 versão é um padrão terminológico utilizado mundialmente para apresentar as doenças de uma maneira classificada e hierarquizada, sendo o padrão oficial brasileiro;

- $\mathrm{CBO}^{7}$ : A base de dados da Classificação Brasileira de Ocupações apresenta a codificação dos profissionais, bem como uma breve descrição da ocupação;

\footnotetext{
${ }^{4}$ SIGTAP: http://sigtap.datasus.gov.br/tabela-unificada/app/sec/inicio.jsp

${ }^{5}$ CNES: http://cnes.datasus.gov.br/

${ }^{6}$ CID-10: http://www.datasus.gov.br/cid10/V2008/cid10.htm

${ }^{7}$ CBO: http://www.mtecbo.gov.br/cbosite/pages/home.jsf
} 


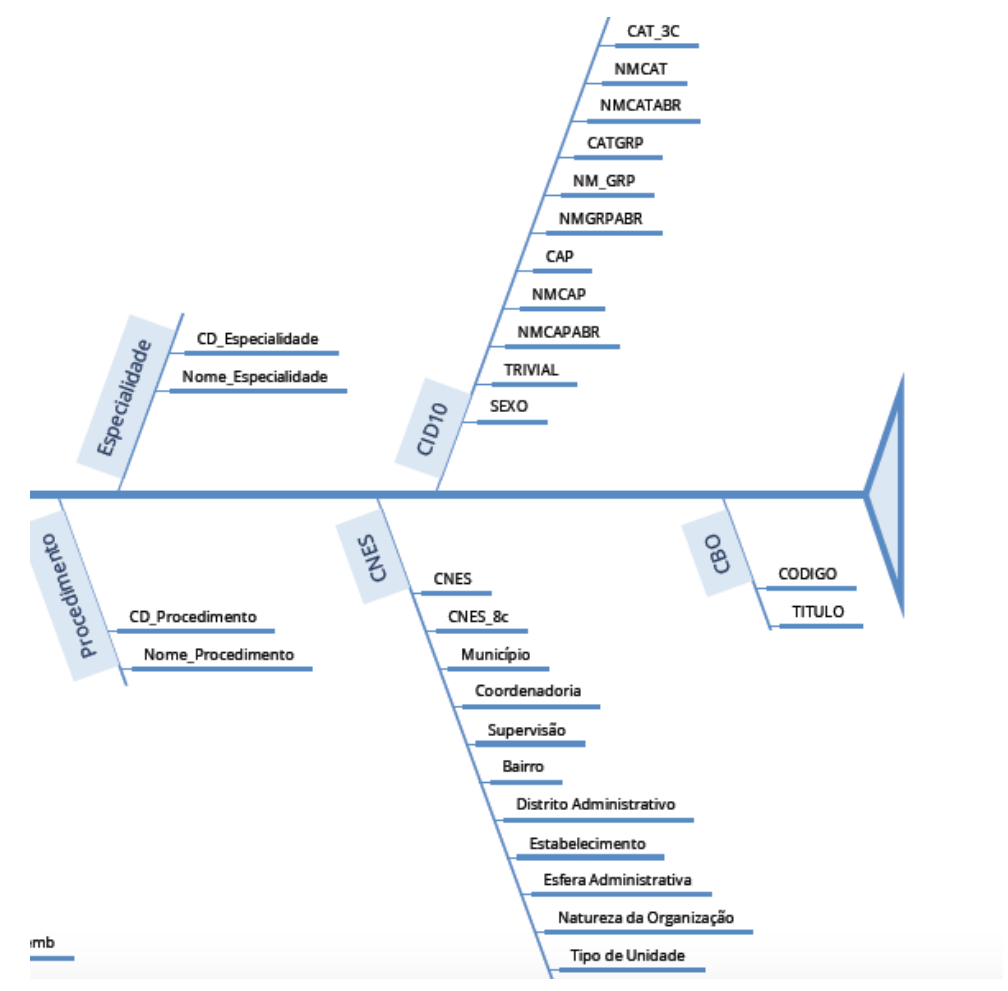

Figura 3.4: Seleção das bases terminológicas

\subsection{Escolha da abordagem de OBDI}

Na literatura, é possível observar a existência de diversas abordagens para a construção de uma solução de OBDI [ESS ${ }^{+}$17, $\mathrm{WVV}^{+}$01], algumas delas estão reapresentadas na Figura 3.5). A fim de auxiliar no processo de escolha da abordagem que mais se ajusta ao problema de pesquisa, [ESS $\left.{ }^{+} 17\right]$ construiu uma árvore de recomendação, apresentada na Figura 3.6, que apresenta diversas afirmações, estas são tidas como verdadeiras ou falsas, de acordo com o contexto. Para o desenvolvimento deste projeto as sentenças sugerida pelos autores foram analisadas com o auxílio dos especialistas da SMS-SP e assim foi constatado que a melhor abordagem para o contexto desta dissertação é a OBDI híbrida, destacada na (Figura 3.5), afinal:

- As fontes de dados não possuem visões similares do domínio. Cada base de dados possui a sua visão para o evento;

- As "visões" locais do domínio são importantes pois cada profissional tem sua abordagem sobre o assunto;

- As bases compartilham de um padrão comum de dados. Este é o único ponto que foi discordante com a escolha da abordagem;

- O tempo e a quantidade de pessoas foi apresentado como adequado à soluções mais complexas;

- A criação e evolução da integração dos dados não seria um protótipo rápido, devido a quantidade de bases de dados e variáveis, bem como a complexidade terminológica delas;

- No entanto, apesar da complexidade terminológica, as relações entre ontologias não vão além das capacidades de representação do framework;

- Não existem ontologias legadas nem podem ser geradas automaticamente devido à complexidade do domínio; 
- Nem é de extraordinária importância preservar a estrutura local das ontologias que representam diretamente o esquema das bases de dados; Historicamente a estrutura das bases de dados utilizadas é restrita aos eventos, não modelando bem o real domínio a que pertencem.

Após a escolha da abordagem de OBDI híbrida foi compreendida a necessidade de adaptação da mesma para o domínio deste projeto. Desse modo, foi desenvolvida uma arquitetura própria que respeita os parâmetros da abordagem mas não se limita a eles, conforme será detalhado no próximo tópico.

$\begin{array}{ll}\text { 1) Abordagem de Ontologia Única } & \text { 2) Abordagem de Múltiplas Ontologias }\end{array}$

3) Abordagem Híbrida

4) Abordagem GAV

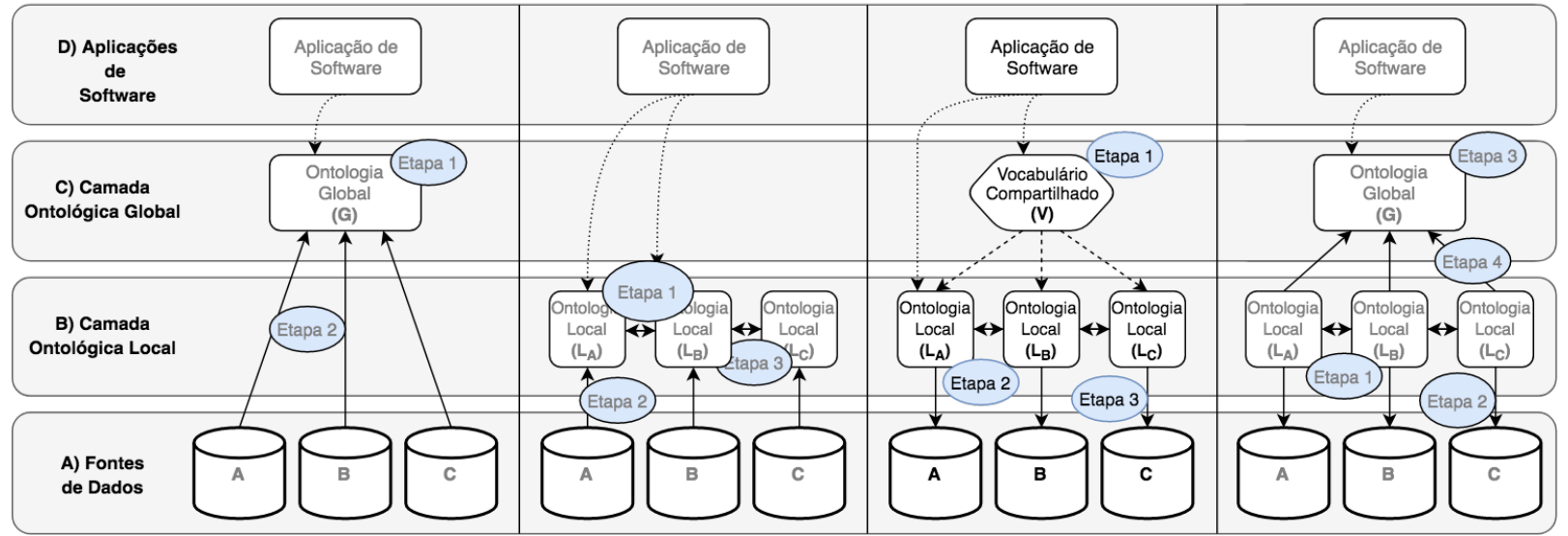

Figura 3.5: Abordagens de OBDI, destaque para a OBDI híbrida. Criada por [ESS ${ }^{+} 17$ ], adaptada pela autora 


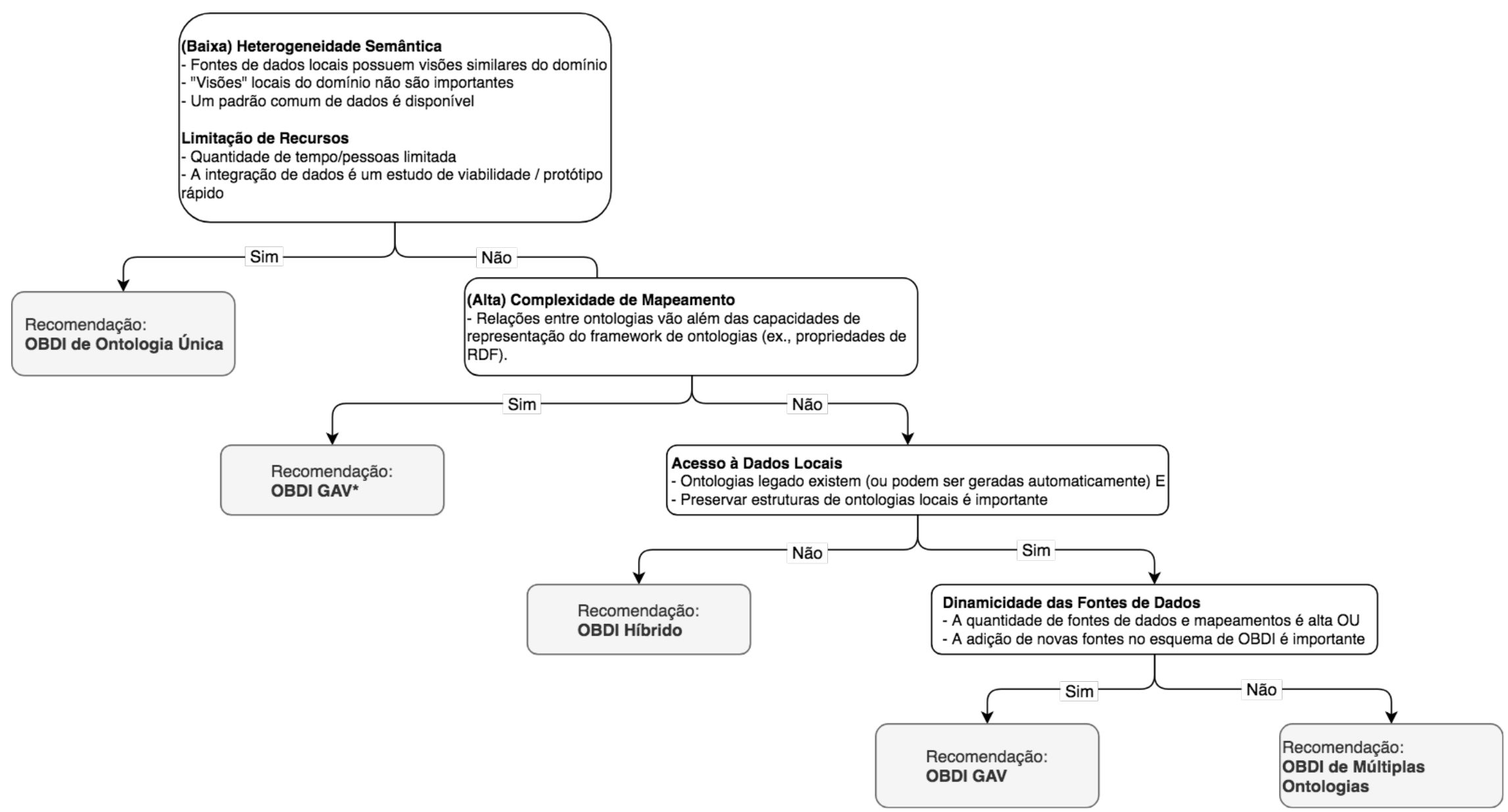

Figura 3.6: Árvore de Recomendação de abordagens de OBDI criada por [ESS ${ }^{+} 1^{\eta}$ ], adaptada pela autora 


\subsection{Desenvolvimento da solução ODBI híbrida}

Como apresentado na seção de conceitos 2.4.1, na abordagem de OBDI híbrida, após a definição das bases de dados que serão utilizadas, o passo seguinte para a construção da solução é o desenvolvimento da ontologia ou vocabulário comum. Em seguida são criadas ontologias locais que compartilharão do vocabulário da ontologia da camada ontológica global e por último serão realizadas as transformações das fontes de dados para as ontologias locais. No entanto, para o desenvolvimento deste projeto, foi percebida a necessidade de fazer algumas modificações na arquitetura da abordagem. Até chegar na forma atual, algumas ideias foram discutidas e podem ser vistas em [PWS18] e [PPSW19]. Foi necessário adicionar uma camada de conversão das bases de dados para RDF, alterando assim a ordem de execução da integração.

\subsubsection{Arquitetura da solução}

A arquitetura da solução OBDI híbrida desenvolvida basea-se nos trabalhos de $\left[\mathrm{VCA}^{+} 15\right.$, LVO16b, LOV17, $\mathrm{BCG}^{+} 18$ ] e possui três camadas de ontologias, como está descrito na Figura 3.7 .

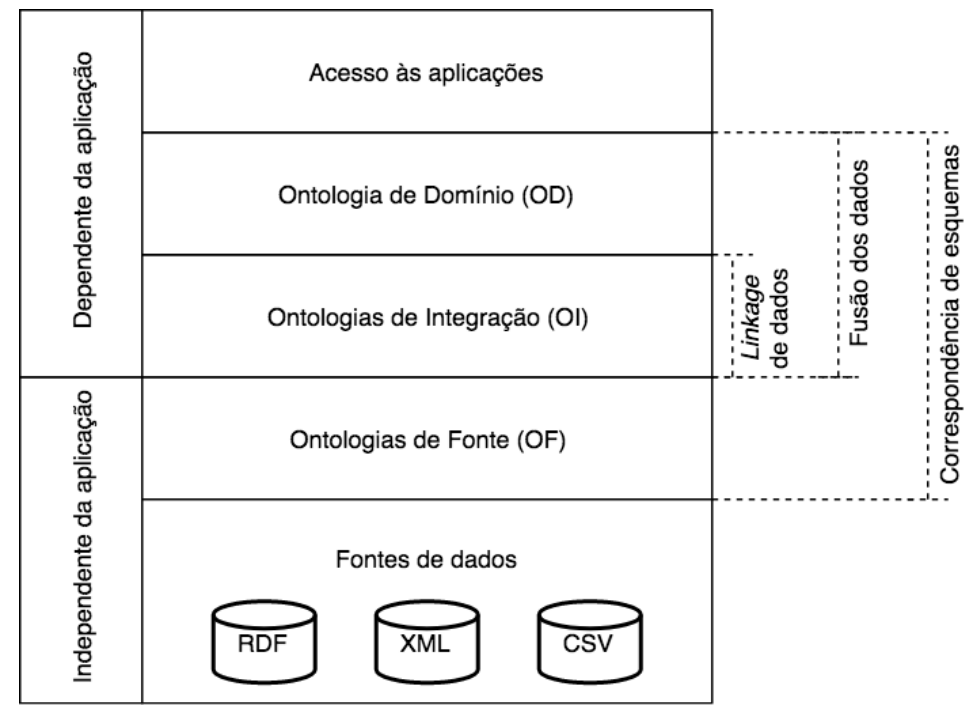

Figura 3.7: Esquema da solução OBDI híbrida desenvolvida

Pela figura 3.7, é possível observar que, parte das ontologias é independente da aplicação pois representam as fontes de dados de um determinado domínio e outra parte é dependente da aplicação pois é construída com base no vocabulário e na visão desejada. Essa divisão será descrita a seguir:

- Independente da Aplicação: A solução foi desenhada para que o acesso às fontes de dados se dê por meio de um conjunto de ontologias e que seja independente da aplicação. Desse modo, mais de uma aplicação poderá ter acesso ao mesmo agrupamento de dados. Fazem parte as camadas de:

- Fontes de Dados: A arquitetura permite o recebimento de dados de diversos formatos. Eles podem estar materializados ou virtualizados, integrados ou não. No entanto, é indispensável que haja algo que possibilite sua integração, como a presença de um identificador único ou a junção de vários identificadores nas fontes. Assim, no uso de fontes de dados já integradas por meio de data linkage, apesar de existir uma única fonte de dados, as ontologias da camada de Ontologias de Fonte (OF) continuam acessando os dados como se fossem bases diferentes, recebendo os mapeamentos independentemente.

- Ontologias de Fonte $(\mathrm{OF})^{8}$ : Como as bases de dados não estão em formato RDF foi

\footnotetext{
${ }^{8}$ No trabalho de $\mathrm{ESS}^{+} 17$ essa camada é chamada de camada de ontologias locais. Já nos em [VCA $\left.{ }^{+} 15\right]$ essa camada é chamada de camada de dados
} 
optado por criar mais uma camada na arquitetura proposta por $\left[\mathrm{WVV}^{+} 01\right]$ e discutida por $\mathrm{ESS}^{+} 17$, nela há ontologias que replicam a estrutura do esquema das bases de dados, assim como foi sugerida por [LVO16b]. Foi esperado que, com a adição dessa camada, a conversão de termos e conceitos entre as fontes de dados e as ontologias de integração fosse mais suave. Outra vantagem é a possibilidade de reaproveitamento dos dados e/ou do esquema para outras aplicações, desse modo, com o mesmo conjunto de dados é possível construir ontologias de domínio para anomalias congênitas e para dias potenciais de gravidez perdidos. Além disso, há o ganho da publicação das fontes de dados do SUS em um formato linked data, independente do uso que se fará delas.

- Dependente da Aplicação: A parte da solução que é dependente da aplicação contém ontologias criadas a partir de questões de competências pertinentes a um determinado contexto. Este determina a maneira como os conceitos se relacionam e o comportamento e existência das regras de fusão dos dados. Fazem parte as camadas de:

- Ontologias de Integração (OI $)^{9}$ : Essa é uma das camadas mais importantes para a solução. Ela contém o vocabulário da camada OD distribuído em suas ontologias e mapeia os conceitos correspondentes da camada OF para a OD. Nela também são estabelecidas as relações de similaridade entre conceitos (sinônimos como os conceitos gravidez e gestação) e entre entidades (estabelecimento da mesma entidade paciente em fontes de dados distintas). Quanto ao acesso às informações, a OI faz parte do primeiro filtro de dados, pois contém apenas os conceitos da OF que são de interesse para a aplicação;

- Ontologia de Domínio (OD) ${ }^{10}$ : É a camada ontológica que estabelece o vocabulário para uma determinada aplicação, onde as consultas são realizadas. Essa camada geralmente é composta por uma única ontologia, esta, no entanto, tende a ser grande, uma vez que estabelece um vocabulário geral que une fontes de dados e conceitos. Quando o tamanho da ontologia impede a realização de consultas em tempo hábil, a solução encontrada é particionar a ontologia, como descrito em $\left[\mathrm{BCG}^{+} 18\right]$;

- Acesso às Aplicações: A porta de acesso às aplicações se dá pelo resultado das consultas realizadas na OD.

Na Figura 3.7 ainda é possível observar onde ocorre cada uma das três tarefas que compõem a integração de dados:

- Linkage de dados: Esta tarefa ocorre com a determinação dos links sameAs em relação aos conceitos recebidos pela camada de OF e integrados com os conceitos recebidos pela camada de OD. No entanto, os links são criados apenas entre as ontologias da camada OI;

- Fusão de dados: Para que ocorra a fusão dos dados é necessário estabelecer regras de preferência entre as origens dos mesmos. A fusão ocorre no processo de retorno do resultado da consulta que ocorre na OD. Quando a camada OD recebe mais de um dado sobre um mesmo conceito, proveniente de fontes distintas, cabe às regras decidirem o que será retornado como resultado;

- Correspondência de esquemas: A correspondência de esquemas ocorre nas três camadas ontológicas. Em todo o processo de compreensão dos conceitos e consulta de dados é feita a adequação do significado das informações, mapeando conceitos e relações, apresentando sinônimos e generalizações.

\footnotetext{
${ }^{9} \mathrm{Em}\left[\mathrm{VCA}^{+} 15\right]$ essa camada é chamada de camada de visões Exportadas e Links Semânticos. Em [dCAVJ19] os autores nomeiam de camada de ontologias locais e em $\left[\mathrm{BCG}^{+} 18\right]$ de camada de base de conhecimento

${ }^{10} \mathrm{Em}\left[\mathrm{VCA}^{+} 15\right]$ essa camada é chamada de camada de Integração Semântica. Em [dCAVJ19] os autores nomeiam de camada de ontologia de domínio e em $\left[\mathrm{ESS}^{+} 17\right]$ de camada ontológica global. Já em [BCG $\left.{ }^{+} 18\right]$ a camada é referida como camada da ontologia de alto nível - upper level ontology
} 
As Figuras 3.8 e 3.9 apresentam outros aspectos da arquitetura desenvolvida, fazendo um paralelo entre cada camada anteriormente representada e seu conjunto de ontologias. São modelos mais detalhados, onde os fluxos de conceitos para a criação das ontologias e os fluxos de informação para a recuperação dos dados são expostos. A estrutura dos diagramas foi baseada nos trabalhos de [VCA ${ }^{+} 15$, LVO16b, LOV17].

O modelo de arquitetura exibido pela Figura 3.8 contém as ontologias que compõem cada camada, bem como as relações entre as camadas, aqui chamadas de mapeamentos $M_{D E} P A R A$, onde DE, simboliza a origem e PARA, o destino do mapeamento. Os conceitos e as relações das fontes de dados se propagam exatamente iguais até a $\mathrm{OF}$, correspondendo ao mapeamento $M_{F D} O F$. A partir desta camada, os mapeamentos na camada OI são convertidos (nomenclatura e relações) para o vocabulário criado na OD. No processo de conversão, referente aos mapeamentos $M_{O F} \_I$, há uma reestruturação dos conceitos de cada fonte de dados, podendo haver a exclusão de conceitos que não são necessários para a aplicação ou a adição, caso ocorra uma decomposição do conceito para melhor contextualizá-lo. Na camada OI há ainda a determinação dos links sameAs, que são mapeamentos entre conceitos similares presentes em mais de uma fonte de dados. A mesma camada ainda recebe os mapeamentos advindos da OD. Esses mapeamentos agrupam os conceitos eleitos por meio das questões de competência de acordo com a(s) fonte(s) de dados correspondente(s).

Camada de Ontologia de Domínio (OD)

Camada de Ontologias de Integração (OI)

Camada de Ontologias de Fontes (OF)

Camada Fontes de Dados
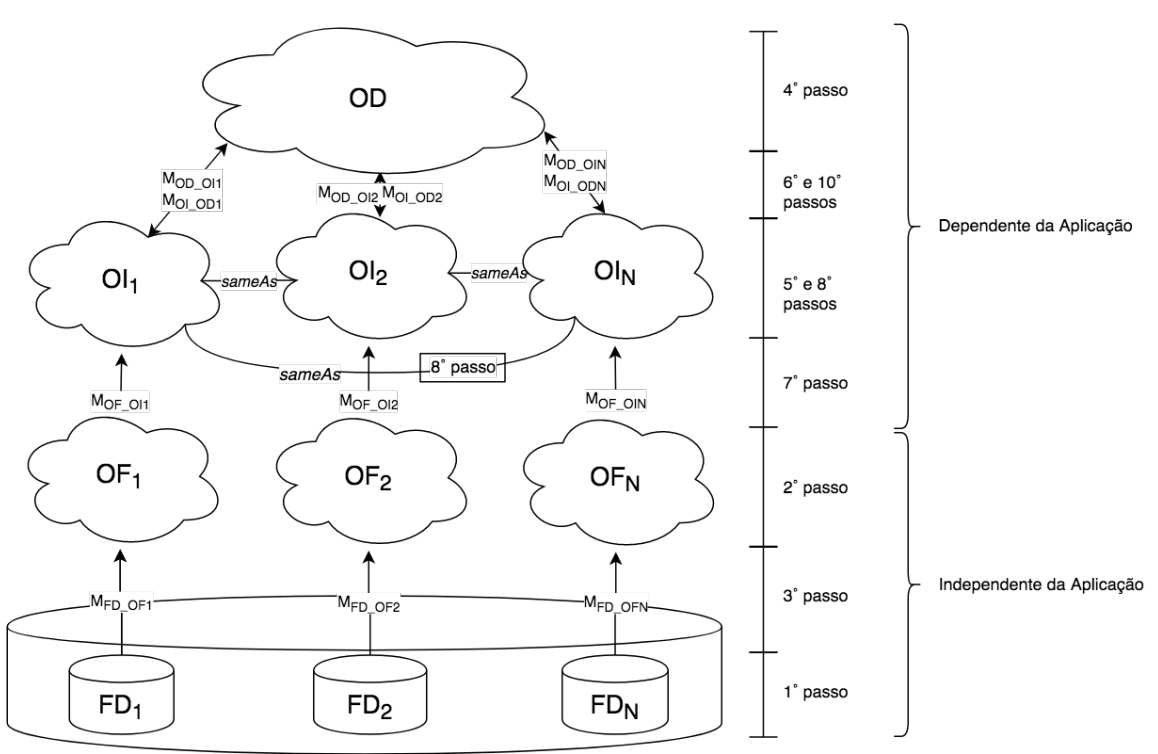

Figura 3.8: Arquitetura da solução OBDI híbrida desenvolvida, com o fluxo de conceitos e a ordem de criação.

Como foi dito, fluxo dos conceitos se propaga da Camada Fonte de Dados em direção à Camada de Ontologia de Domínio e desta, em direção à Camada Fonte de Dados, encontrando-se na Camada de Ontologias de Integração. Compreender esse comportamento é importante para o processo de criação das ontologias, uma vez que algumas camadas herdam conceitos de outras. Ainda na Figura 3.8 é possível observar a presença dos marcadores com a ordem de construção de cada camada e mapeamento.

1. Determinação de quais fontes de dados utilizar, seu formato e se será uma fonte de dados já integrada ou não;

2. Geração das ontologias correspondentes a cada fonte de dados. Essas ontologias servem para igualar o formato dos dados, como foi exposto por $\left[\mathrm{BCG}^{+} 18\right]$;

3. Criação dos mapeamentos $M_{F D} O_{F}$ entre as ontologias da camada OF e suas fontes correspondentes;

4. Desenvolvimento da ontologia de domínio, própria para a aplicação em que será empregada; 
5. Criação do arquivo (vazio) das ontologias da camada OI, correspondendo a primeira fase do desenvolvimento das ontologias dessa camada.

6. Realização dos mapeamentos $M_{O D \_}$, , por meio da importação da ontologia da camada OD nas ontologias da camada OI;

7. Realização dos mapeamentos $M_{O F \_O I}$, comparando os conceitos presentes nas duas camadas;

8. Execução da segunda fase de desenvolvimento das ontologias da camada OI, com a ligação dos conceitos equivalentes presentes nas camadas OF e OD;

9. Efetuação dos links sameAs na camada OI, entre os conceitos presentes em cada ontologia da camada OF;

10. Desenvolvimento dos Mapeamentos $M_{O I}$ OD, apresentando as regras de quais informações das bases serão retornadas, para uma dadā consulta.

A Figura 3.9 apresenta o fluxo das informações durante a realização das consultas, devendo ser lida de cima para baixo. Inicia-se assim com um pedido por $x y z$, onde tanto $x$ quanto $y$ estão presentes na fonte de dados $F D_{1}$. y também está presente na $F D_{2}$ e a identificação deste estado se dá na camada OI. $z$ está na $F D_{3}$. Entre as camadas OD e OI ocorre a separação de cada conceito e o endereçamento para as fontes correspondentes. A cada nova camada ocorre o mapeamento do conceito solicitado e o retorno dos dados. É novamente entre as camadas OD e OI que acontece a junção dos resultados. Nela são determinados quais dados de quais fontes serão apresentadas.

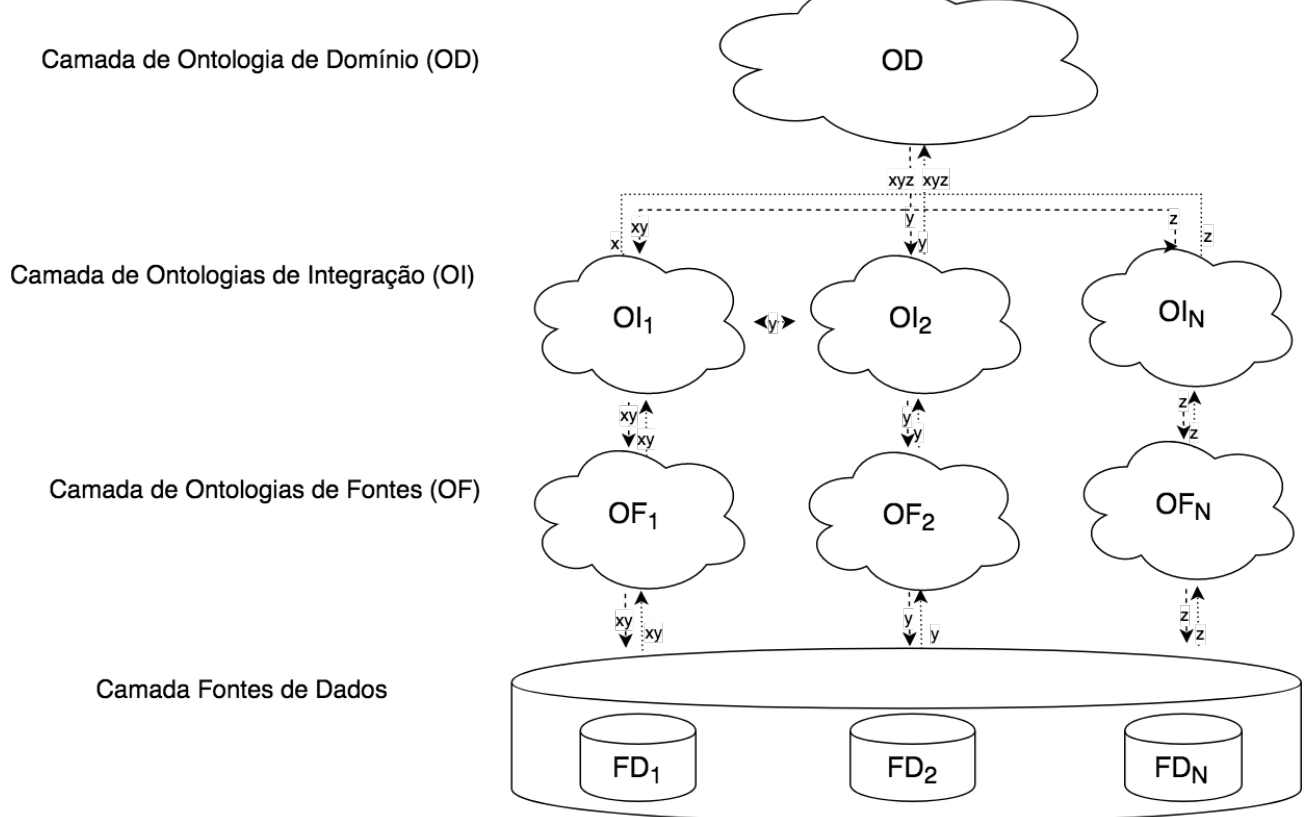

Figura 3.9: Arquitetura da solução OBDI híbrida desenvolvida, com o fluxo das informaçôes durante as consultas. 


\section{Capítulo 4}

\section{Desenvolvimento das ontologias e mapeamentos independentes da aplicação}

Integram esse bloco da solução os passos: de Avaliação das Fontes de Dados (4.1) que compõem a Camada Fontes de Dados; do Desenvolvimento das Ontologias da Camada OF (4.2); e do Desenvolvimento dos Mapeamentos FD_OF (4.3).

\subsection{Avaliação das Fontes de Dados}

A escolha das bases de dados que seriam utilizadas na solução, a curto (SINASC e SIM) e longo prazo (demais bases citadas em Compreensão do Problema e Escolha das Fontes de Dados - 3.1), foi tomada no início do projeto, nas primeiras conversas com os técnicos da SMS-SP e com a equipe da Faculdade de Saúde Pública da USP. No entanto, a forma como estas seriam operadas foi definida apenas após a seleção da abordagem de OBDI.

Para a realização da integração das fontes de dados, em especial as bases de dados relacionais, é necessário ter acesso às mesmas ou, ao menos, ao esquema relacional ou ao dicionário dos dados [BPDH10]. Por questões de privacidade, foi optado por desenvolver o sistema apenas com o acesso ao modelo do formulário de preenchimento, ao dicionário dos dados, dados públicos e dados não identificados advindos da SMS-SP. Não foi possível ter acesso ao diagrama do esquema relacional das bases de dados, sendo assim, necessário recriá-lo, ainda que de maneira simplificada. Havia duas possibilidades de recriação: Assumir que existia apenas uma tabela para cada base de dados, com todos os atributos das fichas pertencerem a ela; Ou assumir que há uma estrutura um pouco mais complexa, com a presença de várias tabelas e relações, dando as variáveis uma aproximação da estrutura das ontologias. Esta foi a opção escolhida.

As fichas de preenchimento serviram de guia para a reconstrução da estrutura. Desse modo, cada agrupamento conceitual presente nas fichas de preenchimento (capítulo ou bloco) foi adotado como uma tabela e os campos do capítulo, como os atributos da respectiva tabela. As relações entre as tabelas foram reconstruídas a partir das informações levantadas com os especialistas. Como consequência, nem todas as tabelas/classes possuem chave-primária com um identificador forte como um número, o que não é um problema para a solução semântica, mas que futuramente deverá ser tratado com a adição do esquema real das bases, caso ele seja mais complexo (contenha mais de uma tabela) ou com o acesso ao sistema de banco de dados que recebe os dados diretamente do sistema de informações. Um recorte dos diagramas de entidade relacionamento das bases de dados é apresentado no Apêndice A.

Os primeiros testes do sistema de integração utilizaram dados públicos do SINASC e do SIM, disponíveis no site do DATASUS ${ }^{1}$. Os dados disponibilizados pelo DATASUS estão no formato

\footnotetext{
${ }^{1}$ Dados públicos disponíveis no site do DATASUS: http://www2.datasus.gov.br/DATASUS/index.php?area=0901
} 
DBC. Desse modo, foi necessário convertê-los em CSV para importá-los para um banco de dados relacional. Assim, foi utilizado o plug-in em Pyhton pySUS ${ }^{2}$, para converter os arquivos de DBC para DBF e o plug-in simpledbf ${ }^{3}$ para transformar o DBF em CSV.

Também foram realizados testes com a base de dados fornecida pela Secretaria Municipal da Saúde de São Paulo, chamada de DNDO. A base apresentada foi o resultado de um linkage entre as bases de dados do SINASC e do SIM, de modo que cada registro correspondesse a um indivíduo presente no SINASC e no SIM ou só no SINASC. A integração que gerou a DNDO ocorreu por meio de algumas regras e de um algoritmo de Busca Fonética em português, desenvolvido pelos técnicos da SMS-SP e que teve como base o Soundex, [Rus18]. Para obter as informações sobre óbitos de menores de 1 ano, o número da declaração de nascido vivo foi utilizado como identificador que integrou os registros nas bases de dados do SINASC com o SIM. Já para relacionar o óbito de mães de menores de 1 ano que tiveram o registro de óbito foi necessário utilizar como identificador o número do CNS (Cartão Nacional de Saúde) da mulher, presente em ambas as bases. Nos casos em que o CNS está ausente, o algoritmo de busca fonética foi executado, levando em conta o nome da mulher. Os registros que obtiveram similaridade de $85 \%$ ou mais foram tratados como pertencentes ao mesmo indivíduo. Já aqueles que não atingiram o escore, foram descartados da DNDO. Então, foi adicionada uma coluna com um valor gerado como novo identificador do indivíduo. Para manter a anonimização dos registros foi necessária a exclusão de algumas variáveis. Nessa base também foram adicionados alguns campos que tornaram a interpretação dos dados mais significativa, como a conversão do tempo de gestação para dias. A DNDO foi disponibilizada pela SMS-SP em formato CSV e então o arquivo foi importado para um banco de dados relacional. Para a realização de testes de conceitos foram criadas duas bases de dados, uma povoada com algumas dezenas de registros advindos das bases do SINASC, SIM e DNDO, e outra para facilitar a exemplificação, povoada com indivíduos representantes da Família Real Britânica.

A integração das bases de dados do SINASC com o SIM revelou alguns grupos de indivíduos, apresentados na Tabela 4.1, destes, três são mais importantes para as análises que os técnicos da SMS-SP desejam realizar: Os menores de 1 ano que tiveram o registro de óbito; As mães, de menores de 1 ano, que tiveram o registro de óbito; e os Menores de 1 ano que não tiveram o registro de óbito.

Tabela 4.1: Tipos de indivíduos encontrados na integração das bases de dados do SINASC e SIM

\begin{tabular}{|c|c|c|c|}
\cline { 3 - 4 } \multicolumn{2}{c|}{} & \multicolumn{2}{c|}{ SINASC } \\
\cline { 3 - 4 } SIM & Presente & $\begin{array}{c}\text { Menores de 1 ano que tiveram } \\
\text { o registro de óbito OU } \\
\text { Mães, de menores de 1 ano, } \\
\text { que tiveram o registro de óbito }\end{array}$ & $\begin{array}{c}\text { Outros óbitos, incluindo mulheres } \\
\text { em idade fértil e óbitos fetais }\end{array}$ \\
\cline { 3 - 4 } & Ausente & $\begin{array}{c}\text { Menores de 1 ano que não } \\
\text { tiveram o registro de óbito }\end{array}$ & $\begin{array}{c}\text { População não registrada } \\
\text { nesses eventos }\end{array}$ \\
\hline
\end{tabular}

\subsection{Desenvolvimento das Ontologias da Camada OF}

Devido às particularidades das bases de dados, tais como o acesso parcial aos dados e a necessidade de realizar os testes com bases de dados públicas que não contêm todas as variáveis dos sistemas, como as de identificação foi decidido por realizar essa etapa manualmente, e não de maneira automática ou semi-automática. Também foi optado por não utilizar as ontologias desenvolvidas pelo projeto SemanticSUS ${ }^{4}$, da professora Vânia Vidal, por não conter todos os campos das fontes de dados públicas, nem por reutilizá-las por não termos acesso ao arquivo rdf ou owl.

\footnotetext{
${ }^{2}$ Plug-in pySUS: https://github.com/fccoelho/PySUS/blob/master/pysus/utilities/readdbc.py

${ }^{3}$ Plug-in simpledbf: https://pypi.org/project/simpledbf/

${ }^{4}$ SemanticSUS: https://semanticsus.github.io/semanticSUS/index.html
} 
Assim, o desenvolvimento das ontologias da Camada de Ontologias de Fonte (OF) seguiu, em parte, o algoritmo discutido e melhorado por [HMS17].

As ontologias dessa camada caracterizam-se por repetir a descrição exata do esquema relacional das bases de dados (o DER foi utilizado na modelagem) e também o mesmo vocabulário. Desse modo, foram criadas ontologias das três bases de dados disponíveis: do SINASC, do SIM e da DNDO; gerando as ontologias: $O F_{S I N A S C}, O F_{S I M}$ e $O F_{D N D O}$, respectivamente. A adição dos campos na DNDO fez com que fosse optado por construir uma ontologia específica para a DNDO que herdou as definições das ontologias do SINASC e do SIM. Assim a estrutura das ontologias do SINASC e do SIM foi mantida e está apta para ser utilizada em outros projetos. Com isso, a generalidade da solução foi prezada, preservando a estrutura das bases originais. Isso mostra a flexibilidade da solução em adicionar novas bases de dados. O fato de ter ontologias que representam bases integradas e não integradas mostra como a solução se comporta nas duas situações. Sendo possível realizar consultas com mapeamento semântico em ambas as abordagens. Assim, ao replicar a solução apresentada, os próximos usuários poderão escolher se manterão a estrutura das ontologias conforme as bases de dados disponibilizadas pelo DATASUS ou se farão alterações, caso haja necessidade.

O desenvolvimento das ontologias foi realizado no Protégé $e^{5}$, um editor de ontologias open-source, desenvolvido pela Universidade de Stanford. Tendo conhecimento do algoritmo de conversão de bases de dados para ontologias, foi determinado que antes de criar as ontologias no Protégé, deveriam ser criados diagramas que representassem a estrutura esperada. Os diagramas, que também podem ser entendidos como um vocabulário, foram baseados no diagrama de classes da linguagem $\mathrm{UML}^{6} \mathrm{e}$ também têm como objetivo tornar claro para os especialistas de domínio os conceitos e as relações utilizadas. Neles, o título de cada caixa representa uma classe e o restante do conteúdo da caixa representa as propriedades de dados e a base de dados de origem da propriedade. As relações são representadas pelas setas entre as caixas. A Figura 4.1 apresenta uma legenda para o que é representado no diagrama. No entanto, nem tudo que está contido na legenda está presente em todos os diagramas.

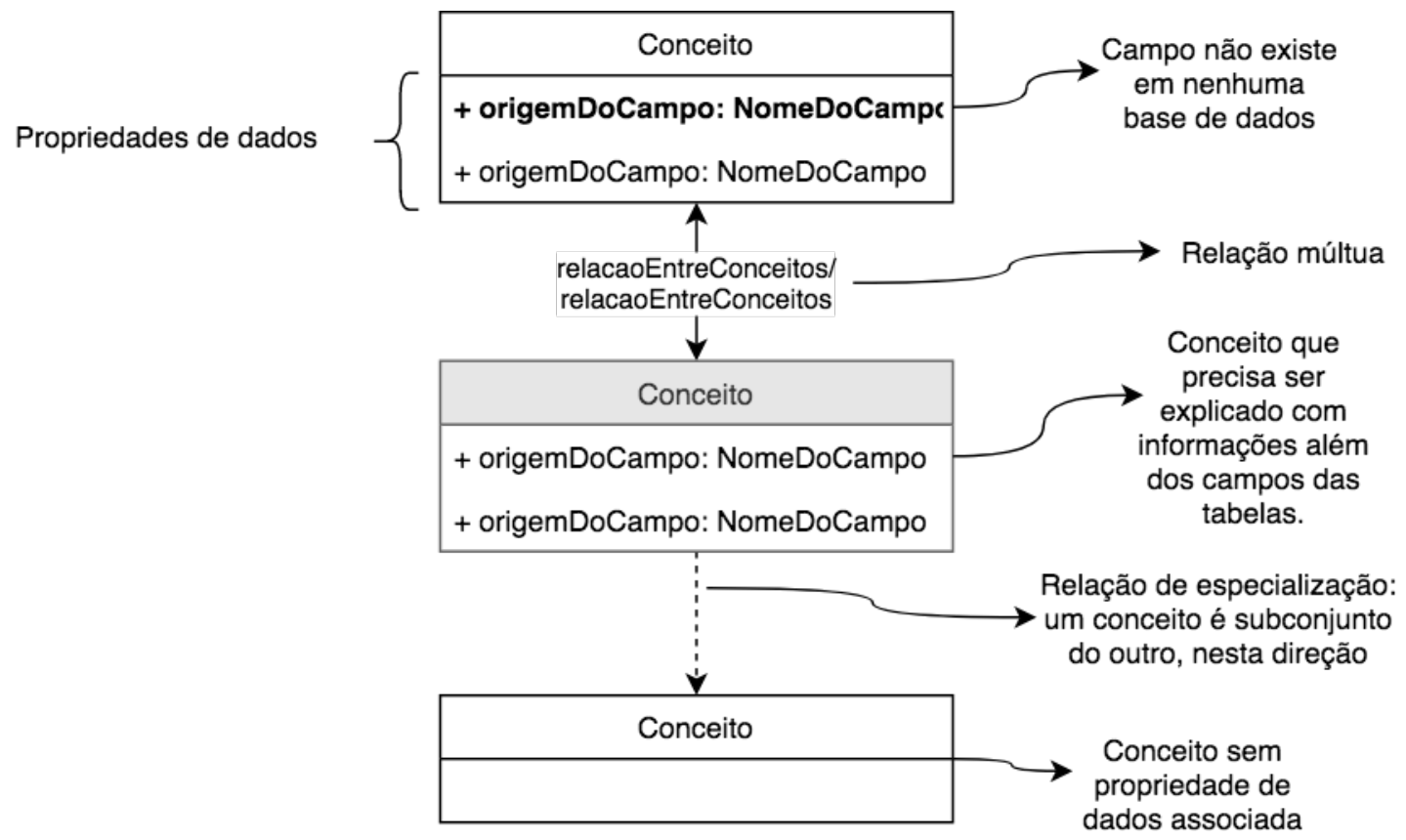

Figura 4.1: Legenda para os diagramas das ontologias

A versão final dos diagramas gerados para as ontologias $O F_{S I N A S C}, O F_{S I M}$ e $O F_{D N D O}$ é apresentada nas Figuras 4.2, 4.3 e 4.4.

\footnotetext{
${ }^{5}$ Protégé: https://protege.stanford.edu/
}

${ }^{6}$ UML: http://www.uml.org/ 


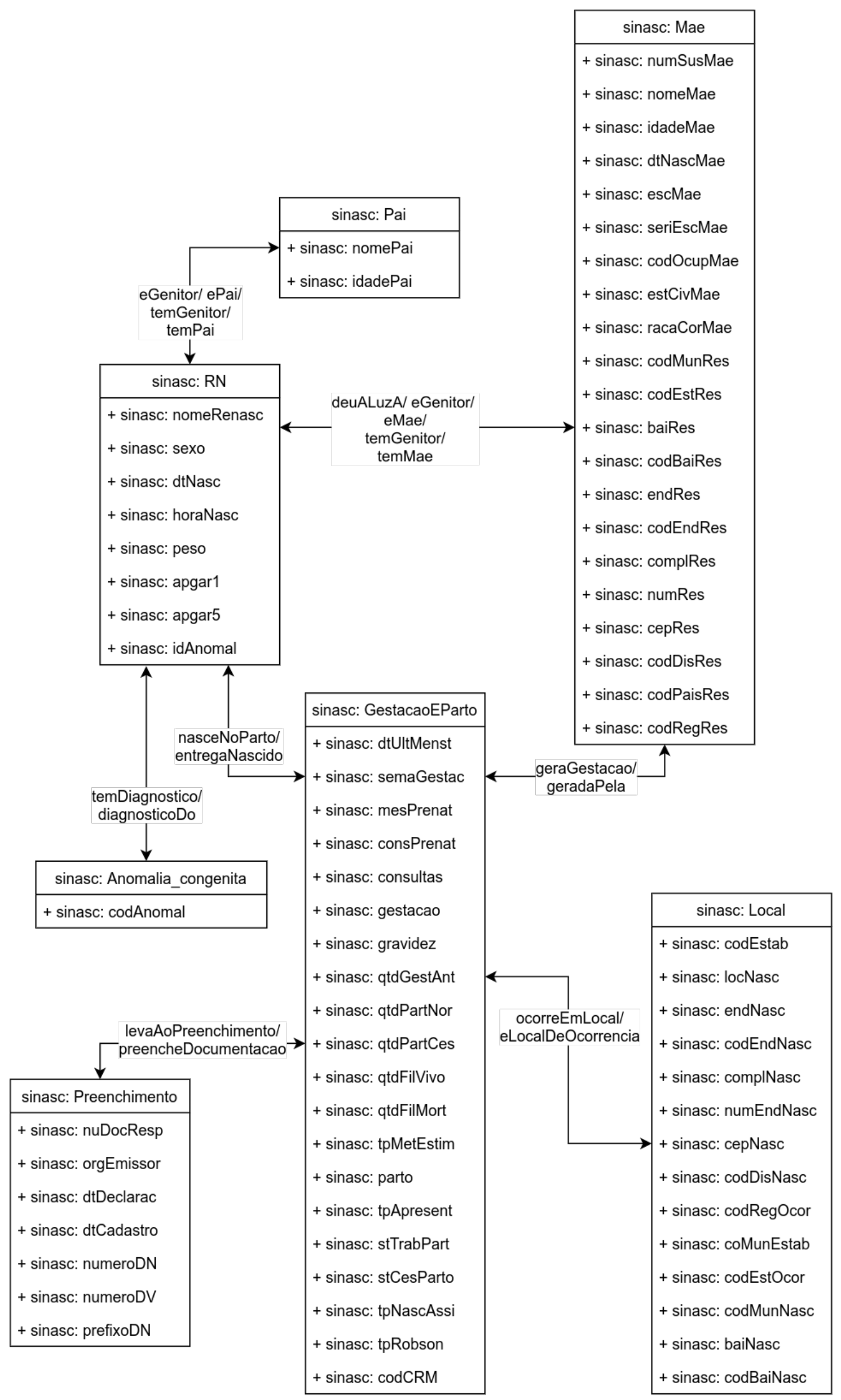

Figura 4.2: Diagrama correspondente a ontologia OF $O_{S I N A S C}$ 


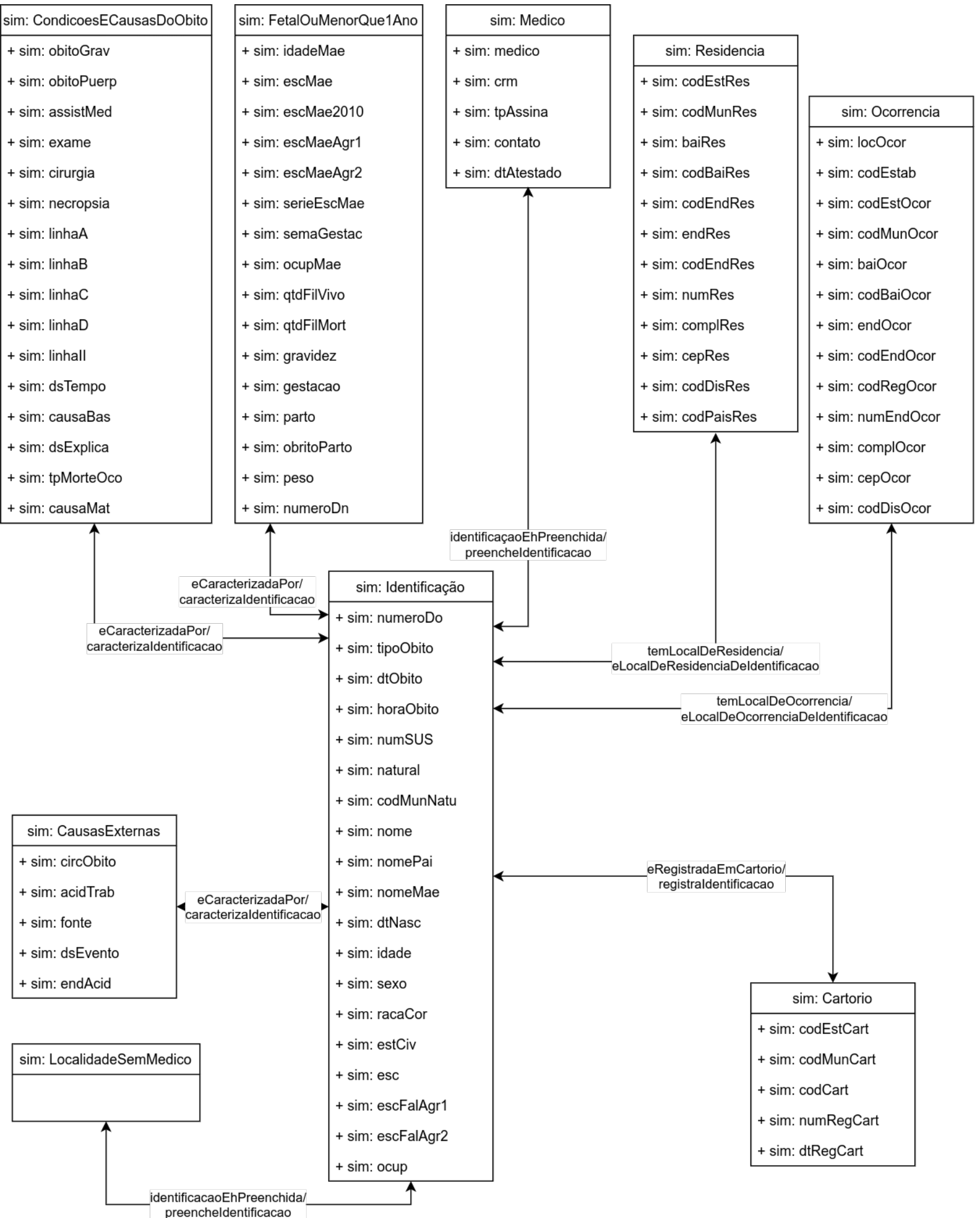

Figura 4.3: Diagrama correspondente a ontologia $O F_{S I M}$ 


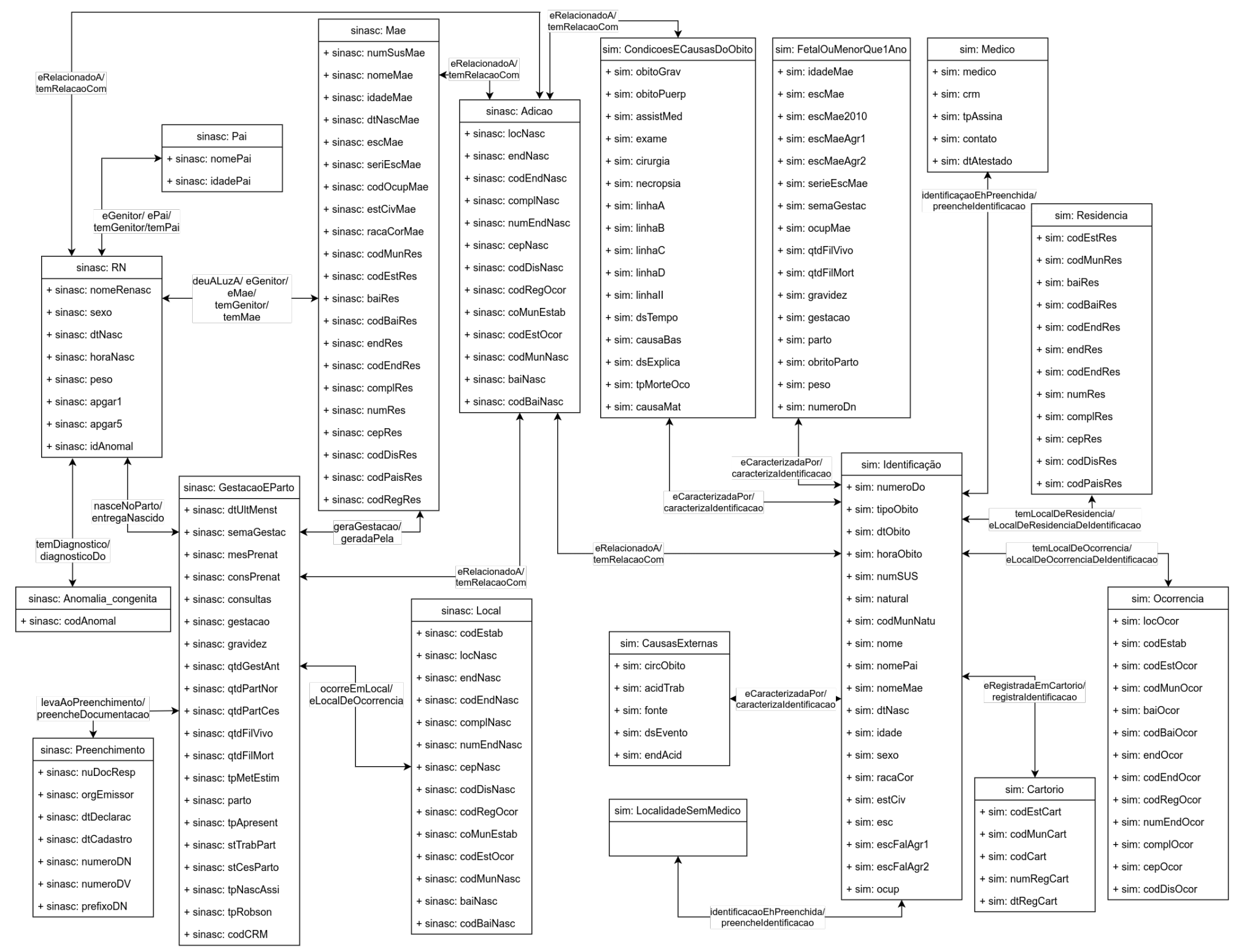

Figura 4.4: Diagrama correspondente a ontologia $O F_{D N D O}$ 
Como mencionado, o algoritmo apresentado em [HMS17] foi seguido e adaptado para a criação das ontologias $O F_{S I N A S C}$ e $O F_{S I M}$, de acordo com as características das fontes de dados. Os passos para a construção foram:

1. Mapeamento de tabelas para classes $O W L$ : Os autores definem que cada tabela da base de dados deve ser traduzida como uma classe de mesmo nome na ontologia. Como foi referido anteriormente não houve acesso aos diagramas com a estrutura relacional das bases de dados, sendo necessário recriá-los, do contrário existiria apenas uma classe para casa sistema. Desse modo, os capítulos presentes da ficha de preenchimentos foram adotados como tabelas. $\mathrm{Na}$ Figura 4.5 pode ser visto um recorte da ficha de preenchimento do SINASC com o foco no capítulo V:"Gestação e Parto" e seus campos. O capítulo V: "Gestação e Parto" tornou-se uma classe e os campos presentes nesse grupo tornaram-se Propriedades de Dados deste. A Figura 4.6, contém parte da ontologia $O F_{S I N A S C}$, as classes geradas a partir dos capítulos e as propriedades referentes a classe GestacaoEParto;

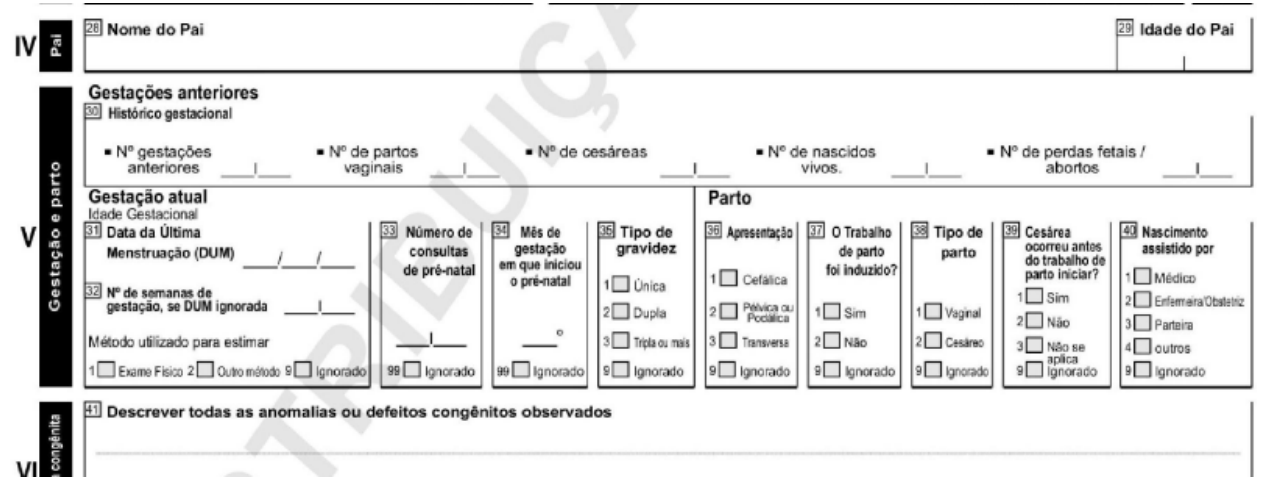

Figura 4.5: Recorte da ficha de preenchimento do SINASC

\begin{tabular}{|c|c|}
\hline Class hierarchy: GestacaoEParto & ?ㅂㅁ \\
\hline 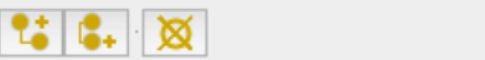 & Asserted $\hat{\imath}$ \\
\hline $\begin{array}{l}\text { owl:Thing } \\
\text { AnomaliaCongenita } \\
\text { GestacaoEParto } \\
\text { Local } \\
\text { Mae } \\
\text { Pai } \\
\text { PreenchimentoCadastral } \\
\text { RN }\end{array}$ & \\
\hline
\end{tabular}

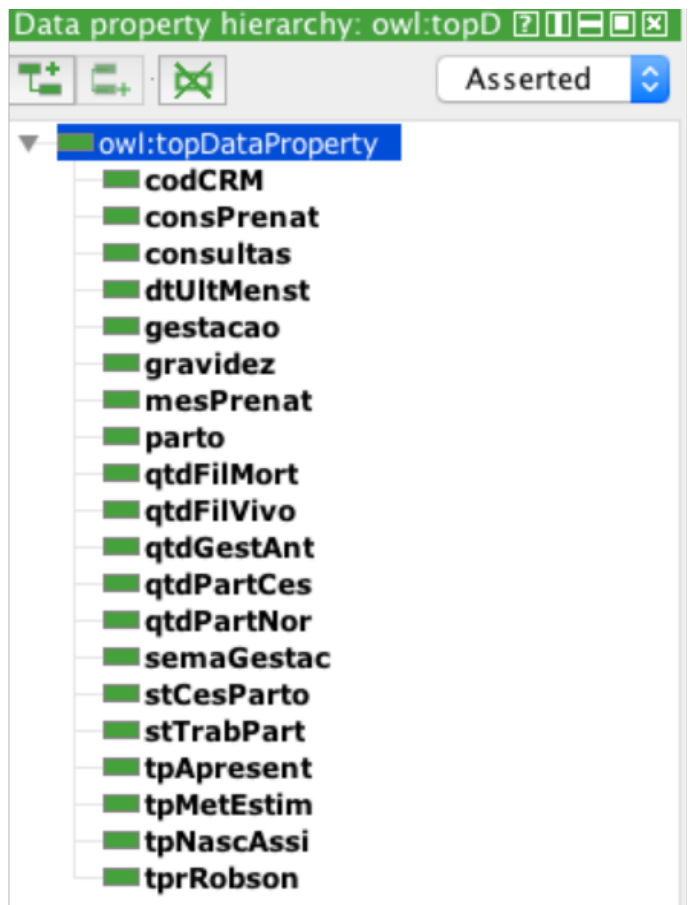

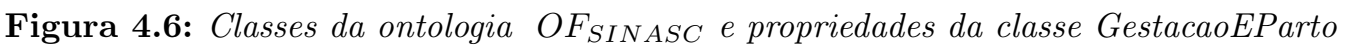

2. Tratamento de tabelas de atributos multi-valorados: Nessa etapa os autores alertam para a localização de tabelas de atributos multi-valorados e como elas devem ser modeladas de modo diferente das outras tabelas. No entanto, não foi encontrada nenhuma tabela de atributos multi-valorados nas fontes de dados; 
3. Mapeamento dos relacionamentos de integridade referenciais para hierarquia de herança: Nesta etapa, tabelas com chave estrangeira são rearranjadas como subclasses da classe correspondente a tabela que possui a chave primária. Ao seguir esse passo na $O F_{S I M}$, as classes CausasExternas e FetalOuMenorQue1Ano viraram subclasses de CondicoesECausasDoObito, uma vez que ambas são extensões do conceito de Condicoes ECausasDoobito;

4. Mapeamento de colunas de integridade não referenciais para propriedades de tipos de dados: Aqui as colunas das bases de dados (os campos que fazem parte dos capítulos das folhas de preenchimento) foram mapeadas para Propriedades de Dados, como pode ser visto no exemplo das Figuras 4.5 e 4.6, exceto as colunas que representam as chaves estrangeiras;

5. Representação de propriedades de dados como dominio e tipos de dados como escopo - range: Nessa etapa foram configurados o domínio e escopo das propriedades de dados. O domínio é a classe em que a propriedade está alocada e o escopo do tipo de dados que ela recebe. Segundo os dicionários de dados (Anexos B e D), todas as variáveis possuem o tipo de dados "caracter". Identificada essa generalização foi acordado que não haveria a formalização dos tipos de dados nas ontologias da Camada de Fontes;

6. Mapeamento dos relacionamentos (chave estrangeira) para propriedades do objeto: Nesse passo, todos os relacionamentos de tabelas que possuem uma chave estrangeira foram mapeadas em Propriedades de Objeto. Assim, são formadas duas propriedades de objeto para cada relacionamento: uma para o relacionamento e outra para o relacionamento inverso. A Figura 4.7 apresenta a propriedade de objeto diagnosticadocom que possui como inverso diagnosticoDo, da ontologia OF SINASC;

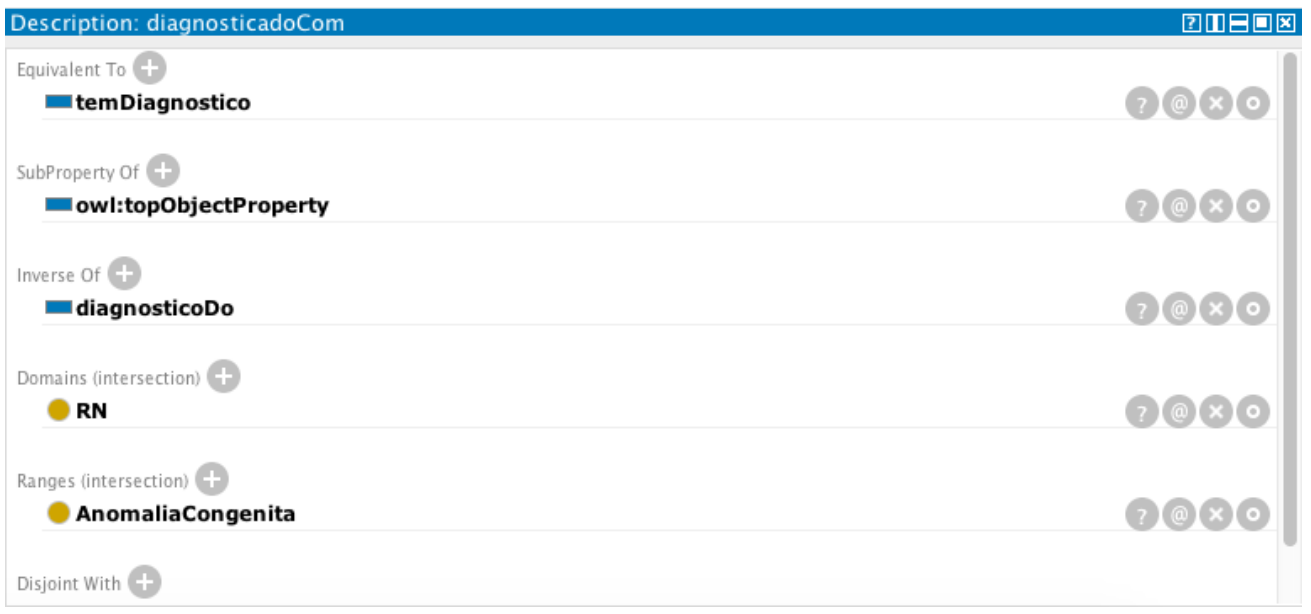

Figura 4.7: Propriedade de Objeto diagnosticadoCom da ontologia OF $F_{S I N A S C}$

7. Representação das propriedades do objeto: Aqui foram representadas as propriedades de objeto e adicionados o domínio e o escopo de cada propriedade. A Figura 4.7 também apresenta o domínio e o escopo da propriedade de objeto diagnosticadocom;

8. Mapeamento de restrições de integridade de chave para propriedades de cardinalidade: Os passos 8 e 9 tiveram a ordem de excussão invertida no presente trabalho. Nessa etapa são ajustadas as restrições de integridade que as ontologias herdam. No entanto, foi estabelecido que não haveria essa configuração, uma vez que esta não estava bem estabelecida nem nenhuma parte da documentação das bases de dados;

9. Mapeamento de tuplas para indivíduos: O mapeamento das tuplas para indivíduos será descrito em 4.3; 
A expressividade da lógica de descrição utilizada nas ontologias $O F_{S I N A S C}$ e $O F_{S I M}$ é $\mathcal{A L C H} \mathcal{I}(\mathcal{D})$. As ontologias estão disponíveis no repositório https://gitlab.com/beliefchangetools/ diasus.

A primeira fase de testes das ontologias ocorreu antes de serem realizados os mapeamentos com o banco de dados. Um exemplo com alguns indivíduos da Família Real Britânica serviu para povoar as ontologias e testá-las quanto a consistência, rodando o raciocinador HermiT, versão 1.3.8.413. As propriedades de dados, e de objetos e as classes foram relacionadas aos indivíduos e foi possível fazer consultas SPARQL relativas ao conteúdo de cada ontologia. As Figuras 4.8 e apresentam um recorte da ontologia $O F_{S I N A S C}$ e $O F_{S I M}$, respectivamente, com os indivíduos criados. $\mathrm{Na} O F_{S I N A S C}$, ao analisar o indivíduo QueenElizabethII é possível observar as propriedades de dados e de objetos relacionadas a ele e é fácil constatar que ela é mãe (eMae) e genitora (eGenitor) do Príncipe Charles (PriceCharles) e da Princessa Mary (Princessmary) e é filha do Rei Jorge IV (KingJorgeIV) e da Rainha Elizabeth II, a Rainha Mãe (QueenElizabethQueenMother). Atenta-se também para a presença das propriedades de dados contendo a data de nascimento e o sexo. No entanto, as classes não estavam disjuntas, o que permitiu que o indivíduo QueenElizabethII fosse dos tipos DN, GestacaoEParto, Mae e RN ao mesmo tempo. Com a disjunção esse indivíduo só pode ser, ao mesmo tempo, dos tipos Mae e RN.

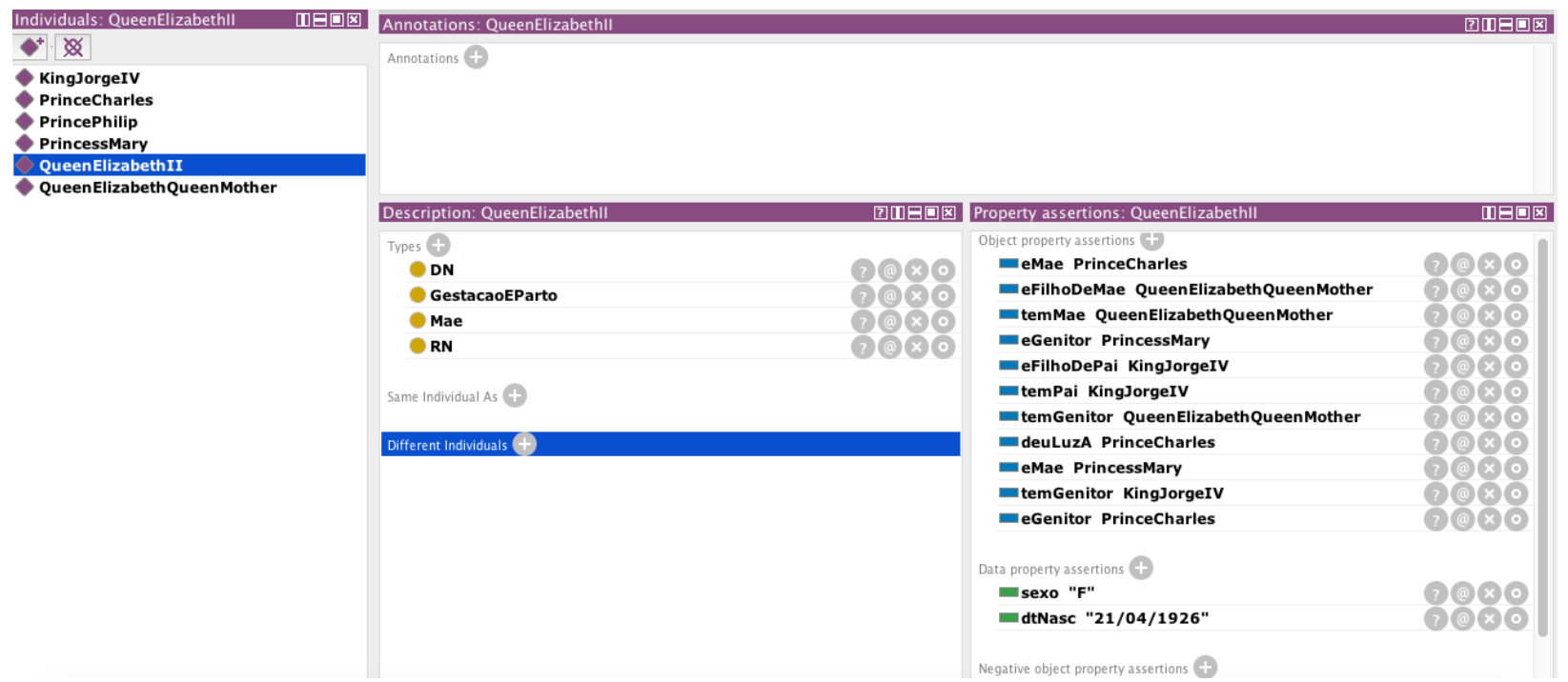

Figura 4.8: Exemplo da ontologia $O F_{S I N A S C}$ preenchida com indivíduos da Família Real Britânica

Foram realizadas as consultas apresentadas no Anexo B.

A construção da ontologia $O F_{D N D O}$ ocorreu por meio da importação das ontologias $O F_{S I M}$ e $O F_{S I N A S C}$, e da adição da classe Acrescimo - Acréscimo, cujas propriedades de dados correspondem aos campos adicionados na base de dados da DNDO. Também foram incluídas as propriedades de objeto relacionadas a essa nova classe. A ontologia gerada possui expressividade $\mathcal{A L U I}(\mathcal{D})$ e também está localizada no repositório supracitado. As consultas apresentadas acima também foram testadas na $O F_{D N D O}$ e o resultado foi o mesmo. Adicionalmente foi testada a seguinte consulta:

- Quais são as declarações de nascimento do SINASC que tiveram óbito registrado no SIM? Figura 4.9 


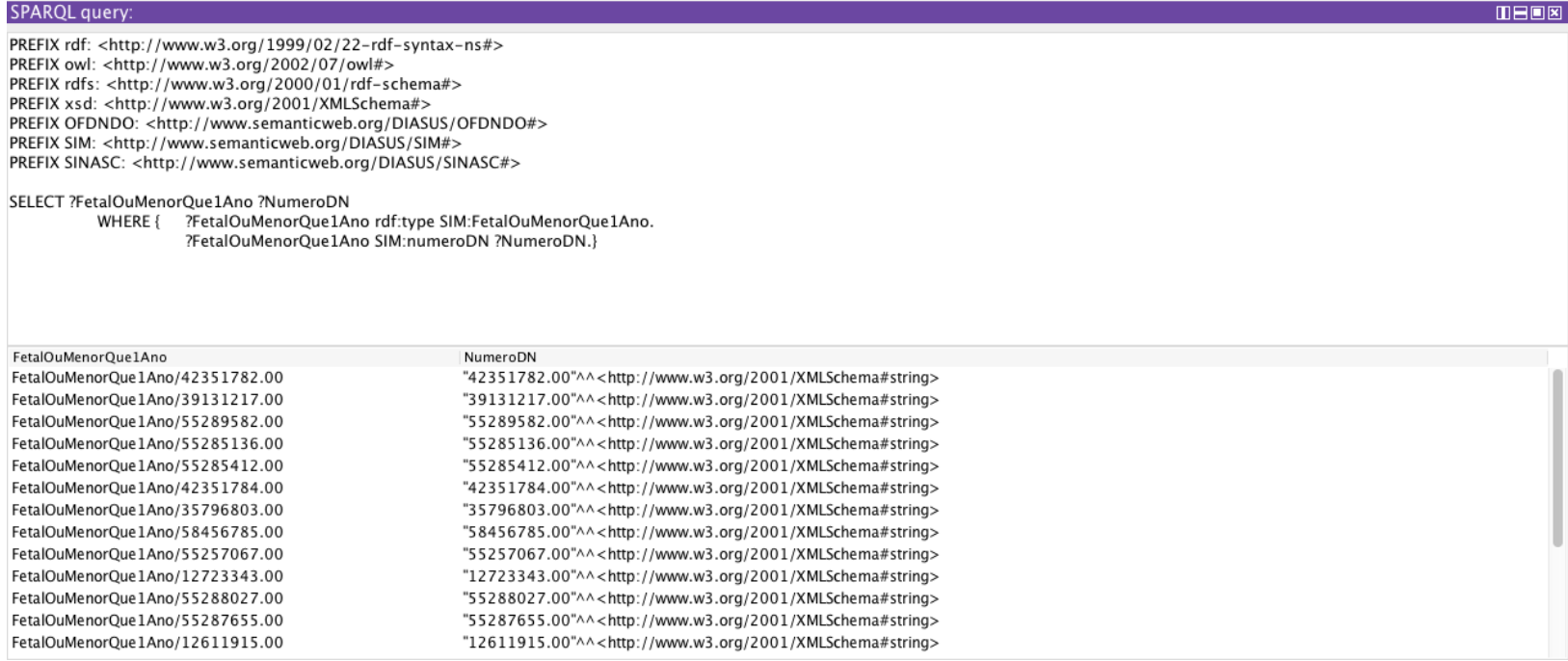

Figura 4.9: Consulta exemplo das declarações de nascimento do SINASC que tiveram óbito registrado no $S I M$, ontologia $O F_{D N D O}$

\subsection{Desenvolvimento dos Mapeamentos FD OF}

O mapeamento das bases de dados para as ontologias, FD OF, ocorreu dentro do Protégé, utilizando o plug-in do Ontop ${ }^{7}$, desenvolvido pela Universidade de Bolzano. Nele é possível acessar os dados que estão em um sistema gerenciador de bases de dados - SGBD, construir as regras, materializar os mapeamentos e realizar consultas. Para isso, foi preciso configurar o Ontop com o acesso do SGBD, baixando a versão mais recente do Java Runtime Environment ${ }^{8}$, e o JDBC Driver $^{9}$ do Postgres. A Figura 4.10 apresenta a tela de configuração do Ontop no Protégé, na aba Datasource manager.

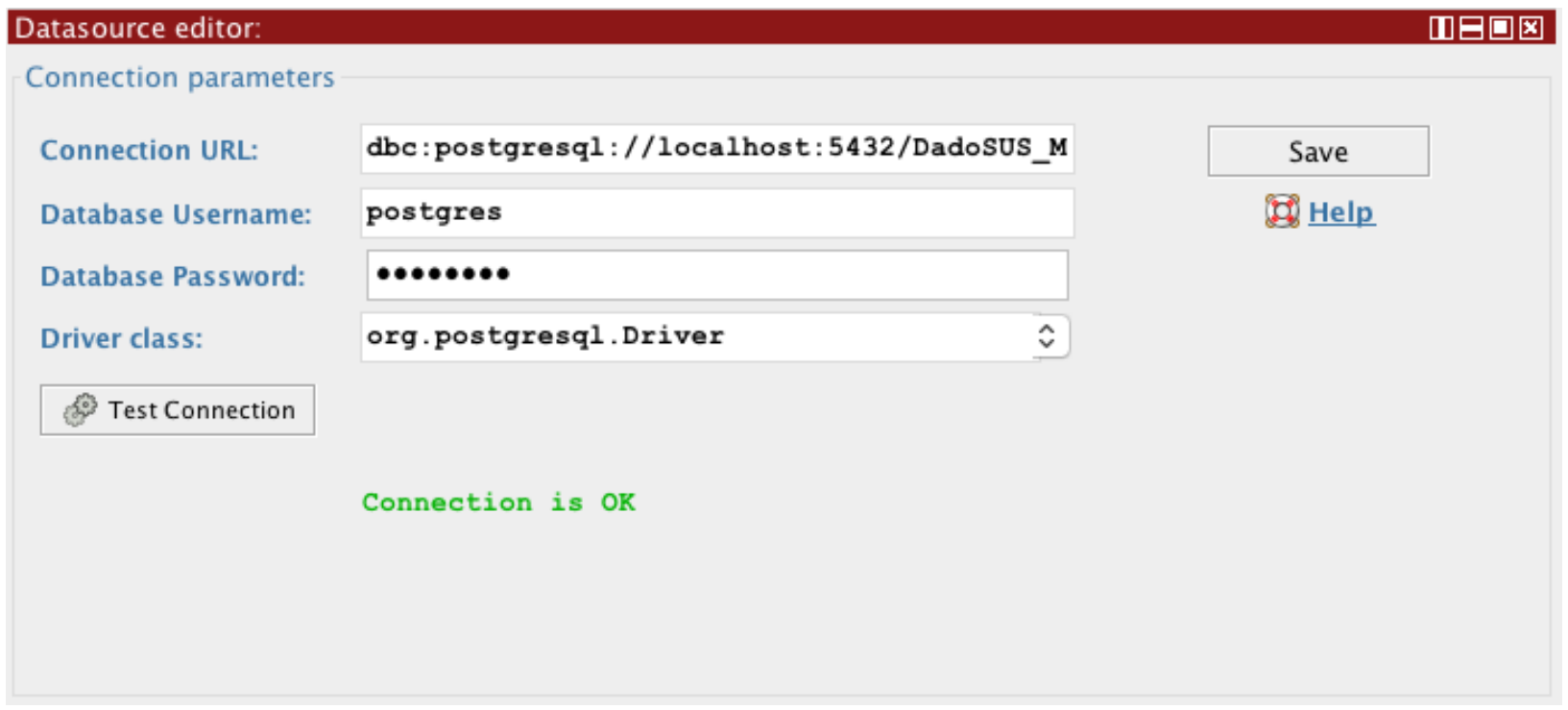

Figura 4.10: Configuração do plug-in do Ontop no Protégé

A aba Mapping Assistant do Ontop, Figura 4.11, serve de auxílio para a construção dos mapeamentos de classes, propriedades de dados e de objetos para uma base de dados. No campo Data Set foi selecionada a base de dados que seria mapeada. No entanto, só é possível mapear

\footnotetext{
${ }^{7}$ Ontop: https://ontop.inf.unibz.it/

${ }^{8}$ https://www.java.com/pt_BR/download/mac_download.jsp

${ }^{9}$ https://jdbc.postgresql.org/
} 
uma base de dados por vez. Foram mapeadas separadamente as ontologias $O F_{S I N A S C}, O F_{S I M}$ e $O F_{D N D O}$.

Em Focus on URI, foi configurado o identificador do indivíduo que será mapeado. Sabendo que a estrutura das ontologias (derivada do DER) não é similar a da base de dados (arquivo csv), a ausência de uma chave primaria para cada classe foi ajustada adotando o nome das classes somado ao identificador de cada base como sendo o identificador de cada indivíduo pertencente às classes. Assim, na aba Focus on URI cada uma das classes da ontologia foi adicionada de modo a receber a combinação NomeDaClasse/\{identificador\}, como apresentado com a classe Mae na Figura 4.11. Isso significa que cada indivíduo daquela classe levará consigo as informação referentes ao indivíduo da base. Desse modo, a Mãe que está relacionada a declaração de nascido vivo de número 03386479, será representada como Mae/"03386479" assim como todas as outras classes que tiverem informações relacionadas a esse número de declaração de nascido vivo. Esse formato permite um ganho quando comparado a apresentação dos dados no .csv pois se aproxima da visualização de dados da ficha de preenchimento, agrupando todos os campos relativos a mesma classe. O identificador utilizado para a base do SINASC foi o número da declaração de nascido vivo (numerodn), o da base do SIM, o número da declaração de óbito (numerodo) e o da base da DNDO, o nudn, o número de identificação gerado a partir da base de dados do SINASC.

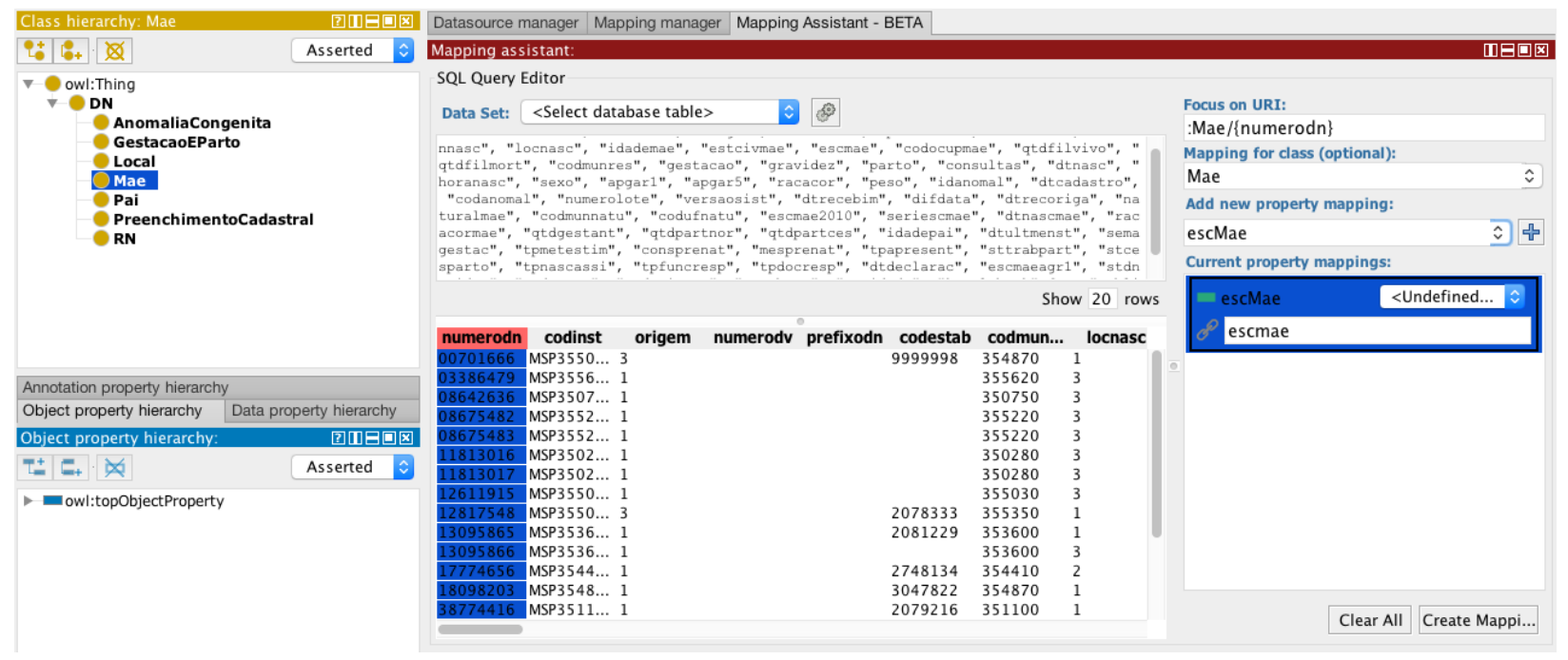

Figura 4.11: Aba Mapping assistant, do Ontop

No campo Mapping for class foi selecionada a classe da ontologia a que a URI anteriormente preenchida se referia. Em Add new property mapping cada propriedade de dado e de objeto é associada a classe que está sendo mapeada. Ao clicar no botão de mais, "+", essa propriedade aparece no campo Current property mappings que associa cada propriedade a uma variável da base de dados. A Figura 4.11 apresenta o conceito de escolaridade da mãe (escMae) sendo mapeado na variável (escmae) da base de dados do SINASC. E assim, todas as propriedades de dados de uma classe foram mapeadas para suas respectivas variáveis.

O resultado dos mapeamentos criados na aba Mapping Assistant aparecem na aba Mapping Manager e tem o formato apresentado nas Figuras 4.12 e 4.13. Ao observar atentamente o mapeamento apresentado na Figura 4.12, é possível notar que nem todas as propriedades de dados presentes na ontologia foram mapeadas para a base de dados, uma vez que nem todas as variáveis estavam presentes na base de dados, afinal as bases utilizadas para o teste foram bases de dados públicas. O resultado do mapeamento das propriedades de objetos, no entanto, é um pouco diferente do das propriedades de dados, uma vez que não associa classes, mas identificadores onde as classes já estão embutidas, como pode ser visto na Figura 4.13. 


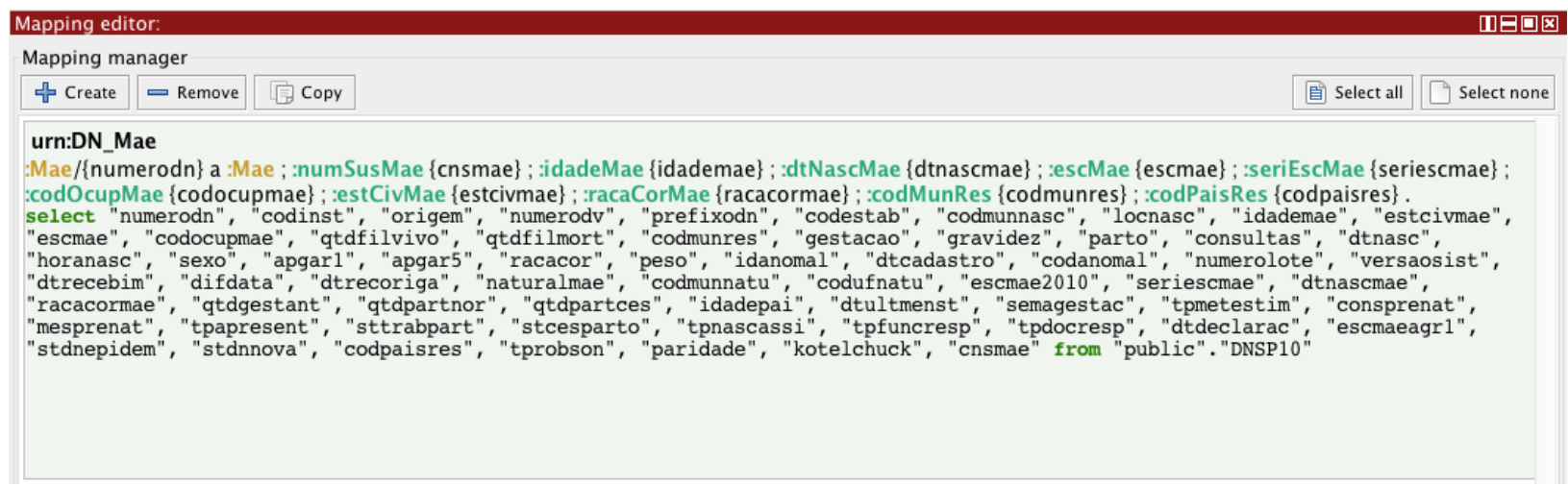

Figura 4.12: Mapeamento de uma classe com suas propriedades de dados

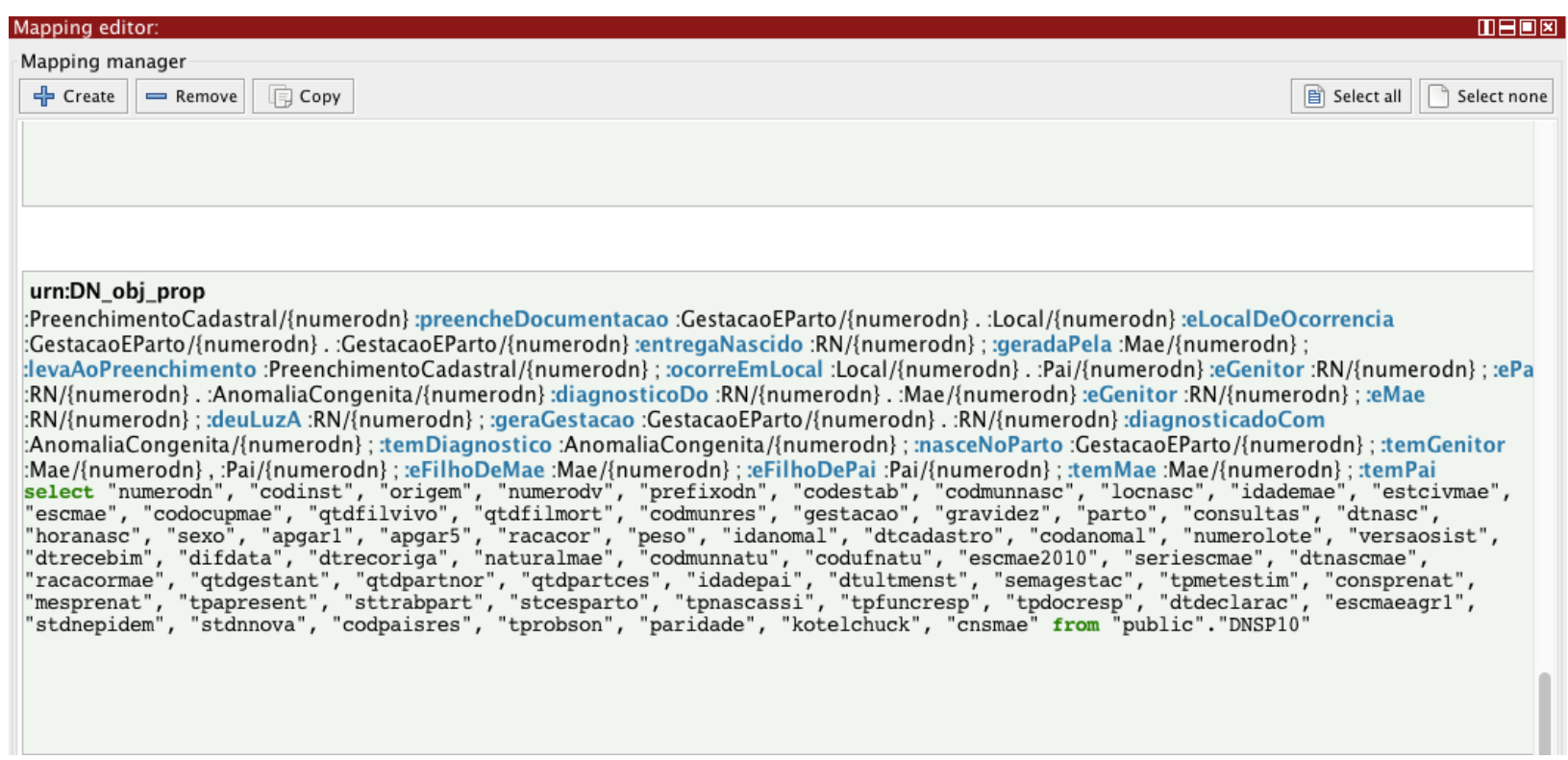

Figura 4.13: Mapeamento de uma classe com suas propriedades de objetos

Esse processo de acesso a bases de dados por meio de ontologias levando assim a criação de mapeamentos entre as ontologias e os dados gera um novo arquivo, este possui a extensão obda, de Ontology Based Data Access. O acesso ao novo arquivo se dará automaticamente através do acesso ao arquivo ontologia, em formato owl.

Realizar mapeamentos possibilita efetuar consultas SPARQL nas bases de dados a partir da ontologia, virtualizados ou materializar o conteúdo das bases de dados, adicionando-o à ontologia. A Figura 4.14 apresenta um recorte dos indivíduos da base de dados do SINASC materializados na ontologia $O F_{S I N A S C}$. É possível notar o padrão NomeDaClasse/\{identificador\} para nomear cada indivíduos, como discutido anteriormente. Assim o indivíduo Mae/"03386479" pode ser lido como a Mãe que está associada a declaração de nascido vivo de número 03386479, sendo mãe (eMae) do recém nascido RN/"03386479", possuindo a ocupação cujo código da CBO é 214505 (codOcupMae "214505"). 


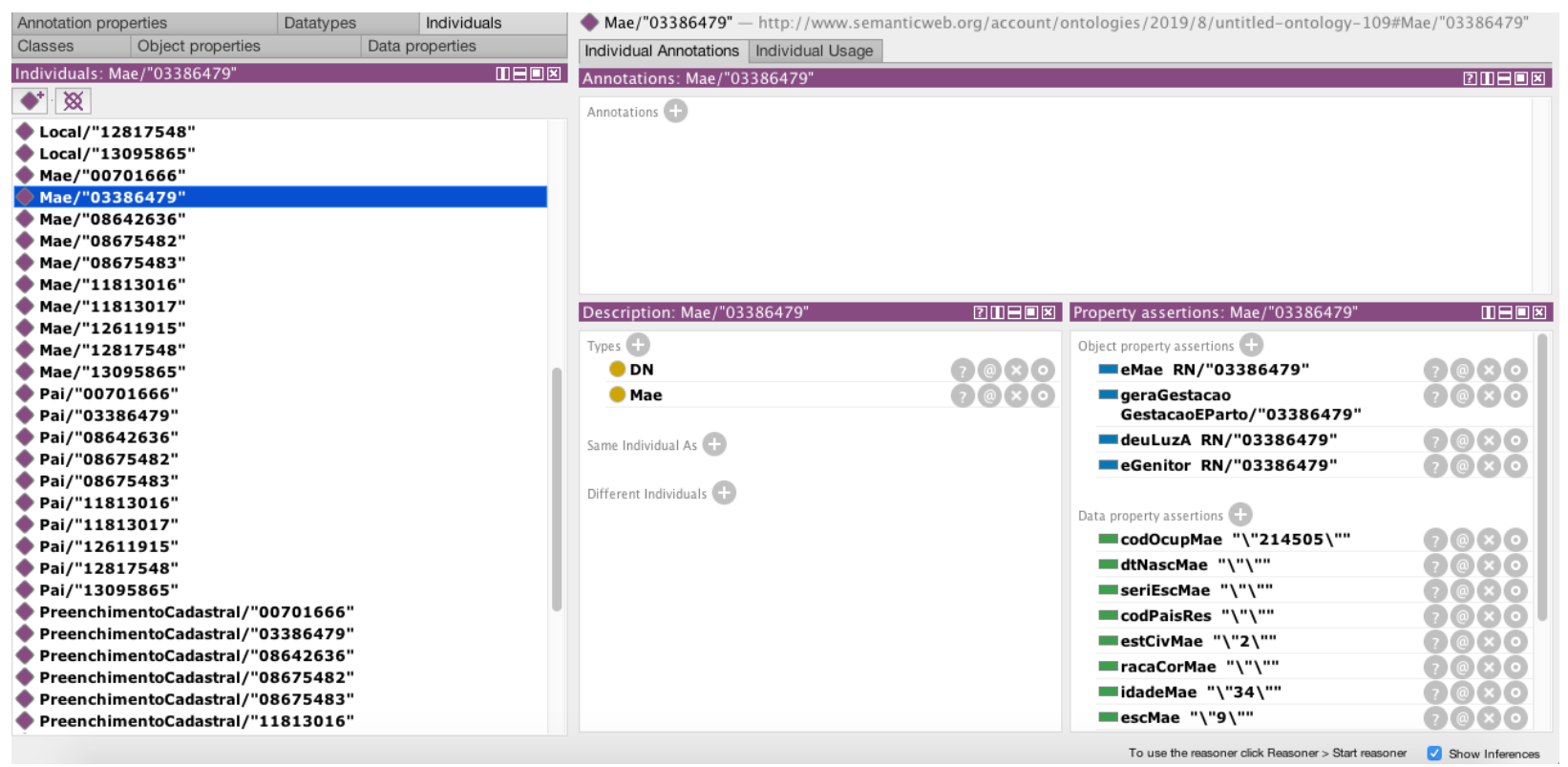

Figura 4.14: Indivíduos da base de dados do SINASC materializados na ontologia OF $F_{S I N A S C}$

A fim de validar os mapeamentos, foram repetidas as mesmas consultas SPARQL apresentadas anteriormente, agora com o acesso aos dados da base de dados por meio da ontologia e com um pequeno conjunto de dados materializados na ontologia. $\mathrm{O}$ resultado foi similar ao anterior. As Figuras 4.15 e 4.16 apresentam o resultado da consulta "Quem são os recém nascidos presentes na ontologia do SINASC?", com os dados virtualizados e materializados na ontologia, respectivamente. Ao final do processo, as bases de dados públicas do município de São Paulo relativas ao SINASC e ao SIM do ano de 2015 foram materializadas nas ontologias correspondentes e disponibilizadas no mesmo repositório supracitado.

Query Editor

PREFIX obda: <https://w3id.org/obda/vocabulary\#>

PREFIX rdf: <http://www.w3.org/1999/02/22-rdf-syntax-ns\#>

PREFIX sinasc: <http://www.semanticweb.org/account/ontologies/2019/8/untitled-ontology-109\#>

SELECT ?RecemNascido

WHERE $\{$ ?RecemNascido rdf:type sinasc:RN.

\begin{tabular}{|c|c|c|c|c|c|c|c|}
\hline Execution time: $0.003 \mathrm{sec}-$ Number of rows retrieved: 10 & Show: & 100 & All & Short IRI & + Attach Prefixes & Execute & 回 Save Changes \\
\hline \multicolumn{8}{|l|}{ RecemNascido } \\
\hline \multicolumn{8}{|l|}{ "00701666" } \\
\hline \multicolumn{8}{|l|}{ "03386479" } \\
\hline \multicolumn{8}{|l|}{ "08642636" } \\
\hline \multicolumn{8}{|l|}{ "08675482" } \\
\hline \multicolumn{8}{|l|}{ "08675483" } \\
\hline \multicolumn{8}{|l|}{ "11813016" } \\
\hline \multicolumn{8}{|l|}{ "11813017" } \\
\hline \multicolumn{8}{|l|}{ "12611915" } \\
\hline \multicolumn{8}{|l|}{ "12817548" } \\
\hline "13095865" & & & & & & & \\
\hline
\end{tabular}

Figura 4.15: Exemplo de consulta SPARQL com os indivíduos virtualizados 
PREFIX rdf: <http://www.w3.org/1999/02/22-rdf-syntax-ns\#>

PREFIX rdf: <http: //www.w3.org/1999/02/22-rdf-
PREFIX owl: <http://www.w3.org/2002/07/ / wl \#>

PREFIX rdfs: <http://www.w3.org/2000/01/rdf-schema\#>

PREFIX xsd: <http://www.w3.org/2001/XMLSchema\#>

PREFIX sinasc: <http://www.semanticweb.org/account/ontologies/2019/8/untitled-ontology-109\#>

SELECT ?RecemNascido

WHERE\{ \{RecemNascido rdf:type sinasc:RN.\}

Figura 4.16: Exemplo de consulta $S P A R Q L$ com os indivíduos materializados

O próximo capítulo tratará do desenvolvimento das ontologias e mapeamentos dependentes da aplicação, ou seja, das ontologias que terão foco na saúde materno-infantil e no desenvolvimento do indicador de saúde DPGP, não mais nas bases de dados do SINASC e do SIM. 


\section{Capítulo 5}

\section{Desenvolvimento das ontologias e mapeamentos dependentes da aplicação}

Esse bloco da solução apresenta as ontologias e os mapeamentos que são dependentes da aplicação e que assim foram desenvolvidos a partir das questões de competências elencadas pelos especialistas do domínio pensando na saúde materno-infantil e na produção do indicador de saúde DPGP. Fazem parte desta etapa o desenvolvimento das ontologias de Domínio (OD) 5.1 e de Integração (OI) 5.2 e 5.5, bem como o dos mapeamentos da camada de ontologia de domínio para a de ontologias de integração $M_{O D} O I$ 5.3, da camada de ontologias de fonte para a de ontologias de integração, $M_{O F \_}$OI 5.4, os links sameAs na camada de ontologias de integração 5.6 e os mapeamentos da camada de ontologias de integração para a de ontologia de domínio, $M_{O I \_O D}$ 5.7, como está destacado na Figura 5.1.

Camada de Ontologia de Domínio (OD)

Camada de Ontologias de Integração (OI)

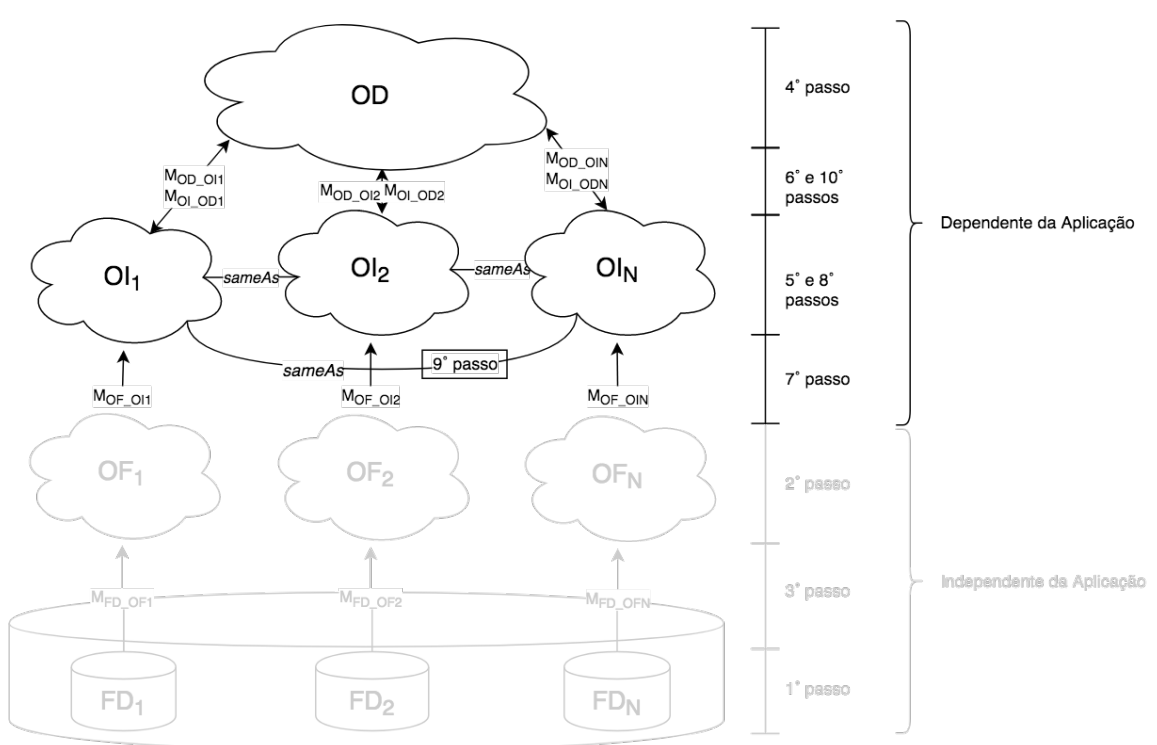

Figura 5.1: Arquitetura da solução OBDI híbrida desenvolvida, com o fluxo de conceitos e a ordem de criação, destaque para a etapa dependente da aplicação.

\subsection{Desenvolvimento da Ontologia da Camada OD}

Para o desenvolvimento da ontologia da camada OD foi utilizada a técnica de [GF95] onde os passos seguidos para a construção de ontologias foram: Cenário Motivador, Questões de Competência Informais, Especificação Formal: Terminologia e Formalização das Questões de Competência. 


\subsubsection{Cenário Motivador}

Durante toda a fase de compreensão do escopo do projeto e em todos os estudos de caso elencados, o mesmo problema foi mencionado: Os dados necessários para realizar análises mais profundas ou acompanhamentos a médio e longo prazo estão em bases de dados distintas e o processo para a realização da integração é custoso, atualmente sendo realizado quase que manualmente ou em ferramentas como o Microsoft Access ${ }^{1}$, voltadas para bancos de dados e soluções menores e menos complexas. Além disso, as análises dependem de pessoal especializado no conteúdo e formatação das bases, sendo difícil para um profissional com pouca experiência nas bases de dados realizá-las, mesmo que este seja da área da saúde.

Foram propostos três cenários distintos com a mesma temática de atenção a saúde maternoinfantil no Sistema Único de Saúde do Município de São Paulo, que utilizam as mesmas bases ou parte delas. Foram eles: A necessidade de localização dos indivíduos com anomalia congênita nas diversas bases de dados; a identificação de quais variáveis das bases de dados relacionam-se com a saúde materno infantil a fim de gerar um indicador de saúde para potenciais dias de gravidez perdidos - DPGP; e a compreensão do padrão de deslocamento de gestantes e de recém nascidos para o acesso a equipamentos de saúde que realizam internações. Desses, a temática da saúde materno infantil voltada para o desenvolvimento do indicador do DPGP, foi eleita como caso de uso central. A escolha foi guiada pelos especialistas nas bases e os colaboradores da Faculdade de Saúde Pública, principalmente por conta da facilidade de acesso aos dados e ao conhecimento do domínio.

A fim de compreender o escopo e as necessidades pertinentes à temática, foram realizadas três reuniões com os especialistas do domínio. Foram ouvidas em torno de 20 pessoas entre técnicos da Secretaria Municipal da Saúde de São Paulo e professores e alunos de pós-graduação da Faculdade de Saúde Pública da USP. Os especialistas realizaram seminários para apresentar o contexto do problema e o que esperam como resultado, bem como apresentaram o diagrama de espinha de peixe, descrito na Figura A.1.

\subsubsection{Questões de Competência Informais}

A partir dos seminários e do diagrama contendo as bases de dados e campos, foram elencadas questões de competência relacionadas ao tema. A principal preocupação na elaboração das questões de competência foi delimitar um escopo global para o projeto. Desse modo todos os resultados e conceitos esperados no contexto foram listados. A lista completa com as questões de competência está descrita no Apêndice C. As questões de competência foram divididas em quatro grupos: Mãe, Gestação, Parto e Nascido Vivo, Filho ou Recém Nascido. Em seguida foram avaliadas, editadas e revisadas pelos especialistas de domínio. A construção completa do sistema que responderá a todas as questões de competência vai além desta dissertação de mestrado, sendo relatada na seção de trabalhos futuros. Desse modo, apenas as questões que podem ser respondidas com pelo menos umas das bases de dados representadas (SINASC e SIM) foram eleitas para este trabalho. Existem níveis de dificuldade para responder às questões de competência. Há aquelas que:

1. Podem ser respondidas de um único modo e que necessitam de:

(a) Uma variável de apenas uma base;

(b) Mais de uma variável da mesma base, geralmente numa apresentação que remodela os dados;

(c) Mais de uma variável de mais de uma base;

2. Podem ser respondidas de diversos modos pois a mesma informação está localizada em mais de uma base de dados, assim, pode conter até as três subdivisões descritas no modo 1.

\footnotetext{
${ }^{1}$ Microsoft Access: https://products.office.com/pt-br/access
} 
Uma tabela com a classificação das questões de competência e as bases de dados utilizadas para respondê-las é encontrada no Apêndice C. Algumas questões de competência, o que é necessário para respondê-las e o que foi modelado neste projeto será apresentado, a fim de exemplificar a classificação:

- Questão que pode ser respondida com apenas uma variável de uma base de dados:

\section{Qual o peso do filho ao nascer?}

Para responde a essa questão de competência é necessário:

- Formalizar os conceitos de filho, filho ao nascer ou seja recém nascido, nascido vivo, peso e peso ao nascer, associar o conceito de peso ao nascer ao filho ao nascer e ao de recém nascido;

- Associar o nascido vivo a uma entrada na base de dados do SINASC.

- Verificar o valor do resultado na variável presente na base de dados do SINASC.

Esta é uma consulta simples, que pode ser respondida apenas com o acesso a uma variável de uma base de dados, o SINASC.

- Questão que necessita de mais de uma variável da mesma base de dados:

\section{Quais informações existem na base sobre a mãe do recém nascido que possui registro de anomalia congênita?}

Para responder a essa consulta é necessário:

- Formalizar os conceitos de mãe, recém nascido e anomalia congênita e associar o conceito de mãe ao de recém nascido e o de anomalia congênita ao de recém nascido;

- Ter formalizados conceitos relacionados a mãe presentes nas bases de dados;

- Definir os mapeamentos dos conceitos das ontologias nas bases de dados;

Esta é uma questão que necessita da existência de mapeamentos entre os conceitos que foram feitos previamente para responder a outras questões de competência. Além disso, para respondê-la é necessário utilizar-se de mais de uma variável (como as variáveis mãe e filho e as informações existentes sobre a mãe) da mesma base de dados, o SINASC.

- Questões que necessitam de mais de uma variável de mais de uma base de dados:

\section{Houve óbito de algum recém nascido que têm registro de anomalia congênita no SINASC?}

Para responder a essa questão de competência é necessário:

- Formalizar os conceitos de óbito, recém nascido e anomalia congênita e associar os conceitos de recém nascido com anomalia congênita e de recém nascido com óbito;

- Realizar o mapeamento dos conceitos de recém nascido e anomalia congênita na base de dados do SINASC;

- Realizar o mapeamento dos conceitos de óbito e recém nascido na base de dados do SIM;

- Realizar a integração da informação contida nas duas bases de modo que seja localizado o mesmo indivíduo na base de dados do SINASC e do SIM; 
Embora simples, essa consulta necessita de um mapeamento entre a ontologia e mais de uma base de dados, bem como da integração dos dados para que a resposta seja unificada.

Segue um segundo exemplo, com uma questão de competência mais complexa:

\section{A mãe possui diagnóstico de alguma doença que possa ter levado à anomalia congênita do recém nascido?}

Para responder a essa questão de competência é necessário:

- Definir os conceitos de mãe, diagnóstico, doença, anomalia congênita, recém nascido e associar o conceito de recém nascido à mãe, de diagnóstico à doença e de doença à anomalia congênita;

- Definir o conjunto de CIDs ou características presentes no recém nascido que significam anomalia congênita;

- Identificar o diagnóstico de anomalia congênita no recém nascido. O que pode ser feito observando os campos idAnomal e codAnomal da tabela do SINASC;

- Identificar que essa anomalia é passível de ter sido constituída devido a um diagnóstico anterior da mãe, como sífilis, verificando essa informação nos dados do SIGA;

- Elaborar uma lista de diagnósticos maternos que a literatura afirma poderem levar ao desenvolvimento de anomalia congênita no recém nascido;

- Relacionar os conceitos a indivíduos presentes nas bases de dados SINASC, SIA, SIH e SIM;

Este é um tipo de consulta que depende de várias bases de dados integradas e de modelagem dos dados que estão nas bases, como o mapeamento de quais CIDs estão relacionados ao conceito de anomalia congênita. No presente trabalho não é possível responder a esse tipo de questão de competência que necessita da romalização de outras bases que não sejam a SINASC e a SIM.

- Questão que pode ser respondida de dois modos:

\section{Quantas consultas pré-natal foram realizadas durante a gestação do RN?}

Os modos para responder a esta questão de competência são:

- Utilizando apenas a base de dados do SINASC:

* Formalizar os conceitos de consultas pré-natal, gestação e recém nascido, bem como a relação de consultas pré-natal com gestação e de recém nascido com gestação;

* Associar o conceito consultas pré-natal à variável consPrenat e os conceitos gestação e recém nascido a indivíduos da base de dados;

* Verificar o valor do resultado da variável consP renat presente na base de dados do SINASC. Onde a resposta esperada agrupa as quantidades de consultas, sendo uma das seguintes: 1 - Nenhuma; 2 - de 1 a 3 consultas; 3 - de 4 a 6 consultas; $4-7$ consultas ou mais; 9 - o campo foi ignorado durante o preenchimento do formulário;

- Utilizando as bases de dados do SINASC, SIGA e do SIA:

* Formalizar os conceitos de consulta pré-natal, gestação, data da última menstruação - relativa ao início da gestação, data de nascimento do recém nascido, duração da gestação e recém nascido, bem como identificar todas as relações; 
* Realizar a contagem das consultas de acordo com os registros presentes nas bases de dados do SIGA e do SIA, seguindo o número identificador do recém nascido ou da gestante através dos registos. Caso ocorra a opção pelo registro da gestante ainda será necessário formalizar os conceitos de gestante e genitora e suas relações com o recém nascido;

Nesta consulta ficou nítida a necessidade de fazer uma escolha de limitar o escopo, selecionando as bases de dados que originariam as ontologias. Por questão de tempo, foi optado por responder a essa consulta do primeiro modo, utilizando apenas a base do SINASC, embora não seja possível obter a melhor resposta. O segundo modo seria o mais acurado, no entanto era necessário que outras bases além da SINASC fossem modeladas, como a SIGA e a SIA.

\subsubsection{Especificação Formal: Terminologia}

Com base nas questões de competência elencadas anteriormente, aqui foi realizada a escolha dos termos e relações que compõem a ontologia da camada de domínio, $O D_{S M I}$, ontologia da saúde materno - infantil, bem como a implementação da mesma. Apesar da solução apresentada neste trabalho responder apenas uma parte das questões de competência, o desenvolvimento da $O D_{S M I}$ buscou representar completamente os conceitos presentes todas as questões de competência. Em cada questão de competência foram identificados e listados os conceitos e as relações necessárias para chegar a uma resposta, independentemente se esta seria alcançada apenas com as bases de dados do SINASC e do SIM ou não. A partir dessa lista foi elaborado um diagrama similar ao das ontologias da camada de dados. O processo de construção deste diagrama seguiu o dos outros, no entanto a avaliação com os especialistas ocorreu em diversos momentos ao longo do processo de montagem, não apenas no início e final dele. Nesses momentos, os especialistas auxiliaram na determinação das classes e das propriedades de dados, bem como das propriedades de objetos e termos adotados. Também houve o uso de textos técnicos para comprovar a veracidade das definições.

O diagrama desenvolvido para a $O D_{S M I}$, apresentado na Figura 5.2, é mais complexo que os anteriores, devido ao maior volume de conceitos e relações. No entanto, a mesma legenda apresentada na Figura 4.1 pode ser utilizada. Nele há a hierarquização de algumas classes. Isso levou a existência de classes especializadas e generalizadas, cuja relação é expressa pelas setas tracejadas. As classes generalizadas podem ou não ter propriedades de dados associadas, como a Classe Diagnostico - Diagnóstico, que generaliza DoencaTransm - Doença transmissível, Vicio - Vício, DoencaCronica - Doença crônica e AnomaliaCongenita - Anomalia congênita, que não possui propriedades de dados diretamente relacionadas a ela, Figura 5.3.

Há também a representação de classes que necessitam de uma definição que vá além dos campos atualmente presentes nas bases de dados, sendo necessária a realização de cálculos externos a ontologia ou a inclusão desses campos. Essas são as classes que têm uma marcação cinza, como é o caso das classes Neonato - Neonato, NeonatoPrecoce - Neonato precoce e NeonatoTardio - Neonato tardio, Figura 5.4. As definições de equivalência entre as classes não foram inclusas no diagrama, embora tenham sido posteriormente representadas na ontologia em owl, como é o caso da Classe Falecido, que é equivalente a Usuario que é levadoAoobito.

As propriedades de dados inclusas no diagrama são provenientes de campos das bases de dados, com exceção daquelas que estão em negrito. Algumas propriedades de dados estão presentes em mais de uma classe, o que evidencia uma relação entre essas classes, embora a descrição de intersecção ou conjunção fique clara apenas no arquivo da ontologia.

Embora o foco desta etapa seja a especificação formal dos conceitos e não o mapeamento desses ou a verificação da existência dos mesmos nas bases de dados, foi observada a necessidade de iniciar essa análise concomitante com a definição dos conceitos, uma vez que existiam muitos termos e muitas bases. Assim, na representação das propriedades de dados do diagrama foi mantida a apresentação das bases de dados que contêm o conceito, ainda que esse tenha originalmente uma outra nomenclatura. Um exemplo é o termo nome - nome, pertencente a classe Usuario - Usuário, que está presente nas bases SIGA, SINASC, SIM, SIH e SIA. Cada conceito foi ligado a uma variável 


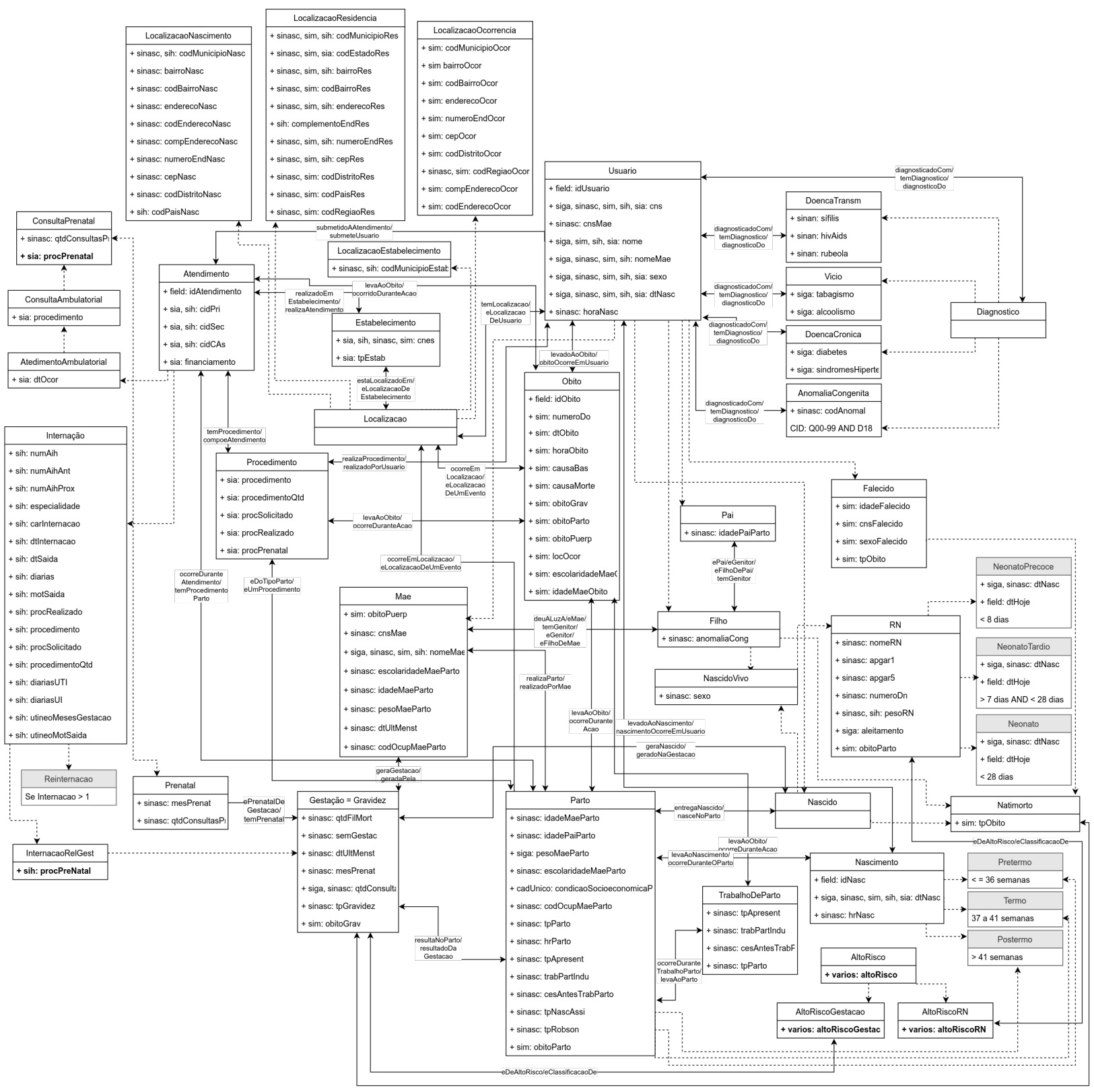

Figura 5.2: Diagrama da ontologia de dominio, $O D_{S M I}$ 


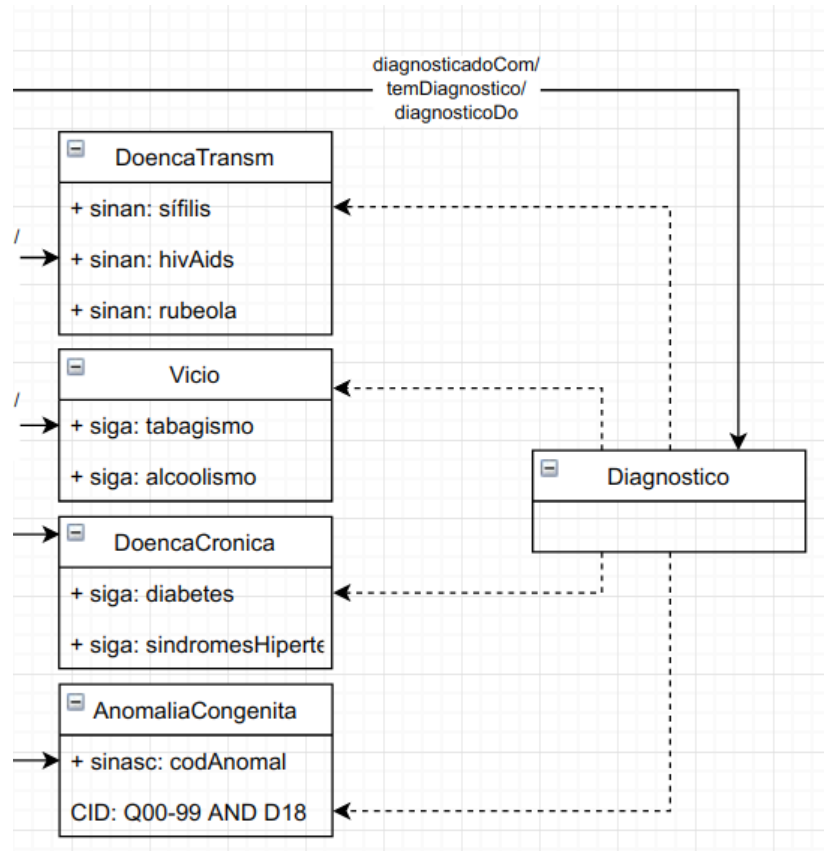

Figura 5.3: Recorte do diagrama da ontologia OD $D_{S M I}$, foco nas classes superclasse Diagnostico Diagnóstico e suas subclasses

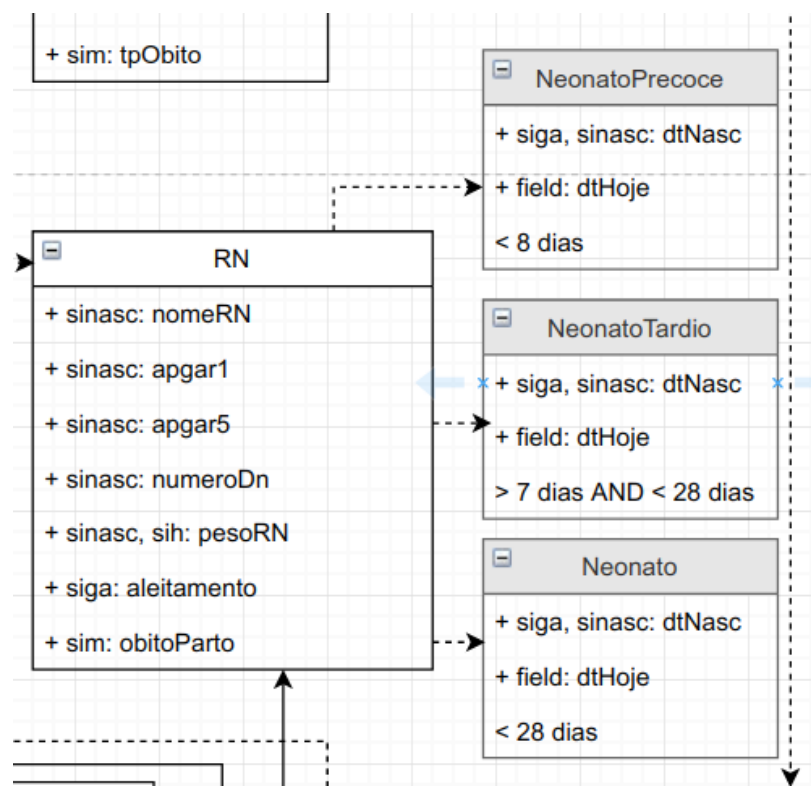

Figura 5.4: Recorte do diagrama da ontologia $O D_{S M I}$, foco nas classes que precisam de definições externas, como Neonato - Neonato 
da fonte de dados. Para o caso de mais de uma base de dados possuir o mesmo conceito foi adotado o nome mais explicativo na ontologia. Nesta etapa não houve a preocupação com a apresentação do dado, mas com os conceitos presentes nas questões de competência que teriam correspondência com as bases de dados.

O diagrama deu origem a ontologia, construída dentro do software Protégé. No Protégé os conceitos que possuem palavras sinônimas tiveram essa informação adicionada nas anotações da classe, como é o caso da classe Gestacao - Gestação, que tem o termo Gravidez como sinônimo em sua anotação. Futuramente planeja-se adicionar um mecanismo na solução para que a busca de informações na ontologia ocorra mais próxima da linguagem natural, podendo ser realizada com qualquer um dos sinônimos. Também foram adicionadas as equivalências de classes e as especificações de domínio e range das propriedades.

Ao modelar as propriedades de dados no software, foi optado por não especificar seus tipos de dados nem valores possíveis porquê seria necessário garantir o tipo de entrada ou modelar ou adaptar outras ontologias para alguns campos, tais como: CID, CBO, CEP, CNES, SIGTAP; o que foge do escopo da presente dissertação, mas está elencado nos trabalhos futuros.

A ontologia possui 737 axiomas e está enquadrada com a expressividade da lógica de descrição SRI(D). Após a finalização da construção da ontologia, esta foi povoada com alguns indivíduos a fim de testar sua consistência, o raciocinador HermiT (versão 1.4.3.456) também foi empregado nesse processo. Em seguida foi utilizado o algorítmos do OOPS! (OntOlogy Pitfall Scanner!) ${ }^{2}$, desenvolvido por [PVGPSF14], para testar a ontologia contra algumas armadilhas de modelagem. O OOPS! classifica os erros como críticos - que podem afetar a consistência, raciocínio e aplicabilidade da ontologia, importantes - que não afetam o funcionamento da ontologia mas fazem diferença na modelagem e secundários - que trarão a ontologia uma modelagem mais elegante. Os erros encontrados foram corrigidos até que nenhum aviso de erro crítico aparecesse. Restaram alguns erros considerados importantes e secundários, como pode ser visto na Figura 5.5.

\begin{tabular}{|c|c|}
\hline Results for P08: Missing annotations. & 240 cases $\mid$ Minor $\bigcirc$ \\
\hline Results for P11: Missing domain or range in properties. & 128 cases | Important $\bigcirc$ \\
\hline Results for P13: Inverse relationships not explicitly declared. & 24 cases | Minor $\bigcirc$ \\
\hline Results for P41: No license declared. & ontology* | Important $\odot$ \\
\hline
\end{tabular}

Figura 5.5: Resultado da análise do OOPS! para a ontologia $O D_{S M I}$

Os erros importantes relacionados a armadilha P11 - Ausência de domínio ou range nas propriedades, referem-se a falta de modelagem dos tipos de dados, como mencionado anteriormente. A ausência de licença, P41, foi suprida num momento posterior. Já os erros secundários relacionados a P08 - Ausência de anotações e P13 - Relações inversas não explicitamente declaradas, serão analisados num segundo momento do projeto.

\subsubsection{Formalização das Questões de Competência}

Como apresentado anteriormente, apenas as questões de competência que podem ser respondidas com as bases de dados do SINASC e do SIM foram tomadas como objeto de estudo neste trabalho. Essas questões de competência foram formalizadas em SPARQL e testadas na ontologia $O D_{S M I}$ com alguns indivíduos imputados manualmente. A Figura 5.6 apresenta a ontologia $O D_{S M I}$ povoada com os indivíduos baseados na Família Real Britânica. Aqui foi necessário acrescentar informações e membros inexistentes, para preencher os conceitos da ontologia. A fim de demarcar o acréscimo, um asterisco $\left(^{*}\right)$ foi colocado na URI de cada indivíduo.

\footnotetext{
${ }^{2}$ OOPS! http://oops.linkeddata.es/
} 


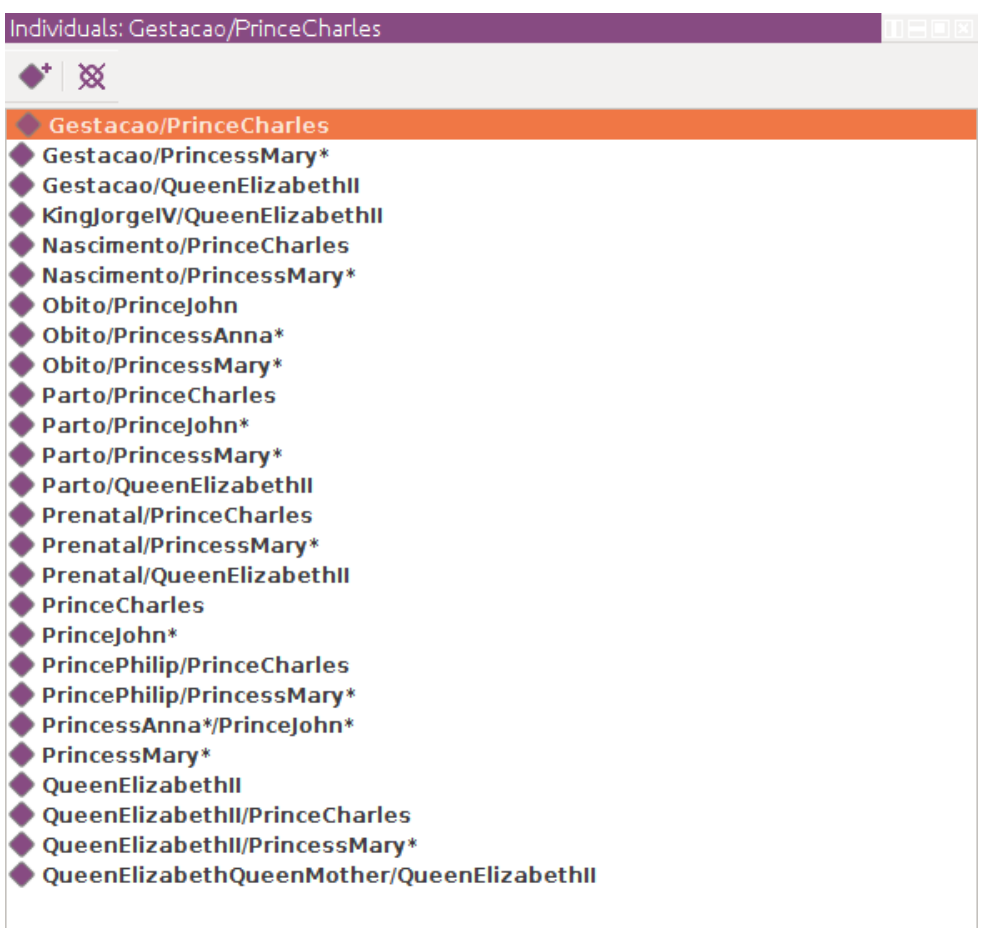

Figura 5.6: Indivíduos de teste da $O D_{S M I}$

A nomeação dos indivíduos seguiu o mesmo padrão da nomeação dos indivíduos das ontologias $O F_{S I N A S C}$ e $O D_{S I M}$ : Nome da classe ou do indivíduo que faz parte da classe (para ficar mais fácil compreender o exemplo), barra, nome do indivíduo a que a classe se refere. No destaque da Figura 5.6 existe o indivíduo Gestacao/PrinceCharles que se refere à gestação do príncipe Charles. A única exceção ao padrão de nomeação, sãos os indivíduos fins, geralmente Recém Nascidos, como é o caso de Princecharles.

Algumas questões de competência respondidas serão apresentadas a seguir:

- Mãe.21 - Após o parto (no período de puerpério), houve óbito materno? Se sim, apresentar a mãe.

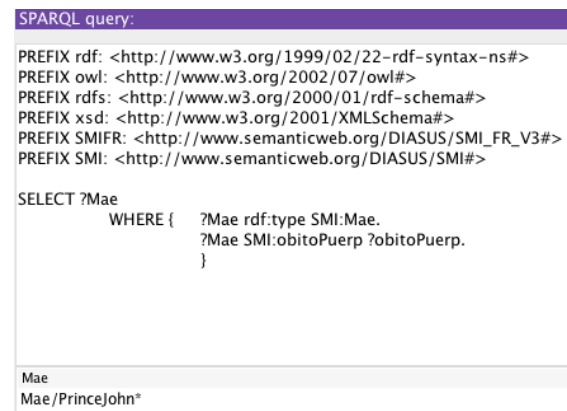

Figura 5.7: Resposta da questão de competência sobre óbito materno após o parto, ontologia $O D_{S M I}$

- Mãe.23 - A mãe possui registro de abortos ou perdas fetais anteriores a esse parto? Se sim, apresentar a mãe e a quantidade de filhos mortos anteriores a essa gestação. 


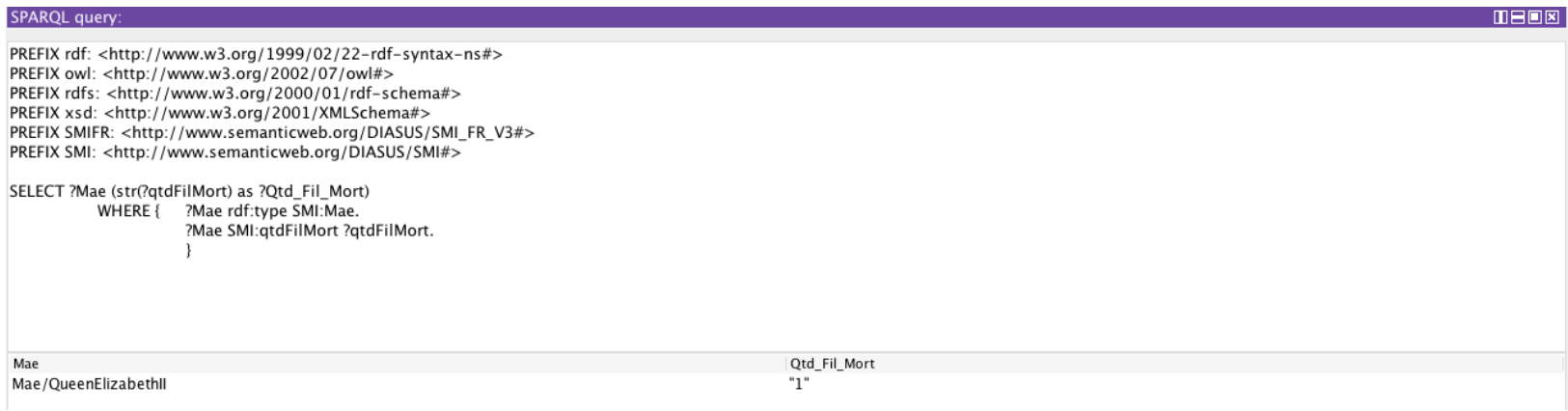

Figura 5.8: Resposta da questão de competência sobre registro de abortos ou perdas fetais anteriores ao parto, ontologia $O D_{S M I}$

- Nascido Vivo.01 - Qual o peso do filho ao nascer? Apresentar o recém nascido e seu peso correspondente.

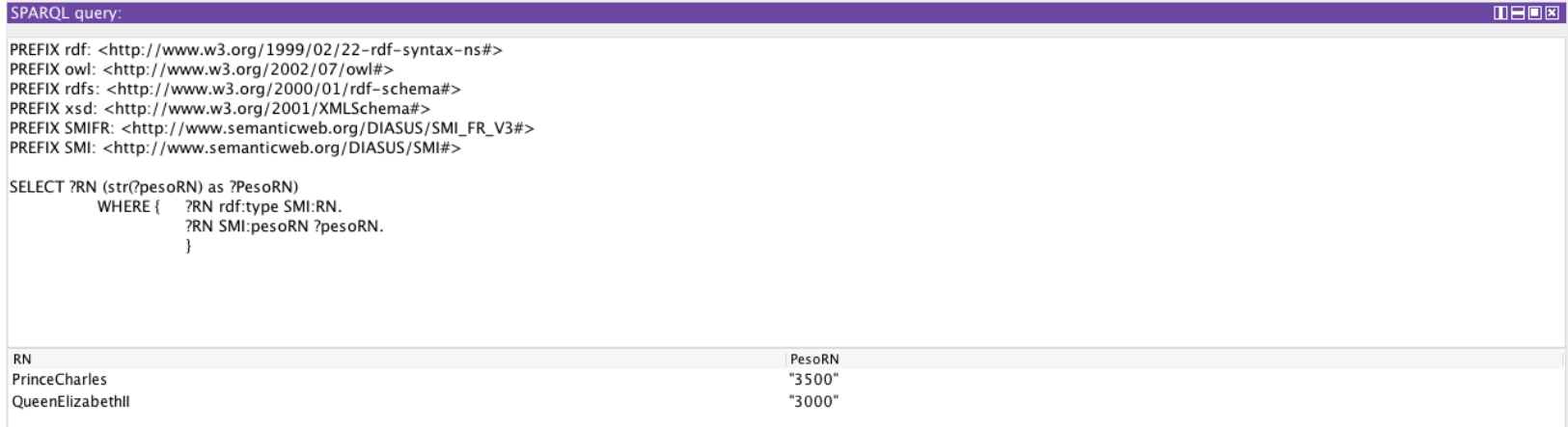

Figura 5.9: Resposta da questão de competência sobre o peso do filho ao nascer, ontologia $O D_{S M I}$

- Nascido Vivo.15 - Houve óbito de algum recém nascido que tem registro de anomalia congênita no SINASC? Apresentar o recém nascido, o número da declaração de nascido vivo, o número da declaração de óbito e o código da anomalia congênita.

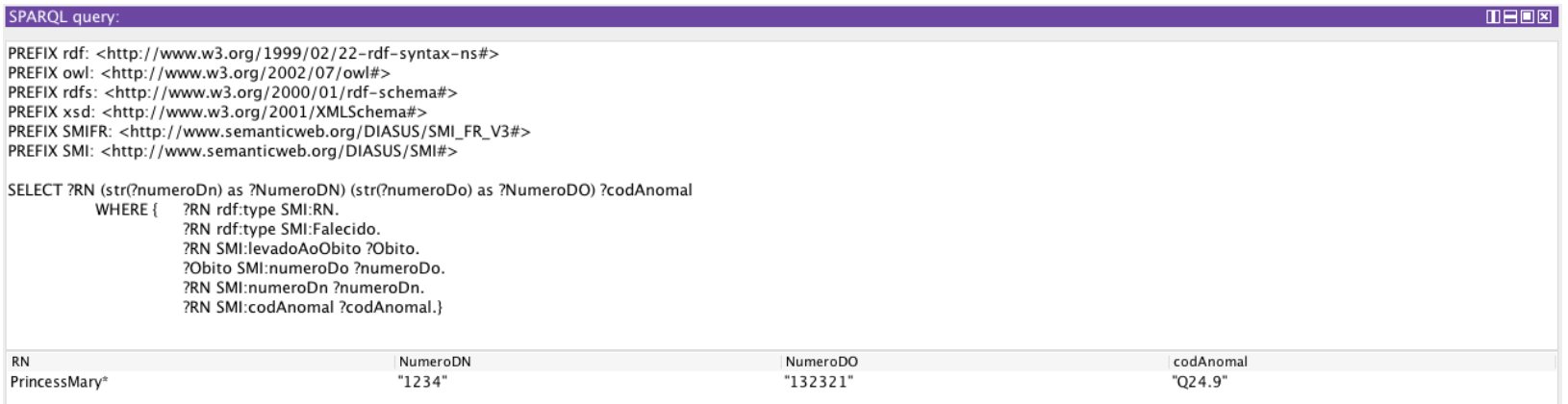

Figura 5.10: Resposta da questão de competência sobre óbito de recém nascido com diagnóstico de anomalia congênita no SINASC, ontologia $O D_{S M I}$

A Figura 5.11 apresenta o caminho percorrido através das ontologias para responder à questão de competência Nascido Vivo 15. Nela, Ob. significa Óbito; RN, recém nascido vivo; e ACon, Anomalia Congênita. A solicitação da consulta é recebida pela $O D_{S M I}$ que passa a consulta para a camada de integração que a particionará de acordo com os conceitos presentes em cada uma das ontologias. Também é nessa camada que os conceitos similares são mapeados e integrados. Então a solicitação da consulta segue para a camada de ontologias de fonte que mapeará os conceitos nas fontes de dados. Essas retornarão a consulta com o resultado. A 
resposta da consulta seguirá o caminho inverso, sendo apresentado em cada uma das camadas e verificado na transição da camada de integração para a de domínio.

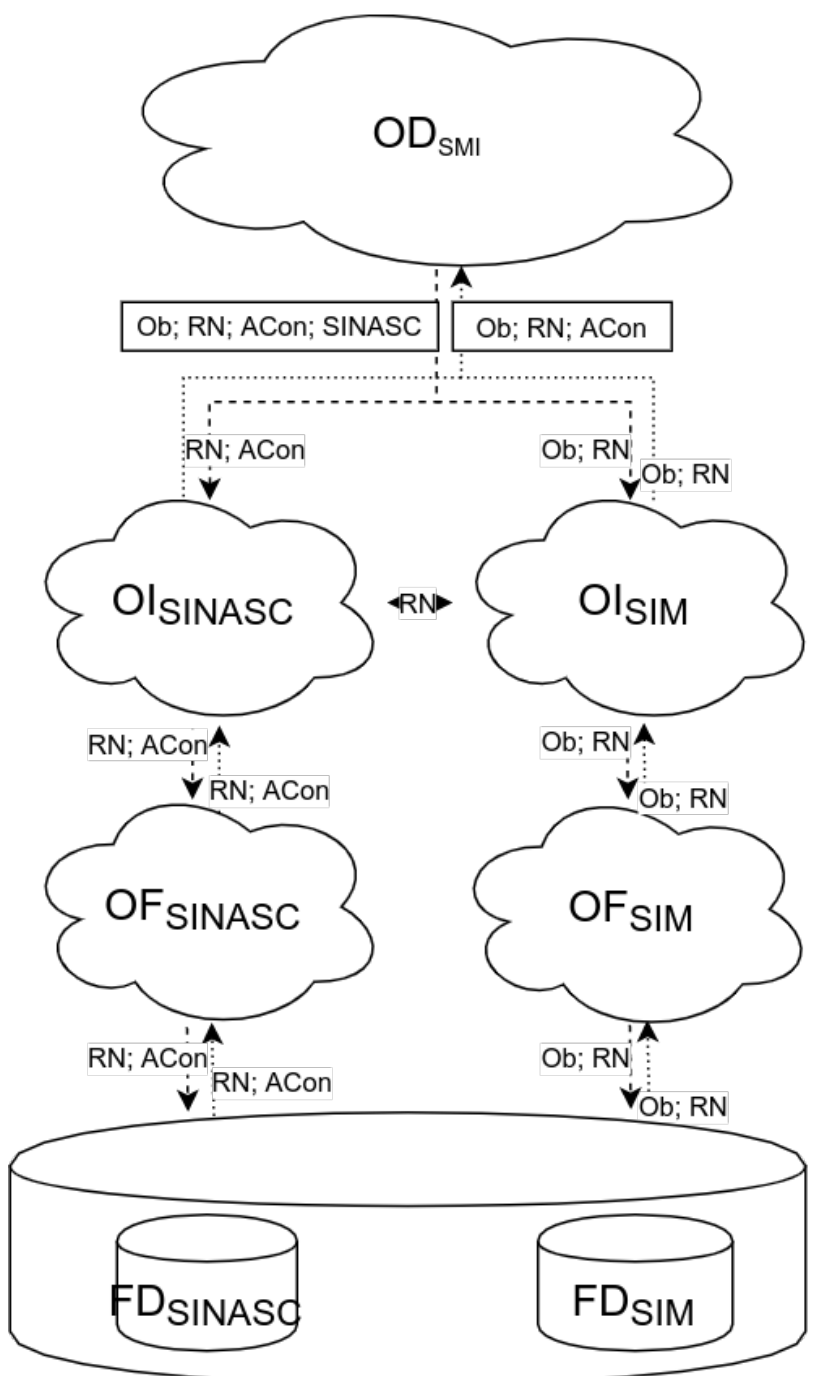

Figura 5.11: Diagrama representando o caminho percorrido para responder à questão de competência Houve óbito de algum recém nascido que tem registro de anomalia congênita no SINASC?

- Nascido Vivo.16 - Caso tenha havido óbito do RN, quais as causas básicas do óbito? Apresentar o recém nascido, o número da declaração de nascido vivo, o número da declaração de óbito, o código da anomalia congênita e o código da causa básica do óbito.

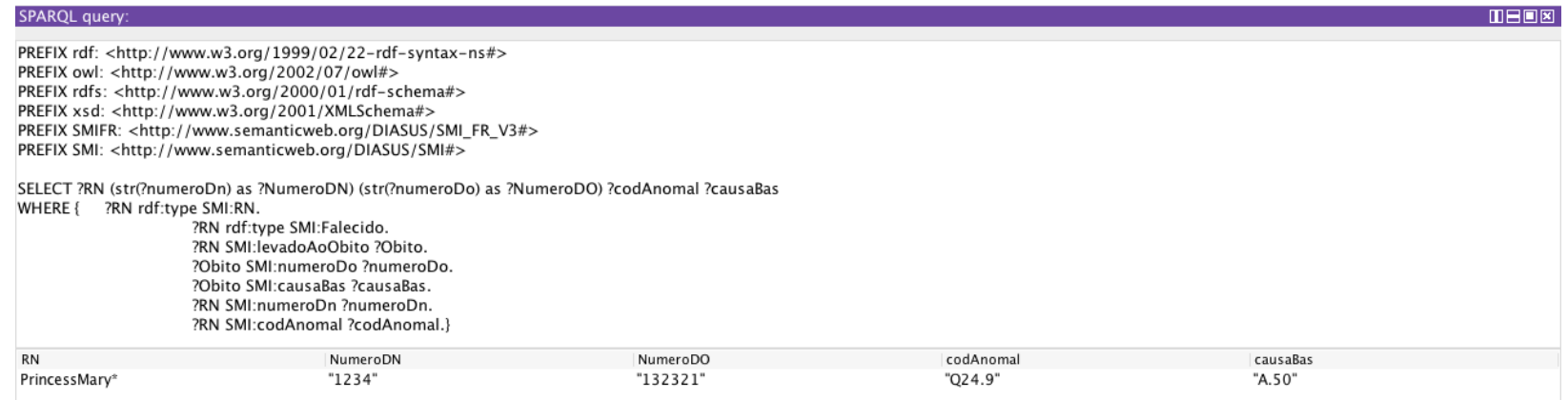

Figura 5.12: Resposta da questão de competência sobre as causas do óbito de recém nascido, ontologia $O D_{S M I}$ 
- Nascido Vivo.18 - O RN tem diagnóstico de anomalia congênita? Apresentar o recém nascido e o código da anomalia congênita.

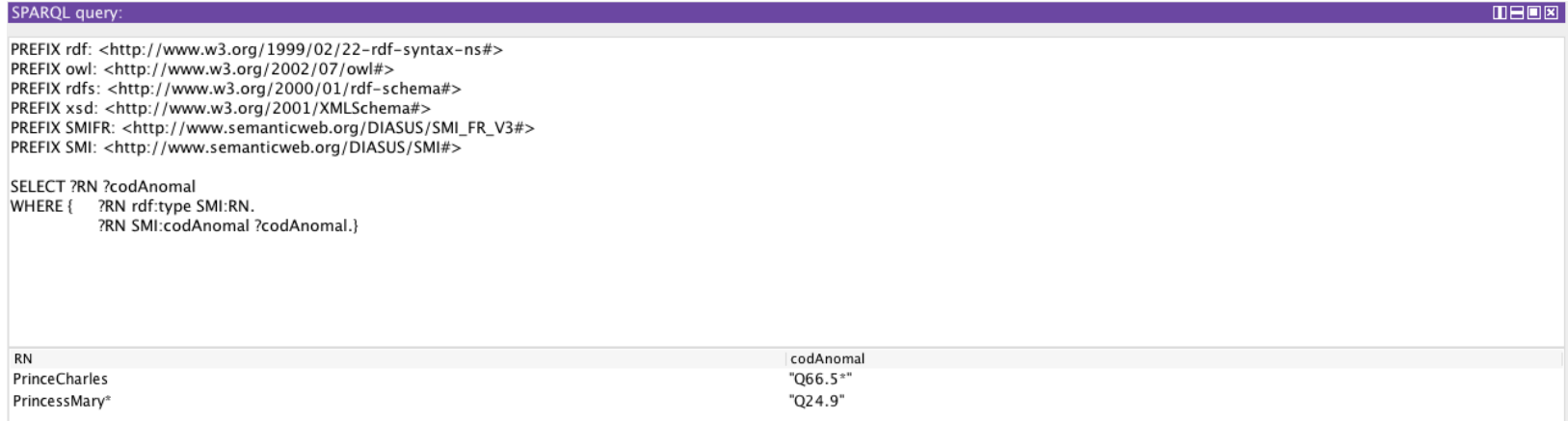

Figura 5.13: Resposta da questão de competência sobre a presença de diagnóstico de anomalia congênita do recém nascido, ontologia $O D_{S M I}$

- Gestação.01 - Quantas consultas pré-natal foram realizadas durante a gestação do RN? Apresentar o pré-natal e a quantidade de consultas.

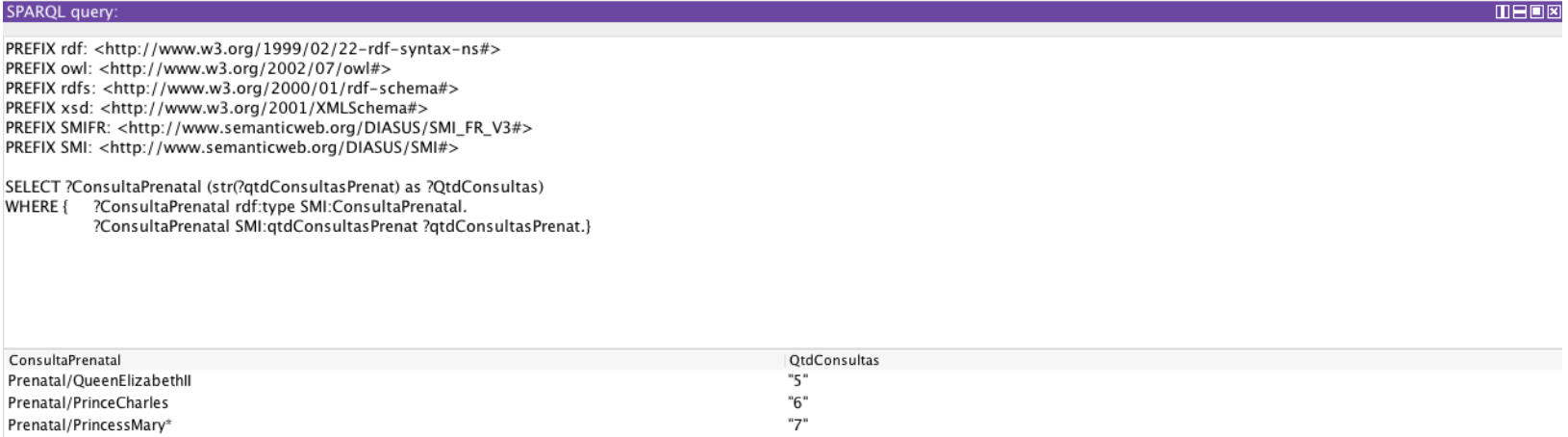

Figura 5.14: Resposta da questão de competência sobre a quantidade de consultas pré-natal realizadas durante a gestação, ontologia $O D_{S M I}$

- Gestação.07 Houve óbito fetal? Se sim, apresentar o indivíduo que teve tipo de óbito igual a 1 (que codifica o óbito fetal).

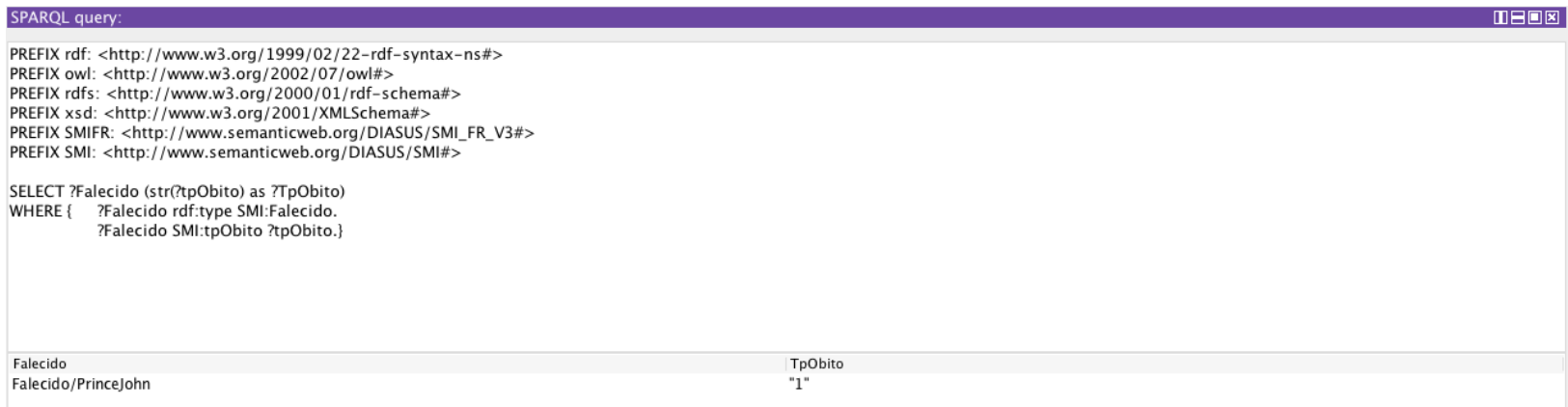

Figura 5.15: Resposta da questão de competência sobre a existência de óbito fetal, ontologia $O D_{S M I}$

- Parto.01 - Qual foi(ram) a(s) hora(s) do(s) nascimento(s) do(s) RN(s)? Apresentar além da hora também a data de nascimento e o recém nascido. 


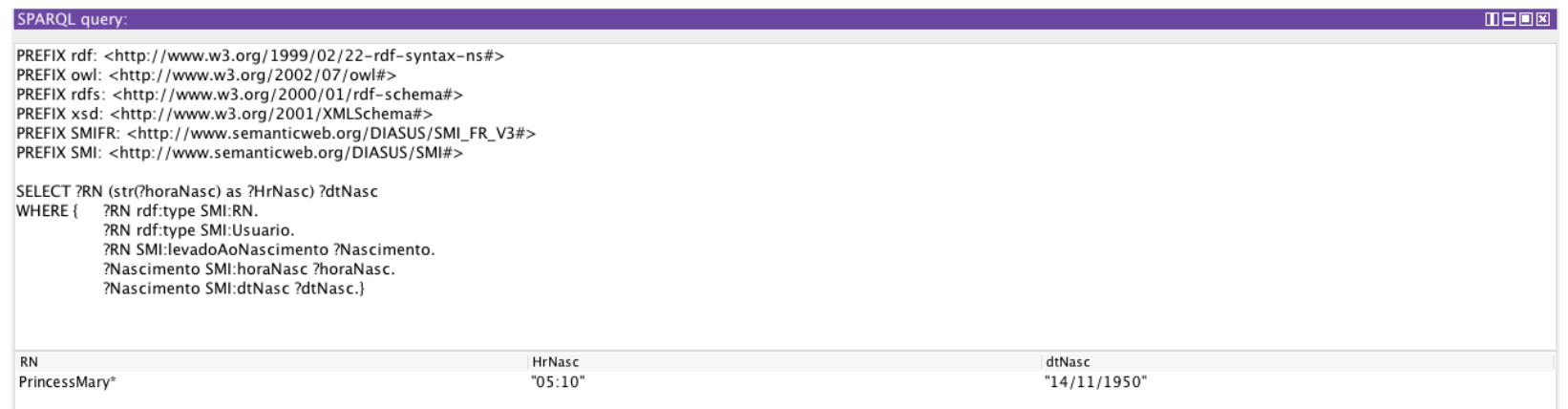

Figura 5.16: Resposta da questão de competência sobre a hora do nascimento do recém nascido, ontologia $O D_{S M I}$

\subsection{Desenvolvimento das Ontologias da Camada OI: Primeira Parte}

As ontologias da camada OI integram as fontes de dados e os conceitos presentes nas questões de competência. Assim, a construção dessas ontologias depende da compreensão da presença e estrutura dos dados nas ontologias de fonte e de como o conhecimento está representado na ontologia de domínio.

O desenvolvimento das ontologias da camada OI começou com a criação dos arquivos correspondentes às ontologias $O I_{S I N A S C}, O I_{S I M}$ e $O I_{D N D O}$, no Protégé, seguido pela importação da ontologia da camada OD, $O D_{S M I}$, em cada um dos arquivos.

\subsection{Desenvolvimento dos Mapeamentos OD OI}

Existem dois níveis de mapeamentos OD_OI: o mapeamento dos conceitos presentes na ontologia OD para o auxílio na construção das ontologias da camada OI e o mapeamento de acesso às informações da camada OD pela camada OI, para a realização da consulta entre as camadas do sistema, assim como ocorreu no mapeamento FD_OF, por meio do Ontop. Esta subseção tratará do primeiro nível de mapeamento, uma vez que o segundo só será desenvolvido durante a próxima etapa do projeto. É esperado que os mapeamentos do sistema sejam realizados utilizando o framework $\mathrm{R}_{2} \mathrm{R}^{3}$, indicado para a integração de fontes de dados em formato de linked data, o framework SPARQLFederator ${ }^{4}$, ou outras soluções de alinhamento de ontologias como as apresentadas em [THHT19].

Como falado anteriormente, o mapeamento OD_OI apresentado aqui ocorreu para delimitar qual recorte de vocabulário da ontologia $O D_{S M I}$ cada uma das ontologias da camada de integração receberia. Afinal, cada ontologia da camada OI é um subconjunto da ontologia $O D_{S M I}$ ao mesmo tempo que tem uma correspondência com uma ontologia da camada OF. Desse modo, é esperado que os recortes tenham os conceitos que exitem nas fontes de dados que são essenciais para responder às questões de competência.

Então foi recorrido à lista de conceitos e fontes de dados, descrita no diagrama da ontologia $O D_{S M I}$. A presença da origem dos dados no diagrama auxiliou no processo de marcação das classes e das propriedades que fariam parte das ontologias da camada de integração.

Esse tipo de mapeamento será importante na etapa de recuperação dos dados, quando o usuário solicitar a resposta das questões de competência, ele também é significativo para que os gestores das bases de dados tenham o conhecimento de como as informações estão distribuídas.

\footnotetext{
${ }^{3}$ Framework R2R: http://wifo5-03.informatik.uni-mannheim.de/bizer/r2r/

${ }^{4}$ Framework SPARQLFederator: https://github.com/djogopatrao/SPARQLFederator
} 


\subsection{Desenvolvimento dos Mapeamentos OF_OI}

Estes mapeamentos também podem ser divididos nos dois níveis: o de conceitos entre as duas ontologias, visando a criação das ontologias da camada OI e o de acesso aos dados das ontologias da camada de fontes para as de integração. Novamente, aqui será descrito apenas o mapeamento entre os conceitos. O desenvolvimento do acesso aos dados se dará na próxima fase do projeto, com a mesma solução que será utilizada nos mapeamentos OD_OI.

Tendo em vista o mapeamento entre os conceitos e termos presentes nas duas camadas de ontologias, foi necessário fazer uma listagem de quais estavam presentes em cada fonte de dados. Também foi realizado o processo de verificação de heterogeneidades esquemáticas e semânticas. A cada propriedade de dados, derivada de uma variável (campo) das bases de dados, presente nas duas camadas de ontologia foi verificada a existência de heterogeneidade esquemática, quando há diferentes representações do mesmo dado, e assim foi criado um dicionário mapeando as heterogeneidades. O dicionário completo com as conversões entre os termos presentes nas ontologias da camada OF e a ontologia da camada OD está descrito no Apêndice D. Dois tipos de heterogeneidade esquemática foram encontrados:

- Nomes de campos diferentes para o mesmo conteúdo:

- Os campos referentes ao código CNES do estabelecimento de onde ocorreu o evento estão descritos na Tabela 5.1:

Tabela 5.1: Campos referentes ao CNES

\begin{tabular}{c|c}
\hline Origem & Nome do campo \\
\hline SINASC & CODESTAB \\
SIM & CODESTAB \\
SIM & CODESTABOCOR \\
SIH & AH_CNES \\
SIA & PA_CODUNI \\
\hline
\end{tabular}

\section{- Campos com conteúdo condensado:}

- Na base de dados do SIA, o campo PA_UFMUN contém a informação do código da unidade da federação e do município em que ocorreu o atendimento, enquanto que nas outras bases há um campo para cada dado.

- Enquanto as bases SINASC, SIH e SIA apresentam o campo para a idade em anos ou apresentam dois campos, um correspondente a unidade da idade e outro ao valor da idade, na base de dados do SIM, a representação da idade é composta um único campo, com dois subcampos. O primeiro com a unidade da idade e os seguintes com a quantidade de unidades. Os termos estão descritos na Tabela 5.2. Para contornar esse tipo de situação, foram criados campos na DNDO, com a padronização do conteúdo.

Tabela 5.2: Apresentação da idade na tabela do SIM

\begin{tabular}{|c|c|c|}
\hline Unidade da idade & $\begin{array}{c}\text { Variação da quantidade } \\
\text { de unidades }\end{array}$ & Legenda \\
\hline 0 & $01-59$ & Idade inferior a uma hora \\
1 & $01-23$ & Idade, em horas \\
2 & $01-29$ & Idade, em dias \\
3 & $01-11$ & Idade, em meses \\
4 & $00-99$ & Idade, em anos \\
5 & $00-99$ & Idade superior a 100 anos \\
\hline
\end{tabular}


Durante os mapeamentos foi percebida a necessidade de uma integração dos campos, pois existia mais de um campo com conteúdos semanticamente similares na mesma base de dados, na SIH. Os campos AH_Diag_Sec_1, 2, . ., 9 foram transformados apenas em Diagsec. O mesmo acontece com as causas do óbito, que podem estar descritas nos campos: LINHAA, LINHAB, LINHAC, LINHAD, LINHAII, que passaram a ser causaMorte-Causa da morte.

Nos mapeamentos foram identificados campos que representam coisas similares mas não idênticas. Um exemplo são aqueles referentes a localização, onde alguns dizem respeito a residência, outros de ocorrência do evento, a localização do estabelecimento de saúde e ao local de nascimento. Assim, é possível criar uma hierarquia de campos, mas não é possível considerar todos como o mesmo conceito. Com a adição da hierarquia o usuário poderá procurar por todas as localizações ou por localizações específicas.

Também foram observadas propriedades de dados que estavam relacionadas a classes diferentes nas ontologias da OF em relação à ontologia da OD. É o caso das propriedades relacionadas ao local de residência da mãe, na $O F_{S I N A S C}$, que têm ligação apenas com a classe Mae - Mãe, enquanto que na $O D_{S M I}$ têm ligação com a classe LocalizacaoResidencia - Localização da Residência, que é subclasse de Localizacao - Localização e que por sua vez está relacionada à classe Usuario Usuário, cuja uma de suas subclasses é Mae - Mae. Outro exemplo é a propriedade qtdFilMort - Quantidade de filhos mortos anteriores a esta gestação, que na $O F_{S I N A S C}$ está ligada à classe GestacaoEParto, enquanto que na $O D_{S M I}$ está ligada às classes Gestacao - Gestação ou Mae - Mãe.

\subsection{Desenvolvimento das Ontologias da Camada OI: Segunda Parte}

Com as listagens dos mapeamentos OD_OI e OF_OI em mãos, o processo de desenvolvimento das ontologias da camada OI foi retornado. Em cada uma das ontologias da camada OI foram geradas novas classes e propriedades e então foram atribuídas equivalência às classes e propriedades originais da camada OD. Esses novos axiomas correspondem aqueles que estão relacionados a cada uma das fonte de dados, descritas no diagrama da $O D_{S M I}$. A Figura 5.17 apresenta o recorte da ontologia $O I_{S I N A S C}$ com as classes equivalentes às da ontologia $O D_{S M I}$.

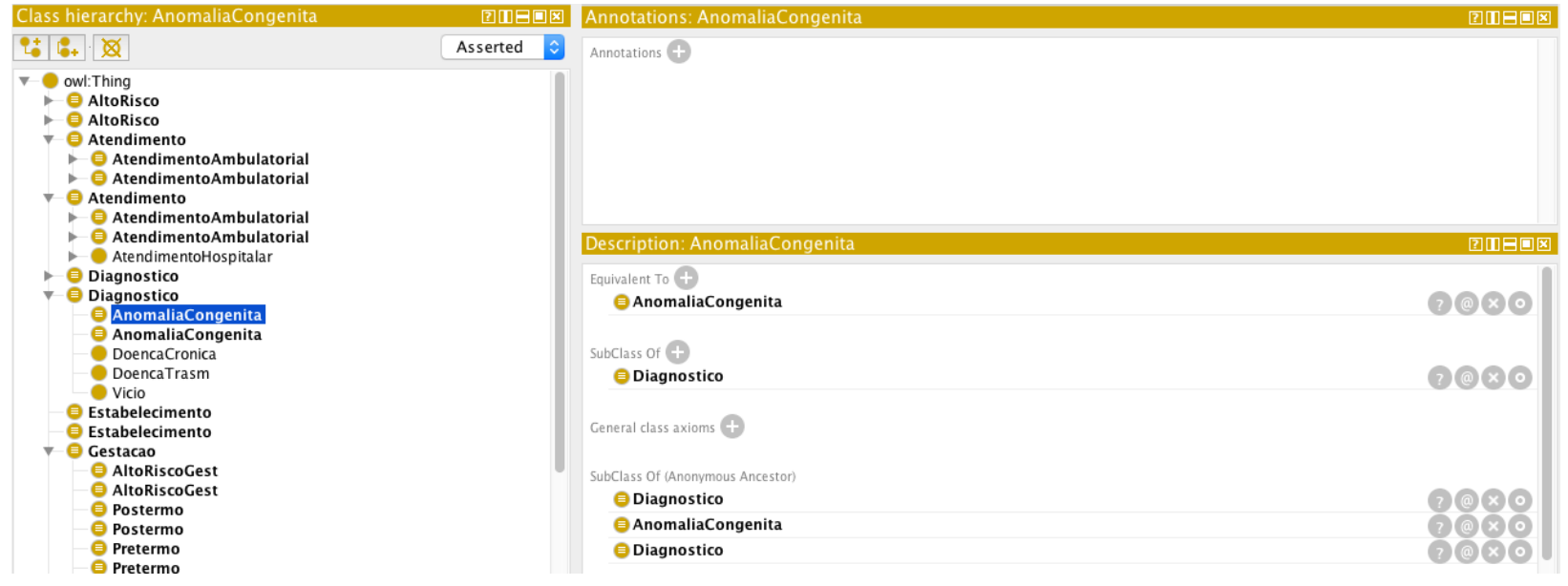

Figura 5.17: Recorte da ontologia $O I_{S I N A S C}$

Em seguida, as classes e propriedades foram conferidas quanto a presença nas ontologias de fonte $O F_{S I N A S C}, O F_{S I M}$ e $O F_{D N D O}$. Houve casos em que as propriedades de dados estavam presentes nas ontologias da camada OF mas não estavam nas ontologias da camada OD e por isso não foram mapeadas para a camada OI. O inverso também ocorreu, uma vez que nem todas as questões de competência poderiam ser respondidas apenas com as fontes de dados modeladas até o

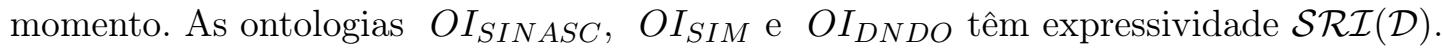




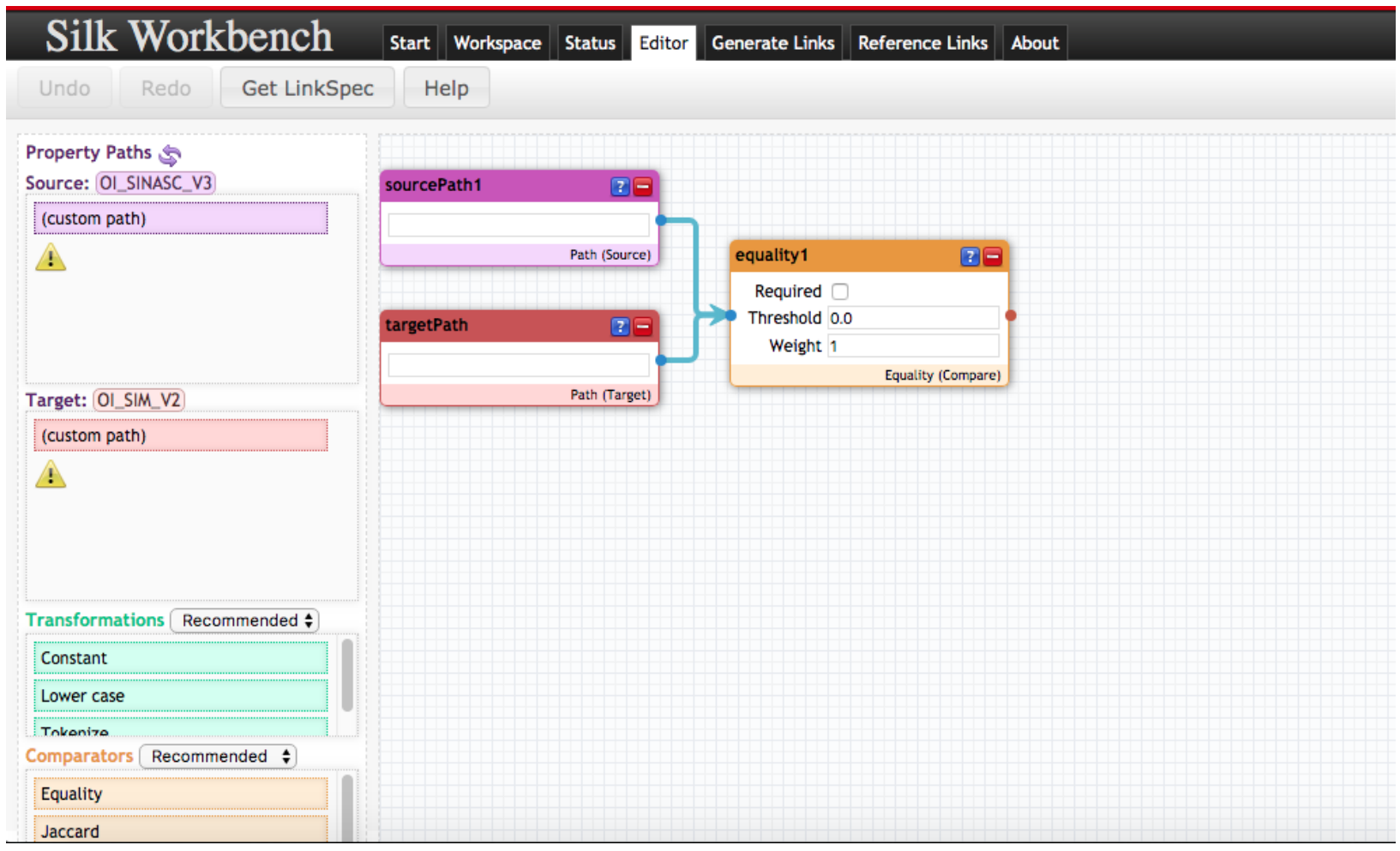

Figura 5.18: Recorte da tela do framework SILK já com as ontologias $O I_{S I N A S C}$ e OISIM

\subsection{Desenvolvimento dos Links sameAs}

Com os dicionários de heterogeneidades em mãos, foram listadas as classes e as propriedades de dados que estavam presentes em mais de uma fonte de dados e que assim, representam a mesma entidade no mundo real. Na próxima etapa do projeto espera-se utilizar o framework SILK $^{5}$, Figura 5.18 , para a formalização desses links no sistema.

Ao observar as fontes de dados foi constatado que parte das variáveis presentes no SIM derivava diretamente do SINASC. Isso ocorre essencialmente no capítulo "Fetal ou Menor que 1 ano"que foi convertido na classe FetalOuMenorQue1Ano da $O F_{S I M}$, cujas informações vieram dos capítulos "Mãe", "Identificação do Recém-nascido"e "Gestação e Parto"do SINASC. Como o indivíduo da classe FetalOuMenorQuelAno, da ontologia $O F_{S I M}$, corresponde a várias classes na ontologia $O F_{S I N A S C}$, não foi possível fazer o mapeamento entre as classes. Assim, o mapeamento ocorreu no nível das propriedades de dados.

Também foi listada a variável (propriedade de dados) tpMorteocor que está relacionada ao óbito de mulheres em idade fértil. Ela aponta quando o óbito ocorreu: na gravidez, no parto, no aborto, até 42 dias após o parto, de 43 dias a 1 ano após o parto ou se ele não ocorreu nestes períodos. Caso a resposta esteja associada a uma gestação e nascimento, essa mulher que veio a óbito, indivíduo da classe Identificacao - Identificação da ontologia $O F_{S I M}$, é considerada como o mesmo indivíduo da classe Mae - Mãe, da ontologia $O F_{S I N A S C}$.

\subsection{Desenvolvimento dos Mapeamentos OI OD}

O mapeamento OI_OD diz respeito a quais informações serão retornadas para o usuário quando este realiza uma busca. Ele se baseia em regras que futuramente serão implementadas a partir do framework SIEVE $^{6}$. As regras consistem em informar que todas as informações advindas da fonte de dados do SINASC têm mais prioridade do que as do SIM, caso sejam encontradas as mesmas

\footnotetext{
${ }^{5}$ Framework SILK: http://silkframework.org/

${ }^{6}$ Framework SIEVE: https://sieve.wbsg.de/
} 
informações nos dois sistemas. Por exemplo, quando a consulta requerer informações sobre o recém nascido que veio a óbito ou sobre sua mãe, a resposta, se existir nas duas bases (SINASC e SIM), deverá sempre vir da base do SINASC, por ser considerada a mais bem preenchida.

Esse capítulo apresentou a metodologia de desenvolvimento das ontologias e mapeamentos relacionados a uma aplicação, sendo exemplificado com o caso de uso da saúde materno-infantil, voltado para a compreensão das bases do SINASC e do SIM no contexto do desenvolvimento do indicador de saúde DPGP. 
64 DESENVOLVIMENTO DAS ONTOLOGIAS E MAPEAMENTOS DEPENDENTES DA APLICAÇÃO 


\section{Capítulo 6}

\section{Conclusão}

Neste trabalho, foram abordadas questões relacionadas à integração semântica de dados, sendo a motivação, os sistemas de informação do SUS. Apesar de muitos desses sistemas estarem disponíveis para download na Web, a análise dos seus dados está prejudicada pela baixa qualidade da documentação sobre o contexto de preenchimento e o significado dos campos, restringindo o uso dos dados a especialistas do domínio. Além disso, não existe um identificador comum para todas as bases e o acesso aos dados individualizados, que auxiliariam no processo de integração, é restrito às Secretarias Municipais da Saúde.

Visando a integração semântica das bases de dados, de nascimento - SINASC e mortalidade - SIM, do município de São Paulo e o uso dessa integração para compreensão do domínio de saúde materno-infantil voltado para o desenvolvimento do indicador de saúde de Dias Potenciais de Gravidez Pedidos, foi firmada uma parceria com a Secretaria Municipal da Saúde de São Paulo e a Faculdade de Saúde Pública da USP, no âmbito do projeto de formulação do indicador. Nela, os técnicos da Secretaria forneceram informações sobre o contexto dos dados e o acesso a um conjunto de dados individualizado. Também foram realizadas reuniões com o grupo de trabalho de especialistas em saúde materno-infantil, formado por professores e alunos da Faculdade de Saúde Pública da USP. Desse modo, o estudo de caso dessa dissertação se deu com os dados dos sistemas de natalidade e mortalidade do município de São Paulo, voltado a análise para a saúde materno-infantil e o indicador DPGP.

Uma vez apresentado o conjunto de dados e compreendido o contexto, foram selecionadas as tecnologias necessárias para a integração semântica e a metodologia de Ontology-Based Data Integration foi escolhida. Após análise junto com os especialistas, a abordagem híbrida de integração foi eleita como a mais adequada para o problema de pesquisa. Nela, são construídos um vocabulário compartilhado e ontologias locais que herdam a terminologia desse vocabulário e mapeiam-na para as fontes de dados. No entanto, devido à particularidades no acesso aos dados e ao tamanho e complexidade das fontes, foi necessário fazer modificações na arquitetura da solução, adicionando mais uma camada que servia para converter o vocabulário das fontes de dados em ontologias.

Assim, foram desenvolvidas três camadas de ontologias:

- A camada de ontologias de fonte (OF): com três ontologias das bases de dados ( OF $F_{\text {SINASC, }}$, $\left.O F_{S I M}, O F_{D N D O}\right)$; três ontologias povoadas com o exemplo da família real; três ontologias com dez indivíduos materializados das respectivas bases; e três arquivos ontológicos (em .owl) com a materialização completa das bases de dados do ano de 2010 no município de São Paulo.

- A camada de ontologias de integração (OI): com três ontologias das bases de dados $\left(O I_{S I N A S C}\right.$, $\left.O I_{S I M}, O I_{D N D O}\right)$; e os mapeamentos de sinônimos e correspondências de termos entre as ontologias da camada de fonte e de domínio.

- A camada de ontologias de domínio (OD): com a ontologia de domínio ( $O D_{S M I}$ ), construída a partir de 58 questões de competência relacionadas à saúde materno-infantil e ao indicador de Dias Potenciais de Gravidez Perdidos; e uma ontologia povoada com o exemplo da família real. 
As contribuições deste projeto estão relacionadas à integração semântica dos registros de nascimento e mortalidade do SUS com as bases de dados do município de São Paulo. Para isso, foi realizado o mapeamento terminológico e das relações entre as duas fontes de dados. Durante esse processo, houve contribuições para os profissionais da Secretaria Municipal da Saúde e da Faculdade de Saúde Pública, em termos da compreensão do esforço semântico necessário para a interpretação os dados e das relações entre os conceitos. Foi apresentada também uma visão geral dos conceitos relacionados às duas fontes de dados, mostrando o fluxograma dos dados e como eles são interpretados. Por fim, as bases que já eram públicas, referentes ao ano de 2015, foram remodeladas e também disponibilizadas em formato de linked data, junto com as ontologias do modelo e os mapeamentos entre as camadas de ontologia da solução. É esperado que as ontologias possam ser reutilizadas em outros trabalhos e seu uso estendido para além dos dados do município de São Paulo, uma vez que todos os municípios brasileiros possuem o mesmo formato de dados. A maior expectativa é de que Secretarias Municipais e Estaduais da Saúde tenham acesso a esses mapeamentos, uma vez que possuem os dados identificados, tornando o processo de integração possível. No entanto, pesquisadores fora essa esfera podem fazer uso desse conhecimento para compreenderem os conteúdos das bases de dados e como eles se relacionam.

\subsection{Trabalhos Futuros}

Como trabalho futuro, planeja-se modelar e adicionar, nas ontologias, os metadados presentes nas bases de dados do SINASC e SIM, tais como Código Brasileiro de Ocupações - CBO e o Código Internacional de Doenças - CID. Será também feita a implementação das interfaces entre as camadas das ontologias. Pretende-se ainda, utilizar os dados integrados e o conhecimento inferido para gerar dados para o projeto do indicador de Dias Potenciais de Gravidez Perdidos.

A médio prazo, será feita a adição de novas bases de dados, como a de internações hospitalares SIH. Também ocorrerá a integração da solução desenvolvida com o dashboard do InternaSUS ${ }^{1}$, outro projeto relacionado ao INCT InterSCity. Planeja-se também integrar as ontologias diretamente a outras iniciativas, como a do SemanticSUS ${ }^{2}$ e à coorte de 100 milhões de brasileiros ${ }^{3}$, do CIDACS $^{4}$.

\footnotetext{
${ }^{1}$ InternaSUS: http://healthdashboard.interscity.org/about

${ }^{2}$ SemanticSUS: https://semanticsus.github.io/semanticSUS/index.html

${ }^{3}$ Coorte de 100 milhões de brasileiros: https://cidacs.bahia.fiocruz.br/plataforma/ coorte-de-100-milhoes-de-brasileiros

${ }^{4}$ DIDACS: http://cidacs.bahia.fiocruz.br/
} 


\section{Apêndice A}

\section{Diagramas Entidade Relacionamento}

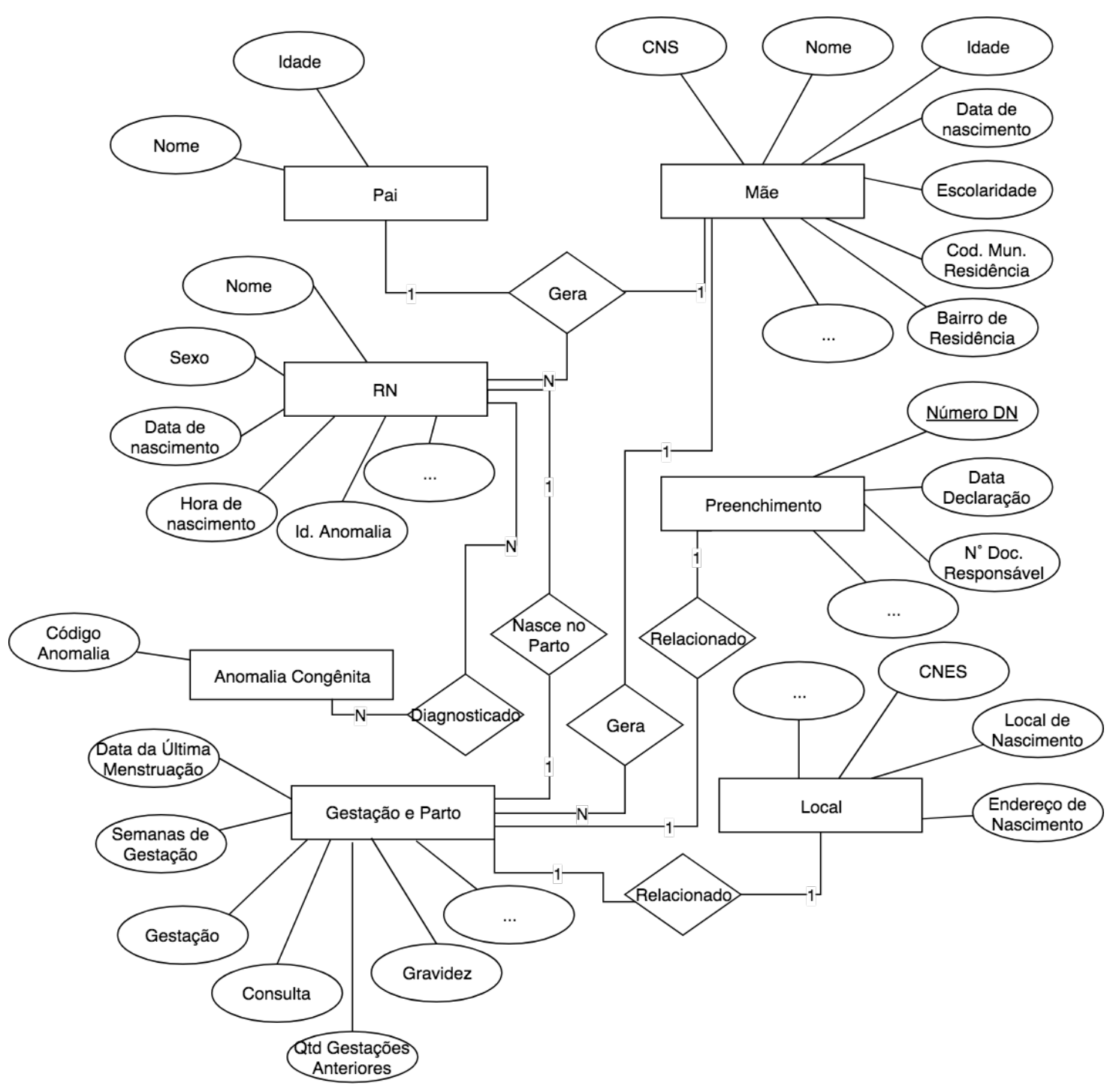

Figura A.1: Diagrama Entidade Relacionamento - SINASC 


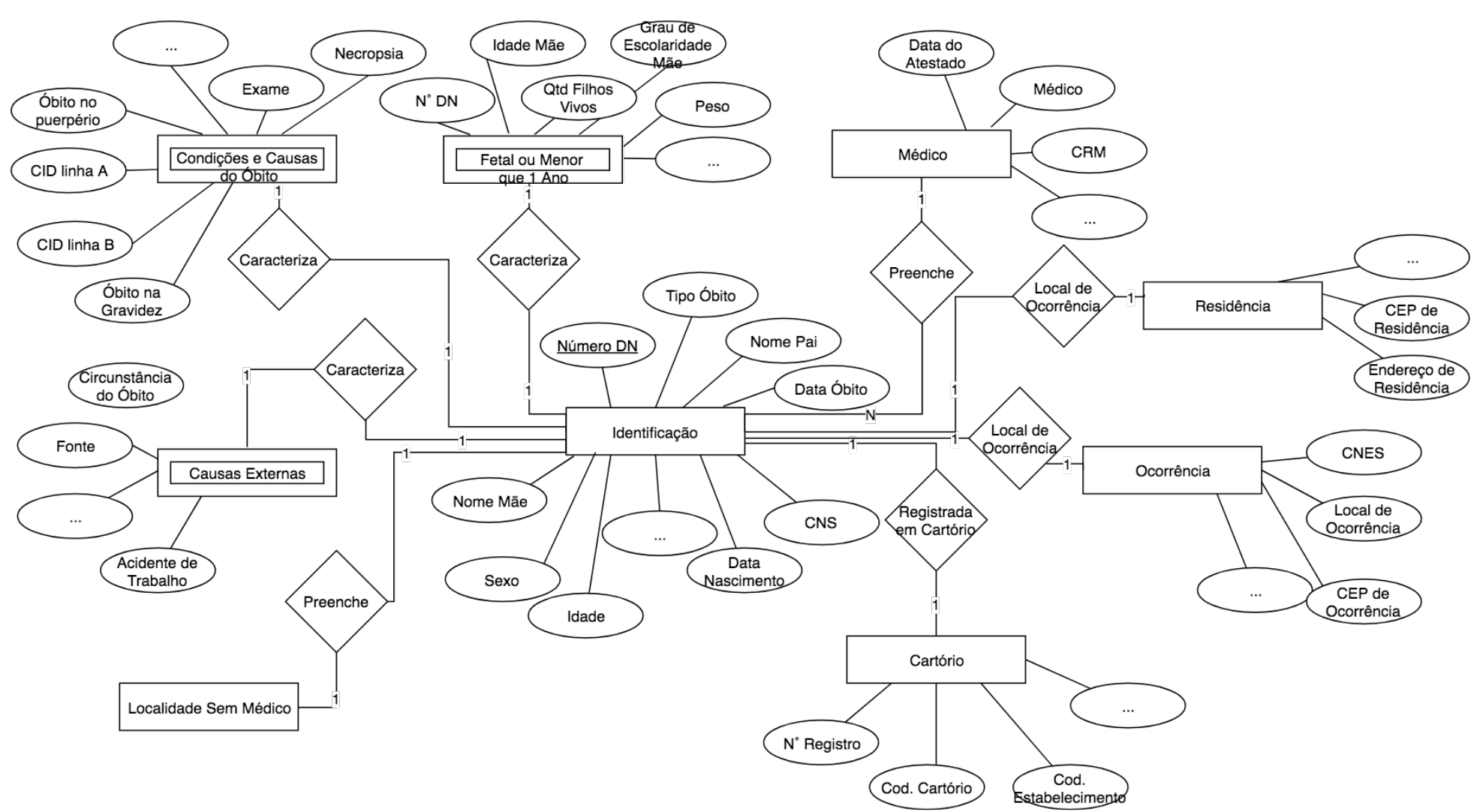

Figura A.2: Diagrama Entidade Relacionamento - SIM 


\section{Apêndice B}

\section{Consultas nas ontologias da camada OF}

Aqui são apresentadas as consultas realizadas a partir das ontologias da camada OF.

- Quem são os recém nascidos presentes na ontologia $O F_{S I N A S C}$ - FR? Figura B.1.

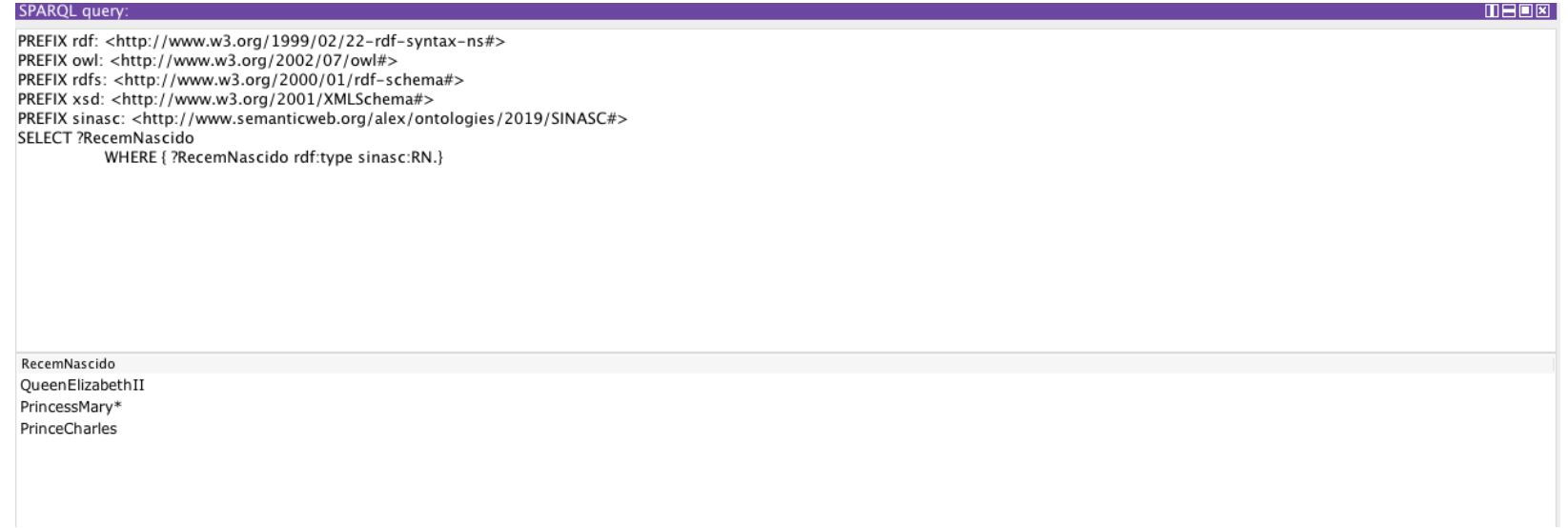

Figura B.1: Consulta exemplo de recém nascidos presentes na ontologia do $O F_{S I N A S C}-F R$

- Quem são os recém nascidos que têm anomalia congênita? E quais são suas anomalias congênitas? Figura B.2.

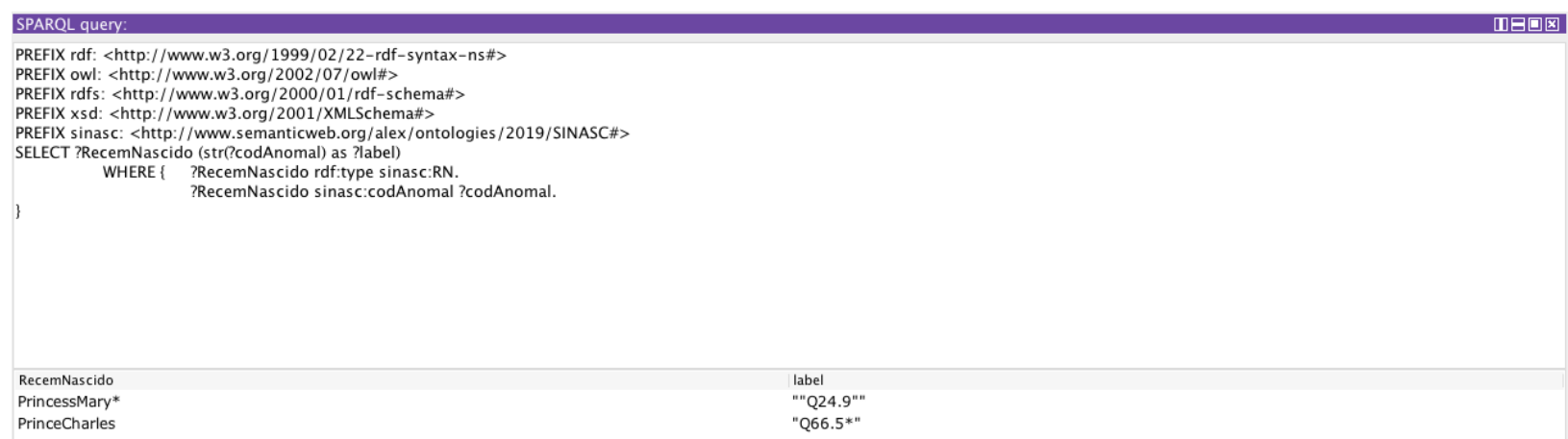

Figura B.2: Consulta exemplo de recém nascidos com anomalia congênita presentes na ontologia $O F_{S I N A S C}-F R$

- De acordo com os dados da $O F_{S I M}$ populada com os indivíduos da Família Real Britânica, houve óbito fetal ou de menores de 1 ano? Se sim, apresentar o(s) indivíduo(s). Figura B.3. 
PARQL quer :

PREFIX rdf: <http://www.w3.org/1999/02/22-rdf-syntax-ns\#>
PREFIX owl: <http://www.w3.org/2002/07/owl\#>

PREFIX rdfs: <http://www.w3.org/2000/01/rdf-schema\#>

PREFIX Xsd: <http://www.w3.org/2001/XMLSchema\# >

PREFIX sim: <http://www.semanticweb.org/alex/ontologies/2019/4/SIM\#>

SELECT ?fetalOuMeno

?fetalOuMenor rdf:type sim:FetalOuMenorQue1Ano.

fetalOuMenor

PrincessMary*

Figura B.3: Consulta exemplo de óbitos de menores de 1 ano presentes na ontologia do OFSIM - FR

- Qual a data de nascimento dos indivíduos menores de 1 ano que tiveram óbito? Quem são esses indivíduos? Figura B.4.

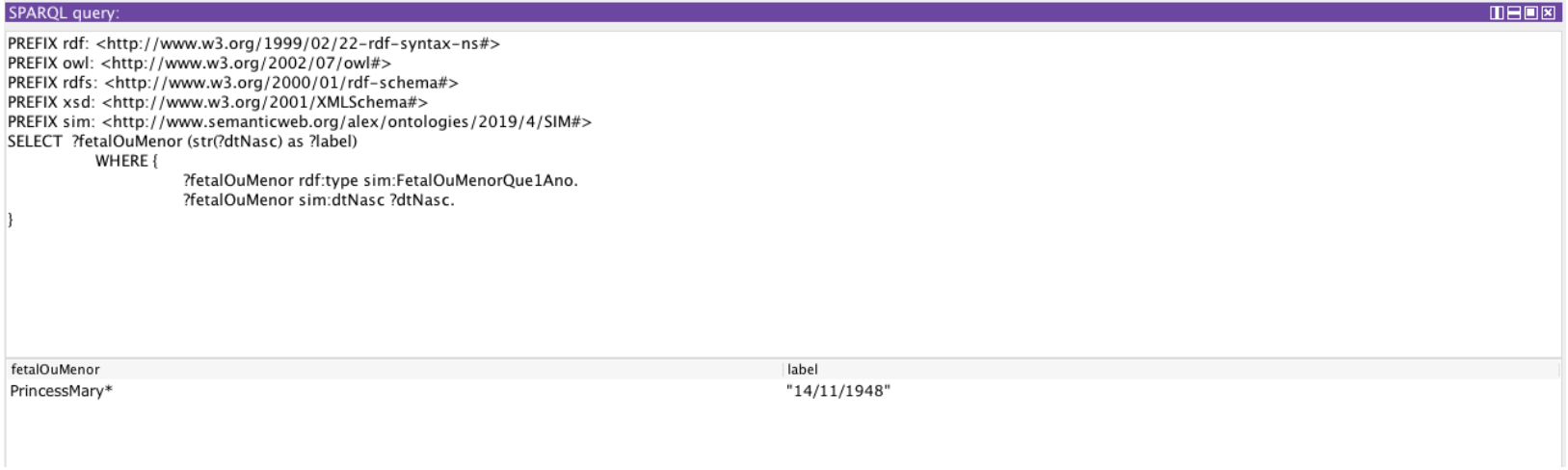

Figura B.4: Consulta exemplo da data de nascimento dos óbitos de menores de 1 ano presentes na ontologia $O F_{S I M}-F R$ 


\section{Apêndice C}

\section{Questões de Competência}

A seguir são apresentas as questões de competência elaboradas a partir das reuniões, diagrama e seminários apresentados pelos especialistas de domínio. As questões em negrito são aquelas que podem ser respondidas com a solução construída nesta dissertação.

- Objeto de estudo: Mãe

1. Quais são as condições socioeconômicas da mãe?

2. Qual a escolaridade da mãe?

3. Qual a idade da mãe?

4. Qual o peso da mãe?

5. A mãe tem diagnóstico de diabetes?

6. A mãe teve diagnóstico de diabetes em algum momento anterior à gestação?

7. Caso diabética, o bebê foi a óbito?

8. A mãe tem diagnóstico de síndromes hipertensivas?

9. A mãe teve diagnóstico de síndromes hipertensivas em algum momento anterior à gestação?

10. Caso diagnosticada com síndrome hipertensiva, o bebê foi a óbito?

11. A mãe é tabagista?

12. Há registro de tabagismo em algum momento anterior à gestação?

13. A mãe é alcoólatra?

14. Há registro de alcoolismo em algum momento anterior à gestação?

15. A mãe apresenta diagnóstico de doenças transmissíveis? Tais como Sífilis, HIV-AIDS, Rubéola.

16. A mãe teve internação? A internação está relacionada à gravidez?

17. A mãe teve internação na UTI? A internação está relacionada à gravidez?

18. Quais foram os procedimentos realizados pela mãe durante a internação? Quais são o CID principal e o secundário associados a essa internação?

19. Quais foram os procedimentos realizados na mãe durante o pré-natal no SUS?

20. Quais foram os procedimentos realizados no mãe durante o primeiro ano de vida do RN?

21. Após o parto, houve óbito materno?

22. Caso tenha havido óbito materno, quais as causas básicas do óbito?

23. A mãe possui registro de abortos ou perdas fetais anteriores a esse parto?

24. Quantos quilômetros a gestante precisou se deslocar de sua residência até ser atendida para a realização do parto? 
- Objeto de estudo: Nascido Vivo, Filho ou Recém Nascido (RN)

1. Qual o peso do RN ao nascer?

2. O APGAR do RN foi superior a 7 , no $5^{\circ}$ minuto?

3. O RN apresenta diagnóstico de doenças transmissíveis? Tais como Sífilis, HIV-AIDS, Rubéola

4. Quais foram os procedimentos de alto custo realizados pelo RN? Quais são o CID principal e o secundário associados a esses procedimentos?

5. O RN teve internação?

6. O RN teve internação na UTI?

7. Quais foram os procedimentos realizados pelo RN durante a internação? Quais são o CID principal e o secundário associados a essa internação?

8. O RN teve reinternação? A reinternação ocorreu pelo SUS? Qual o tipo de financiamentos está associado a essa reinternação?

9. O RN tem sido aleitado?

10. O RN recebeu procedimentos de fototerapia e/ou oxigenoterapia?

11. Quais foram os procedimentos realizados no RN durante o pré-natal?

12. Quais foram os procedimentos realizados no RN durante o primeiro ano de vida?

13. Houve óbito perinatal do RN?

14. Houve óbito do RN antes deste completar 1 ano de idade?

15. Houve óbito de RN que tem registro de anomalia congênita na base de dados do SINASC?

16. Caso tenha havido óbito do RN, quais as causas básicas do óbito?

17. O RN é de alto risco?

18. O RN tem diagnóstico de anomalias congênitas? Tais como: Perda auditiva, retinopatia, cardiopatia, Síndrome de Down.

19. Quais são as características dos RNs com o diagnóstico de anomalias congênitas na cidade de São Paulo?

20. Segundo o SINASC, onde os RNs com diagnóstico de determinada anomalia congênita residem?

21. Onde é feito o tratamento/acompanhamento da anomalia congênita?

22. De onde veio a informação do diagnóstico de anomalia congênita desse RN?

23. Qual o caminho de cuidado a que cada RN tem sido submetido?

24. A mãe tem diagnóstico de alguma doença que possa ter levado à anomalia congênita do RN?

- Objeto de estudo: Gestação

1. Quantas consultas pré-natal foram realizadas durante a gestação?

2. Quantas consultas pré-natal foram realizadas por médicos durante a gestação?

3. Quantas consultas pré-natal foram realizadas por enfermeiros durante a gestação?

4. Em qual grupo de Robson a gestação está enquadrada?

5. A gestação é de alto risco?

6. Caso a gestação seja de alto risco, em quantas consultas ambulatoriais a mãe passou?

7. Houve óbito fetal? 


\section{- Objeto de estudo: Parto}

\section{Qual foi a hora do nascimento? \\ 2. Qual foi o tipo de financiamento associado a esse parto? \\ 3. Quem fez a assistência desse parto?}

A seguir são apresentadas tabelas que contêm as palavras chaves das questões de competência, as bases de dados necessárias para respondê-las e a qual sua classificação, levando em conta o agrupamento apresentado em 5.1.2 para cada um dos objetos de estudo apresentados anteriormente. O símbolo de interrogação (?) que segue a classificação significa que não há o conhecimento concreto sobre a classificação, uma vez que não se teve o acesso ao dicionário de dados da base ou à própria base de dados.

\begin{tabular}{|c|c|c|c|}
\hline Numeração & Palavras chave/ Questões de competência & Bases de dados & Classificação \\
\hline 1 & Condições socioeconômicas mãe & SIGA & 1.a (?) \\
\hline 2 & Escolaridade mãe & SINASC, SIM & 2.a \\
\hline 3 & Idade mãe & SINASC, SIM & 2.a \\
\hline 4 & Peso mãe & SIGA & 1.a $(?)$ \\
\hline 5 & Diagnóstico diabetes mãe & SIGA & 1.a (?) \\
\hline 6 & $\begin{array}{l}\text { Diagnóstico diabetes anterior à } \\
\text { gestação mãe }\end{array}$ & SIGA & 1.a (?) \\
\hline 7 & $\begin{array}{l}\text { Diagnóstico diabetes anterior à } \\
\text { gestação mãe óbito RN }\end{array}$ & SIGA, SIM & 1.c $(?)$ \\
\hline 8 & Diagnóstico síndromes hipertensivas mãe & SIGA & 1. a (?) \\
\hline 9 & $\begin{array}{c}\text { Diagnóstico síndromes hipertensivas } \\
\text { anterior à gestação mãe }\end{array}$ & SIGA & 1.a $(?)$ \\
\hline 10 & $\begin{array}{l}\text { Diagnóstico síndromes hipertensivas } \\
\text { anterior à gestação mãe óbito RN }\end{array}$ & SIGA, SIM & 1.c $(?)$ \\
\hline 11 & Tabagista mãe & SIGA & 1. a (?) \\
\hline 12 & Tabagista anterior à gestação mãe & SIGA & 1. a (?) \\
\hline 13 & Alcoólatra mãe & SIGA & 1. a (?) \\
\hline 14 & Alcoólatra anterior à gestação mãe & SIGA & 1. a (?) \\
\hline 15 & Diagnóstico doenças transmissíveis mãe & SINAN & 1. b (?) \\
\hline 16 & Internação internação gravidez mãe & $\mathrm{SIH}$ & 1. b (?) \\
\hline 17 & Internação UTI internação gravidez mãe & $\mathrm{SIH}$ & 1. b (?) \\
\hline 18 & $\begin{array}{l}\text { Internação procedimentos CID principal } \\
\text { CID secundário mãe }\end{array}$ & $\mathrm{SIH}$ & 1. b (?) \\
\hline 19 & Procedimentos pré-natal mãe & SIGA, SIH, SIA & 2. c (?) \\
\hline 20 & Procedimentos mãe primeiro ano $\mathrm{RN}$ & $\begin{array}{l}\text { SIGA, SIH, SIA, } \\
\text { SINASC }\end{array}$ & 2. c (?) \\
\hline 21 & Óbito materno após parto $\mathrm{RN}$ & SINASC, SIM & 2. $a$ ou b \\
\hline 22 & Causas óbito materno & SIM & 1. b \\
\hline 23 & Abortos perdas fetais parto mãe & SINASC, SIM & 2. a \\
\hline 24 & $\begin{array}{c}\text { Deslocamento gestante residência } \\
\text { hospital parto }\end{array}$ & SINASC, SIH & 1. c (?) \\
\hline
\end{tabular}

Tabela C.1: Descrição das questões de competência - Objeto de estudo: Mãe 


\begin{tabular}{|c|c|c|c|}
\hline Numeração & Palavras chave/ Questões de competência & Bases de dados & Classificação \\
\hline 1 & Peso ao nascer RN & SINASC & 1. $\mathbf{a}$ \\
\hline 2 & APGAR5 superior 7 RN & SINASC & 1. $\mathrm{a}$ \\
\hline 3 & Diagnóstico doenças transmissíveis $\mathrm{RN}$ & SINAN & 1. a (?) \\
\hline 4 & $\begin{array}{l}\text { Procedimentos de alto custo } \\
\text { CID principal CID secundário RN }\end{array}$ & SIGA, SIA & 1. c (?) \\
\hline 5 & Internação RN & $\mathrm{SIH}$ & 1. a (?) \\
\hline 6 & Internação UTI RN & $\mathrm{SIH}$ & 1. a (?) \\
\hline 7 & $\begin{array}{l}\text { Internação procedimentos CID } \\
\text { principal CID secundário RN }\end{array}$ & $\mathrm{SIH}$ & 1. a (?) \\
\hline 8 & $\begin{array}{l}\text { Reinternação tipo de } \\
\text { financiamento SUS RN }\end{array}$ & $\mathrm{SIH}$ & 1. b (?) \\
\hline 9 & Aleitamento RN & SIGA & 1. a (?) \\
\hline 10 & $\begin{array}{c}\text { Procedimentos fototerapia } \\
\text { oxigenoterapia RN }\end{array}$ & SIGA, SIA & 1. c (?) \\
\hline 11 & Procedimentos pré-natal RN & SIGA, SIH, SIA & 2. a (?) \\
\hline 12 & Procedimentos primeiro ano $\mathrm{RN}$ & $\begin{array}{l}\text { SIGA, SIH, } \\
\text { SIA, SINASC }\end{array}$ & 2. c (?) \\
\hline 13 & Óbito perinatal $\mathrm{RN}$ & SIM & 1. $a$ \\
\hline 14 & Óbito primeiro ano $\mathrm{RN}$ & SIM & 1. $\mathbf{a}$ \\
\hline 15 & $\begin{array}{c}\text { Óbito anomalia } \\
\text { congênita RN SINASC }\end{array}$ & SIM, SINASC & 1. $\mathrm{c}$ \\
\hline 16 & Causas básicas óbito RN & SIM & 1. $\mathrm{b}$ \\
\hline 17 & Alto risco $\mathrm{RN}$ & SIGA & 1. c (?) \\
\hline 18 & Anomalias congênitas $\mathrm{RN}$ & SINASC & 1. $\mathrm{b}$ \\
\hline 19 & $\begin{array}{l}\text { Anomalias congênitas RNs } \\
\text { cidade de São Paulo }\end{array}$ & $\begin{array}{c}\text { SINASC, SIM, } \\
\text { SIH, SINAN, } \\
\text { CADUNICO, SIA }\end{array}$ & $\begin{array}{l}\text { 2. a ou b } \\
\text { ou c }\end{array}$ \\
\hline 20 & $\begin{array}{l}\text { SINASC anomalia congênita } \\
\text { residência RN }\end{array}$ & SINASC & 1. $\mathrm{b}$ \\
\hline 21 & $\begin{array}{c}\text { Local tratamento acompanhamento } \\
\text { anomalia congênita RN }\end{array}$ & $\begin{array}{l}\text { SIGA, SIH, } \\
\text { SIA, SINASC }\end{array}$ & 2. c (?) \\
\hline 22 & $\begin{array}{c}\text { SIM SINASC RN } \\
\text { anomalia congênita }\end{array}$ & SINASC, SIM & 1. $\mathrm{c}$ \\
\hline 23 & Caminho de cuidado $\mathrm{RN}$ & SIGA & 1. c (?) \\
\hline 24 & $\begin{array}{l}\text { Mãe diagnóstico doença } \\
\text { anomalia congênita } R N\end{array}$ & $\begin{array}{l}\text { SIGA, SINAN, } \\
\text { SIM, SINASC }\end{array}$ & 2. c (?) \\
\hline
\end{tabular}

Tabela C.2: Descrição das questões de competência - Objeto de estudo: Nascido Vivo, Filho ou Recém Nascido $(R N)$ 


\begin{tabular}{|c|c|c|c|}
\hline Numeração & Palavras chave/ Questões de competência & Bases de dados & Classificação \\
\hline 1 & $\begin{array}{l}\text { Quantidade consulta } \\
\text { pré-natal gestação }\end{array}$ & SIGA, SINASC & 2. a (?) \\
\hline 2 & $\begin{array}{l}\text { Quantidade consulta pré-natal } \\
\text { médico gestação }\end{array}$ & SIGA & 1. a (?) \\
\hline 3 & $\begin{array}{l}\text { Quantidade consulta pré-natal } \\
\text { enfermeiro gestação }\end{array}$ & SIGA & 1. a (?) \\
\hline 4 & Grupo de Robson gestação & SIGA, SINASC & 2. a (?) \\
\hline 5 & Alto risco gestação & $\begin{array}{l}\text { SIGA, SINAN, } \\
\text { SINASC }\end{array}$ & 1. c (?) \\
\hline 6 & $\begin{array}{l}\text { Alto risco gestação } \\
\text { quantidade consulta } \\
\text { ambulatorial mãe }\end{array}$ & $\begin{array}{l}\text { SIGA, SINAN, } \\
\text { SINASC }\end{array}$ & 1. c (?) \\
\hline
\end{tabular}

Tabela C.3: Descrição das questões de competência - Objeto de estudo: Gestação

\begin{tabular}{|c|c|c|c|} 
Numeração & Palavras chave/ Questões de competência & Bases de dados & Classificação \\
\hline $\mathbf{1}$ & Hora nascimento & SINASC & $\mathbf{1} \cdot \mathbf{a}$ \\
$\mathbf{2}$ & Tipo financiamento parto & SINASC & $\mathbf{1 .} \mathbf{a}$ \\
$\mathbf{3}$ & Tipo assistência parto & SINASC & $\mathbf{1 . a}$
\end{tabular}

Tabela C.4: Descrição das questões de competência - Objeto de estudo: Parto 
76 QUESTÕES DE COMPETÊNCIA 


\section{Apêndice D}

\section{Dicionário de Mapeamento de Termos entre OFs e OD}

\begin{tabular}{c|c|c|} 
Sistema de origem & $\begin{array}{c}\text { Nome do campo na } \\
\text { fonte de dados e nas OFs }\end{array}$ & $\begin{array}{c}\text { Nome do termo na } \\
\text { ontologia OD }\end{array}$ \\
\hline SINASC & codAnomal & codAnomal
\end{tabular}

Tabela D.1: Anomalia Congênita

\begin{tabular}{|c|c|c|}
\hline Sistema de origem & $\begin{array}{c}\text { Nome do campo na } \\
\text { fonte de dados e nas OFs }\end{array}$ & $\begin{array}{c}\text { Nome do termo na } \\
\text { ontologia OD }\end{array}$ \\
\hline FIELD & idAtendimento & idAtendimento \\
ahFinanciamento & financiamento \\
SIH & ahDiagPri & cidPri \\
SIH & diagse1 & cidSec \\
SIH & diagse2 & cidSec \\
SIH & diagse3 & cidSec \\
SIH & diagse4 & cidSec \\
SIH & diagse5 & cidSec \\
SIH & diagse6 & cidSec \\
SIH & diagse7 & cidSec \\
SIH & diagse8 & cidSec \\
SIH & diagse9 & cidSec \\
SIH & paTpFin & financiamento \\
SIA & paCidPri & cidPri \\
SIA & paCidSec & cidSec \\
SIA & paCidCAs & cidCas \\
SIA &
\end{tabular}

Tabela D.2: Atendimento

\begin{tabular}{c|c|c} 
Sistema de origem & $\begin{array}{c}\text { Nome do campo na } \\
\text { fonte de dados e nas OFs }\end{array}$ & $\begin{array}{c}\text { Nome do termo na } \\
\text { ontologia OD }\end{array}$ \\
\hline SIA & dtOcor & dtOcor
\end{tabular}

Tabela D.3: Atendimento Ambulatorial 


\begin{tabular}{c|c|c} 
Sistema de origem & $\begin{array}{c}\text { Nome do campo na } \\
\text { fonte de dados e nas OFs }\end{array}$ & $\begin{array}{c}\text { Nome do termo na } \\
\text { ontologia OD }\end{array}$ \\
\hline SIA & paProcId & procedimento
\end{tabular}

Tabela D.4: Consulta Ambulatorial

\begin{tabular}{|c|c|c|} 
Sistema de origem & $\begin{array}{c}\text { Nome do campo na } \\
\text { fonte de dados e nas OFs }\end{array}$ & $\begin{array}{c}\text { Nome do termo na } \\
\text { ontologia OD }\end{array}$ \\
\hline SINASC & consultas & qtdConsultasPrenat \\
SINASC & consPrenat & qtdConsultasPrenat \\
SIA & - & procPrenatal
\end{tabular}

Tabela D.5: Consulta Pré-natal

\begin{tabular}{|c|c|c|} 
Sistema de origem & $\begin{array}{c}\text { Nome do campo na } \\
\text { fonte de dados e nas OFs }\end{array}$ & $\begin{array}{c}\text { Nome do termo na } \\
\text { ontologia OD }\end{array}$ \\
\hline SIGA & - & diabetes \\
SIGA & - & sindromesHipertensivas
\end{tabular}

Tabela D.6: Doença Crônica

\begin{tabular}{|c|c|c|} 
Sistema de origem & $\begin{array}{c}\text { Nome do campo na } \\
\text { fonte de dados e nas OFs }\end{array}$ & $\begin{array}{c}\text { Nome do termo na } \\
\text { ontologia OD }\end{array}$ \\
\hline SINAN & - & sifilis \\
SINAN & - & hivAids \\
SINAN & - & rubeola
\end{tabular}

Tabela D.7: Doença Transmissivel

\begin{tabular}{|c|c|c|} 
Sistema de origem & $\begin{array}{c}\text { Nome do campo na } \\
\text { fonte de dados e nas OFs }\end{array}$ & $\begin{array}{c}\text { Nome do termo na } \\
\text { ontologia OD }\end{array}$ \\
\hline SIA & paCoduni & cnes \\
SINASC & codEstab & cnes \\
SIH & ahCnes & cnes \\
SIM & codEstab & cnes \\
SIM & codEstOcor & cnes \\
SINASC & codEstOcor & cnes \\
SIA & paTpUps & tpEstab \\
\hline
\end{tabular}

Tabela D.8: Estabelecimento

\begin{tabular}{|c|c|c|} 
Sistema de origem & $\begin{array}{c}\text { Nome do campo na } \\
\text { fonte de dados e nas OFs }\end{array}$ & $\begin{array}{c}\text { Nome do termo na } \\
\text { ontologia OD }\end{array}$ \\
\hline SIM & idade & idadeFalecido \\
SIM & numSUS & cnsFalecido \\
SIM & sexo & sexoFalecido \\
SIM & tipoObito & tpObito
\end{tabular}

Tabela D.9: Falecido 


\begin{tabular}{c|c|c} 
Sistema de origem & $\begin{array}{c}\text { Nome do campo na } \\
\text { fonte de dados e nas OFs }\end{array}$ & $\begin{array}{c}\text { Nome do termo na } \\
\text { ontologia OD }\end{array}$ \\
\hline SINASC & idAnomal & anomaliaCong
\end{tabular}

Tabela D.10: Filho

\begin{tabular}{|c|c|c|} 
Sistema de origem & $\begin{array}{c}\text { Nome do campo na } \\
\text { fonte de dados e nas OFs }\end{array}$ & $\begin{array}{c}\text { Nome do termo na } \\
\text { ontologia OD }\end{array}$ \\
\hline SINASC & qtdFilMort & qtdFilMort \\
SINASC & semaGestac & semGestac \\
SINASC & gestacao & semGestac \\
SINASC & dtUltMenst & dtUltMenst \\
SINASC & mesPrenat & mesPrenat \\
SINASC & gravidez & tpGravidez \\
SINASC & consultas & qtdConsultasPrenat \\
SINASC & consPrenat & qtdConsultasPrenat \\
SIM & obitoGrav & obitoGrav
\end{tabular}

Tabela D.11: Gestação

\begin{tabular}{|c|c|c|} 
Sistema de origem & $\begin{array}{c}\text { Nome do campo na } \\
\text { fonte de dados e nas OFs }\end{array}$ & $\begin{array}{c}\text { Nome do termo na } \\
\text { ontologia OD }\end{array}$ \\
\hline SIH & ahNumAih & numAih \\
SIH & ahNumAihAnt & numAihAnt \\
SIH & ahNumAihProx & numAihProx \\
SIH & ahEspecialidade & especialidade \\
SIH & ahCarInternacao & carInternacao \\
SIH & ahDtInternacao & dtInternacao \\
SIH & ahDtSaida & dtSaida \\
SIH & ahDiarias & diarias \\
SIH & ahMotSaida & motSaida \\
SIH & ahProcRealizado & procedimento \\
SIH & paProcedimento & procedimento \\
SIH & ahProcSolicitado & procSolicitado \\
SIH & paProcedimentoQtd & procedimentoQtd \\
SIH & ahDiariasUti & diariasUTI \\
SIH & ahDiariasUi & diariasUI \\
SIH & ahUtineoMesesGestacao & utineoMesesGestacao \\
SIH & ahUtineoMotSaida & utineoMotSaida \\
\hline
\end{tabular}

Tabela D.12: Internação

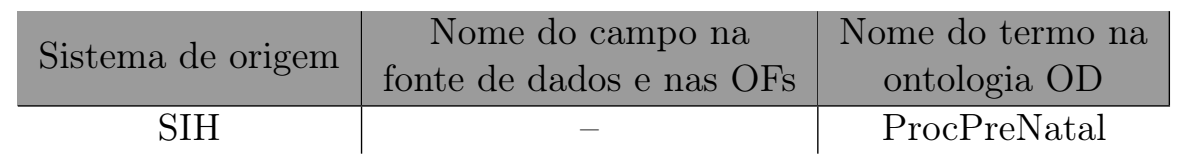

Tabela D.13: Internação Relacionada à Gravidez 


\begin{tabular}{|c|c|c|} 
Sistema de origem & $\begin{array}{c}\text { Nome do campo na } \\
\text { fonte de dados e nas OFs }\end{array}$ & $\begin{array}{c}\text { Nome do termo na } \\
\text { ontologia OD }\end{array}$ \\
\hline SIM & baiOcor & bairroOcor \\
SIM & cepOcor & cepOcor \\
SIM & codBaiOcor & codBairroOcor \\
SIM & codDisOcor & codDistritoOcor \\
SIM & codEndOcor & codEnderecoOcor \\
SIM & codMunOcor & codMunicipioOcor \\
SINASC & codRegOcor & codRegiaoOcor \\
SIM & codRegOcor & codRegiaoOcor \\
SIM & complOcor & compEnderecoOcor \\
SIM & endOcor & enderecoOcor \\
SIM & numEndOcor & numeroEndOcor \\
\hline
\end{tabular}

Tabela D.14: Localização da Ocorrência

\begin{tabular}{|c|c|c|}
\hline Sistema de origem & $\begin{array}{c}\text { Nome do campo na } \\
\text { fonte de dados e nas OFs }\end{array}$ & $\begin{array}{l}\text { Nome do termo na } \\
\text { ontologia OD }\end{array}$ \\
\hline SINASC & baiRes & baiRes \\
\hline SIM & baiRes & baiRes \\
\hline $\mathrm{SIH}$ & ahPacienteLogrBairro & baiRes \\
\hline SIM & cepRes & cepRes \\
\hline $\mathrm{SIH}$ & ahPacienteLogrCep & cepRes \\
\hline SINASC & codBaiRes & codBaiRes \\
\hline SIM & codBaiRes & codBaiRes \\
\hline SINASC & codDisRes & codDisRes \\
\hline SIM & codDisRes & codDisRes \\
\hline SINASC & codEndRes & codEndRes \\
\hline SIM & codEndRes & codEndRes \\
\hline SINASC & codEstRes & codEstRes \\
\hline SIM & codEstRes & codEstRes \\
\hline $\mathrm{SIH}$ & ahPacienteLogrUF & codEstRes \\
\hline SINASC & codMunRes & codMunRes \\
\hline SIM & codMunRes & codMunRes \\
\hline $\mathrm{SIH}$ & ahPacienteLogrMunicipio & codMunRes \\
\hline SINASC & codPaisRes & codPaisRes \\
\hline SIM & codPaisRes & codPaisRes \\
\hline SINASC & codRegRes & codRegRes \\
\hline SIM & codRegRes & codRegRes \\
\hline SINASC & complRes & complEndRes \\
\hline SIM & complRes & complEndRes \\
\hline $\mathrm{SIH}$ & ahPacienteLogrCompl & complEndRes \\
\hline SINASC & endRes & endRes \\
\hline SIM & endRes & endRes \\
\hline $\mathrm{SIH}$ & ahPacienteLogr & endRes \\
\hline SINASC & numRes & numEndRes \\
\hline SIM & numRes & numEndRes \\
\hline $\mathrm{SIH}$ & ahPacienteLogrNumero & numEndRes \\
\hline
\end{tabular}

Tabela D.15: Localização da Residência 


\begin{tabular}{c|c|c} 
Sistema de origem & $\begin{array}{c}\text { Nome do campo na } \\
\text { fonte de dados e nas OFs }\end{array}$ & $\begin{array}{c}\text { Nome do termo na } \\
\text { ontologia OD }\end{array}$ \\
\hline SIA & paUfMun & codEstCodMunEstab
\end{tabular}

Tabela D.16: Localização do Estabelecimento

\begin{tabular}{|c|c|c|} 
Sistema de origem & $\begin{array}{c}\text { Nome do campo na } \\
\text { fonte de dados e nas OFs }\end{array}$ & $\begin{array}{c}\text { Nome do termo na } \\
\text { ontologia OD }\end{array}$ \\
\hline SINASC & baiNasc & bairroNasc \\
SINASC & cepNasc & cepNasc \\
SINASC & codBaiNasc & codBairroNasc \\
SINASC & codDisNasc & codDistritoNasc \\
SINASC & codEndNasc & codEnderecoNasc \\
SINASC & codMunNasc & codMunicipioNasc \\
SIH & ahPacienteMunOrigem & codMunicipioNasc \\
SIH & ahPacienteNacionalidade & codPaisNasc \\
SINASC & complNasc & complementoEndNasc \\
SINASC & endNasc & enderecoNasc \\
SINASC & numEndNasc & numeroEndNasc \\
\hline
\end{tabular}

Tabela D.17: Localização do Nascimento

\begin{tabular}{|c|c|c|} 
Sistema de origem & $\begin{array}{c}\text { Nome do campo na } \\
\text { fonte de dados e nas OFs }\end{array}$ & $\begin{array}{c}\text { Nome do termo na } \\
\text { ontologia OD }\end{array}$ \\
\hline SIM & obitoPuerp & obitoPuerp \\
SINASC & idadeMae & idadeMaeParto \\
SIGA & pesoMae & escMaeParto \\
SINASC & - & escolaridadeMaeParto \\
CADUNICO & codOcupMae & codOcupocioeconomica \\
SINASC & numSusMae & cnsMae \\
SINASC & nomeMae & nomeMae \\
SINASC & ahPacienteNomeMae & nomeMae \\
SIH & nomeMae & nomeMae \\
SIM & & \\
\hline
\end{tabular}

Tabela D.18: Mãe

\begin{tabular}{c|c|c} 
Sistema de origem & $\begin{array}{c}\text { Nome do campo na } \\
\text { fonte de dados e nas OFs }\end{array}$ & $\begin{array}{c}\text { Nome do termo na } \\
\text { ontologia OD }\end{array}$ \\
\hline SINASC & sexo & sexo
\end{tabular}

Tabela D.19: Nascido Vivo 


\begin{tabular}{|c|c|c|} 
Sistema de origem & $\begin{array}{c}\text { Nome do campo na } \\
\text { fonte de dados e nas OFs }\end{array}$ & $\begin{array}{c}\text { ome do termo na } \\
\text { ontologia OD }\end{array}$ \\
\hline SIM & tipoObito & tpObito \\
SINASC & dtNasc & dtNasc \\
SIM & dtNasc & dtNasc \\
SIH & ahPacienteDtNascimento & dtNasc \\
SIA & dtNasc & dtNasc \\
SINASC & horaNasc & horaNasc
\end{tabular}

Tabela D.20: Nascimento

\begin{tabular}{c|c|c|} 
Sistema de origem & $\begin{array}{c}\text { Nome do campo na } \\
\text { fonte de dados e nas OFs }\end{array}$ & $\begin{array}{c}\text { Nome do termo na } \\
\text { ontologia OD }\end{array}$ \\
\hline SIM & tipoObito & tpObito
\end{tabular}

Tabela D.21: Natimorto

\begin{tabular}{|c|c|c|} 
Sistema de origem & $\begin{array}{c}\text { Nome do campo na } \\
\text { fonte de dados e nas OFs }\end{array}$ & $\begin{array}{c}\text { Nome do termo na } \\
\text { ontologia OD }\end{array}$ \\
\hline SIM & numeroDo & numeroDo \\
SIM & dtObito & dtObito \\
SIM & horaObito & causaBas \\
SIM & causaBas & causaMorte \\
SIM & causaMorte & locOcor \\
SIM & locOcor & obitoParto \\
SIM & obitoParto & obitoGrav \\
SIM & obitoGrav & obitoPuerp \\
SIM & obitoPuerp & escMae \\
SIM & idadeMae & idadeMaeObito \\
SIM &
\end{tabular}

Tabela D.22: Obito

\begin{tabular}{c|c|c} 
Sistema de origem & $\begin{array}{c}\text { Nome do campo na } \\
\text { fonte de dados e nas OFs }\end{array}$ & $\begin{array}{c}\text { Nome do termo na } \\
\text { ontologia OD }\end{array}$ \\
\hline SINASC & idadePai & idadePaiParto
\end{tabular}

Tabela D.23: Pai 


\begin{tabular}{|c|c|c|}
\hline Sistema de origem & $\begin{array}{c}\text { Nome do campo na } \\
\text { fonte de dados e nas OFs }\end{array}$ & $\begin{array}{l}\text { Nome do termo na } \\
\text { ontologia OD }\end{array}$ \\
\hline SINASC & idadeMae & idadeMaeParto \\
\hline SINASC & idadePai & idadePaiParto \\
\hline SIGA & pesoMae & pesoMaeParto \\
\hline SINASC & escMae & escolaridadeMaeParto \\
\hline CADUNICO & - & condicaoSocioeconomicaParto \\
\hline SINASC & codOcupMae & codOcupMaeParto \\
\hline SINASC & parto & tpParto \\
\hline SINASC & horaNasc & horaParto \\
\hline SINASC & tpApresent & tpApresent \\
\hline SINASC & stTrabParto & trabPartIndu \\
\hline SINASC & stCesParto & cesAntesTrabParto \\
\hline SINASC & tpNascAssi & tpNascAssi \\
\hline SINASC & tpRobson & tpRobson \\
\hline SIM & obitoParto & obitoParto \\
\hline
\end{tabular}

Tabela D.24: Parto

\begin{tabular}{|c|c|c|} 
Sistema de origem & $\begin{array}{c}\text { Nome do campo na } \\
\text { fonte de dados e nas OFs }\end{array}$ & $\begin{array}{c}\text { Nome do termo na } \\
\text { ontologia OD }\end{array}$ \\
\hline SINASC & mesPrenat & mesPrenat \\
SINASC & consultas & qtdConsultasPrenat \\
SINASC & consPrenat & qtdConsultasPrenat
\end{tabular}

Tabela D.25: Pré-natal

\begin{tabular}{|c|c|c|} 
Sistema de origem & $\begin{array}{c}\text { Nome do campo na } \\
\text { fonte de dados e nas OFs }\end{array}$ & $\begin{array}{c}\text { Nome do termo na } \\
\text { ontologia OD }\end{array}$ \\
\hline SIA & procRealizado & procedimentoRealizado \\
SIA & procSolicitado & procSolicitado \\
SIA & procedimentoQtd & procedimentoQtd \\
SIA & procedimento & procedimento \\
\hline
\end{tabular}

Tabela D.26: Procedimento

\begin{tabular}{|c|c|c|} 
Sistema de origem & $\begin{array}{c}\text { Nome do campo na } \\
\text { fonte de dados e nas OFs }\end{array}$ & $\begin{array}{c}\text { Nome do termo na } \\
\text { ontologia OD }\end{array}$ \\
\hline SINASC & nomeRenasc & nomeRN \\
SINASC & apgar1 & apgar1 \\
SINASC & apgar5 & apgar5 \\
SINASC & numeroDn & numeroDn \\
SINASC & peso & pesoRN \\
SIH & ahUtineoPeso & pesoRN \\
SIGA & - & aleitamento \\
SIM & obitoParto & obitoParto
\end{tabular}

Tabela D.27: Recém-nascido 


\begin{tabular}{|c|c|c|} 
Sistema de origem & $\begin{array}{c}\text { Nome do campo na } \\
\text { fonte de dados e nas OFs }\end{array}$ & $\begin{array}{c}\text { Nome do termo na } \\
\text { ontologia OD }\end{array}$ \\
\hline SINASC & parto & tpParto \\
SINASC & tpApresent & tpApresent \\
SINASC & stTrabParto & trabPartIndu \\
SINASC & stCesParto & cesAntesTrabParto
\end{tabular}

Tabela D.28: Trabalho de Parto

\begin{tabular}{|c|c|c|}
\hline Sistema de origem & $\begin{array}{l}\text { Nome do campo na } \\
\text { fonte de dados e nas OFs }\end{array}$ & $\begin{array}{l}\text { Nome do termo na } \\
\text { ontologia OD }\end{array}$ \\
\hline $\mathrm{SIH}$ & ahPacienteNumeroCns & cns \\
\hline SIA & paCns & cns \\
\hline SINASC & cns & $\mathrm{cns}$ \\
\hline SIM & numSUS & cns \\
\hline SINASC & numSusMae & cnsMae \\
\hline $\mathrm{SIH}$ & ahPacienteDtNascimento & dtNasc \\
\hline SINASC & dtNasc & dtNasc \\
\hline SINASC & dtNascMae & dtNasc \\
\hline SIM & dtNasc & dtNasc \\
\hline SIA & dtNasc & dtNasc \\
\hline SINASC & horaNasc & horaNasc \\
\hline $\mathrm{SIH}$ & ahPacienteNome & nome \\
\hline SIM & nome & nome \\
\hline SIGA & - & nome \\
\hline SINASC & nomeMae & nomeMae \\
\hline $\mathrm{SIH}$ & ahPacienteNomeMae & nomeMae \\
\hline SIM & nomeMae & nomeMae \\
\hline $\mathrm{SIH}$ & ahPacienteSexo & sexo \\
\hline SINASC & sexo & sexo \\
\hline SIA & apSexo & sexo \\
\hline SIM & sexo & sexo \\
\hline
\end{tabular}

Tabela D.29: Usuário

\begin{tabular}{c|c|c|} 
Sistema de origem & $\begin{array}{c}\text { Nome do campo na } \\
\text { fonte de dados e nas OFs }\end{array}$ & $\begin{array}{c}\text { Nome do termo na } \\
\text { ontologia OD }\end{array}$ \\
\hline SIGA & - & tabagismo \\
SIGA & - & alcoolismo
\end{tabular}

Tabela D.30: Vício 
Anexo A

Bases de dados para integração 


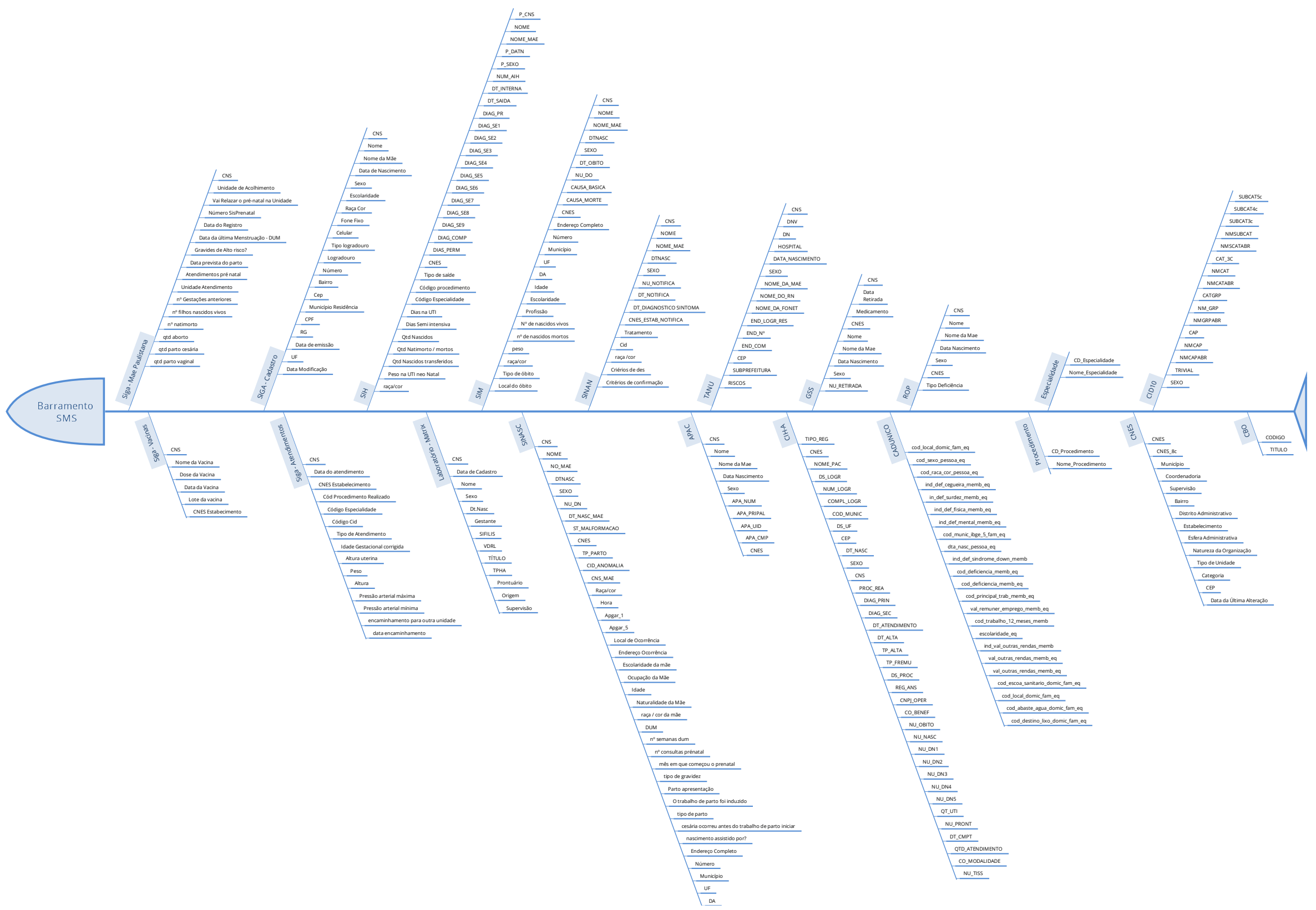

Figura A.1: Bases de dados do SIS-SUS criada em conjunto com a Secretaria Municipal da Saúde de São Paulo 
As bases de dados que foram listadas na Figura A.1 mas desconsideradas para esta etapa do projeto são:

- $\mathrm{SIH}^{1}$ : Sistema de Informações Hospitalares. Sistema responsável pelo registro de internações hospitalares remuneradas pelo SUS;

- $\mathrm{SIA}^{2}$ : Sistema de Informações Ambulatoriais, também relacionado a remuneração de procedimentos pelo SUS. O SIA é sub-dividido em:

- BPA-I: Boletim de Produção Ambulatorial Individualizado;

- APAC: Autorização de Procedimentos de Alta Complexidade, para procedimentos de alto custo;

- TANU ${ }^{3}$ : A Triagem Auditiva Neonatal Universal, deve ser aplicada em todos os recém nascidos do país. Os dados municipais dessa triagem estão sob o domínio das SMS;

- GSS ${ }^{4}$ : Gestão de Sistemas de Saúde e um sistema presente no município de São Paulo cujo objetivo é fazer o controle de estoques de materiais (tais como medicamentos) das unidades básicas de saúde que prestam serviço para o SUS;

- SIGA $^{5}$ : Sistema Integrado de Gestão da Assistência à Saúde. Sistema presente no município de São Paulo onde há: o cadastro de usuários do SUS do município, os atendimentos e os registros do SISPreNatal, sistema para o registro e acompanhamento de gestantes. Assim, nele há bases com:

- Cadastro: Cadastro dos usuário do SUS do município;

- Mãe Paulistana: Informações sobre os registros do SISPreNatal, sistema de pré-natal, bem como acompanhamento das gestantes;

- Atendimento: Registro dos atendimentos ambulatoriais do município;

- Vacinas: Registro da dispensação de vacinas pelas unidades de saúde;

- Matrix: Sistema que contém os dados de resultados de exames laboratoriais realizados pelo SUS na cidade de São Paulo;

- SINAN ${ }^{6}$ : Sistema de Informação de Agravos de Notificação. Nesse sistema há várias bases de dados, cada uma relacionada a um tipo de evento para a notificação: casos de tuberculose, AIDS, dengue, entre outras;

- CIH-A ${ }^{7}$ : A Comunicação de Informação Ambulatorial e Hospitalar informa sobre as internações hospitalares e os procedimentos ambulatoriais custeados por planos de saúde e seguros privados de assistência à saúde;

- CADUNICO ${ }^{8}$ : A base de dados do Cadastro Único para Programas Sociais do Governo Federal contém informações socioeconômicas e demográficas de famílias de baixa renda que têm acesso a programas sociais do Governo Federal;

- ROP: Base de dados de triagem oftalmológica neonatal do município de São Paulo;

\footnotetext{
${ }^{1} \mathrm{SIH}:$ http://www2.datasus.gov.br/SIHD/institucional

${ }^{2}$ SIA: http://datasus.saude.gov.br/sistemas-e-aplicativos/ambulatoriais/sia

${ }^{3}$ Manual sobre a TANU: http://bvsms.saude.gov.br/bvs/publicacoes/diretrizes_atencao_triagem_auditiva_ neonatal.pdf

${ }^{4}$ Manual com informações sobre o GSS: http://www.esfma.org.br/manuais/gss.pdf

${ }^{5}$ Manual sobre o SIGA: http://www.esfma.org.br/manuais/siga_saude.psf

${ }^{6}$ SINAN: http://portalsinan.saude.gov.br/o-sinan

${ }^{7}$ CIH-A: http://ciha.datasus.gov.br/CIHA/index.php?area $=01$

${ }^{8}$ CADUNICO: http://mds.gov.br/assuntos/cadastro-unico
} 
Anexo B

Exemplo da Declaração de Nascido Vivo 
ANEXO A - Modelo da Declaração de Nascido Vivo

República Federativa do Brasil Ministério da Saúde

$1^{\text {a }}$ VIA - SECRETARIA DE SAÚDE

\section{Declaração de Nascido Vivo}

$\|$

11 Nome do Recém-nascido

Data e hora do nascimento

2 Data

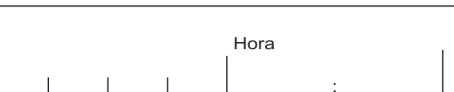

3 Sexo

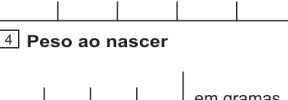

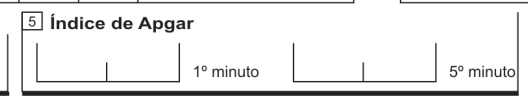

M-Masculino $\square$ F-Feminino

$\square$ I-Ignorado

7 Local da ocorrência

$1 \square$ Hospital

$3 \square$ Domicilio

Ignorado 8 Estabelecimento

Detectada alguma anomalia congênita?

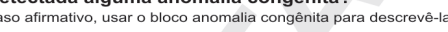
$1 \square \operatorname{sim} \quad 2 \square$ Não $\quad 9 \square$ Ignorado

$2 \square$ Outros estab. saúde $4 \square$ Outros 99

9 Endereço da ocorrência, se fora do estab. ou da resid. da Mãe (rua, praça, avenida, etc)

Número

Complemento 10 CEP

\begin{tabular}{|l|l|l|}
\hline 11 Bairro/Distrito & Código & 12 Municipio de ocorrência
\end{tabular}

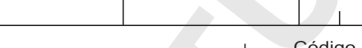

Código CNES

\begin{tabular}{l|c|}
11 Bairro/Distrito & Código \\
& +1
\end{tabular}

14 Nome da Mãe

Código

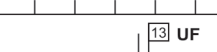

III

16 Escolaridade (última série concluida)

Nivel

$\square$ Sem escolaridade $\quad 3 \square$ Médio (antigo $2^{\circ}$ grau)

$1 \square$ Fundamental I ( $1^{\mathrm{a}}$ a $4^{\mathrm{a}}$ série) $\quad 4 \square$ Superior incompleto

$2 \square$ Fundamental II (5 $5^{\mathrm{a}}$ a $8^{\mathrm{a}}$ série) $\quad 5 \square$ Superior completo

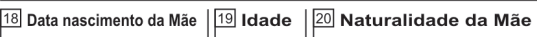

\begin{tabular}{|l|l|l}
$\square$ & \\
\hline
\end{tabular}

11

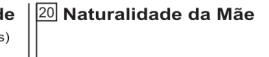

21 Situação conjuga

Código CBO 2002

Residência da Mãe

Municipio / UF (se estrangeiro informar Pais)

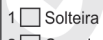

$1 \square$ Solteira
$2 \square$ Casada

$3 \square$ Viúva

15 Cartão sus

23 Logradouro

Número Complemento 24 CEP

\begin{tabular}{|l|l|}
\hline 25 Bairro/Distrito & Código
\end{tabular}

IV $\bar{\alpha}$

28 Nome do Pai

29 Idade do Pai

Gestações anteriores

30 Histórico gestacional

- No gestações

anteriores

$-\quad N^{\circ}$ de partos
vaginais

$-\mathrm{N}^{\circ}$ de nascidos vivos

- $\mathrm{N}^{\circ}$ de perdas fetais $/$

Gestação atual

Idade Gestacional

Menstruação (DUM)

\begin{tabular}{l|l|l|l|l|}
33 & Número de & 34 & Mês de & 35 \\
Tipo de
\end{tabular}

№ de semanas de
gestação, se DUM Ignorada

Método utilizado para estima

$1 \square$ Exame Fisico $2 \square$ Outro método $9 \square$ Ignorado $99 \square$ Ignorado $99 \square$ Ignorado $9 \square$ Ignorado

41 Descrever todas as anomalias congênitas observadas

$\mathrm{V}$

VII

42 Data do preenchimento 43 Nome do responsável pelo preenchimento

44 Função

$1 \square$ Médico $2 \square$ Enfermeiro $3 \square$ Parteira $4 \square$ Func. Cartório

45 Tipo documento

$4 \mathrm{~N}^{\circ}$ do documento

$46 \mathbf{N}^{\circ}$ do documento $\square$ Outros (descrever)

$1 \square$ CNES $2 \square$ CRM $3 \square$ COREN $4 \square$ RG $5 \square$ CPF

VIII

48 Cartório

51 Município

Órgão emissor

ATENÇÃO: ESTE DOCUMENTO NÃO SUBSTITUI A CERTIDÃO DE NASCIMENTO

Para registrar esta criança, O Registro de Nascimento é obrigatório por lei. Versão 01/10 - 2a Impressão 11/2010 


\section{Anexo C}

\section{Variáveis do SINASC}

O dicionário de dados com as especificações das variáveis também está disponível no seguinte endereço:

- SINASC - DN: http://svs.aids.gov.br/download/Dicionario_de_Dados_SINASC_tabela_ DN.pdf 
TABELA: DN

Os campos pintados, em azul, são os novos campos criados em 2009.

\begin{tabular}{|c|c|c|c|c|c|}
\hline $\begin{array}{c}\text { Nome da } \\
\text { coluna no } \\
\text { arquivo DBF }\end{array}$ & $\begin{array}{l}\text { Nome da } \\
\text { variáveis } \\
\text { no Tabwin }\end{array}$ & $\begin{array}{c}\text { Nome do } \\
\text { arquivo CNV }\end{array}$ & Tipo & Tam & Descrição \\
\hline NUMERODN & & & caracter & 8 & Número da DN \\
\hline NUMERODV & & & caracter & 1 & Número do Dígito Verificador \\
\hline PREFIXODN & & & caracter & 2 & Prefixo da DN \\
\hline CODCART & & & caracter & 8 & Código do cartório \\
\hline CODESTCART & & & caracter & 2 & Código da UF do cartório \\
\hline CODMUNCART & & & caracter & 7 & Código do município do cartório \\
\hline NUMREGCART & & & caracter & 10 & Número do registro civil (cartório) \\
\hline DTREGCART & & & caracter & 8 & Data do registro no cartório \\
\hline CODESTAB & $\begin{array}{l}\text { Esfera Adm } \\
2006\end{array}$ & ESFERA.cnv & caracter & 7 & $\begin{array}{l}\text { Código do estabelecimento de saúde onde ocorreu o } \\
\text { nascimento }\end{array}$ \\
\hline CODESTAB & $\begin{array}{l}\text { Esfera Admin } \\
2007\end{array}$ & ESFEDN07.CNV & & & \\
\hline CODESTAB & Estab & ndn.cnv & & & \\
\hline CODESTAB & $\begin{array}{l}\text { Estabelecim } \\
\text { Saude }\end{array}$ & $\begin{array}{l}\text { C: } \backslash T A B W I N \backslash E S \\
\text { TABEL.DBF }\end{array}$ & & & \\
\hline CODESTAB & Hosp Amigo & HAMIGO.CNV & & & \\
\hline CODESTAB & $\begin{array}{l}\text { Nat Org Estab } \\
2007\end{array}$ & NATDN07.CNV & & & \\
\hline CODESTAB & $\begin{array}{l}\text { Natur Organiz } \\
2006\end{array}$ & NAT_ORG.CNV & & & \\
\hline COMUNESTAB & & & caracter & 7 & Código do município do estabelecimento de saúde \\
\hline ENDNASC & & & caracter & 30 & Endereço do local de nascimento \\
\hline CODESTOCOR & & & caracter & 2 & Código da UF de ocorrência \\
\hline CODMUNNASC & Capital Ocorr & CAPITAIS.CNV & caracter & 7 & Código do município de nascimento \\
\hline CODMUNNASC & $\begin{array}{l}\text { Munic Ocorr- } \\
\text { AC }\end{array}$ & MUNICAC.CNV & & & \\
\hline CODMUNNASC & $\begin{array}{l}\text { Munic Ocorr- } \\
\text { AL }\end{array}$ & MUNICAL.CNV & & & \\
\hline CODMUNNASC & $\begin{array}{l}\text { Munic Ocorr- } \\
\text { AM }\end{array}$ & $\begin{array}{l}\text { MUNICAM.CN } \\
\mathrm{V}\end{array}$ & & & \\
\hline CODMUNNASC & $\begin{array}{l}\text { Munic Ocorr- } \\
\text { AP }\end{array}$ & MUNICAP.CNV & & & \\
\hline CODMUNNASC & $\begin{array}{l}\text { Munic Ocorr- } \\
\text { BA }\end{array}$ & MUNICBA.CNV & & & \\
\hline CODMUNNASC & $\begin{array}{l}\text { Munic Ocorr- } \\
\text { BR }\end{array}$ & MUNICBR.CNV & & & \\
\hline CODMUNNASC & $\begin{array}{l}\text { Munic Ocorr- } \\
\text { CE }\end{array}$ & MUNICCE.CNV & & & \\
\hline CODMUNNASC & $\begin{array}{l}\text { Munic Ocorr- } \\
\text { DF }\end{array}$ & MUNICDF.CNV & & & \\
\hline CODMUNNASC & $\begin{array}{l}\text { Munic Ocorr- } \\
\text { ES }\end{array}$ & MUNICES.CNV & & & \\
\hline CODMUNNASC & $\begin{array}{l}\text { Munic Ocorr- } \\
\text { GO }\end{array}$ & $\begin{array}{l}\text { MUNICGO.CN } \\
\mathrm{V}\end{array}$ & & & \\
\hline CODMUNNASC & $\begin{array}{l}\text { Munic Ocorr- } \\
\text { MA }\end{array}$ & $\begin{array}{l}\text { MUNICMA.CN } \\
\mathrm{V}\end{array}$ & & & \\
\hline
\end{tabular}




\begin{tabular}{|c|c|c|c|c|c|}
\hline CODMUNNASC & \begin{tabular}{|l} 
Munic Ocorr- \\
MG
\end{tabular} & \begin{tabular}{|l|} 
MUNICMG.CN \\
\end{tabular} & & & \\
\hline CODMUNNASC & \begin{tabular}{|l|} 
Munic Ocorr- \\
MS
\end{tabular} & \begin{tabular}{|l} 
MUNICMS.CN \\
V \\
\end{tabular} & & & \\
\hline CODMUNNASC & \begin{tabular}{|l} 
Munic Ocorr- \\
MT
\end{tabular} & $\begin{array}{l}\text { MUNICMT.CN } \\
\text { V } \\
\end{array}$ & & & \\
\hline CODMUNNASC & $\begin{array}{l}\text { Munic Ocorr- } \\
\text { PA }\end{array}$ & MUNICPA.CNV & & & \\
\hline CODMUNNASC & \begin{tabular}{|l} 
Munic Ocorr- \\
PB
\end{tabular} & MUNICPB.CNV & & & \\
\hline CODMUNNASC & $\begin{array}{l}\text { Munic Ocorr- } \\
\text { PE }\end{array}$ & MUNICPE.CNV & & & \\
\hline CODMUNNASC & Munic Ocorr-PI & MUNICPI.CNV & & & \\
\hline CODMUNNASC & \begin{tabular}{|l} 
Munic Ocorr- \\
PR
\end{tabular} & MUNICPR.CNV & & & \\
\hline CODMUNNASC & \begin{tabular}{|l|} 
Munic Ocorr- \\
RJ
\end{tabular} & MUNICRJ.CNV & & & \\
\hline CODMUNNASC & \begin{tabular}{|l|} 
Munic Ocorr- \\
RN
\end{tabular} & MUNICRN.CNV & & & \\
\hline CODMUNNASC & \begin{tabular}{|l} 
Munic Ocorr- \\
RO
\end{tabular} & MUNICRO.CNV & & & \\
\hline CODMUNNASC & \begin{tabular}{|l} 
Munic Ocorr- \\
RR
\end{tabular} & \begin{tabular}{|l|} 
MUNICAM.CN \\
V \\
\end{tabular} & & & \\
\hline CODMUNNASC & \begin{tabular}{|l|} 
Munic Ocorr- \\
RS
\end{tabular} & MUNICRS.CNV & & & \\
\hline CODMUNNASC & $\begin{array}{l}\text { Munic Ocorr- } \\
\text { SC }\end{array}$ & MUNICSC.CNV & & & \\
\hline CODMUNNASC & $\begin{array}{l}\text { Munic Ocorr- } \\
\text { SE }\end{array}$ & MUNICSE.CNV & & & \\
\hline CODMUNNASC & $\begin{array}{l}\text { Munic Ocorr- } \\
\text { SP }\end{array}$ & MUNICSP.CNV & & & \\
\hline CODMUNNASC & \begin{tabular}{|l} 
Munic Ocorr- \\
TO
\end{tabular} & MUNICTO.CNV & & & \\
\hline CODMUNNASC & \begin{tabular}{|l|} 
Região \\
Ocorrencia
\end{tabular} & REGIAO.CNV & & & \\
\hline CODMUNNASC & & REGIAOC.CNV & & & \\
\hline CODMUNNASC & UF Ocorrencia & UF.CNV & & & \\
\hline CODMUNNASC & & UFC.CNV & & & \\
\hline BAINASC & & & caracter & 30 & Bairro de nascimento \\
\hline CODBAINASC & & & caracter & 8 & Código do bairro de nascimento \\
\hline LOCNASC & \begin{tabular}{|l|} 
Local \\
Ocorrencia
\end{tabular} & LOCOCOR.CNV & caracter & 1 & $\begin{array}{l}\text { Local de nascimento: } 1 \text { - Hospital; } 2 \text { - Outros estabelecimentos } \\
\text { de saúde; } 3 \text {-Domicílio; } 4 \text { - Outros. }\end{array}$ \\
\hline CODENDNASC & & & caracter & 12 & Código de endereço de nascimento \\
\hline COMPLNASC & & & caracter & 20 & Complemento do endereço de nascimento \\
\hline NUMENDNASC & & & caracter & 10 & Número do endereço de nascimento \\
\hline CEPNASC & & & caracter & 9 & CEP do endereço de nascimento \\
\hline CODDISNASC & & & caracter & 8 & Código do distrito de nascimento \\
\hline CODREGOCOR & & & caracter & 5 & Código da regional de ocorrência \\
\hline NOMEMAE & & & caracter & 70 & Nome da mãe \\
\hline NUMSUSMAE & & & caracter & 15 & Número do cartão SUS da mãe \\
\hline IDADEMAE & Fx Etaria 11 & \begin{tabular}{|l} 
FXTABNET.CN \\
$\mathrm{V}$ \\
\end{tabular} & caracter & 2 & Idade da mãe \\
\hline IDADEMAE & Fx Etaria & FXIDADZ.CNV & & & \\
\hline
\end{tabular}




\begin{tabular}{|c|c|c|c|c|c|}
\hline & Mae(8) & & & & \\
\hline IDADEMAE & \begin{tabular}{|l|l} 
Fx.Et \\
Detalhada \\
\end{tabular} & IDADET.CNV & & & \\
\hline IDADEMAE & $\begin{array}{l}\text { Fx.Etaria } \\
\text { Mae(5) } \\
\end{array}$ & IDADE5.CNV & & & \\
\hline IDADEMAE & $\begin{array}{l}\text { Fx.Mae } \\
\text { adolescen }\end{array}$ & IDADOL.CNV & & & \\
\hline IDADEMAE & Fx.Padrão Mae & $\begin{array}{l}\text { IDADEMAE.CN } \\
\text { V }\end{array}$ & & & \\
\hline IDADEMAE & Fx.Padrão Mãe & \begin{tabular}{|l|} 
IDADEMAE.CN \\
$\mathrm{V}$
\end{tabular} & & & \\
\hline CONFIDADE & & & caracter & 1 & |------------------ \\
\hline ESTCIVMAE & Estado Civil & ESTCIV.CNV & caracter & 1 & $\begin{array}{l}\text { Situação conjugal da mãe: 1- Solteira; 2- Casada; 3- Viúva; 4- } \\
\text { Separada judicialmente/divorciada; 5- União estável; 9- } \\
\text { Ignorada. }\end{array}$ \\
\hline ESTCIVMAE & $\begin{array}{l}\text { Situacao } \\
\text { Conjugal }\end{array}$ & SITCONJU.CNV & & & \\
\hline ESCMAE & Esc Mae Anos & INSTRUC.CNV & caracter & 1 & $\begin{array}{l}\text { Escolaridade, em anos de estudo concluídos: } 1 \text { - Nenhuma; } 2- \\
1 \text { a } 3 \text { anos; } 3-4 \text { a } 7 \text { anos; } 4-8 \text { a } 11 \text { anos; } 5 \text { - } 12 \text { e mais; } 9- \\
\text { Ignorado. }\end{array}$ \\
\hline CODOCUPMAE & $\begin{array}{l}\text { Oc Gr Sist } \\
\text { Antigo }\end{array}$ & \begin{tabular}{|l|} 
GRUPOCUP.CN \\
$\mathrm{V}$
\end{tabular} & caracter & 6 & $\begin{array}{l}\text { Código de ocupação da mãe conforme tabela do CBO (Código } \\
\text { Brasileiro de Ocupações). }\end{array}$ \\
\hline CODOCUPMAE & $\begin{array}{l}\text { Oc Subgrupo } \\
\text { Princ }\end{array}$ & GRUPO2.CNV & & & \\
\hline CODOCUPMAE & $\begin{array}{l}\text { Ocup Grande } \\
\text { Grupo }\end{array}$ & GRUPO1.CNV & & & \\
\hline CODOCUPMAE & $\begin{array}{l}\text { Ocup Sist } \\
\text { Antigo }\end{array}$ & OCUPA.CNV & & & \\
\hline CODOCUPMAE & $\begin{array}{l}\text { Ocup } \\
\text { Subgrupo 3d } \\
\end{array}$ & GRUPO3.CNV & & & \\
\hline CODOCUPMAE & $\begin{array}{l}\text { Ocupac Familia } \\
4 \mathrm{~d}\end{array}$ & GRUPO4.CNV & & & \\
\hline CODOCUPMAE & Ocupacao & CBO2002.CNV & & & \\
\hline QTDFILVIVO & \begin{tabular}{|l|} 
Filhos \\
Nasc.Vivos \\
\end{tabular} & FILTIDO.CNV & caracter & 2 & Número de filhos vivos \\
\hline QTDFILMORT & \begin{tabular}{|l|} 
Filhos \\
Nasc.Mortos \\
\end{tabular} & FILTIDO.CNV & caracter & 2 & Número de perdas fetais e abortos \\
\hline CODESTRES & & & caracter & 2 & Código da UF de residência \\
\hline CODMUNRES & $\begin{array}{l}\text { Capital } \\
\text { Residencia }\end{array}$ & CAPITAIS.CNV & caracter & 7 & Código do município de residência \\
\hline CODMUNRES & $\begin{array}{l}\text { Munic Resid- } \\
\text { AC } \\
\end{array}$ & MUNICAC.CNV & & & \\
\hline CODMUNRES & $\begin{array}{l}\text { Munic Resid- } \\
\text { AL }\end{array}$ & MUNICAL.CNV & & & \\
\hline CODMUNRES & $\begin{array}{l}\text { Munic Resid- } \\
\text { AM }\end{array}$ & $\begin{array}{l}\text { MUNICAM.CN } \\
\mathrm{V}\end{array}$ & & & \\
\hline CODMUNRES & $\begin{array}{l}\text { Munic Resid- } \\
\text { AP }\end{array}$ & MUNICAP.CNV & & & \\
\hline CODMUNRES & $\begin{array}{l}\text { Munic Resid- } \\
\text { BA }\end{array}$ & MUNICBA.CNV & & & \\
\hline CODMUNRES & $\begin{array}{l}\text { Munic Resid- } \\
\text { BR }\end{array}$ & MUNICBR.CNV & & & \\
\hline CODMUNRES & $\begin{array}{l}\text { Munic Resid- } \\
\text { CE }\end{array}$ & MUNICCE.CNV & & & \\
\hline CODMUNRES & $\begin{array}{l}\text { Munic Resid- } \\
\text { DF }\end{array}$ & MUNICDF.CNV & & & \\
\hline
\end{tabular}




\begin{tabular}{|c|c|c|c|c|c|}
\hline CODMUNRES & Munic Resid-ES & MUNICES.CNV & & & \\
\hline CODMUNRES & \begin{tabular}{|l} 
Munic Resid- \\
GO
\end{tabular} & $\begin{array}{l}\text { MUNICGO.CN } \\
\mathrm{V}\end{array}$ & & & \\
\hline CODMUNRES & $\begin{array}{l}\text { Munic Resid- } \\
\text { MA }\end{array}$ & \begin{tabular}{|l|} 
MUNICMA.CN \\
$\mathrm{V}$
\end{tabular} & & & \\
\hline CODMUNRES & $\begin{array}{l}\text { Munic Resid- } \\
\text { MG }\end{array}$ & \begin{tabular}{|l|} 
MUNICMG.CN \\
$\mathrm{V}$
\end{tabular} & & & \\
\hline CODMUNRES & $\begin{array}{l}\text { Munic Resid- } \\
\text { MS }\end{array}$ & $\begin{array}{l}\text { MUNICMS.CN } \\
\mathrm{V}\end{array}$ & & & \\
\hline CODMUNRES & $\begin{array}{l}\text { Munic Resid- } \\
\text { MT }\end{array}$ & $\begin{array}{l}\text { MUNICMT.CN } \\
\mathrm{V}\end{array}$ & & & \\
\hline CODMUNRES & $\begin{array}{l}\text { Munic Resid- } \\
\text { PA }\end{array}$ & MUNICPA.CNV & & & \\
\hline CODMUNRES & $\begin{array}{l}\text { Munic Resid- } \\
\text { PB }\end{array}$ & MUNICPB.CNV & & & \\
\hline CODMUNRES & $\begin{array}{l}\text { Munic Resid- } \\
\text { PE }\end{array}$ & MUNICPE.CNV & & & \\
\hline CODMUNRES & Munic Resid-PI & MUNICPI.CNV & & & \\
\hline CODMUNRES & $\begin{array}{l}\text { Munic Resid- } \\
\text { PR }\end{array}$ & MUNICPR.CNV & & & \\
\hline CODMUNRES & Munic Resid-RJ & MUNICRJ.CNV & & & \\
\hline CODMUNRES & $\begin{array}{l}\text { Munic Resid- } \\
\text { RN }\end{array}$ & MUNICRN.CNV & & & \\
\hline CODMUNRES & $\begin{array}{l}\text { Munic Resid- } \\
\text { RO }\end{array}$ & MUNICRO.CNV & & & \\
\hline CODMUNRES & $\begin{array}{l}\text { Munic Resid- } \\
\text { RR }\end{array}$ & MUNICRR.CNV & & & \\
\hline CODMUNRES & $\begin{array}{l}\text { Munic Resid- } \\
\text { RS }\end{array}$ & MUNICRS.CNV & & & \\
\hline CODMUNRES & $\begin{array}{l}\text { Munic Resid- } \\
\text { SC }\end{array}$ & MUNICSC.CNV & & & \\
\hline CODMUNRES & Munic Resid-SE & MUNICSE.CNV & & & \\
\hline CODMUNRES & Munic Resid-SP & MUNICSP.CNV & & & \\
\hline CODMUNRES & $\begin{array}{l}\text { Munic Resid- } \\
\text { TO }\end{array}$ & MUNICTO.CNV & & & \\
\hline CODMUNRES & Regiao Resid & REGIAO.CNV & & & \\
\hline CODMUNRES & & REGIAOC.CNV & & & \\
\hline CODMUNRES & UF Residencia & UF.CNV & & & \\
\hline CODMUNRES & & UFC.CNV & & & \\
\hline CODMUNRES & UF/Regiao & UFREG.CNV & & & \\
\hline BAIRES & & & caracter & 30 & Descrição do bairro de residência \\
\hline CODBAIRES & Bairro Res & $\begin{array}{l}\text { Criarumarquiv } \\
\text { oBAIRRO.DBF } \\
\end{array}$ & caracter & 8 & Código do bairro de residência \\
\hline ENDRES & & & caracter & 40 & Endereço de residência \\
\hline CODENDRES & $\begin{array}{l}\text { Logradouro } \\
\text { Res }\end{array}$ & LOGRAD.DBF & caracter & 12 & Código de endereço de residência \\
\hline COMPLRES & & & caracter & 20 & Complemento do endereço de residência \\
\hline NUMRES & & & caracter & 10 & Número do endereço de residência \\
\hline CEPRES & & & caracter & 9 & CEP da residência \\
\hline CODDISRES & & & caracter & 8 & Código do distrito de residência \\
\hline CODPAISRES & Pais Residencia & TABPAIS.CNV & caracter & 3 & Código do país de residência \\
\hline CODREGRES & & & caracter & 5 & Código da região de residência \\
\hline
\end{tabular}




\begin{tabular}{|c|c|c|c|c|c|}
\hline GESTACAO & $\begin{array}{l}\text { Duracao } \\
\text { Gestação }\end{array}$ & SEMANAS.CNV & caracter & 1 & $\begin{array}{l}\text { Semanas de gestação: } 1 \text { - Menos de } 22 \text { semanas; } 2-22 \text { a } 27 \\
\text { semanas; 3- } 28 \text { a } 31 \text { semanas; } 4-32 \text { a } 36 \text { semanas; 5- } 37 \text { a } 41 \\
\text { semanas; } 6-42 \text { semanas e mais; 9- Ignorado. }\end{array}$ \\
\hline GRAVIDEZ & $\begin{array}{l}\text { Tipo de } \\
\text { Gravidez }\end{array}$ & GRAVIDEZ.CNV & caracter & 1 & $\begin{array}{l}\text { Tipo de gravidez: 1- Única; 2- Dupla; 3- Tripla ou mais; 9- } \\
\text { Ignorado. }\end{array}$ \\
\hline PARTO & Tipo de Parto & PARTO.CNV & caracter & 1 & Tipo de parto: 1-Vaginal; 2-Cesário; 9- Ignorado \\
\hline CONSULTAS & Cons Pre-Natal & CONSULT.CNV & caracter & 1 & $\begin{array}{l}\text { Número de consultas de pré-natal. Valores: } 1-\text { Nenhuma; } 2-\text { de } \\
1 \text { a } 3 ; 3-\text { de } 4 \text { a } 6 ; 4-7 \text { e mais; } 9 \text { - Ignorado. }\end{array}$ \\
\hline CONSULTAS & Consultas & CONSULT.CNV & & & \\
\hline DTNASC & $\begin{array}{l}\text { Ano do } \\
\text { Nascimento }\end{array}$ & ANO.CNV & caracter & 8 & Data de nascimento: $\mathrm{dd} \mathrm{mm}$ aaaa \\
\hline DTNASC & \begin{tabular}{|l|} 
Mes do \\
Nascimento \\
\end{tabular} & MESES.CNV & & & \\
\hline HORANASC & Hora Nasc & $\begin{array}{l}\text { HORAOBITO.C } \\
\text { NV }\end{array}$ & caracter & 5 & Horário de nascimento \\
\hline SEXO & Sexo & SEXO.CNV & caracter & 1 & Sexo: M-Masculino; F-Feminino; I-ignorado \\
\hline SEXO & & SEXOC.CNV & & & \\
\hline APGAR1 & $\begin{array}{l}\text { Apgar 10 } \\
\text { Minuto }\end{array}$ & APGAR.CNV & caracter & 2 & Apgar no $1^{\circ}$ minuto \\
\hline APGAR5 & $\begin{array}{l}\text { Apgar 5음 } \\
\text { Minuto }\end{array}$ & APGAR.CNV & caracter & 2 & Apgar no 5ㅇ minuto \\
\hline RACACOR & $\begin{array}{l}\text { Raca Cor } \\
\text { Nascido } \\
\end{array}$ & RACA.CNV & caracter & 1 & $\begin{array}{l}\text { Tipo de raça e cor do nascido: 1- Branca; 2- Preta; 3- Amarela; } \\
\text { 4-Parda; 5- Indígena. }\end{array}$ \\
\hline PESO & Peso (6) & PESO1.CNV & caracter & 4 & Peso ao nascer em gramas. \\
\hline PESO & Peso ao Nascer & PESO.CNV & & & \\
\hline PESO & \begin{tabular}{|l|} 
Peso ao \\
Nascer(6) \\
\end{tabular} & PESO1.CNV & & & \\
\hline IDANOMAL & $\begin{array}{l}\text { Anomalia } \\
\text { detectada }\end{array}$ & $\begin{array}{l}\text { IDANOMAL.CN } \\
\mathrm{V}\end{array}$ & caracter & 1 & Anomalia identificada: 1-Sim; 2- Não; 9- Ignorado \\
\hline DTCADASTRO & $\begin{array}{l}\text { Mes do } \\
\text { Cadastro } \\
\end{array}$ & MESES.CNV & caracter & 8 & Data do cadastro da DN no sistema \\
\hline CONFPESO & & & caracter & 1 & |---------------- \\
\hline CODANOMAL & \begin{tabular}{|l} 
Anomal Agrup \\
1 \\
\end{tabular} & ECLAMC.CNV & caracter & 20 & Código da anomalia (CID 10) \\
\hline CODANOMAL & \begin{tabular}{|l} 
Anomal Agrup \\
2
\end{tabular} & ECLAMC.CNV & & & \\
\hline CODANOMAL & \begin{tabular}{|l} 
Anomal Agrup \\
3
\end{tabular} & ECLAMC.CNV & & & \\
\hline CODANOMAL & $\begin{array}{l}\text { Anomal Agrup } \\
4\end{array}$ & ECLAMC.CNV & & & \\
\hline CODANOMAL & $\begin{array}{l}\text { Anomal Agrup } \\
5\end{array}$ & ECLAMC.CNV & & & \\
\hline CODANOMAL & Anomalia 1 & CID1017.CNV & & & \\
\hline CODANOMAL & Anomalia 2 & CID1017.CNV & & & \\
\hline CODANOMAL & Anomalia 3 & CID1017.CNV & & & \\
\hline CODANOMAL & Anomalia 4 & CID1017.CNV & & & \\
\hline CODANOMAL & Anomalia 5 & CID1017.CNV & & & \\
\hline NUMEROLOTE & & & caracter & 8 & Número do lote \\
\hline CRITICA & & & caracter & 2 & |-------------------- \\
\hline CODINST & Instalacao & CODINST.CNV & caracter & 18 & $\begin{array}{l}\text { Código de configuração da instalação: - 10 caracter: nível de } \\
\text { instalação (M - municipal; R - regional; E - estadual); - 2ำ e } 3 \text { o } \\
\text { caracter: UF de instalação; - 4o ao 9o caracter: código do } \\
\text { município de instalação; - 10 ao 13o caracter: no da máquina }\end{array}$ \\
\hline
\end{tabular}




\begin{tabular}{|c|c|c|c|c|c|}
\hline & & & & & de instalação. \\
\hline CODINST & $\begin{array}{l}\text { Munic } \\
\text { instalacao } \\
\end{array}$ & MUNICBR.CNV & & & \\
\hline CODINST & Numero Micro & MICRO.CNV & & & \\
\hline VERSAOSIST & & & caracter & 7 & Versão do sistema \\
\hline RETROALIM & \begin{tabular}{|l|} 
Retroalimentac \\
ao
\end{tabular} & RETRO.CNV & caracter & 1 & $\begin{array}{l}\text { Status da Retroalimentação (R-indica que o registro foi } \\
\text { retroalimentado) }\end{array}$ \\
\hline DTRECEBIM & $\begin{array}{l}\text { Ano } \\
\text { Recebimento }\end{array}$ & ANO.CNV & caracter & 8 & Data do último recebimento do lote, dada pelo Sisnet. \\
\hline DTRECEBIM & $\begin{array}{l}\text { Mes } \\
\text { Recebimento }\end{array}$ & MESES.CNV & & & \\
\hline DIFDATA & & & caracter & 8 & $\begin{array}{l}\text { Diferença entre a data de óbito e data do recebimento original } \\
\text { da DO ([DTNASC] - [DTRECORIG]) }\end{array}$ \\
\hline DTRECORIG & $\begin{array}{l}\text { Ano 10 } \\
\text { Recebimento }\end{array}$ & ANO.CNV & caracter & 8 & Data do 19 recebimento do lote, dada pelo Sisnet. \\
\hline DTRECORIG & $\begin{array}{l}\text { Mes 1은 } \\
\text { Recebimento }\end{array}$ & MESES.CNV & & & \\
\hline NATURALMAE & & & caracter & 3 & $\begin{array}{l}\text { Se a mãe for estrangeira, constará o código do país de } \\
\text { nascimento. }\end{array}$ \\
\hline $\begin{array}{l}\text { CODMUNNAT } \\
U\end{array}$ & $\begin{array}{l}\text { Mun Natural } \\
\text { Mae }\end{array}$ & MUNICBR.CNV & caracter & 7 & Código do município de naturalidade da mãe \\
\hline CODUFNATU & $\begin{array}{l}\text { UF Natural } \\
\text { Mae }\end{array}$ & UFC.CNV & caracter & 2 & Código da UF de naturalidade da mãe \\
\hline ESCMAE2010 & $\begin{array}{l}\text { Esc Mae Serie } \\
\text { Concl }\end{array}$ & ESC2010.CNV & caracter & 1 & $\begin{array}{l}\text { Escolaridade 2010. Valores: } 0 \text { - Sem escolaridade; } 1 \text { - } \\
\text { Fundamental I (1a a 4ạ série); } 2 \text { - Fundamental II (5a a 8a série); } \\
3 \text { - Médio (antigo 2o Grau); } 4 \text { - Superior incompleto; } 5 \text { - } \\
\text { Superior completo; } 9 \text { - Ignorado. }\end{array}$ \\
\hline SERIESCMAE & & & caracter & 1 & Série escolar da mãe. Valores de 1 a 8. \\
\hline DTNASCMAE & & & caracter & 8 & Data de nascimento da mãe: $\mathrm{dd} \mathrm{mm}$ aaaa \\
\hline RACACORMAE & $\begin{array}{l}\text { Raca Cor da } \\
\text { Mae }\end{array}$ & RACA.CNV & caracter & 1 & $\begin{array}{l}\text { Tipo de raça e cor da mãe: 1- Branca; 2- Preta; 3- Amarela; 4- } \\
\text { Parda; 5- Indígena. }\end{array}$ \\
\hline QTDGESTANT & $\begin{array}{l}\text { Gest } \\
\text { Anteriores }\end{array}$ & GESTANT.CNV & caracter & 2 & Número de gestações anteriores \\
\hline QTDPARTNOR & $\begin{array}{l}\text { Partos Vag } \\
\text { Anter }\end{array}$ & PARTON.CNV & caracter & 2 & Número de partos vaginais \\
\hline QTDPARTCES & $\begin{array}{l}\text { N Cesareas } \\
\text { Anter }\end{array}$ & PARTON.CNV & caracter & 2 & Número de partos cesáreos \\
\hline NOMEPAI & & & caracter & 70 & Nome do pai \\
\hline IDADEPAI & Idade do Pai & IDADEPAI.CNV & caracter & 2 & Idade do pai \\
\hline DTULTMENST & & & caracter & 8 & Data da última menstruação (DUM): dd mm aaaa \\
\hline SEMAGESTAC & $\begin{array}{l}\text { Semanas Gest } \\
\text { Detalh }\end{array}$ & $\begin{array}{l}\text { SEMADUM.CN } \\
\mathrm{V}\end{array}$ & caracter & 2 & Número de semanas de gestação. \\
\hline TPMETESTIM & $\begin{array}{l}\text { Metodo } \\
\text { Estimar }\end{array}$ & $\begin{array}{l}\text { TPMETODO.C } \\
\text { NV }\end{array}$ & caracter & 2 & $\begin{array}{l}\text { Método utilizado. Valores: 1- Exame físico; 2- Outro método; } \\
\text { 9- Ignorado. }\end{array}$ \\
\hline CODCRM & & & caracter & 10 & Código do CRM do médico. \\
\hline MESPRENAT & $\begin{array}{l}\text { Mes } 1 \underline{a} \\
\text { Consulta }\end{array}$ & MEGEST.CNV & caracter & 2 & Mês de gestação em que iniciou o pré-natal \\
\hline TPAPRESENT & & & caracter & 2 & $\begin{array}{l}\text { Tipo de apresentação do RN. Valores: 1- Cefálico; 2- Pélvica ou } \\
\text { podálica; 3- Transversa; 9- Ignorado. }\end{array}$ \\
\hline STTRABPART & & & caracter & 1 & $\begin{array}{l}\text { Trabalho de parto induzido? Valores: 1-Sim; 2- Não; 3- Não } \\
\text { se aplica; 9- Ignorado. }\end{array}$ \\
\hline STCESPARTO & $\begin{array}{l}\text { Cesarea Ocorr } \\
\text { TParto }\end{array}$ & STPARTO.CNV & caracter & 1 & $\begin{array}{l}\text { Cesárea ocorreu antes do trabalho de parto iniciar? Valores: 1- } \\
\text { Sim; 2- Não; 3- Não se aplica; 9- Ignorado. }\end{array}$ \\
\hline TPNASCASSI & Nasc Assistido & TPASSIST.CNV & caracter & 2 & Nascimento foi assistido por? Valores: 1- Médico; 2- \\
\hline
\end{tabular}




\begin{tabular}{|c|c|c|c|c|c|}
\hline & & & & & Enfermeira/obstetriz; 3- Parteira; 4- Outros; 9- Ignorado. \\
\hline NOMERNASC & & & caracter & 70 & Nome do recém-nascido \\
\hline NOMERESPO & & & caracter & 70 & Nome do responsável pelo preenchimento \\
\hline TPFUNCRESP & & & caracter & 1 & $\begin{array}{l}\text { Tipo de função do responsável pelo preenchimento. Valores: } \\
\text { 1- Médico; 2- Enfermeiro; 3- Parteira; 4- Funcionário do } \\
\text { cartório; 5- Outros. }\end{array}$ \\
\hline DSFUNCRESP & & & caracter & 70 & $\begin{array}{l}\text { Descrição da função do responsável pelo preenchimento, se a } \\
\text { função for "5-Outros". }\end{array}$ \\
\hline CODPROF & & & caracter & 15 & Código da profissão, se a função for " 5 - Outros". \\
\hline PROFISSION & & & caracter & 70 & Nome do Profissional, se a função for "5-Outros". \\
\hline COREN & & & caracter & 60 & Nome do profissional enfermeiro \\
\hline CODCOREN & & & caracter & 8 & Código do COREN \\
\hline TPDOCRESP & & & caracter & 1 & $\begin{array}{l}\text { Tipo do documento do responsável. Valores: 1-CNES; 2-CRM; 3- } \\
\text { COREN; 4-RG; 5-CPF. }\end{array}$ \\
\hline NUDOCRESP & & & caracter & 20 & Número do documento do responsável pelo preenchimento. \\
\hline CONSPRENAT & $\begin{array}{l}\text { Consultas } \\
\text { Detalh }\end{array}$ & $\begin{array}{l}\text { SEMADUM.CN } \\
\text { V }\end{array}$ & caracter & 2 & Número de consultas pré-natal \\
\hline ORGEMISSOR & & & caracter & 20 & $\begin{array}{l}\text { Descrição do órgão emissor do documento do responsável pelo } \\
\text { preenchimento. }\end{array}$ \\
\hline DTDECLARAC & & & caracter & 8 & Data da declaração: dd mm aaaa \\
\hline ESCMAEAGR1 & $\begin{array}{l}\text { Esc Mae } \\
\text { Agregegado }\end{array}$ & ESCAGR1.CNV & caracter & 2 & $\begin{array}{l}\text { Escolaridade } 2010 \text { agregada. Valores: } 00 \text { - Sem Escolaridade; } \\
01 \text { - Fundamental I Incompleto; } 02 \text { - Fundamental I Completo; } \\
03 \text { - Fundamental II Incompleto; } 04 \text { - Fundamental II } \\
\text { Completo; } 05 \text { - Ensino Médio Incompleto; } 06 \text { - Ensino Médio } \\
\text { Completo; } 07 \text { - Superior Incompleto; } 08 \text { - Superior Completo; } \\
09 \text { - Ignorado; } 10 \text { - Fundamental I Incompleto ou Inespecífico; } \\
11 \text { - Fundamental II Incompleto ou Inespecífico; } 12 \text { - Ensino } \\
\text { Médio Incompleto ou Inespecífico. }\end{array}$ \\
\hline ESCMAEAGR2 & & & caracter & 2 & |------------------- \\
\hline TPROBSON & $\begin{array}{l}\text { Monitor } \\
\text { cesarea }\end{array}$ & ROBSON.CNV & caracter & 2 & Código do Grupo de Robson, gerado pelo sistema \\
\hline STDNEPIDEM & $\begin{array}{l}\text { DN } \\
\text { epidemiologica }\end{array}$ & DNNOVA.CNV & caracter & 1 & Status de DO Epidemiológica. Valores: 1 - SIM; 0 - NÃO. \\
\hline STDNNOVA & $\begin{array}{l}\text { DN novo } \\
\text { modelo }\end{array}$ & DNNOVA.CNV & caracter & 1 & Status de DO Nova. Valores: 1 - SIM; 0 - NÃO. \\
\hline
\end{tabular}


Anexo D

Exemplo da Declaração de Óbito 


\section{República Federativa do Brasil \\ Ministćrio da Saúde}

$1^{*}$ VIA - SECRETARIA DE SAÚUE

\section{Declaração de Óbito}

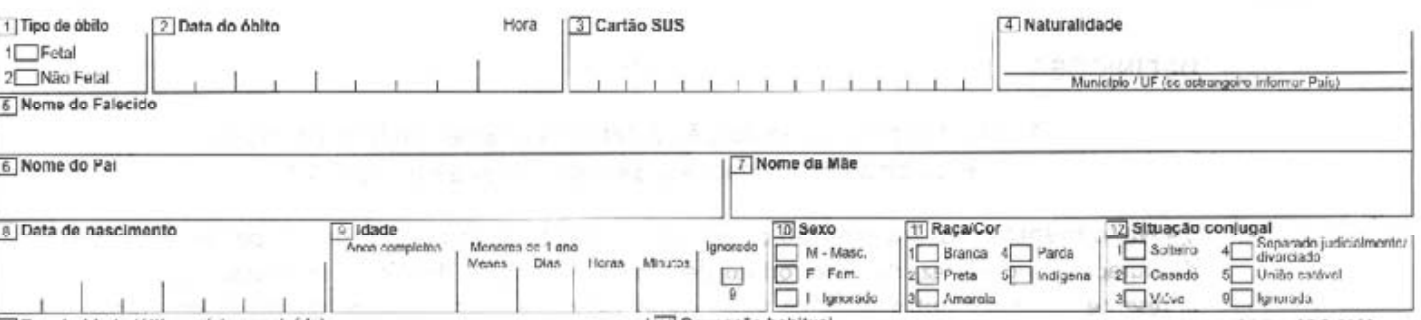

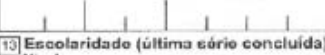

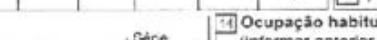

al Sem eqcoigrivade

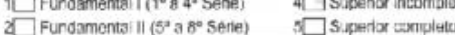

in Logradouro (rua, praça, avenida, etc)

\section{[rol Lucel de ucontûncia do óbito}

$\left.\right|_{1} ^{\cos 90}$

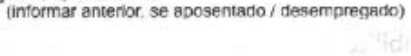

Enstabulocimento

\section{Municipio de residéncia}

Nömero

Compiemanto [16]CEP

Uutros estab sauce $4 \square$ via pubica on indigen

Endoroço do ocorróncia (rua, praça, svenlids, ete)

24 Bairro/Distrito Código 25 Municipio dẹ ocorrència

REENCHIMENTO EXCLUSIVO PARA ÓBITOS FETAIS E DE MENORES DE 1 ANO - INFORMACCOES SOBREAMÅE

20. Idado
(ans)

20. Escolaridado (ultima Eörio concluida)
Nivel
$\square$ Siem esconaricace

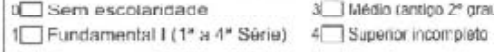

$2 \square$ Fundamental II ( $5^{\circ}$ a $8^{\circ}$ Sorio) $5 \square$ Superior competo

IV

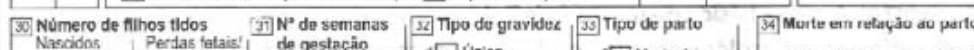

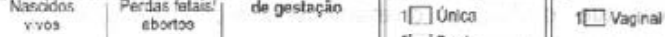

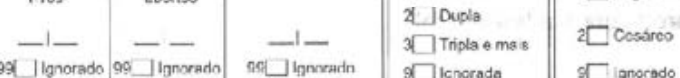

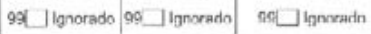

OBITO DE MULHER EM IDADE FERTIL

27 A morto ocorrou

$1 \square$ Na gravidez $3 \square$ No abortamento

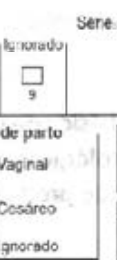

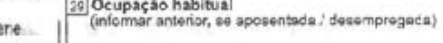

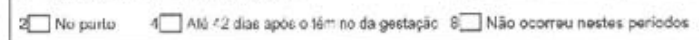

$1 \square$ Antes $2 \square$ Duranto

COSSgO CNES

(40) CALUSAS DA MORTE

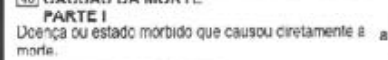

causas antecedentes

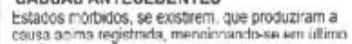

thar oc

ANOTE SOMENTE UM DIAGNOSTICO POR LNHA

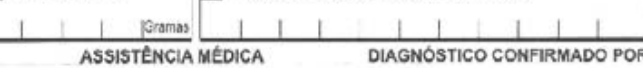

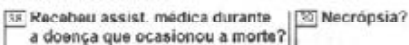

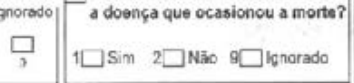

$1 \square$ Sim $2 \square$ Nao $9 \square$ ignoraco

PARTE II

Outras conndiḉes sionificativas que contribuirar para a mototo, c que näo entraram, portm, na

11) Nome do Médico

b) Devido ou esmo congequéncia de:
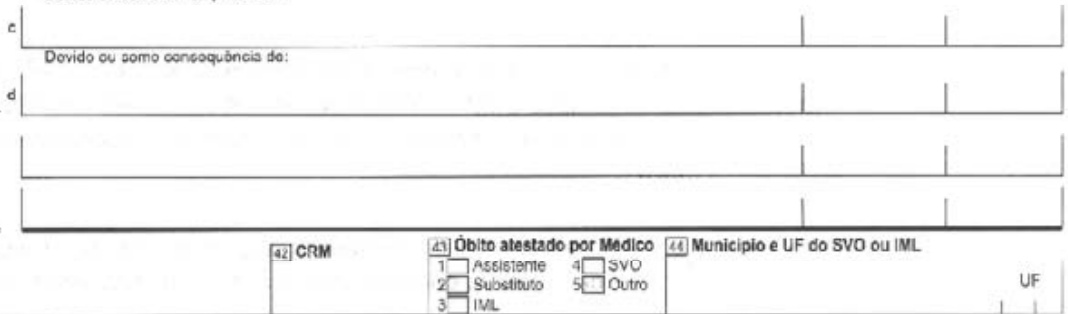

Meio de contato (telefone, fax, e-mall, etc.)

Dota do atestado Substituto 5 Outro

Tempo aproximado
entve o inlcio da
dosençut es a murts

PROVAVEIS CIRCUNSTANCIAS DE MORTE NAO NATURAL fintormacoes de carater estrtitemente epidemiologico)

[40 Tipo

$1 \square$ Moidonto
$2 \square$ sueics

${ }_{4}^{3} \square$ Homicidio

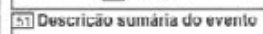

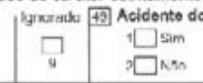

lynou ade 国 Fonte de informaçäo
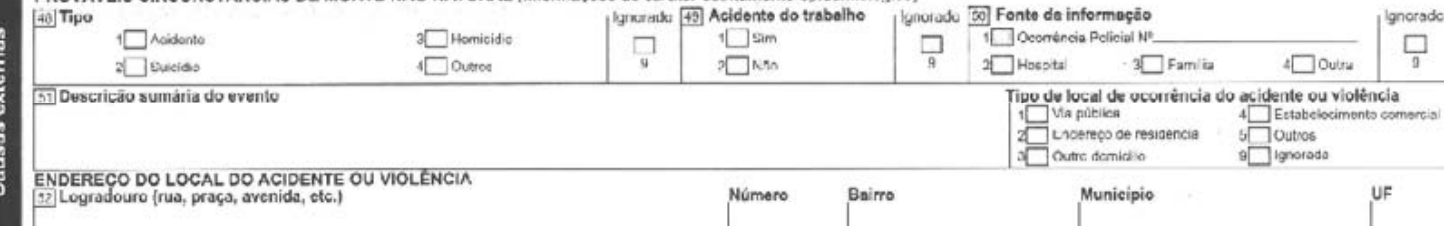

ENDERECO DO LOCAL DO ACIDENTE OU VIOLENCIA
9. Logrodouro (rus, praça, avenida, ete.)

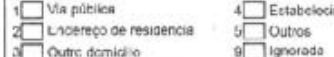

Anexo II

Modelo de Declaração de Nascidos Vivos - DN

(à Resoluçăo SS-, de de outubro de 2014)

casa 


\section{Anexo E}

\section{Variáveis do SIM}

O dicionário de dados com as especificações das variáveis também está disponível no seguinte endereço:

- SIM - DO: http://svs.aids.gov.br/download/Dicionario_de_Dados_SIM_tabela_DO.pdf 


\section{TABELA: DO}

Os campos pintados em azul são campos novos da declaração de óbitos (DO)

\begin{tabular}{|c|c|c|c|c|c|}
\hline $\begin{array}{l}\text { Nome da coluna no } \\
\text { arquivo DBF }\end{array}$ & $\begin{array}{c}\text { Nome da variáveis no } \\
\text { Tabwin }\end{array}$ & $\begin{array}{l}\text { Nome do arquivo } \\
\text { CNV }\end{array}$ & Tipo & Tam & Descrição \\
\hline NUMERODO & ------------ & ------------ & Caracter & 8 & Número da DO \\
\hline NUMERODV & ------------ & ------------ & Caracter & 1 & Número do Dígito Verificador \\
\hline CODESTCART & ------------ & ------------ & Caracter & 7 & Código da UF do cartório \\
\hline CODMUNCART & ----------- & ---------- & Caracter & 7 & Código do município do cartório \\
\hline CODCART & ----------- & ------------ & Caracter & 8 & Código do cartório \\
\hline NUMREGCART & ----------- & ----------- & Caracter & 8 & Número do registro do cartório \\
\hline DTREGCART & ----------- & ----------- & Caracter & 8 & Data do registro do cartório: $\mathrm{dd} \mathrm{mm}$ aaaa \\
\hline TIPOBITO & Tipo Óbito & TIPOBITO.CNV & Caracter & 1 & Tipo do óbito: 1 - fetal; 2- não fetal. \\
\hline \multirow{2}{*}{ DTOBITO } & Ano do Óbito & ANO.CNV & \multirow{2}{*}{ Caracter } & \multirow{2}{*}{8} & \multirow{2}{*}{ Data do óbito: dd mm aaaa } \\
\hline & Mês do Óbito & MESES.CNV & & & \\
\hline HORAOBITO & ---------- & ----------- & Caracter & 5 & Horário do óbito \\
\hline NUMSUS & 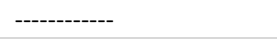 & 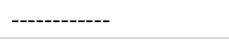 & Caracter & 15 & Número do cartão SUS \\
\hline \multirow[t]{2}{*}{ NATURAL } & Naturalidade & NATURAL.CNV & \multirow{2}{*}{ Caractere } & \multirow{2}{*}{3} & \multirow{2}{*}{ Naturalidade } \\
\hline & Naturalidade & NAT1212.CNV & & & \\
\hline NOME & ----------- & ------------ & Caracter & 50 & Nome do falecido \\
\hline NOMEPAI & ------------ & ------------ & Caracter & 45 & Nome do pai do falecido \\
\hline NOMEMAE & ------------ & ------------ & Caracter & 45 & Nome da mãe do falecido \\
\hline DTNASC & ----------- & ----------- & Caracter & 8 & Data do nascimento: dd mm aaaa \\
\hline \multirow{8}{*}{ IDADE } & Faixa Etária (13) & FXIDADP.CNV & \multirow{8}{*}{ Caracter } & \multirow{8}{*}{3} & \multirow{8}{*}{$\begin{array}{l}\text { Idade: composto de dois subcampos. O primeiro, de } 1 \text { dígito, indica } \\
\text { a unidade da idade, conforme a tabela a seguir. O segundo, de dois } \\
\text { dígitos, indica a quantidade de unidades: } 0 \text { - Idade menor de } 1 \\
\text { hora, o subcampo varia de } 01 \text { e } 59 ; 1 \text { - Hora, o subcampo varia de } \\
01 \text { a } 23 ; 2 \text { - Dias, o subcampo varia de } 01 \text { a } 29 ; 3 \text { - Meses, o } \\
\text { subcampo varia de } 01 \text { a } 11 ; 4 \text { - Anos, o subcampo varia de } 00 \text { a } 99 \text {; } \\
\text { 5-Anos (mais de } 100 \text { anos), o segundo subcampo varia de } 0 \text { a } 99 \text {. }\end{array}$} \\
\hline & Faixa Etária (5) & FXIDAD5.CNV & & & \\
\hline & Faixa Etária (9) & FXIDAD9.CNV & & & \\
\hline & Faixa Etária OMS & FXIDAWHO.CNV & & & \\
\hline & Faixa Etária pad(5-5) & FXIDADP5.CNV & & & \\
\hline & Fx.Etar.Infant.1 & FXINFAN1.CNV & & & \\
\hline & Fx.Etar.Infant.2 & FXINFAN2.CNV & & & \\
\hline & Idade Detalhada & IDADE.CNV & & & \\
\hline SEXO & Sexo & SEXOC.CNV & Caracter & 1 & Sexo: M-masculino; F-feminino; I ignorado. \\
\hline RACACOR & Raça/Cor & RACA.CNV & Caracter & 1 & Raça: 1 - Branca; 2 - Preta; 3 - Amarela; 4 - Parda; 5 -Indígena. \\
\hline ESTCIV & Estado Civil & ESTCIV.CNV & Caracter & 1 & $\begin{array}{l}\text { Situação conjugal: } 1 \text { - Solteiro; } 2 \text { - Casado; } 3 \text { - Viúvo; } 4 \text { - Separado } \\
\text { judicialmente/divorciado; } 5 \text { - União estável; } 9 \text { - Ignorado. }\end{array}$ \\
\hline ESC & Grau de Instrução & INSTRUC.CNV & Caracter & 1 & $\begin{array}{l}\text { Escolaridade em anos. Valores: } 1 \text { - Nenhuma; } 2 \text { - de } 1 \text { a } 3 \text { anos; } 3 \text { - } \\
\text { de } 4 \text { a } 7 \text { anos; } 4 \text { - de } 8 \text { a } 11 \text { anos; } 5 \text { - } 12 \text { anos e mais; } 9 \text { - Ignorado. }\end{array}$ \\
\hline \multirow{7}{*}{ OCUP } & Oc Gr Sist Antigo & GRUPOCUP.CNV & \multirow{7}{*}{ Caracter } & \multirow{7}{*}{6} & \multirow{7}{*}{ Ocupação habitual e ramo de atividade } \\
\hline & Oc Subgrupo Princ & GRUPO2.CNV & & & \\
\hline & Ocup Grande Grupo & GRUPO1.CNV & & & \\
\hline & Ocup Sist Antigo & OCUPA.CNV & & & \\
\hline & Ocup Subgrupo 3d & GRUPO3.CNV & & & \\
\hline & Ocupac Familia 4d & GRUPO4.CNV & & & \\
\hline & Ocupacao & CBO2002.CNV & & & \\
\hline CODESTRES & ---------- & ----------- & Caracter & 7 & Código da UF de residência \\
\hline \multirow{4}{*}{ CODMUNRES } & Capital Res & CAPITAIS.CNV & \multirow{4}{*}{ Caracter } & \multirow{4}{*}{7} & \multirow{4}{*}{ Código do município de residência } \\
\hline & Munic Res - BRA & MUNICBR.CNV & & & \\
\hline & Munic Resid - AC & MUNICAC.CNV & & & \\
\hline & Munic Resid - AL & MUNICAL.CNV & & & \\
\hline
\end{tabular}




\begin{tabular}{|c|c|c|c|c|c|}
\hline & Munic Resid - AM & MUNICAM.CNV & & & \\
\hline & Munic Resid - AP & MUNICAP.CNV & & & \\
\hline & Munic Resid - BA & MUNICBA.CNV & & & \\
\hline & Munic Resid - CE & MUNICCE.CNV & & & \\
\hline & Munic Resid - ES & MUNICES.CNV & & & \\
\hline & Munic Resid - GO & MUNICGO.CNV & & & \\
\hline & Munic Resid - MA & MUNICMA.CNV & & & \\
\hline & Munic Resid - MG & MUNICMG.CNV & & & \\
\hline & Munic Resid - MS & MUNICMS.CNV & & & \\
\hline & Munic Resid - MT & MUNICMT.CNV & & & \\
\hline & Munic Resid - PA & MUNICPA.CNV & & & \\
\hline & Munic Resid - PB & MUNICPB.CNV & & & \\
\hline & Munic Resid - PE & MUNICPE.CNV & & & \\
\hline & Munic Resid - PI & MUNICPI.CNV & & & \\
\hline & Munic Resid - PR & MUNICPR.CNV & & & \\
\hline & Munic Resid - RJ & MUNICRJ.CNV & & & \\
\hline & Munic Resid - RN & MUNICRN.CNV & & & \\
\hline & Munic Resid - RO & MUNICRO.CNV & & & \\
\hline & Munic Resid - RR & MUNICRR.CNV & & & \\
\hline & Munic Resid - RS & MUNICRS.CNV & & & \\
\hline & Munic Resid - SC & MUNICSC.CNV & & & \\
\hline & Munic Resid - SE & MUNICSE.CNV & & & \\
\hline & Munic Resid - SP & MUNICSP.CNV & & & \\
\hline & Munic Resid - TO & MUNICTO.CNV & & & \\
\hline & Regiao Res & REGIAO.CNV & & & \\
\hline & RegMetr Res-BR & REGIAOC.CNV & & & \\
\hline & UF Res Sigla & RMETRBR.CNV & & & \\
\hline & UF Resid & UFC.CNV & & & \\
\hline & UF Resid/Regiao & UFREG.CNV & & & \\
\hline & UF Residencia & UFC.CNV & & & \\
\hline & UF/Regiao & UFREG.CNV & & & \\
\hline BAIRES & ----------- & ----------- & Caracter & 30 & Bairro de residência \\
\hline CODBAIRES & ----------- & ----------- & Caracter & 8 & Código do bairro de residência \\
\hline CODENDRES & ------------ & ------------ & Caracter & 12 & Código do endereço de residência \\
\hline ENDRES & |----------- & ------------ & Caracter & 40 & Endereço de residência \\
\hline CODREGRES & ----------- & ---------- & Caracter & 7 & Código da região de residência \\
\hline NUMRES & |----------- & ------------ & Caracter & 10 & Número da residência \\
\hline COMPLRES & |----------- & ------------ & Caracter & 40 & Complemento da residência \\
\hline CEPRES & ------------ & ------------ & Caracter & 8 & Código de endereçamento postal \\
\hline CODDISRES & |----------- & ------------ & Caracter & 8 & Código do distrito de residência \\
\hline CODPAISRES & ----------- & ----------- & Caracter & 8 & Código do país de residência \\
\hline LOCOCOR & Local Ocorrencia & LOCOCOR.CNV & Caracter & 1 & $\begin{array}{l}\text { Local de ocorrência do óbito: } 1 \text { - hospital; } 2 \text { - outros } \\
\text { estabelecimentos de saúde; } 3 \text { - domicílio; } 4 \text { - via pública; } 5 \text { - } \\
\text { outros; } 9 \text {-ignorado. }\end{array}$ \\
\hline \multirow{3}{*}{ CODESTAB } & Esfera Adm 2006 & ESFERA.cnv & \multirow{3}{*}{ Caracter } & \multirow{3}{*}{8} & \multirow{3}{*}{ Código de estabelecimento } \\
\hline & Estab Saude 2006 & ESTAB06.CNV & & & \\
\hline & Natur Organiz 2006 & NAT_ORG.CNV & & & \\
\hline CODESTOCOR & ----------- & ---------- & Caracter & 7 & Código de estabelecimento de ocorrência \\
\hline \multirow{2}{*}{ CODMUNOCOR } & Capital Ocor & CAPITAIS.CNV & \multirow{2}{*}{ Caracter } & \multirow{2}{*}{8} & \multirow{2}{*}{ Código do município de ocorrência } \\
\hline & Munic Ocor - BRA & MUNICAC.CNV & & & \\
\hline
\end{tabular}




\begin{tabular}{|c|c|c|c|c|c|}
\hline & Munic Ocorr - AC & MUNICAL.CNV & & & \\
\hline & Munic Ocorr - AL & MUNICAM.CNV & & & \\
\hline & Munic Ocorr - AM & MUNICAP.CNV & & & \\
\hline & Munic Ocorr - AP & MUNICBA.CNV & & & \\
\hline & Munic Ocorr - BA & MUNICBR.CNV & & & \\
\hline & Munic Ocorr - CE & MUNICCE.CNV & & & \\
\hline & Munic Ocorr - ES & MUNICGO.CNV & & & \\
\hline & Munic Ocorr - GO & MUNICMA.CNV & & & \\
\hline & Munic Ocorr - MA & MUNICMG.CNV & & & \\
\hline & Munic Ocorr - MG & MUNICMS.CNV & & & \\
\hline & Munic Ocorr - MS & MUNICMT.CNV & & & \\
\hline & Munic Ocorr - MT & MUNICPA.CNV & & & \\
\hline & Munic Ocorr - PA & MUNICPB.CNV & & & \\
\hline & Munic Ocorr - PB & MUNICPE.CNV & & & \\
\hline & Munic Ocorr - PE & MUNICPI.CNV & & & \\
\hline & Munic Ocorr - PI & MUNICPR.CNV & & & \\
\hline & Munic Ocorr - PR & MUNICRJ.CNV & & & \\
\hline & Munic Ocorr - RJ & MUNICRN.CNV & & & \\
\hline & Munic Ocorr - RN & MUNICRO.CNV & & & \\
\hline & Munic Ocorr - RO & MUNICRR.CNV & & & \\
\hline & Munic Ocorr - RR & MUNICRS.CNV & & & \\
\hline & Munic Ocorr - RS & MUNICSC.CNV & & & \\
\hline & Munic Ocorr - SC & MUNICSE.CNV & & & \\
\hline & Munic Ocorr - SE & MUNICSP.CNV & & & \\
\hline & Munic Ocorr - SP & MUNICTO.CNV & & & \\
\hline & Munic Ocorr - TO & REGIAO.CNV & & & \\
\hline & Regiao Ocor & REGIAOC.CNV & & & \\
\hline & RegMetr Ocor-BR & RMETRBR.CNV & & & \\
\hline & UF Ocor & UF.CNV & & & \\
\hline BAIOCOR & ----------- & ----------- & Caracter & 20 & Bairro de ocorrência \\
\hline CODBAIOCOR & ----------- & ----------- & Caracter & 8 & Código do bairro de ocorrência \\
\hline ENDOCOR & ----------- & ----------- & Caracter & 20 & Endereço de ocorrência \\
\hline CODENDOCOR & ----------- & ----------- & Caracter & 12 & Código do endereço de ocorrência \\
\hline CODREGOCOR & ----------- & ------------ & Caracter & 7 & Código da região de ocorrência \\
\hline NUMENDOCOR & ----------- & ----------- & Caracter & 10 & Número do endereço de ocorrência \\
\hline COMPLOCOR & ---------- & ---------- & Caracter & 10 & Complemento do endereço de ocorrência \\
\hline CEPOCOR & |----------- & ------------ & Caracter & 8 & CEP do endereço de ocorrência \\
\hline CODDISOCOR & |--------- & ----------- & Caracter & 8 & Código do distrito de ocorrência \\
\hline IDADEMAE & Idade Mãe & IDADEMA.CNV & Caracter & 2 & Idade da mãe \\
\hline ESCMAE & Escolaridade Mãe & INSTRUC.CNV & Caracter & 1 & $\begin{array}{l}\text { Escolaridade em anos. Valores: } 1 \text { - Nenhuma; } 2 \text { - de } 1 \text { a } 3 \text { anos; } 3 \text { - } \\
\text { de } 4 \text { a } 7 \text { anos; } 4 \text { - de } 8 \text { a } 11 \text { anos; } 5 \text { - } 12 \text { anos e mais; } 9 \text { - Ignorado. }\end{array}$ \\
\hline OCUPMAE & Ocupação Mãe & CBO2002.CNV & Caracter & 6 & Ocupação da mãe \\
\hline QTDFILVIVO & Filhos Vivos & FILTIDO.CNV & Caracter & 2 & Número de filhos vivos \\
\hline QTDFILMORT & Filhos Mortos & FILTIDO.CNV & Caracter & 2 & Número de filhos mortos \\
\hline GRAVIDEZ & Gravidez & GRAVIDEZ.CNV & Caracter & 1 & $\begin{array}{l}\text { Informar o tipo de gravidez: } 1 \text { - única; } 2 \text { - dupla; } 3 \text { - tripla e mais; } 9 \\
\text { - ignorada. }\end{array}$ \\
\hline GESTACAO & Semanas Gestação & SEMANAS.CNV & Caracter & 1 & $\begin{array}{l}\text { Faixa de semanas de gestação: } 1 \text { - Menos } 22 \text { semanas; } 2-22 \text { a } 27 \\
\text { semanas; } 3-28 \text { a } 31 \text { semanas; } 4-32 \text { a } 36 \text { semanas; } 5-37 \text { a } 41 \\
\text { semanas; } 6-42 \text { e + semanas. }\end{array}$ \\
\hline PARTO & Tipo Parto & PARTO.CNV & Caracter & 1 & Informar o tipo de parto: 1 - vaginal; 2 - cesáreo; 9 -ignorado. \\
\hline OBITOPARTO & Obito Parto & OPARTO.CNV & Caracter & 1 & $\begin{array}{l}\text { Informar como foi a morte em relação ao parto: } 1 \text { - antes; } 2 \text { - } \\
\text { durante; } 3 \text { - depois; } 9 \text { - Ignorado. }\end{array}$ \\
\hline PESO & Peso Nascer & PESO.CNV & Caracter & 4 & Peso ao nascer em gramas \\
\hline NUMERODN & ---------- & ----------- & Caracter & 8 & Número da Declaração de Nascido Vivo \\
\hline OBITOGRAV & Obito na Gravidez & OBITOGRA.CNV & Caracter & 1 & Óbito na gravidez: 1 - sim; 2 - não; 9 -ignorado. \\
\hline
\end{tabular}




\begin{tabular}{|c|c|c|c|c|c|}
\hline OBITOPUERP & Obito no Puerp & OBITOPUE.CNV & Caracter & 1 & $\begin{array}{l}\text { Óbito no puerpério: } 1 \text { - Sim, até } 42 \text { dias após o parto; } 2 \text { - Sim, de } \\
43 \text { dias a } 1 \text { ano; } 3 \text { - Não; } 9 \text { - Ignorado. }\end{array}$ \\
\hline ASSISTMED & Assist Medica & ASSMEDIC.CNV & Caracter & 1 & Assistência médica: 1 - sim; 2 - não; 9 -ignorado. \\
\hline EXAME & Exame complem & EXAME.CNV & Caracter & 1 & Exame: 1 - sim; 2 - não; 9 -ignorado. \\
\hline CIRURGIA & Cirurgia & CIRURGIA.CNV & Caracter & 1 & Cirurgia: 1 - sim; 2 - não; 9 - ignorado. \\
\hline NECROPSIA & Necropsia & NECROPS.CNV & Caracter & 1 & $\begin{array}{l}\text { Confirmação do diagnóstico por necrópsia: } 1 \text { - sim; } 2 \text { - não; } 9 \text { - } \\
\text { ignorado. }\end{array}$ \\
\hline LINHAA & 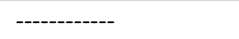 & ----------- & Caracter & 20 & CIDs informados na Linha A da DO \\
\hline LINHAB & ----------- & ------------ & Caracter & 20 & CIDs informados na Linha B da DO \\
\hline LINHAC & ------------ & ----------- & Caracter & 20 & CIDs informados na Linha C da DO \\
\hline LINHAD & ----------- & ----------- & Caracter & 20 & CIDs informados na Linha D da DO \\
\hline LINHAII & ----------- & ----------- & Caracter & 30 & CIDs informados na Parte II da DO \\
\hline DSTEMPO & ------------ & ----------- & Caracter & 10 & Tempo de duração dos CIDs informados \\
\hline \multirow{36}{*}{ CAUSABAS } & Acid transp GRP & actragrp.CNV & \multirow{36}{*}{ Caracter } & \multirow{36}{*}{4} & \multirow{36}{*}{ Causa básica da DO } \\
\hline & C nao Codificadas & CAUSABRA.CNV & & & \\
\hline & Causa (Cap CID10) & CID10CAC.CNV & & & \\
\hline & ----------- & CID10CAP.CNV & & & \\
\hline & Causa (CID10 3C) & CID10_3D.CNV & & & \\
\hline & Causa (CID10 BR) & CID10_BR.CNV & & & \\
\hline & ----------- & CID10BR.CNV & & & \\
\hline & Causa (CID10 CAP) & CID10CAP.CNV & & & \\
\hline & causa inval & cinvalid.cnv & & & \\
\hline & Causas Determin & CID10L.CNV & & & \\
\hline & Causas presumiveis & CAUPRESU.CNV & & & \\
\hline & CID10 4C Cap 01 & CID10_01.CNV & & & \\
\hline & CID10 4C Cap 02 & CID10_02.CNV & & & \\
\hline & CID10 4C Cap 03 & CID10_03.CNV & & & \\
\hline & CID10 4C Cap 04 & CID10_04.CNV & & & \\
\hline & CID10 4C Cap 05 & CID10_05.CNV & & & \\
\hline & CID10 4C Cap 06 & CID10_06.CNV & & & \\
\hline & CID10 4C Cap 07 & CID10_07.CNV & & & \\
\hline & CID10 4C Cap 08 & CID10_08.CNV & & & \\
\hline & CID10 4C Cap 09 & CID10_09.CNV & & & \\
\hline & CID10 4C Cap 10 & CID10_10.CNV & & & \\
\hline & CID10 4C Cap 11 & CID10_11.CNV & & & \\
\hline & CID10 4C Cap 12 & CID10_12.CNV & & & \\
\hline & CID10 4C Cap 13 & CID10_13.CNV & & & \\
\hline & CID10 4C Cap 14 & CID10_14.CNV & & & \\
\hline & CID10 4C Cap 15 & CID10_15.CNV & & & \\
\hline & CID10 4C Cap 16 & CID10_16.CNV & & & \\
\hline & CID10 4C Cap 17 & CID10_17.CNV & & & \\
\hline & CID10 4C Cap 18 & CID10_18.CNV & & & \\
\hline & CID10 4C Cap 20 & CID10_20.CNV & & & \\
\hline & D Isquem Coracao & ISQUEM.CNV & & & \\
\hline & Homicidios & HOMICID.CNV & & & \\
\hline & Imunopreviniveis & CAUMEN.CNV & & & \\
\hline & Neoplasias & NEOPLA.CNV & & & \\
\hline & Presumiveis & caupresu0509.cnv & & & \\
\hline & Suicidios & SUICID.CNV & & & \\
\hline DSEXPLICA & ------------ & ------------ & Caracter & 20 & Descrição da explicação das regras de seleção da causa básica \\
\hline MEDICO & ------------ & 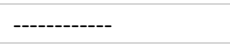 & Caracter & 10 & Nome do médico \\
\hline CRM & ---------- & ----------- & Caracter & 15 & № do CRM \\
\hline TPASSINA & ---------- & ----------- & Caracter & 1 & ---------- \\
\hline CONTATO & ----------- & ----------- & Caracter & 10 & Meio de contato do atestante (telefone, fax, email etc.). \\
\hline DTATESTADO & ----------- & ----------- & Caracter & 8 & Data do atestado: dd mm aaaa \\
\hline CIRCOBITO & Tipo de Violencia & TIPOVIOL.CNV & Caracter & 1 & $\begin{array}{l}\text { Indicar qual foi a provável circunstância de morte não natural: } 1 \text { - } \\
\text { acidente; } 2 \text {-suicídio; } 3 \text {-homicídio; } 4 \text { - outros; } 9 \text {-ignorado. }\end{array}$ \\
\hline
\end{tabular}




\begin{tabular}{|c|c|c|c|c|c|}
\hline ACIDTRAB & Acid Trabalho & ACIDTRAB.CNV & Caracter & 1 & Indicar se foi acidente de trabalho: 1 - sim; 2 - não; 9 - ignorado. \\
\hline FONTE & Fonte Informac & FONTINFO.CNV & Caracter & 1 & $\begin{array}{l}\text { Indicar a fonte da informação, conforme a tabela: } 1 \text { - boletim de } \\
\text { ocorrência; } 2 \text { - hospital; } 3 \text {-família; } 4 \text { - outra; } 9 \text {-ignorado. }\end{array}$ \\
\hline DSEVENTO & ------------ & ----------- & Caracter & 10 & Descrição sumária do acidente \\
\hline ENDACID & ----------- & ------------ & Caracter & 10 & Endereço do acidente \\
\hline NUMEROLOTE & ----------- & ----------- & Caracter & 8 & Número do lote \\
\hline TPPOS & Obito investigado & INVESTIG.CNV & Caracter & 1 & Óbito investigado: 1 - sim; 2 - não. \\
\hline DTINVESTIG & Mes de Investigac & MESES.CNV & Caracter & 8 & Data da investigação: $\mathrm{dd} \mathrm{mm}$ aaaa \\
\hline LINHAA_O & ----------- & ----------- & Caracter & 20 & CIDs informados, originalmente, na Linha A da DO. \\
\hline LINHAB_O & ------------ & ----------- & Caracter & 20 & CIDs informados, originalmente, na Linha B da DO. \\
\hline LINHAC_O & ---------- & ---------- & Caracter & 20 & CIDs informados, originalmente, na Linha C da DO. \\
\hline LINHAD_O & ----------- & ----------- & Caracter & 20 & CIDs informados, originalmente, na Linha D da DO. \\
\hline LINHAII_O & ----------- & --1---- & Caracter & 20 & CIDs informados, originalmente, na Parte II da DO. \\
\hline \multirow{2}{*}{ CAUSABAS_O } & Causa Orig Capit & CID10CAP.CNV & \multirow{2}{*}{ Caracter } & \multirow{2}{*}{4} & \multirow{2}{*}{ Causa básica Original } \\
\hline & Causa Original & CID10_3D.CNV & & & \\
\hline \multirow{2}{*}{ DTCADASTRO } & Ano do Cadastro & ANO.CNV & \multirow{2}{*}{ Caracter } & \multirow{2}{*}{8} & \multirow{2}{*}{ Data do cadastro: $\mathrm{dd} \mathrm{mm}$ aaaa } \\
\hline & Mes do Cadastro & MESES.CNV & & & \\
\hline ATESTANTE & Medico Atest & ATESTANT.CNV & Caracter & 1 & $\begin{array}{l}\text { Indica se o médico que assina atendeu o paciente: } 1 \text { - Sim; } 2 \text { - } \\
\text { Substituto; } 3 \text {-IML; } 4 \text {-SVO; } 5 \text { - Outros. }\end{array}$ \\
\hline DESCACID & ----------- & ----------- & Caracter & 20 & Descrição do acidente \\
\hline CODENDACID & ----------- & ----------- & Caracter & 6 & Código de endereço do acidente \\
\hline NUMENDACID & ----------- & ----------- & Caracter & 6 & Número do endereço do acidente \\
\hline COMPLACID & ---------- & ----------- & Caracter & 20 & Complemento do endereço onde ocorreu o acidente \\
\hline CEPACID & ----------- & ----------- & Caracter & 8 & CEP do endereço do acidente \\
\hline CONFPESO & ---------- & ----------- & Caracter & 1 & ---------- \\
\hline CONFIDADE & ----------- & ----------- & Caracter & 1 & ------------ \\
\hline CONFCAUSA & ---------- & ----------- & Caracter & 1 & ----------- \\
\hline CONFCIDADE & ---------- & ---------- & Caracter & 1 & ---------- \\
\hline CRITICA & ----------- & ----------- & Caracter & 2 & ----------- \\
\hline \multirow{5}{*}{ CODINST } & Instalacao & CODINST.CNV & Caracter & \multirow{5}{*}{18} & \multirow{5}{*}{ 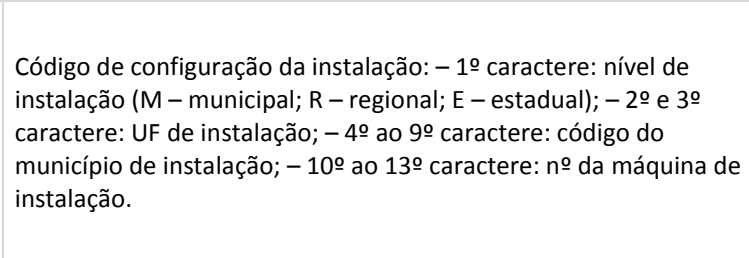 } \\
\hline & Munic Instal & MUNICBR.CNV & & & \\
\hline & Municlnst 1172 & MUNICBRd.CNV & & & \\
\hline & Numero Micro & MICRO.CNV & & & \\
\hline & UF Instal & UFC.CNV & & & \\
\hline STCODIFICA & Com Codificador & CODIFICA.CNV & Caracter & 1 & Status de instalação: se codificadora (valor: S) ou não (valor: N) \\
\hline CODIFICADO & Codificado & CODIFICADO.CNV & Caracter & 1 & Se estiver codificado (valor: S) ou não (valor: N) \\
\hline VERSAOSIST & Versão Sistema & VERSAO.CNV & Caracter & 7 & Versão do sistema \\
\hline VERSAOSCB & Versão SCB & VERSCB.CNV & Caracter & 7 & Versão do seletor de causa básica \\
\hline RETROALIM & Retroalimentacao & RETRO.CNV & Caracter & 1 & Retroalimentação \\
\hline FONTEINV & Fonte Investig & FONTEINV.CNV & Caracter & 8 & $\begin{array}{l}\text { Fonte de investigação. Valores: } 1 \text { - Comitê de Morte Materna e/ou } \\
\text { Infantil; } 2 \text { - Visita domiciliar / Entrevista família; } 3 \text { - } \\
\text { Estabelecimento de Saúde / Prontuário; } 4 \text { - Relacionado com } \\
\text { outros bancos de dados; } 5 \text {-S V 0; 6-I M L; } 7 \text { - Outra fonte; } 8 \text { - } \\
\text { Múltiplas fontes; } 9 \text { - Ignorado. }\end{array}$ \\
\hline \multirow[t]{3}{*}{ DTRECEBIM } & Ano do recebimento & ANO.CNV & \multirow{3}{*}{ Caracter } & \multirow{3}{*}{8} & \multirow{3}{*}{ Data do recebimento: $\mathrm{dd} \mathrm{mm}$ aaaa } \\
\hline & Dia do recebimento & DIAS.CNV & & & \\
\hline & Mes do recebimento & MESES.CNV & & & \\
\hline ATESTADO & ------------ & ------------ & Caracter & 50 & CIDs informado no atestado \\
\hline \multirow{2}{*}{ CAUSABAS_R } & Causa (Cap CID10 R) & CID10CAC.CNV & \multirow{2}{*}{ Caracter } & \multirow{2}{*}{4} & \multirow{2}{*}{ Causa básica resselecionada } \\
\hline & Causa (CID10 3C R) & CID10_3DN.CNV & & & \\
\hline
\end{tabular}




\begin{tabular}{|c|c|c|c|c|c|}
\hline & Causa (CID10 BR R) & CID10_BR.CNV & & & \\
\hline & Causa (CID10CAP R) & CID10CAP.CNV & & & \\
\hline \multirow{3}{*}{ DTRESSELE } & Ano Resselecao & ANO.CNV & \multirow{3}{*}{ Caracter } & \multirow{3}{*}{8} & \multirow{3}{*}{ Data da resseleção: $\mathrm{dd} \mathrm{mm}$ aaaa } \\
\hline & DIA Resselecao & DIAS.CNV & & & \\
\hline & Mes Resselecao & MESES.CNV & & & \\
\hline STRESSELE & StatusRessel S N & SIMNAO.CNV & Caracter & 1 & Status da resseleção: 1 - sim; 2 - não. \\
\hline EXPLICA_R & ----------- & ----------- & Caracter & 50 & Explicação das regras de resseleção de causa básica \\
\hline VRSRESSELE & Versão Resselec & VERSCB.CNV & Caracter & 7 & Versão de resseleção \\
\hline NRESSELE & --------- & ---------- & Caracter & 50 & Descrição da explicação da não resseleção da causa básica. \\
\hline COMPARA_CB & & RESEL1.CNV & Caracter & 8 & $\begin{array}{l}\text { Compara causa básica resselecionada com a informada. Valores: } \\
\text { IGUAL, DIFER. }\end{array}$ \\
\hline \multirow[t]{4}{*}{ CB_PRE } & Causa(Cap CID10pre) & CID10CAC.CNV & Caracter & 4 & Causa básica informada antes da resseleção (NRESSELE) \\
\hline & Causa(CID10 BRpre) & CID10_BR.CNV & & & \\
\hline & Causa(CID103C pre) & CID10_3D.CNV & & & \\
\hline & Causa(CID10CAPpre) & CID10CAP.CNV & & & \\
\hline NPROC & Motivo N RESSELEC & NPROC.CNV & Caracter & 2 & $\begin{array}{l}\text { Códigos da explicação da não resseleção da causa básica. Valores: } \\
1 \text { - Depende de perguntas; } 2 \text { - Causa externa; } 3 \text { - Procedimento } \\
\text { médico; } 4 \text { - Causa básica por CID de paralisia; } 5 \text { - Regra F; } 6 \text { - CID } \\
\text { temporário não pode ser causa básica. }\end{array}$ \\
\hline \multirow[t]{2}{*}{ DIFDATA } & Dias obt 10 receb & difdata.cnv & Caracter & 8 & $\begin{array}{l}\text { Diferença entre a data de óbito e data do recebimento original da } \\
\text { DO ([DTOBITO] - [DTRECORIG]) }\end{array}$ \\
\hline & Oport notif (30d) & dias_notif.cnv & & & \\
\hline VERSCBPRE & Versão Scb_Pre & VERSCB.CNV & Caracter & 7 & Versão do SCB da resseleção \\
\hline \multirow{3}{*}{ DTRECORIG } & Ano 1 - Recebimento & ANO.CNV & \multirow{3}{*}{ Caracter } & \multirow{3}{*}{8} & \multirow{3}{*}{ Data do recebimento original: $\mathrm{dd} \mathrm{mm}$ aaaa } \\
\hline & Dia 1 을 Recebimento & DIAS.CNV & & & \\
\hline & Mes 1 을 Recebimento & MESES.CNV & & & \\
\hline ESC2010 & Escol series & ESCSERIE.CNV & Caracter & 1 & $\begin{array}{l}\text { Escolaridade 2010. Valores: } 0 \text { - Sem escolaridade; } 1 \text { - Fundamenta } \\
\text { I (1 } 1 \text { a } 4 \text { a série); } 2 \text { - Fundamental II ( } 5 \text { a a } 8 \text { a série); } 3 \text { - Médio } \\
\text { (antigo 20 Grau); } 4 \text { - Superior incompleto; } 5 \text { - Superior completo; } 9 \\
\text { - Ignorado. }\end{array}$ \\
\hline SERIESCFAL & ----------- & ----------- & Caracter & 1 & Série escolar do falecido. Valores de 1 a 8. \\
\hline ESCMAE2010 & Esc Mae series & ESCSERIE.CNV & Caracter & 1 & $\begin{array}{l}\text { Escolaridade 2010. Valores: } 0 \text { - Sem escolaridade; } 1 \text { - Fundamental } \\
\text { I (1a a 4a série); } 2 \text { - Fundamental II (5a a } 8 \text { a série); } 3 \text { - Médio } \\
\text { (antigo 20 Grau); } 4 \text { - Superior incompleto; } 5 \text { - Superior completo; } 9 \\
\text { - Ignorado. }\end{array}$ \\
\hline SERIESCMAE & ------------ & ---------- & Caracter & 1 & Série escolar da mãe. Valores de 1 a 8. \\
\hline SEMAGESTAC & Gestac Detalhada & SGESTAC.CNV & Caracter & 3 & Semanas de gestação \\
\hline TPMORTEOCO & Ob Mulher id Fert & TPMORTEOCO & Caracter & 1 & $\begin{array}{l}\text { Informar quando a morte ocorreu: } 1 \text { - na gravidez; } 2 \text { - no parto; } 3 \\
\text { - no aborto; } 4 \text { - até } 42 \text { dias após o parto; } 5 \text { - de } 43 \text { dias a } 1 \text { ano } \\
\text { após o parto; } 8 \text { - não ocorreu nestes períodos; } 9 \text { - ignorado. }\end{array}$ \\
\hline COMUNSVOIM & Munic IML/SVO & MUNICBR.CNV & Caracter & 7 & Código do município do SVO ou do IML \\
\hline CODMUNNATU & Munic Naturalid & MUNICBR.CNV & Caracter & 7 & Código do município de naturalidade do falecido \\
\hline \multirow{2}{*}{ CAUSAMAT } & Causa mat Associada & ST_MAT.CNV & \multirow{2}{*}{ Caracter } & \multirow{2}{*}{4} & \multirow{2}{*}{ Causa externa associada a uma causa materna } \\
\hline & Matern Assoc C Ext & CAUSAMAT.CNV & & & \\
\hline
\end{tabular}




\begin{tabular}{|c|c|c|c|c|c|}
\hline ESCMAEAGR1 & Esc Mae ser agreg & ESCAGR1.CNV & Caracter & 2 & $\begin{array}{l}\text { Escolaridade } 2010 \text { agregada. Valores: } 00 \text { - Sem Escolaridade; } 01 \text { - } \\
\text { Fundamental I Incompleto; } 02 \text { - Fundamental I Completo; } 03 \text { - } \\
\text { Fundamental II Incompleto; } 04 \text { - Fundamental II Completo; } 05 \text { - } \\
\text { Ensino Médio Incompleto; } 06 \text { - Ensino Médio Completo; } 07 \text { - } \\
\text { Superior Incompleto; } 08 \text { - Superior Completo; } 09 \text { - Ignorado; } 10 \text { - } \\
\text { Fundamental I Incompleto ou Inespecífico; } 11 \text { - Fundamental II } \\
\text { Incompleto ou Inespecífico; } 12 \text { - Ensino Médio Incompleto ou } \\
\text { Inespecífico. }\end{array}$ \\
\hline ESCMAEAGR2 & ------------ & ------------ & Caracter & 1 & $\begin{array}{l}\text { Escolaridade em anos. Valores: } 1 \text { - Nenhuma; } 2 \text { - de } 1 \text { a } 3 \text { anos; } 3- \\
\text { de } 4 \text { a } 7 \text { anos; } 4 \text { - de } 8 \text { a } 11 \text { anos; } 5 \text { - } 12 \text { anos e mais; } 9 \text { - Ignorado. }\end{array}$ \\
\hline ESCFALAGR1 & Escol series agreg & ESCAGR1.CNV & Caracter & 2 & $\begin{array}{l}\text { Escolaridade } 2010 \text { agregada. Valores: } 00 \text { - Sem Escolaridade; } 01 \text { - } \\
\text { Fundamental I Incompleto; } 02 \text { - Fundamental I Completo; } 03 \text { - } \\
\text { Fundamental II Incompleto; } 04 \text { - Fundamental II Completo; } 05 \text { - } \\
\text { Ensino Médio Incompleto; } 06 \text { - Ensino Médio Completo; } 07 \text { - } \\
\text { Superior Incompleto; } 08 \text { - Superior Completo; } 09 \text { - Ignorado; } 10 \text { - } \\
\text { Fundamental I Incompleto ou Inespecífico; } 11 \text { - Fundamental II } \\
\text { Incompleto ou Inespecífico; } 12 \text { - Ensino Médio Incompleto ou } \\
\text { Inespecífico. }\end{array}$ \\
\hline ESCFALAGR2 & ------------ & ------------ & Caracter & 1 & $\begin{array}{l}\text { Escolaridade em anos. Valores: } 1 \text { - Nenhuma; } 2 \text { - de } 1 \text { a } 3 \text { anos; } 3- \\
\text { de } 4 \text { a } 7 \text { anos; } 4 \text { - de } 8 \text { a } 11 \text { anos; } 5 \text { - } 12 \text { anos e mais; } 9 \text { - Ignorado. }\end{array}$ \\
\hline STDOEPIDEM & DO epidemiologica & DONOVA.CNV & Caracter & 1 & Status de DO Epidemiológica. Valores: 1 - SIM; 0 - NÃO. \\
\hline STDONOVA & DO novo modelo & DONOVA.CNV & Caracter & 1 & Status de DO Nova. Valores: 1 - SIM; 0 - NÃO. \\
\hline
\end{tabular}


Anexo F

Variáveis da DNDO 


\begin{tabular}{|c|c|c|c|}
\hline Nome do campo & Tipo & Tamanho & Descrição \\
\hline 1 NUDN & Duplo & 8 & Número de identificação \\
\hline 2 NUDO & Duplo & 8 & Número de identificação \\
\hline 2 LOCNASC & Texto & 1 & Local de nascimento: 1 - Hospital; 2 - Outros estabelecimentos de saúde; 3 - Domicílio; 4 - Outros \\
\hline 3 CODMUNNASC & Texto & 6 & Código do Município de nascimento (IBGE) \\
\hline 4 CODESTAB & Duplo & 8 & Código do Estabelecimento de Saúde \\
\hline 5 ESFERA & Texto & 10 & Público; Privado \\
\hline 6 DTNASCMAE & Data/Hora & 8 & Data de nascimento da mãe \\
\hline 7 IDADEMAE & Duplo & & Idade da mãe \\
\hline 8 NATURALMAE & Duplo & 8 & Se a mãe for estrangeira, constará o código do país de nascimento. \\
\hline 9 DESNATURAL & Texto & 102 & Nome do país de país de nascimento da mãe \\
\hline 10 ESTCIVMAE & Texto & 1 & $\begin{array}{l}\text { Código do estado civil da mãe: 1- Solteira; 2- Casada; 3-Viuva; 4- Separada; 5- Uniao Estavel; 9- } \\
\text { Ign. }\end{array}$ \\
\hline 11 DESESTCIVMAE & Texto & 102 & Descrição do estado civil da mãe \\
\hline 12 RACACORMAE & Texto & 1 & Código da raça e cor da mãe: 1- Branca; 2- Preta; 3-Amarela; 4- Parda; 5- Indígena. \\
\hline 13 DESRACACORMAE & Texto & 102 & Descrição do tipo de raça e cor da mãe \\
\hline 14 ESCMAE2010 & Texto & 1 & $\begin{array}{l}\text { Código de Escolaridade 2010. Valores: } 0 \text { - Sem escolaridade; } 1 \text { - Fundamental I ( } 1^{\mathrm{a}} \text { a } 4^{\mathrm{a}} \text { série); } 2 \text { - } \\
\text { Fundamental II (5 a a } 8^{\mathrm{a}} \text { série); } 3 \text { - Médio (antigo } 2^{\circ} \text { Grau); } 4 \text { - Superior incompleto; } 5 \text { - Superior } \\
\text { completo; } 9 \text { - Ignorado }\end{array}$ \\
\hline 15 DESESCMAE2010 & Texto & 102 & Descrição da escolaridade \\
\hline 16 CODPAISRES & Duplo & 8 & Código do país de residência \\
\hline 17 CODMUNRES & Texto & 6 & Código do município de residência (IBGE) \\
\hline 18 GESTACAO & Texto & 1 & $\begin{array}{l}\text { Semanas de gestação: } 1-\text { Menos de } 22 \text { semanas; } 2-22 \text { a } 27 \text { semanas; } 3-28 \text { a } 31 \text { semanas; } 4-32 \text { a } \\
36 \text { semanas; } 5-37 \text { a } 41 \text { semanas; } 6-42 \text { semanas e mais; } 9 \text { - Ignorado. }\end{array}$ \\
\hline 19 GRAVIDEZ & Texto & 1 & Código do tipo de gravidez: 1- Única; 2- Dupla; 3- Tripla ou mais; 9- Ignorado \\
\hline 20 DESGRAVIDEZ & Texto & 102 & Descrição do tipo de gravidez \\
\hline 21 PARTO & Texto & 1 & Código do tipo de parto: 1-Vaginal; 2- Cesário; 9- Ignorado \\
\hline 22 DESPARTO & Texto & 102 & Descrição do tipo de parto \\
\hline 23 CONSULTAS & Texto & 1 & $\begin{array}{l}\text { Número de consultas de pré-natal. Valores: } 1-\text { Nenhuma; } 2-\text { de } 1 \text { a 3; 3- de } 4 \text { a 6; } 4-7 \text { e mais; 9- } \\
\text { Ignorado }\end{array}$ \\
\hline 24 DTNASC & Data/Hora & 8 & Data do nascimento \\
\hline 25 HORANASC & Texto & 10 & Horário de nascimento \\
\hline 26 SEXO & Texto & 1 & Sexo: M - Masculino; F - Feminino; I - ignorado \\
\hline 27 APGAR1 & Duplo & 8 & Índice Apgar $1^{\circ}$ minuto \\
\hline 28 APGAR5 & Duplo & 8 & Índice Apgar $5^{\circ}$ minuto \\
\hline 29 PESO & Duplo & 8 & Peso ao nascer em gramas. \\
\hline 30 IDANOMAL & Texto & 1 & Anomalia identificada: 1- Sim; 2- Não; 9- Ignorado \\
\hline 31 CODBAINASC & Duplo & 8 & Código do bairro de nascimento (distrito admnistrativo/PMSP) \\
\hline 32 CODBAIRES & Duplo & 8 & Código do bairro de residência (distrito admnistrativo/PMSP) \\
\hline 33 DTULTMENST & Data/Hora & 8 & Data da ultima menstruação \\
\hline 34 QTDGESTANT & Duplo & 8 & Número de gestações anteriores \\
\hline 35 QTDPARTNOR & Duplo & 8 & Número de partos vaginais \\
\hline 36 QTDPARTCES & Duplo & 8 & Número de partos cesáreos \\
\hline 37 TPMETESTIM & caracter & & 2 Método utilizado. Valores: 1- Exame físico; 2- Outro método;9- Ignorado. \\
\hline 38 TPMTESTIM2 & Texto & 1 & Método utilizado Valores: 1- Exame físico; 2- Outro método; 3- DUM; 9- Ignorado \\
\hline 39 DESTPMETESTIM2 & Texto & 102 & Descrição do Método utilizado no campo TPMTESTIM2 \\
\hline 40 ANONASC & Texto & 4 & Ano de nascimento do RN \\
\hline
\end{tabular}




\begin{tabular}{|c|c|c|c|c|}
\hline Nome do campo & Tipo & Tamanho & Descrição & \\
\hline 41 ANODUM & Texto & 4 & Ano da última mestruação & \\
\hline 42 ANONASCMAE & Texto & 4 & Ano de nascimento da mãe & \\
\hline 43 CONSPRENAT & Duplo & 8 & Número de consultas pré-natal & \\
\hline 44 QTDFILVIVO & Duplo & 8 & Número de filhos vivos & \\
\hline 45 QTDFILMORT & Duplo & 8 & Número de perdas fetais e abortos & \\
\hline 46 MESPRENAT & Duplo & 8 & Mês de gestação em que iniciou o pré-natal & \\
\hline 47 TPAPRESENT & Texto & 2 & $\begin{array}{l}\text { Tipo de apresentação do RN. Valores: 1- Cefálico; 2- Pélvica ou podálica; 3- Transversa; 9- } \\
\text { Ignorado }\end{array}$ & \\
\hline 48 STTRABPART & Texto & 1 & Trabalho de parto induzido? Valores: 1- Sim; 2- Não; 3- Não se aplica; 9- Ignorado & \\
\hline 49 STCESPARTO & Texto & 1 & $\begin{array}{l}\text { Cesárea ocorreu antes do trabalho de parto iniciar? Valores: 1- Sim; 2- Não; 3- Não se aplica; 9- } \\
\text { Ignorado }\end{array}$ & \\
\hline 50 TPNASCASSI & Texto & 2 & $\begin{array}{l}\text { Nascimento foi assistido por? Valores: 1- Médico; 2- Enfermeira/obstetriz; 3- Parteira; 4- Outros; } \\
\text { 9- Ignorado }\end{array}$ & \\
\hline 51 TPROBSON & Texto & 2 & $\begin{array}{l}\text { 01- Nulíparas com feto único, cefálico, } \geq 37 \text { semanas, em trabalho de parto espontâneo } \\
\text { 02- Nulíparas com feto único, cefálico, } \geq 37 \text { semanas, cujo parto é induzido ou que são } \\
\text { submetidas à cesárea antes do início do trabalho de parto } \\
\text { 03- Multíparas sem cesárea anterior, com feto único, cefálico, } \geq 37 \text { semanas, em trabalho de parto } \\
\text { espontâneo } \\
\text { 04- Multíparas sem cesárea anterior, com feto único, cefálico, } \geq 37 \text { semanas, cujo parto é induzido } \\
\text { ou que são submetidas à cesárea antes do início do trabalho de parto } \\
\text { 05- Todas multíparas com pelo menos uma cesárea anterior, com feto único, cefálico, } \geq 37 \\
\text { semanas } \\
\text { 06- Todas nulíparas com feto único em apresentação pélvica } \\
\text { 07- Todas multíparas com feto único em apresentação pélvica, incluindo aquelas com cesárea(s) } \\
\text { anterior(es) } \\
\text { 08- Todas mulheres com gestação múltipla, incluindo aquelas com cesárea(s) anterior(es) } \\
\text { 09- Todas gestantes com feto em apresentação transversa ou oblíqua, incluindo aquelas com } \\
\text { cesárea(s) anterior(es) } \\
\text { 10- Todas gestantes com feto único e cefálico, }<37 \text { semanas, incluindo aquelas com cesárea(s) } \\
\text { anterior(es) }\end{array}$ & $\begin{array}{l}\text { Grupos } 1 \text { a } 4 \text { - maior chance de parto } \\
\text { vaginal; } \\
\text { Grupo } 5 \text { - alguma chance de parto } \\
\text { vaginal } \\
\text { Grupos } 6 \text { a } 10 \text { - menor chance de parto } \\
\text { vaginal }\end{array}$ \\
\hline 52 DIASGESTAC & Inteiro longo & 4 & Dias de gestação: DTNASC - DTULTMENST, em dias & \\
\hline 53 DPGP & Inteiro longo & 4 & Dias potencias de gravidez perdidos: [(DTNASC - DTULTMENST)em dias -280] & \\
\hline 54 SEMAGESTAC & Inteiro & 2 & Número de semanas de gestação & \\
\hline 55 SEMAGESTAC_SPGP & Inteiro longo & 4 & Semanas potencias de gravidez perdidos: Número de semanas de gestação - 40 semanas & \\
\hline 56 TPOBITO & Texto & 1 & Tipo do óbito: 1 - fetal; 2 - não fetal. & \\
\hline 57 HORAOBITO & Texto & 10 & Horário do óbito & \\
\hline 58 SEXO_DO & Texto & 1 & Sexo do falecido: M - Masculino; F - Feminino; I - ignorado & \\
\hline 59 DTOBITO & Texto & 10 & Data do óbito & \\
\hline 60 ANOBITO & Texto & 4 & Ano do óbito & \\
\hline
\end{tabular}




\begin{tabular}{|c|c|c|c|}
\hline ID Nome do campo & Tipo & Tamanho & Descrição \\
\hline 61 IDADE & Duplo & 8 & $\begin{array}{l}\text { Idade: composto de dois subcampos. O primeiro, de } 1 \text { dígito, indica a unidade da idade, conforme } \\
\text { a tabela } \\
\text { a seguir. O segundo, de dois dígitos, indica a quantidade de unidades: } 0 \text { - Idade menor de } 1 \text { hora, } \\
\text { o } \\
\text { subcampo varia de } 01 \text { e } 59 ; 1 \text { - Hora, o subcampo varia de } 01 \text { a } 23 ; 2 \text { - Dias, o subcampo varia de } \\
01 \text { a 29; } \\
3 \text { - Meses, o subcampo varia de } 01 \text { a } 11 ; 4 \text { - Anos, o subcampo varia de } 00 \text { a 99; } 5 \text { - Anos (mais de } \\
100 \\
\text { anos), o segundo subcampo varia de } 0 \text { a } 99 \text {. }\end{array}$ \\
\hline 62 TP_IDADE & Duplo & 8 & $\begin{array}{l}\text { Primeiro caracter que indica a unidade da idade: } 0 \text { : minutos; } 1 \text { : horas; } 2 \text { : dias; } 3 \text { : meses; } 4 \text { : anos; } 5 \text { : } \\
\text { centenário. }\end{array}$ \\
\hline 63 TP_IDADE2 & Duplo & 8 & Segundo e terceiro caracter da idade que indica quantidade \\
\hline 64 OBITOPARTO & Texto & 1 & Informar como foi a morte em relação ao parto: 1 - antes; 2 - durante; 3 - depois; 9 - Ignorado. \\
\hline 65 OBITOGRAV & Texto & 1 & Óbito na gravidez: 1 - sim; 2 - não; 9 - ignorado \\
\hline 66 OBITOPUERP & Texto & 1 & $\begin{array}{l}\text { Óbito no puerpério: } 1 \text { - Sim, até } 42 \text { dias após o parto; } 2 \text { - Sim, de } 43 \text { dias a } 1 \text { ano; } 3 \text { - Não; } 9 \text { - } \\
\text { Ignorado. }\end{array}$ \\
\hline 67 TPMORTEOCO & Texto & 1 & $\begin{array}{l}\text { Informar quando a morte ocorreu: } 1 \text { - na gravidez; } 2 \text { - no parto; } 3 \text { - no aborto; } 4 \text { - até } 42 \text { dias } \\
\text { após o } \\
\text { parto; } 5 \text { - de } 43 \text { dias a } 1 \text { ano após o parto; } 8 \text { - não ocorreu nestes períodos; } 9 \text { - ignorado. }\end{array}$ \\
\hline 68 CAUSABAS & Texto & 4 & Causa básica da DO \\
\hline 69 ATESTADO & Texto & 100 & CIDs informado no atestado \\
\hline 70 CIDMATERNA & Texto & 4 & Causa externa associada a uma causa materna \\
\hline 71 NMSUBCAT & Texto & 4 & Descrição da causa básica (subcategoria) \\
\hline 72 NMCAT & Texto & 100 & Descrição da causa básica (categoria) \\
\hline 73 NM_GRP & Texto & 100 & Descrição da causa básica (grupo) \\
\hline 74 NMCAPABR & Texto & 100 & Descrição da causa básica (capítulo) \\
\hline 75 CODESTAB_DO & Texto & 7 & Código do Estabelecimento de Saúde do óbito \\
\hline 76 LOCOCOR & Texto & 1 & Local de ocorrência do óbito: 1 - hospital; pública; 5 outros; 9 - ignorado. \\
\hline 77 CODMUNRES_DO & Texto & 6 & Código do Município de nascimento (IBGE) do óbito \\
\hline 78 CODBAIRES_DO & Duplo & 8 & Código do bairro de residência (distrito admnistrativo/PMSP) do óbito \\
\hline 79 CODMUNOCOR & Texto & 6 & Código do Município de nascimento (IBGE) do óbito \\
\hline 80 CODBAIOCOR & Duplo & 8 & Código do bairro de ocorrência (distrito admnistrativo/PMSP) do óbito \\
\hline
\end{tabular}




\section{Bibliografia}

[AVH04] Grigoris Antoniou and Frank Van Harmelen. A semantic web primer. MIT press, 2004. 13,15

[BCG $\left.{ }^{+} 18\right]$ Gintaras Barisevičius, Martin Coste, David Geleta, Damir Juric, Mohammad Khodadadi, Giorgos Stoilos and Ilya Zaihrayeu. Supporting digital healthcare services using semantic web technologies. In International Semantic Web Conference, pages 291-306. Springer, 2018. 29, 30, 31

[BGB $\left.{ }^{+} 16\right]$ CR Bauer, T Ganslandt, B Baum, J Christoph, I Engel, M Löbe, S Mate, S Stäubert, J Drepper, H-U Prokosch, A Winter and Sax U. Integrated data repository toolkit (IDRT). a suite of programs to facilitate health analytics on heterogeneous medical data. Methods of information in medicine, 55(02):125-135, 2016. 6

[BHBL09] Christian Bizer, Tom Heath and Tim Berners-Lee. Linked data - the story so far. International journal on semantic web and information systems, 5(3):1-22, 2009. 1,12

[BL06] Tim Berners-Lee. Linked data, 2006. https://www.w3.org/DesignIssues/ LinkedData.html, 2006. 1, 11, 12, 14

[BLFM98] Tim Berners-Lee, Roy T. Fielding and Larry Masinter. Uniform resource identifiers (URI): Generic syntax. RFC, 2396:1-40, 1998. 13

[BPDH10] Cathy J Bradley, Lynne Penberthy, Kelly J Devers and Debra J Holden. Health services research and data linkages: issues, methods, and directions for the future. Health services research, 45:1468-1488, 2010. 1, 10, 33

[Bra11a] Brasil, Ministério da Saúde, Secretaria de Vigilância em Saúde, Departamento de Análise de Situação de Saúde, http://portalarquivos.saude.gov.br/images/pdf/ 2017/junho/08/inst_dn.pdf. Manual de Instruções para o preenchimento da Declaração de Nascido Vivo, 2011. 24

[Bra11b] Brasil, Ministério da Saúde, Secretaria de Vigilância em Saúde, Departamento de Análise de Situação de Saúde, http://svs.aids.gov.br/download/manuais/Manual_ Instr_Preench_DO_2011_jan.pdf. Manual de Instruções para o Preenchimento da Declaração de Óbito, 2011. 24

[Bra15] Brasil, Ministério da Saúde, Secretaria de Atenção a Saúde, Departamento de Regulação, Avaliação e Controle. Sistemas de Informação da Atenção à Saúde: Contextos Históricos, Avanços e Perspectivas no SUS, 2015. 2

[Bra17] Brasil, Ministério da Saúde, Comitê Gestor da Estratégia eSaúde. Estratégia de eSaúde para o Brasil, 2017. 5

[CFLGP03] Oscar Corcho, Mariano Fernández-López and Asunción Gómez-Pérez. Methodologies, tools and languages for building ontologies. where is their meeting point? Data \& knowledge engineering, 46(1):41-64, 2003. 16 
$\left[\mathrm{CGL}^{+} 18\right]$ Diego Calvanese, Giuseppe De Giacomo, Domenico Lembo, Maurizio Lenzerini and Riccardo Rosati. Encyclopedia of Database Systems, chapter Ontology-Based Data Access and Integration, pages 2590-2596. Springer, New York, NY, 2018. 16, 19

[Chr12] Peter Christen. Data Matching, Data-Centric Systems and Applications, chapter Introduction, pages 3-22. Springer, Berlin, Heidelberg, 2012. 9

[CP17] Michelle Cheatham and Catia Pesquita. Semantic data integration. In Handbook of Big Data Technologies, pages 263-305. Springer, 2017. 11, 12, 15

[CX05] Isabel F Cruz and Huiyong Xiao. The role of ontologies in data integration. International journal of engineering intelligent systems for electrical engineering and communications, 13(4):245-252, 2005. 9, 11, 14, 18

[DC $\left.{ }^{+} 17\right]$ F Dhombres, J Charlet et al. Knowledge representation and management, it's time to integrate! Yearbook of medical informatics, 26(01):148-151, 2017. 1

[dCAVJ19] Matheus Mayron Lima da Cruz, Caio Viktor Silva Avila, Vânia Maria Ponte Vidal and Narciso Moura Arruda Junior. Semanticsus: Um portal semântico baseado em ontologias e dados interligados para acesso, integração e visualização de dados do sus. In Anais Estendidos do XIX Simpósio Brasileiro de Computação Aplicada à Saúde, pages 13-18. SBC, 2019. 30

[DH05] AnHai Doan and Alon Y. Halevy. Semantic-integration research in the database community. AI magazine, 26(1):83-94, Março 2005. 3

[DHI12a] AnHai Doan, Alon Halevy and Zachary Ives. Principles of data integration, chapter Introduction, pages 1-18. Elsevier, 2012. 9

[DHI12b] AnHai Doan, Alon Halevy and Zachary Ives. Principles of data integration, chapter Describing Data Sources, pages 65-94. Elsevier, 2012. 9

[dMMV15] Patricia Graziely Antunes de Mendonça, Cristiano Maciel and José Viterbo. Visualizing aedes aegypti infestation in urban areas: A case study on open government data mashups. Information Polity, 20(2, 3):119-134, 2015. 6

[DNM16] Antonio De Nicola and Michele Missikoff. A lightweight methodology for rapid ontology engineering. Commun. ACM, 59(3):79-86, Fevereiro 2016. 16

[DRQK ${ }^{+}$19] CS Diniz, J Reis-Queiroz, CA Kawai, MR Queiroz, E Bonilha, D Niy, BF Sena and S Lansky. "Dias potenciais de gravidez perdidos" (DPGP): uma medida inovadora da idade gestacional. Revista de Saúde Pública, 2019. No prelo. 3, 5

[ESS ${ }^{+}$17] Fajar J Ekaputra, Marta Sabou, Estefanía Serral, Elmar Kiesling and Stefan Biffl. Ontology-based data integration in multi-disciplinary engineering environments: A review. Open Journal of Information Systems (OJIS), 4(1):1-26, 2017. 19, 20, 21, $26,27,28,29,30$

[FPB16] Ana Carolina C Ferronato, Fernanda Ramos Pires and Flavia Cristina Bernardini. Um modelo para integração e disponibilização de dados na área de saúde governamental. In Anais do XII Simpósio Brasileiro de Sistemas de Informação, pages 124-127. SBC, 2016. 6

[GF95] Michael Grüninger and Mark S Fox. Methodology for the design and evaluation of ontologies. Proceedings of IJCAI'95, 1995. 16, 17, 47

[GPR16] Anika Groß, Cédric Pruski and Erhard Rahm. Evolution of biomedical ontologies and mappings: Overview of recent approaches. Computational and structural biotechnology journal, 14:333-340, 2016. 15 
[GPS ${ }^{+}$15] Veralice Maria Gonçalves, Rosemeri Pedroso, Antônio Marcos dos Santos, Lisia Von Diemen and Flavio Pechansky. Following up crack users after hospital discharge using record linkage methodology: an alternative to find hidden populations. BioMed Research International Journal, 2015, 2015. 3, 10

[Gru93] Thomas R Gruber. A translation approach to portable ontology specifications. Knowledge acquisition, 5(2):199-220, 1993. 14

[HB11] Tom Heath and Christian Bizer. Linked data: Evolving the web into a global data space, volume 1, chapter Principles of Linked Data, pages 7-28. Morgan \& Claypool Publishers, 2011. 12, 14

[HKR ${ }^{+}$04] Matthew Horridge, Holger Knublauch, Alan Rector, Robert Stevens and Chris Wroe. A Practical Guide To Building OWL Ontologies Using The Protégé-OWL Plugin and CO-ODE Tools Edition 1.0, 2004. 16

[HMS17] Su-Cheng Haw, Jiawei Wilson May and Samini Subramaniam. Mapping relational databases to ontology representation: A review. In Proceedings of the International Conference on Digital Technology in Education, pages 54-58. ACM, 2017. 16, 35, 39

[KPTR ${ }^{+}$06] Fábio Natanael Kepler, Christian Paz-Trillo, Joselyto Riani, Márcio Moretto Ribeiro, Karina Valdivia Delgado, Leliane Nunes de Barros and Renata Wassermann. Classifying ontologies. In WONTO, 2006. 16

[KRMZ13] Roman Kontchakov, Mariano Rodriguez-Muro and Michael Zakharyaschev. Reasoning Web. Semantic Technologies for Intelligent Data Access, chapter Ontologybased data access with databases: A short course, pages 194-229. Springer, 2013. 19

[LOV17] Gabriel Lopes, Mauro Oliveira and Vania Vidal. Lais: Towards to a linked data framework to support decision-making on healthcare. 5th International Workshop on ADVANCEs in ICT INfrastructures and Services, 2017. 6, 29, 31

[LVO16a] Gabriel Lopes, Vânia Vidal and Mauro Oliveira. Construção de linked data mashup para integração de dados da saúde pública. In $S B B D$, pages 145-150, 2016. 7

[LVO16b] Gabriel Lopes, Vânia Vidal and Mauro Oliveira. A framework for creation of linked data mashups: A case study on healthcare. In Proceedings of the 22nd Brazilian Symposium on Multimedia and the Web, pages 327-330. ACM, 2016. 6, 29, 30, 31

[MBM12] Eduardo C. Moraes, Kellyton Brito and Silvio Meira. OntoPHC: An Ontology Applied For Primary Health Care. Procedia Computer Science, 9:1543 - 1552, 2012. Proceedings of the International Conference on Computational Science, ICCS 2012. 6

[MFD16] Kgotatso Desmond Mogotlane and Jean Vincent Fonou-Dombeu. Automatic conversion of relational databases into ontologies: A comparative analysis of Protégé plug-ins performances. International Journal of Web and Semantic Technology (IJWesT), 7(3/4), Outubro 2016. 16

$\left[\mathrm{MGL}^{+} 09\right]$ Angelica Espinosa Miranda, Jonathan E Golub, Francisca de Fátima Lucena, Ethel Noia Maciel, Maria de Fátima Gurgel and Reynaldo Dietze. Tuberculosis and AIDS co-morbidity in Brazil: linkage of the tuberculosis and AIDS databases. Brazilian Journal of Infectious Diseases, 13(2):137-141, 2009. 3, 10 
[MSAPLC $^{+}$17] FJ Martin-Sanchez, V Aguiar-Pulido, GH Lopez-Campos, N Peek and L Sacchi. Learning from Experience: Secondary Use of Pacient Data, volume 26, chapter Secondary use and analysis of big data collected for patient care, pages 28-37. Georg Thieme Verlag KG, 2017. 1

[MSMS17] Lívia Teixeira de Souza Maia, Wayner Vieira de Souza, Antonio da Cruz Gouveia Mendes and Aline Galdino Soares da Silva. Use of linkage to improve the completeness of the SIM and SINASC in the Brazilian capitals. Revista de saúde pública, $51: 112,2017.3,10$

[NM01] Natalya F Noy and Deborah L McGuinness. Ontology development 101: A guide to creating your first ontology. Stanford knowledge systems laboratory technical report, 2001. 16

[PdMdSP10] Coordenação de Epidemiologia e Informação CEInfo Prefeitura do Município de São Paulo, Secretaria Municipal da Saúde. Sistema de Informação sobre Nascidos Vivos. Manual do Selo SINASC 2010, 2010. 24

[PM04] Helena Sofia Pinto and João P Martins. Ontologies: How can they be built? Knowledge and information systems, 6(4):441-464, 2004. 16

[PPS $\left.{ }^{+} 18\right]$ Robespierre Pita, Clícia Pinto, Samila Sena, Rosemeire Fiaccone, Leila Amorim, Sandra Reis, Mauricio L Barreto, Spiros Denaxas and Marcos Ennes Barreto. On the accuracy and scalability of probabilistic data linkage over the Brazilian 114 million cohort. IEEE journal of biomedical and health informatics, 22(2):346-353, 2018. 10

[PPSW19] Débora Lina N Ciriaco Pereira, Alexandre Pessoa, Laís Salvador and Renata Wassermann. Semantic Data Integration for Public Health in Brazil. In LatinX in AI Research at ICML 2019, Long Beach, United States, Junho 2019. 29

[PVGPSF14] María Poveda-Villalón, Asunción Gómez-Pérez and Mari Carmen Suárez-Figueroa. OOPS! (OntOlogy Pitfall Scanner!): An on-line tool for ontology evaluation. Int. J. Semant. Web Inf. Syst., 10(2):7-34, Abril 2014. 54

[PWS18] Débora Lina N Ciriaco Pereira, Renata Wassermann and Laís Salvador. Integração semântica das bases de dados do município de São Paulo: Um estudo de caso com anomalias congênitas. Ontobras, 2018. 29

[RP16] Petar Ristoski and Heiko Paulheim. Semantic web in data mining and knowledge discovery. Web Semant., 36(C):1-22, Janeiro 2016. 6

[RROB11] Rogéria Rocha, Mirella Rodrigues, Conceição Oliveira and Cristine Bonfim. Aplicação da técnica de linkage entre as bases de dados de nascidos vivos e óbitos para estudo da mortalidade neonatal no Recife (PE), Brasil. Espaço para a Saúde-Revista de Saúde Pública do Paraná, 12(2):38-44, 2011. 10

[Rus18] Robert C Russell. Index., Abril 1918. US Patent US1261167A. 34

[SB06] Edward H Shortliffe and G Octo Barnett. Biomedical data: Their acquisition, storage, and use. In Biomedical informatics, pages 46-79. Springer, 2006. 1

[SF14] Rômulo Cristovão de Souza and Sergio Miranda Freire. Integração de dados ambulatoriais de quimioterapia e radioterapia nas bases de dados do SUS. Congresso Brasileiro de Engenharia Biomédica, pages 1904-1907, 2014. 10 
[SGSK18] Giorgos Stoilos, David Geleta, Jetendr Shamdasani and Mohammad Khodadadi. A novel approach and practical algorithms for ontology integration. In International Semantic Web Conference, pages 458-476. Springer, 2018. 6

[SGW $\left.{ }^{+} 18\right]$ Giorgos Stoilos, David Geleta, Szymon Wartak, Sheldon Hall, Mohammad Khodadadi, Yizheng Zhao, Ghadah Alghamdi and Renate A Schmidt. Methods and metrics for knowledge base engineering and integration. In WOP@ISWC, pages 72-86, 2018. 6

$\left[\mathrm{STV}^{+}\right.$06] João Paulo Lyra da Silva, Claudia Maria de Rezende Travassos, Miguel Murat de Vasconcellos, Linair Maria Campos et al. Revisão sistemática sobre encadeamento ou linkage de bases de dados secundários para uso em pesquisa em saúde no Brasil. Cadernos Saúde Coletiva, pages 197-224, 2006. 10

[Sã12] São Paulo cidade, Secretaria Municipal da Saúde, Coordenação de Epidemiologia e Informação - CEInfo. Declaração de Nascido Vivo - Manual de Anomalias Congênitas, 2012. 5

[THHT19] Elodie Thiéblin, Ollivier Haemmerlé, Nathalie Hernandez and Cassia Trojahn. Survey on complex ontology matching. Semantic Web, pages 1-39, 2019. 59

[VCA $\left.{ }^{+} 15\right]$ Vânia MP Vidal, Marco A Casanova, Narciso Arruda, Mariano Roberval, Luiz Paes Leme, Giseli Rabello Lopes and Chiara Renso. Specification and incremental maintenance of linked data mashup views. In International Conference on Advanced Information Systems Engineering, pages 214-229. Springer, 2015. 6, 29, 30, 31

[WDA $\left.{ }^{+} 16\right]$ Mark D Wilkinson, Michel Dumontier, IJsbrand Jan Aalbersberg, Gabrielle Appleton, Myles Axton, Arie Baak, Niklas Blomberg, Jan-Willem Boiten, Luiz Bonino da Silva Santos, Philip E Bourne et al. The FAIR guiding principles for scientific data management and stewardship. Scientific data, 3:160018, 2016. 1

[WVV $\left.{ }^{+} 01\right]$ Holger Wache, Thomas Voegele, Ubbo Visser, Heiner Stuckenschmidt, Gerhard Schuster, Holger Neumann and Sebastian Hübner. Ontology-based integration of information - a survey of existing approaches. In IJCAI-01 workshop: ontologies and information sharing, volume 2001, pages 108-117. Citeseer, 2001. 14, 20, 21, 26,30

[XHB $\left.{ }^{+} 18\right]$ Guohui Xiao, Dag Hovland, Dimitris Bilidas, Martin Rezk, Martin Giese and Diego Calvanese. Efficient ontology-based data integration with canonical IRIs. In European Semantic Web Conference, pages 697-713. Springer, 2018. 19

[ZHZZ07] X. Zhang, C. Hu, Q. Zhao and C. Zhao. Semantic data integration in materials science based on semantic model. In Third IEEE International Conference on eScience and Grid Computing (e-Science 2007), pages 320-327, Dec 2007. 6 
